\title{
EVALUACION DE LA INFLUENCIA HIDROLÓGICA DE FORESTACIONES EN LA LLANURA PAMPEANA
}

\section{Tesis doctoral}

DOCTORANDO:

ING. FTAL. SEBASTIÁN I. BESTEIRO (UNLP-CONICET)

DIRECTOR:

DRA. FERNANDA J. GASPARI (UNLP)

CODIRECTOR:

DR. EDUARDO E. KRUSE (UNLP-CONICET) 


\section{Índice general}

HOJA

SIMBOLOGÍA

v

ABREVIATURAS

ix

TABLAS

$\mathrm{x}$

FIGURAS

xiv

GRÁFICOS

$x v i$

AGRADECIMIENTOS

$\mathbf{x x}$

DEDICATORIA

$x x i$

RESUMEN

$x x i i$

ABSTRACT

Xxv

Capítulo 1. Introducción

1.1 INTRODUCCIÓN GENERAL

1.1.1 Situación de los bosques en el mundo

1.1.2 El ciclo del agua y las forestaciones

1.1.3 Efecto de las forestaciones en el ciclo hidrológico

1.1.4 Estado del conocimiento

1.1.5 llanura pampeana

1.2 FUNDAMENTOS DE LA ELECCIÓN DEL TEMA 16

1.3 ELECCIÓN DE LAS ÁREAS DE ESTUDIO

1.3.1 Sistemas llanos en la pampa ondulada

1.3.2 Sistemas llanos en la pampa deprimida

1.4 ORGANIZACIÓN DE LA TESIS

2.1 INTRODUCCIÓN

2.1.1 Antecedentes

a) Forestaciones juveniles

b) Forestaciones adultas 
c) Pinus vs. Eucalyptus 33

d) Forestación vs. Bosque nativo 34

e) Forestación vs. Pastizales 35

2.2 MATERIALES Y MÉTODOS

2.2.1 Área de estudio

2.2.1.1 Estancia el Centauro (EEC) 37

a. Clima $\quad 37$

b. Hidrología 39

C. Uso y cobertura del suelo 40

2.2.1.2 Predio Forestal Dolores (PFD) 44

a. Clima 45

b. Hidrología 45

C. Uso y cobertura del suelo 46

2.2.2 Precipitación 51

2.2.3 Intercepción $\quad 56$

2.3 RESULTADOS

$\begin{array}{ll}\text { 2.3.1 Precipitación } & 60\end{array}$

2.3.2 Intercepción $\quad 67$

2.4 DISCUSIÓN

Capítulo 3. Escurrimiento superficial

3.1 INTRODUCCIÓN

3.1.1 Sistemas hidrológicos atípicos 88

$\begin{array}{ll}\text { 3.1.2 Escurrimiento bajo forestaciones } & 89\end{array}$

3.2 MATERIALES Y MÉTODOS

$\begin{array}{ll}\text { 3.2.1 Morfometría } & 91\end{array}$

$\begin{array}{ll}\text { 3.2.2 Escurrimiento superficial } & 96\end{array}$

3.3 RESULTADOS

3.3.1 Morfometría de la Estancia El Centauro (EEC) 100

3.3.2 Morfometría del Predio Forestal Dolores (PFD) 103

$\begin{array}{ll}\text { 3.3.3 Escurrimiento superficial } & 106\end{array}$

3.4 DISCUSIÓN 


\subsection{INTRODUCCIÓN}

4.1.1 Infiltración y recarga freática 115

4.1.2 Métodos de estimación 118

4.1.3 Aguas subterráneas y las forestaciones $\quad 119$

4.2 MATERIALES Y MÉTODOS

4.2.1 Área de estudio

4.2.1.1 Estancia EI Centauro (EEC)

a. Características edáficas 124

b. Descripción de series de suelos 127

c. Características geológicas 127

d. Variables de interés 128

4.2.1.2 Predio Forestal Dolores (PFD)

a. Características edáficas 130

b. Descripción de series de suelos 132

c. Características geológicas 132

d. Variables de interés 134

4.2.2 Infiltración 135

4.2.3 Flujos subterráneos $\quad 138$

4.3 RESULTADOS

4.3.1 Infiltración $\quad 141$

4.3.2 Flujos subterráneos $\quad 152$

4.4 DISCUSIÓN 158

\section{Capítulo 5. Evapotranspiración}

5.1 INTRODUCCIÓN

5.1.1 Concepto de evapotranspiración 163

5.1.2 Evapotranspiración potencial, real y de referencia $\quad 164$

$\begin{array}{ll}\text { 5.1.3 Metodologías de cálculo } & 166\end{array}$

5.1.4 Evapotranspiración en plantaciones de pino y eucalipto $\quad 168$

5.2 MATERIALES Y MÉTODOS

5.2.1 Cálculo de $\mathrm{ET}_{0}$ por el método de FAO Penman-Monteith 173 
5.2.2 Determinación de $\mathbf{E T}_{\mathrm{C}}$ para vegetación atípica

\subsection{RESULTADOS}

5.3.1 Valores de $\mathrm{E}_{\mathrm{C}}$ por desarrollo de método FAO 56

5.4 DISCUSIÓN

Capítulo 6. Consideraciones finales

6.1 CONSIDERACIONES FINALES

\section{Capítulo 7. Conclusiones}

7.1 CONCLUSIONES

\section{Bibliografía}

BIBLIOGRAFÍA

\section{Anexos}

ANEXOS

237

Página | iv 


\section{Simbología}
A
$\mathrm{AB}$
AET
AFE
ai
Alm
Ap
$\mathrm{C}_{\mathrm{I}}$
$\mathrm{C}_{\mathrm{C}}$
$\mathrm{C}(\mathrm{x}, \mathrm{y})$
DAP
$\mathrm{DAP}_{\mathrm{m}}$
Dd
$D_{d t}$
Def
$\mathrm{D}_{\mathrm{e}, \mathrm{i}-1}$
E
$\mathrm{E}_{\mathrm{CM}}$
$\mathrm{E}_{\mathrm{CM}}=\mathrm{V}(\mathrm{x}-\mathrm{y})$
$\mathrm{E}_{\mathrm{f} 0}$
$\mathrm{E}_{\mathrm{f}}$
ET
$\mathrm{ET}_{0}$
$\mathrm{ET}_{\mathrm{c}}$
$\mathrm{ET}_{\mathrm{c} \text { aj }}$
ETP
ETR
$\mathrm{ET}_{\mathrm{r}}$
Área de la cuenca
Área basal
Agua evapotranspirable total [mm]
Agua fácilmente evapotranspirable [mm]
Área entre cotas
Almacenaje
Ancho promedio de la cuenca
Coeficiente de Inconsistencia
Coeficiente de Consistencia
Covarianza entre las muestras x e y
Diámetro a la altura de pecho $(1,3 \mathrm{~m})$
Diámetro a la altura de pecho promedio $(1,3 \mathrm{~m})$
Densidad de drenaje de una cuenca
Densidad total de un rodal (árb/ha)
Déficit
Valor acumulado de $\mathrm{ET}_{0}$ desde el día en que llueve
Evaporación
Error cuadrático medio
Varianza de la razón entre muestras
Cantidad de lluvia por encima de la cual comienza el escurrimiento fustal
Escurrimiento fustal (flujo caulinar o stemflow)
Evapotranspiración
Evapotranspiración de referencia basada en Penman-Monteith
Evapotranspiración del cultivo en condiciones estándar
Evapotranspiración del cultivo en condiciones no estándar
Evapotranspiración Potencial
Evapotranspiración Real
Evapotranspiración de referencia 


\begin{tabular}{|c|c|}
\hline Exc & Excesos hídricos \\
\hline $\mathrm{F}$ & Infiltración acumulada real \\
\hline $\mathrm{f}$ & Infiltración instantánea real \\
\hline$f_{c}$ & Cobertura forestal $(0,01-1)$ \\
\hline $\mathrm{Ff}$ & Factor de forma o de Gravelius \\
\hline $\mathrm{F}_{\mathrm{p}}$ & Infiltración acumulada bajo encharcamiento \\
\hline $\mathrm{f}_{\mathrm{p}}$ & Infiltración potencial o capacidad de infiltración \\
\hline $\mathrm{f}_{\mathrm{ss}}$ & Infiltración efectiva o eficaz \\
\hline gT & Número de pixeles de una imagen plana ortogonal con vista libre del cielo \\
\hline$\Delta \mathrm{G}$ & Almacenamiento de agua subterránea \\
\hline $\mathrm{H}$ & Diferencia de altura entre el punto más alto y más bajo de una cuenca \\
\hline $\mathrm{H}$ & Equidistancia entre curvas de nivel topográfico \\
\hline $\mathrm{h}$ & Altura máxima promedio de árboles dominantes \\
\hline$\Delta \mathrm{H}$ & Cambio de altura de capa freática \\
\hline$\Delta \mathrm{h}$ & Adición de agua en equivalentes de profundidad \\
\hline hi & Altitud media entre par de cotas \\
\hline $\mathrm{Hm}$ & Altitud media del terreno \\
\hline Hmáx & Cota máxima sobre el curso de agua \\
\hline Hmín & Cota mínima sobre el curso de agua \\
\hline $\mathrm{HR}_{\min }$ & Humedad relativa mínima diaria \\
\hline I & Intercepción \\
\hline Io & Pérdidas o abstracciones iniciales \\
\hline $\mathrm{I}_{0}$ & Lluvia necesaria para saturar la capacidad de retención del dosel forestal \\
\hline J & Pendiente media del cauce \\
\hline $\mathrm{J}$ & Día juliano \\
\hline K & Conductividad hidráulica \\
\hline Kc & Índice de compacidad o de Gravelius \\
\hline $\mathrm{K}_{\mathrm{c}}$ & Coeficiente de cultivo \\
\hline $\mathrm{K}_{\mathrm{cb}}$ & Coeficiente basal o de transpiración del cultivo \\
\hline $\mathrm{K}_{\mathrm{cb} \text { aj }}$ & Coeficiente de transpiración del cultivo ajustado \\
\hline
\end{tabular}




\begin{tabular}{|c|c|}
\hline $\mathrm{K}_{\mathrm{cb} \text { med }}$ & Coeficiente de transpiración del cultivo para la etapa media de desarrollo \\
\hline $\mathrm{K}_{\mathrm{cb} \text { medaj }}$ & Coeficiente de transpiración del cultivo ajustado para la etapa media de desarrollo \\
\hline $\mathrm{K}_{\mathrm{e}}$ & Coeficiente de evaporación del suelo \\
\hline $\mathrm{K}_{\mathrm{e} \text { aj }}$ & Coeficiente de evaporación del suelo ajustado \\
\hline L & Longitud de: curvas de nivel topográfico; cauces; río más largo \\
\hline La & Longitud axial de la cuenca \\
\hline Ln & Sumatoria de las longitudes de todos los cursos de agua de una cuenca \\
\hline$P$ & Perímetro de la cuenca \\
\hline $\mathrm{P}$ & Precipitación total \\
\hline $\mathrm{P}_{0}$ & Precipitación efectiva \\
\hline PM & Pendiente media del terreno \\
\hline $\mathrm{P}_{\mathrm{n}}$ & Precipitación neta \\
\hline $\mathrm{P}_{\mathrm{r}}$ & Percolación profunda \\
\hline Q & Escurrimiento total \\
\hline$\varphi$ & Latitud en radianes \\
\hline $\mathrm{R}$ & Escurrimiento superficial \\
\hline $\mathrm{Ra}$ & Coeficiente de rugosidad de una cuenca \\
\hline $\mathrm{Rh}$ & Relación hipsométrica \\
\hline $\mathrm{R}_{\text {ss }}$ & Escurrimiento subsuperficial \\
\hline $\mathrm{R}_{\text {subt }}$ & Escurrimiento subterráneo \\
\hline$S$ & Abstracción potencial de una cuenca luego de un exceso de lluvia \\
\hline$\Delta \mathrm{S}$ & Almacenamiento de agua en el suelo \\
\hline S & Coeficiente de almacenamiento \\
\hline $\mathrm{Si}$ & Área debajo de la curva hipsométrica \\
\hline Ss & Área sobre la curva hipsométrica \\
\hline Sy & Porosidad eficaz \\
\hline $\mathrm{T}$ & Transpiración \\
\hline Tc & Tiempo de concentración \\
\hline $\mathrm{T}_{\mathrm{r}}$ & Trascolación (Precipitación directa o throughfall) \\
\hline $\mathrm{U}_{2}$ & Velocidad del viento \\
\hline
\end{tabular}


$\mathrm{V}_{\mathrm{Alm}}$

Variación de almacenaje

$\mathrm{V}(\mathrm{x})$

Varianza de la muestra $\mathrm{x}$

$\mathrm{V}(\mathrm{y})$

Varianza de la muestra y

Página | viii 


\section{Abreviaturas}

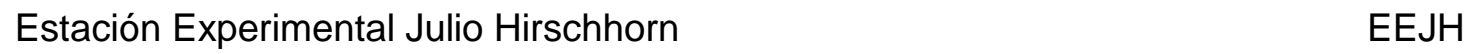

Estación Meteorológica Aeródromo Dolores $\quad$ EMAD

Estancia El Centauro $\quad$ EEC

Geographic Information System $\quad$ GIS

Grupos Hidrológicos $\quad$ GH

Instituto Geográfico Nacional IGN

Long-Term Hydrologic Impact Assessment L-THIA

Microcuenca del Arroyo La Paloma $\quad$ MALP

$\begin{array}{ll}\text { Número de Curva } & \text { NC }\end{array}$

$\begin{array}{ll}\text { Predio Forestal Dolores } & \text { PFD }\end{array}$

Sistemas de Información Geográfica $\quad$ SIG

$\begin{array}{ll}\text { Soil Conservation Service } & \text { SCS }\end{array}$

Subsecretaría de Recursos Hídricos de la Nación $\quad$ SSRH 


\section{Índice de tablas}

II.1. Distribución estacional de las lluvias, en valores medios, para el período 1909-2005, partido de La Plata. Adaptado de (Hurtado et al., 2006).

II.2. Balance hídrico medio mensual (1909-2005) para el partido de La Plata. Adaptado de Hurtado et al. (2006).

II.3. Fuente de datos pluviométricos, ubicación, frecuencia de datos y distancia de las estaciones meteorológicas de los sitios de estudio.

II.4. Precipitación anual media para la serie histórica (53 años) y serie de muestreos (3 años).

II.5. Precipitaciones acumuladas mensuales y estacionales para la serie de muestreos (3 años), junto con el número de semanas con lluvia para el total de la serie de muestreos y los valores de precipitación mensual media, máxima y mínima.

II.6. Redistribución de las precipitaciones mensuales y estacionales sobre una forestación de $P$. radiata de la pampa ondulada para el período: ene.2009dic.2011. Adaptado de Besteiro y Rodríguez (2012).

II.7. Redistribución de las precipitaciones mensuales y estacionales sobre una forestación de E. viminalis de la pampa ondulada para el período: ene.2009-dic.2011. Adaptado de Besteiro y Rodríguez (2012).

II.8. Redistribución de las precipitaciones mensuales y estacionales sobre una forestación de $E$. viminalis de la pampa deprimida para el período: sep.2009-ago.2012.

II.9. Redistribución de las precipitaciones mensuales y estacionales sobre una forestación de E. camaldulensis de la pampa deprimida para el período: sep.09-ago.12.

II.10. Redistribución de las precipitaciones mensuales y estacionales sobre una forestación de E. camaldulensis de la pampa deprimida para el período: sep.09-ago.12.

II.11. Redistribución de las precipitaciones mensuales y estacionales sobre una forestación de E. camaldulensis de la pampa deprimida para el período: sep.09-ago.12.

II.12. Redistribución de las precipitaciones mensuales y estacionales sobre una forestación de E. camaldulensis de la pampa deprimida para el período: sep.09-ago.12.

II.13. Características dasométricas de los rodales estudiados, junto a los componentes porcentuales de la redistribución de las lluvias que inciden sobre ellos y capacidad máxima de retención de agua en troncos y dosel forestal. 
III.1. Cuadro de clases de formas correspondientes a distintos rangos del índice de compacidad adaptado de Mármol (2006)

III.2. Valores de número de curva para suelos con diferentes usos. Adaptado de Gaspari et al. (2009).

III.3. Condiciones de humedad antecedente en función de la precipitación acumulada de 5 días. Adaptado de Gaspari et al. (2009).

III.4. Porcentajes de ocupación de los valores de NC y escurrimiento superficial en los sitios de estudio.

III.5. Porcentajes de ocupación de los valores de NC y escurrimiento superficial en los sitios de estudio, para una situación hipotética donde las forestaciones son reemplazadas por la actividad predominante en la zona.

III.6. Porcentajes de ocupación de los valores de NC y escurrimiento superficial en los sitios de estudio, para una situación hipotética donde los pastizales son reemplazados por forestaciones de rápido crecimiento.

IV.1. Algunos modelos empíricos para la determinación de la infiltración. Adaptado de Martín de Santa Olalla et al. (2005).

IV.2. Detalle de las unidades taxonómicas correspondientes a los suelos de la Estancia El Centauro y alrededores.

IV.3. Variables edáficas e hidrogeológicas de la Estancia El Centauro y alrededores.

IV.4. Detalle de las unidades taxonómicas presentes en el Predio Forestal Dolores y alrededores. Adaptado de INTA (2011).

IV.5. Variables edáficas e hidrogeológicas del Predio Forestal Dolores y alrededores.

IV.6. Red de monitoreo freático de las áreas de estudio, indicando los códigos, profundidad y cota.

IV.7. Variaciones máximas y medias del nivel de capa freática entre los distintos usos/coberturas del suelo en EEC.

IV.8. Variaciones máximas y medias del nivel de capa freática entre los distintos usos/coberturas del suelo en PFD.

IV.9. Variaciones mensuales de las reservas de agua subterránea (freática) en la EEC, producto del aporte o remoción de agua en el perfil.

IV.10. Variaciones mensuales de las reservas de agua subterránea (freática) en el PFD, producto del aporte o remoción de agua en el perfil.

IV.11. Variaciones totales de las reservas de agua subterránea (freática) para el período septiembre de 2009-diciembre de 2011 en EEC y PFD.

IV.12. Variaciones totales de las reservas de agua subterránea (freática) para el período septiembre de 2009-diciembre de 2011 en EEC y PFD. 
IV.13. Variaciones de contenido de agua freática por aporte horizontal a nivel predial, expresadas como láminas acumuladas anuales. Parámetros para el cálculo de los caudales subterráneos de entrada y salida modales en los predios EEC y PFD.

V.1. Evaluación de métodos de estimación de $\mathbf{E T}_{\mathbf{0}}$ frente a datos lisimétricos en cinco localidades de climas húmedos (HR $\geq 60 \%)$ y seis localidades de climas áridos $(H R<60 \%)$. Extraído de Smith (2000).

V.2. Resumen de valores de $\mathbf{k}_{\mathbf{C}}$ encontrados en la bibliografía internacional y nacional, indicando las especies y autor/s del trabajo.

V.3. Valores medios mensuales de $\mathbf{P}$ y $\mathbf{E T}_{\mathbf{0}}$ expresados en $\mathrm{mm}$, para cada sitio de estudio, calculados por la metodología FAO Penman-Monteith.

V.4. Valores medios mensuales $\mathbf{E T}_{\mathbf{c}}$ expresados en $\mathrm{mm}$, para distintos rodales y situaciones de pastizal.

V.5. Valores mínimos (mín), medios (med) y máximos (máx) mensuales de los coeficientes únicos de cultivo $\left(\mathbf{K}_{\mathbf{c}}\right)$ correspondientes a las plantaciones forestales y situación natural de la Estancia El Centauro (EEC).

V.6. Valores mínimos (mín), medios (med) y máximos (máx) mensuales de los coeficientes únicos de cultivo $\left(\mathbf{K}_{\mathbf{c}}\right)$ correspondientes a las plantaciones forestales y situación natural del Predio Forestal Dolores (PFD).

V.7. Balance hidrológico mensual de Thornthwaite, con un factor de cultivo general correspondiente a un pastizal de la EEC $(K c=0,7)$ y un valor de retención de agua útil en el suelo de $200 \mathrm{~mm}$.

V.8. Balance hidrológico mensual de Thornthwaite, con un factor de cultivo general correspondiente a un pastizal del PFD $\left(\mathbf{K}_{\mathbf{C}}=0,7\right)$ y un valor de retención de agua útil en el suelo de $180 \mathrm{~mm}$.

V.9. Balance hidrológico mensual de Thornthwaite ajustado en función de un factor de cultivo diario, calculado para una plantación de $P$. radiata de la pampa ondulada y un valor de retención de agua útil del suelo de $838,8 \mathrm{~mm}$.

V.10. Balance hidrológico mensual de Thornthwaite ajustado en función de un factor de cultivo diario, calculado para una plantación de $E$. viminalis de la pampa ondulada y un valor de retención de agua útil del suelo de $838,8 \mathrm{~mm}$.

V.11. Balance hidrológico mensual de Thornthwaite ajustado en función de un factor de cultivo diario, calculado para una plantación de $E$. viminalis de la pampa deprimida (Parcela 1) y un valor de retención de agua útil del suelo de $841,2 \mathrm{~mm}$.

V.12. Balance hidrológico mensual de Thornthwaite ajustado en función de un factor de cultivo diario, calculado para una plantación de E. camaldulensis de la pampa deprimida (Parcela 2) y un valor de retención de agua útil del suelo de $841,2 \mathrm{~mm}$. 
V.13. Balance hidrológico mensual de Thornthwaite ajustado en función de un factor de cultivo diario, calculado para una plantación de E. camaldulensis de la pampa deprimida (Parcela 3 ) y un valor de retención de agua útil del suelo de $841,2 \mathrm{~mm}$.

V.14. Balance hidrológico mensual de Thornthwaite ajustado en función de un factor de cultivo diario, calculado para una plantación de E. camaldulensis de la pampa deprimida (Parcela 4) y un valor de retención de agua útil del suelo de $841,2 \mathrm{~mm}$.

V.15. Balance hidrológico mensual de Thornthwaite ajustado en función de un factor de cultivo diario, calculado para una plantación de $E$. camaldulensis de la pampa deprimida (Parcela 5) y un valor de retención de agua útil del suelo de $841,2 \mathrm{~mm}$.

V.16. Principales componentes del balance hidrológico anual para los tres años de estudio en EEC y PFD. 


\section{Índice de figuras}

I.1. Distribución porcentual de los componentes del balance hídrico junto con el tiempo de permanencia general indicada para cuencas hidrográficas pequeñas en buenas condiciones de cobertura forestal y en condiciones de clima templado. Extraído de Giraldo López (2002)

I.2. Componentes del ciclo hidrológico para un árbol individual de la llanura pampeana tomado como sistema objetivo.

I.3. Ubicación geográfica de los sitios experimentales utilizados como áreas de estudio y señalados como EEC (Estancia El Centauro) y PFD (Predio Forestal Dolores) dentro de la provincia de Buenos Aires, Argentina. Se indican además las cuencas, regiones y subregiones a las cuales pertenecen estas áreas de estudio.

II.1. Localización geográfica de la Estancia el Centauro (EEC), vías de acceso e hidrografía característica.

II.2. Límites de la Estancia El Centauro junto con la red hidrográfica correspondiente al Arroyo La Paloma, montada sobre una imagen del Google Earth@ como fondo.

II.3. Estancia El Centauro y zonificación del uso del suelo.

II.4. Imágenes originales y procesadas para el cálculo de cobertura forestal de pino.

II.5. Imágenes originales y procesadas para el cálculo de cobertura forestal de eucalipto en la EEC.

II.6. Detalle fotográfico del pastizal natural modificado de la EEC.

II.7. Localización geográfica del Predio Forestal Dolores (PFD), con caminos de acceso e hidrografía característica.

II.8. Predio Forestal Dolores y tipos de coberturas y usos del suelo.

II.9. Plano del loteo del campo, con los rodales donde se colocó el instrumental de muestreo.

II.10. Imágenes de la cobertura forestal en el PFD, ordenada de a pares por parcela de muestreo. Se muestra la imagen no procesada en color junto a la procesada en banco y gris.

II.11. Ubicación de estación experimental Ingeniero Julio Hirschhorn y pluviómetros de la Estancia El Centauro. De fondo se muestra un mosaico de imágenes Google Earth junto a la red caminera.

II.12. Ubicación de la estación del Servicio Meteorológico Nacional, Aeródromo Dolores, y de la estación meteorológica y pluviómetro del Predio Forestal Dolores. De fondo se muestra un mosaico de imágenes Google Earth junto a la red caminera. 
II.13. Secuencia de imágenes (de izquierda a derecha y de arriba hacia abajo) indicando la instalación de un colector de escurrimiento fustal en un árbol de pino.

II.14. Secuencia de imágenes mostrando el instrumental de fabricación y distintos pluviómetros instalados bajo la canopea forestal.

III.1. Localización geográfica de la MALP.

III.2. Orden de los cursos de agua correspondiente a la Microcuenca Arroyo La Paloma según la metodología de Horton. De fondo se muestra el modelo de elevación del terreno (dem).

III.3. Localización de la Cuenca del Arroyo Langueyú. Adaptado del Atlas 2010 de Cuencas y Regiones Hídricas la República Argentina.

III.4. Mapas de Grupo Hidrológico adaptados al modelo L-THIA, correspondientes a la EEC (izquierda) y PFD (derecha).

III.5. Mapas base de usos del suelo para las áreas de estudio, correspondientes a la EEC (izquierda) y PFD (derecha).

III.6. Mapa de NC y precipitación efectiva o escurrimiento superficial en $\mathrm{mm}(\mathbf{R})$, obtenido por procesamiento automático con L-THIA, de la base de datos vectorial y lluvias diarias, correspondientes a la EEC (izquierda) y PFD (derecha).

IV.1. Mapa de unidades cartográficas de suelos en la EEC y área de influencia. Adaptado de INTA (2010).

IV.2. Mapa de suelos del Predio Forestal Dolores. Adaptado de INTA (2011).

IV.3. Estratigrafía del Predio Forestal Dolores.

IV.4. Ubicación de la red de monitoreo de niveles freáticos en la Estancia EI Centauro (izquierda) y Predio Forestal Dolores (derecha). De fondo de observa las cartas topográficas correspondientes a la hojas Ignacio Correas (EEC) y Estancia El Sermón (PFD).

IV.5. Cinta métrica adaptada para medición de los niveles de capa freática.

V.1. Evapotranspiración del cultivo de referencia $\left(\mathbf{E T}_{\mathbf{0}}\right)$, bajo condiciones estándar $\left(\mathbf{E T}_{\mathbf{c}}\right)$ y bajo condiciones no estándar $\left(\mathbf{E T}_{\mathbf{c} \mathbf{a j}}\right)$. Extraído de Allen et al. (2006)

V.2. Esquema del movimiento vertical del agua en el suelo. 


\section{Índice de gráficos}

II.1. Precipitaciones acumuladas anuales de la Experimental J. Hirschhorn (EEJH en verde) y del Aeródromo Dolores (EMAD en rojo) para las series 1918-2011 y 1959-2011 respectivamente. En líneas punteadas se muestra la precipitación media anual para el período 1959-2011, correspondiente a cada estación.

II.2. Análisis de doble masa para una serie de 53 años (período 1959-2011), correspondiente a las estaciones EEJH y EMAD.

II.3. Análisis de doble masa para las series de precipitaciones acumuladas mensuales de 53 años (1959-2011), correspondientes a la experimental Julio Hirschhorn (EEJH) y el Aeródromo Dolores (EMAD).

II.4. Análisis de doble masa para una serie de precipitaciones diarias acumuladas de 14 años (1998-2011), correspondientes a EEJH y EMAD.

II.5. Precipitaciones mensuales registradas en la EEJH (azul) y testigo EEC (rojo), para el período de tres años (36 meses).

II.6. Precipitaciones mensuales registradas en la EMAD (azul) y testigo PFD (rojo), para el período de tres años (36 meses).

II.7. Análisis de dobles masas acumuladas de las lluvias mensuales registradas en la EEJH y EEC, para el período de estudio de tres años (36 meses).

II. 8. Análisis de dobles masas acumuladas de las lluvias mensuales registradas en la EMAD y PFD, para el período de estudio de tres años (36 meses).

II.9. Distribución de los componentes precipitación neta $\left(\mathbf{P}_{\mathbf{n}}\right)$, trascolación $\left(\mathbf{T}_{\mathbf{r}}\right)$ y escurrimiento fustal $\left(\mathbf{E}_{\mathbf{f}}\right)$ en relación de la precipitación que incide sobre una plantación de $P$. radiata en la EEC. Regresiones lineales junto a funciones y coeficientes de ajuste. Adaptado de Besteiro y Rodríguez (2012).

II.10. Distribución de los componentes precipitación neta $\left(\mathbf{P}_{\mathbf{n}}\right)$, trascolación $\left(\mathbf{T}_{\mathbf{r}}\right)$ y escurrimiento fustal $\left(\mathbf{E}_{\mathbf{f}}\right)$ en relación de la precipitación que incide sobre una plantación de E. viminalis en la EEC. Regresiones lineales junto a funciones y coeficientes de ajuste. Adaptado de Besteiro y Rodríguez (2012).

II.11. Distribución de los componentes precipitación neta $\left(\mathbf{P}_{\mathbf{n}}\right)$, trascolación $\left(\mathbf{T}_{\mathbf{r}}\right)$ y escurrimiento fustal $\left(\mathbf{E}_{\mathbf{f}}\right)$ en relación de la precipitación que incide sobre una plantación de E. viminalis en el PFD (Parcela 1). Regresiones lineales junto a funciones y coeficientes de ajuste.

II.12. Distribución de los componentes precipitación neta $\left(\mathbf{P}_{\mathbf{n}}\right)$, trascolación $\left(\mathbf{T}_{\mathbf{r}}\right)$ y escurrimiento fustal $\left(\mathbf{E}_{\mathbf{f}}\right)$ en relación de la precipitación que incide sobre una plantación de E. camaldulensis en el PFD (Parcela 2). Regresiones lineales junto a funciones y coeficientes de ajuste. 
II.13. Distribución de los componentes precipitación neta $\left(\mathbf{P}_{\mathbf{n}}\right)$, trascolación $\left(\mathbf{T}_{\mathbf{r}}\right)$ y escurrimiento fustal $\left(\mathbf{E}_{\mathbf{f}}\right)$ en relación de la precipitación que incide sobre una plantación de E. camaldulensis en el PFD (Parcela 3). Regresiones lineales junto a funciones y coeficientes de ajuste.

II.14. Distribución de los componentes precipitación neta $\left(\mathbf{P}_{\mathbf{n}}\right)$, trascolación $\left(\mathbf{T}_{\mathbf{r}}\right)$ y escurrimiento fustal $\left(\mathbf{E}_{\mathbf{f}}\right)$ en relación de la precipitación que incide sobre una plantación de E. camaldulensis en el PFD (Parcela 4). Regresiones lineales junto a funciones y coeficientes de ajuste.

II.15. Distribución de los componentes precipitación neta $\left(\mathbf{P}_{\mathbf{n}}\right)$, trascolación $\left(\mathbf{T}_{\mathbf{r}}\right)$ y escurrimiento fustal $\left(\mathbf{E}_{\mathbf{f}}\right)$ en relación de la precipitación que incide sobre una plantación de E. camaldulensis en el PFD (Parcela 5). Regresiones lineales junto a funciones y coeficientes de ajuste.

II.16. Redistribución porcentual de las distintas láminas de lluvia acumulada que inciden sobre en una plantación de $P$. radiata de la pampa ondulada.

II.17. Redistribución porcentual de las distintas láminas de lluvia acumulada que inciden sobre en una plantación de $E$. viminalis de la pampa ondulada.

II.18. Redistribución porcentual de las distintas láminas de lluvia acumulada que inciden sobre en una plantación de E. viminalis de la pampa deprimida (Parcela 1).

II.19. Redistribución porcentual de las distintas láminas de lluvia acumulada que inciden sobre en una plantación de E. camaldulensis de la pampa deprimida (Parcela 2).

II.20. Redistribución porcentual de las distintas láminas de lluvia acumulada que inciden sobre en una plantación de E. camaldulensis de la pampa deprimida (Parcela 3).

II.21. Redistribución porcentual de las distintas láminas de lluvia acumulada que inciden sobre en una plantación de E. camaldulensis de la pampa deprimida (Parcela 4).

II.22. Redistribución porcentual de las distintas láminas de lluvia acumulada que inciden sobre en una plantación de E. camaldulensis de la pampa deprimida (Parcela 5).

III.1 Curvas hipsométricas características del ciclo de erosión de Strahler. Adaptado de Gaspari et al., 2009

III.2. Descomposición de la precipitación en el tiempo. Fuente: López Cadenas del Llano (1998).

III.3. Curva hipsométrica correspondiente a la MALP.

III.4. Curva hipsométrica relativa correspondiente a la MALP.

III.5. Curva hipsométrica correspondiente a la Cuenca Langueyú. 105

III.6. Curva hipsométrica relativa correspondiente a la Cuenca Langueyú. 106 
IV.1. Curva de infiltración potencial instantánea en un suelo encharcado. Fuente: Muñoz y Ritter (2005).

IV.2. Evolución de los niveles de capa freática bajo cuatro coberturas vegetales de la pampa ondulada. Niveles de capa freática expresados en metros sobre el nivel del mar (msnm).

IV.3. Evolución de los niveles de capa freática bajo tres coberturas vegetales de la pampa deprimida. Niveles de capa freática expresados en metros sobre el nivel del mar (msnm).

IV.4. Precipitaciones acumuladas $(\mathrm{mm})$ y niveles de capa freática (mbnt) de la red de monitoreo de pozos en EEC, para un período de tres años de registros semanales.

IV.5. Precipitaciones acumuladas $(\mathrm{mm})$ y niveles de capa freática (mbnt) de la red de monitoreo de pozos de PFD, para un período de tres años de registros semanales.

IV.6. Isofreáticas y direcciones de flujo correspondientes para los puntos de inflexión de los niveles de capa freática de EEC. Máximos a la izquierda y mínimos a la derecha (Período: enero de 2009-diciembre de 2011).

IV.7. Isofreáticas y direcciones de flujo correspondientes para los puntos de inflexión de los niveles de capa freática en PFD. Máximos a la izquierda y mínimos a la derecha (Período: septiembre de 2009-agosto de 2012).

V.1. Repartición de la evapotranspiración en evaporación y transpiración durante el período de crecimiento de un cultivo anual. Extraído de Allen et al. (2006)

V.2. Comportamiento de la ETP, $\mathbf{P}$ y ETR (expresados en $\mathrm{mm}$ de lámina) para un ciclo hidrológico promedio de un pastizal de la EEC.

V.3. Comportamiento de la ETP, P y ETR (expresados en $\mathrm{mm}$ de lámina) para un ciclo hidrológico promedio de un pastizal del PFD.

V.4. Comportamiento de la ETP, P y ETR (expresados en mm de lámina) para un ciclo hidrológico promedio de una plantación de $P$. radiata de la pampa ondulada.

V.5. Comportamiento de la ETP, P y ETR (expresados en $\mathrm{mm}$ de lámina) para un ciclo hidrológico promedio de una plantación de $E$. viminalis de la pampa ondulada.

V.6. Comportamiento de la ETP, P y ETR (expresados en $\mathrm{mm}$ de lámina) para un ciclo hidrológico promedio de una plantación de $E$. viminalis de la pampa deprimida (Parcela 1).

V.7. Comportamiento de la ETP, P y ETR (expresados en mm de lámina) para un ciclo hidrológico promedio de una plantación de E. camaldulensis de la pampa deprimida (Parcela 2). 
V.8. Comportamiento de la ETP, P y ETR (expresados en $\mathrm{mm}$ de lámina) para un ciclo hidrológico promedio de una plantación de E. camaldulensis de la pampa deprimida (Parcela 3).

V.9. Comportamiento de la ETP, P y ETR (expresados en $\mathrm{mm}$ de lámina) para un ciclo hidrológico promedio de una plantación de E. camaldulensis de la pampa deprimida (Parcela 4).

V.10. Comportamiento de la ETP, P y ETR (expresados en $\mathrm{mm}$ de lámina) para un ciclo hidrológico promedio de una plantación de E. camaldulensis de la pampa deprimida (Parcela 5).

V.11. Evolución temporal de los componentes $\mathbf{P}$ y ETP correspondiente a la situación de referencia $\left(\mathbf{E T}_{\mathbf{0}}\right)$; a la plantación de $P$. radiata $\left(\mathbf{E T}_{\mathbf{P i n o}}\right)$; a la plantación de E. viminalis ( $\left.\mathbf{E T}_{\text {Evim }}\right)$, y a una situación de pastizal $\left(\mathbf{E T}_{\text {Past }}\right)$ en la EEC.

V.12. Evolución temporal de los componentes acumulados de $\mathbf{P}$ y ETP correspondiente a la situación de referencia $\left(\mathbf{E T}_{\mathbf{0}}\right)$; a la plantación de $P$. radiata $\left(\mathbf{E T}_{\mathbf{P i n o}}\right)$; a la plantación de E. viminalis $\left(\mathbf{E T}_{\text {Evim }}\right)$, y a una situación de pastizal (ET Past $_{\text {) }}$ en la EEC.

V.13. Evolución temporal de los componentes $\mathbf{P}$ y ETP correspondiente a la situación de referencia $\left(\mathbf{E T}_{\mathbf{0}}\right)$; la plantación de E. viminalis de la parcela 1

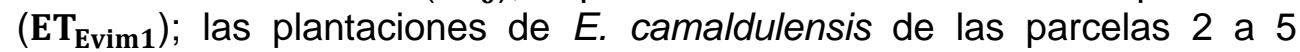
$\left(\mathbf{E T}_{\text {Evim2 }}-\mathbf{E T}_{\text {Evim5 }}\right)$, y la de una situación de pastizal (ET Past $\left._{\text {f }}\right)$ en el PFD.

V.14. Evolución temporal de los componentes acumulados de $\mathbf{P}$ y ETP correspondiente a la situación de referencia $\left(\mathbf{E T}_{\mathbf{0}}\right)$; la plantación de $E$. viminalis de la parcela 1 ( $\mathbf{E T}_{\text {Evim1 } 1}$; las plantaciones de E. camaldulensis de las parcelas 2 a 5 (ET Evim2 $\left._{\text {- }} \mathbf{E T}_{\text {Evim5 }}\right)$, y la de una situación de pastizal

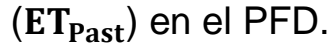




\section{Agradecimientos}

Quiero agradecer a CONICET por haber hecho posible la ejecución de mis estudios doctorales a través de su sistema de becas y a la Facultad de Ciencias Agrarias y Forestales de La Plata por ser el lugar donde he logrado formarme como profesional, tanto de grado como de postgrado, y donde siempre me he sentido muy cómodo en el desempeño de mis actividades.

También quiero mencionar, el increíble aporte que realizaron los evaluadores de esta tesis que no solo han hecho que mejore la misma, sino que han abierto nuevas inquietudes para investigaciones futuras.

Agradezco con inmensa gratitud a mis directores y colegas, considerados a todos como amigos. A los primeros porque han respetado mis tiempos y maneras de trabajo con buena predisposición y apoyo, y han sabido transmitirme sus conocimientos de forma clara y amena cuando fueron requeridos. A los segundos, por hacer del trabajo diario una actividad placentera y estar presentes desde el principio compartiendo trabajo y experiencias.

Por último, pero no por eso menos importante, agradezco a mis padres, hermanos y amigos que han sabido soportar todas mis ausencias haciéndome sentir todo su apoyo y confianza, y especialmente a mi señora, hijo e hija en viaje -los amores de mi vida-, cuya existencia y compañía valoro por sobre todas las cosas. 


\section{Dedicatoria}

Dedico este trabajo a Sara y Facu, tal vez los más deformados por mi formación 


\section{Resumen}

Desde el siglo XIX se ha resaltado la importancia de incluir forestaciones en la llanura pampeana argentina, atribuyéndoles cualidades únicas para modificar la dinámica hídrica de estos ambientes. Las escasas pendientes, suelos salino-sódicos y capa freáticas de poca profundidad, conforman un ambiente de gran fragilidad que se encuentra amenazado por el avance progresivo de la agricultura e intensa carga animal. Todas estas características condicionan largos períodos de sequías seguidos de inundaciones con severas consecuencias en la producción pecuaria. En estas condiciones los procesos erosivos dependen en gran medida de los cambios de uso del suelo y a las actividades productivas. La demanda de productos forestales a nivel mundial y el apoyo fiscal, ha puesto en la mira estos ambientes para el desarrollo de la actividad forestal. Sin embargo, el efecto de las forestaciones, resulta poco evidente dado que han sido introducidas en chacras y estancias de forma circunscripta y aisladas entre sí. Un entendimiento adecuado de la incidencia de una forestación en el sistema hidrológico, puede favorecer la búsqueda de criterios que mejoren el manejo del agua y por ende, de la actividad productiva muchas veces significativamente afectada por problemas de anegamiento y sequías.

Con el objetivo de evaluar la influencia hidrológica de forestaciones de rápido crecimiento de dos localidades en la llanura pampeana, como base para reconocer pautas de manejo del agua en ambientes de llanura, se realizó el presente estudio. Se determinaron y analizaron, durante tres años, los componentes del balance hidrológico sobre forestaciones de Pinus radiata Don y Eucalyptus viminalis Labill de la pampa ondulada y sobre forestaciones de Eucalyptus camaldulensis Dehnh y Eucalyptus viminalis Labill de la pampa deprimida. Con este fin se establecieron los siguientes objetivos específicos: 1) Analizar la redistribución de las precipitaciones bajo plantaciones forestales adultas de Pinus radiata Don, Eucalyptus viminalis Labill y Eucalyptus camaldulensis Dehnh en los dos predios de la llanura pampeana; 2) Modelizar el componente de escurrimiento superficial bajo las condiciones de uso actual de los predios analizados y simular posibles escenarios de cambio de uso en la conversión pastizal-forestación; 3) Evaluar las fluctuaciones del nivel de capa freática a nivel predial, como base para determinar las relaciones de recarga/descarga bajo los usos/coberturas considerados en cada sitio de estudio, y 4) Establecer una metodología sencilla para la estimación de los 
coeficientes de cultivo de las especies forestales a fin de cuantificar la evapotranspiración de los distintos cultivos evaluados.

Los resultados obtenidos en cuanto a la redistribución de las precipitaciones, permitieron concluir que la capacidad de intercepción de los pinos estudiados supera a la de los eucaliptos y que hay una relación directa entre la capacidad de intercepción y la edad de los rodales. Por su parte, la aplicación de la metodología del número de curva a través del modelo hidrológico L-THIA NPS, permitió establecer una importante reducción del escurrimiento superficial anual en la conversión de pastizales por forestaciones. Este modelo demostró ser una poderosa herramienta de diagnóstico en el estudio del comportamiento de los escurrimientos superficiales en situaciones hipotéticas de uso de la tierra. A nivel subterráneo, fue posible verificar que las forestaciones estudiadas en pampa deprimida favorecieron los procesos de infiltración ante períodos de excesos hídricos, a la vez que acentuaron los períodos de déficits al incrementar la descarga del acuífero freático en períodos con baja pluviometría. Las forestaciones de la pampa ondulada en cambio, demostraron atenuar los procesos de descarga en épocas secas o de baja pluviometría al tiempo que favorecieron los procesos de infiltración ante períodos de excesos hídricos. De esta manera, se observó que mientras que algunos rodales actuaron como sitios preferenciales de descarga, otros fueron capaces de facilitar o interrumpir la recarga al ser comparado con otros usos/coberturas. Por último, la metodología desarrollada para el cálculo de la evapotranspiración permitió demostrar que la conversión de pastizales por forestaciones de rápido crecimiento generó un aumento del $51-87 \%$ en la evapotranspiración con respecto a la situación natural y tornó los rendimientos hídricos de positivos a marcadamente negativos durante gran parte del tiempo. Esto representó un aporte del 35-67\% por encima de la precipitación media anual y dejó el precedente de que el rodal de pino presenta un menor rendimiento hídrico (descarga freática) frente a los de eucalipto y, dentro de estos, que los rodales de E. viminalis enseñan un rendimiento hídrico que supera al de E. camaldulensis.

Se concluye finalmente que las forestaciones realizan un uso más exhaustivo del agua frente a las coberturas herbáceas. Sus canopeas determinan altos porcentajes de intercepción que reducen el agua que alcanza el suelo, y una vez que lo hace, se encuentra con un mantillo que reduce la posibilidad de escurrir superficialmente y facilita su infiltración en el suelo. Esta infiltración, facilitada por un aumento de la porosidad y la hidrofobicidad de la materia orgánica, es rápidamente absorbida por la forestación y 
liberada al ambiente. La existencia de un acuífero libre a menos de $6 \mathrm{~m}$ de la superficie del suelo constituye un aporte de agua extra para las forestaciones, que la utilizan activamente cuando las condiciones ambientales son propicias, al punto de generar depresiones de más de $2 \mathrm{~m}$ de profundidad y convertir sitios naturales de recarga en sitios de descarga neta. Uno de los problemas más alarmantes del consumo de agua por parte de las plantas esta dado por la posibilidad de salinización de los suelos y napas, cuestión que ha sido abordada intensamente por estudios locales y es necesario seguir profundizando. 


\section{Abstract}

Since the XIXth Century the importance of including afforestation in the Argentinean Pampas has been highlighted because of its unique capacity to modify the water dynamics of these environments. The low slopes, the saline-sodic soils and the shallow water table constitute a very fragile environment threatened by the progressive advance of agriculture and intense animal use. All these characteristics determine long periods of drought followed by floods with severe consequences to the livestock production. Under these conditions erosive processes depend largely on changes in land use and productive activities. Worldwide demand for forest products as well as fiscal support has turned the attention towards these environments for the development of afforestation. Nevertheless, the effect of afforestation is not clearly evident due to the fact that it has been introduced in farms in a circumscribed and isolated way. A proper understanding of the effect of afforestation in the water system can help to find ways to improve the management of water, and hence, to improve the productive activities that are very often affected by floods and droughts.

The aim of the present study is to evaluate the hydrological effects of fast growing afforestation in two localities of the pampean prairie in order to identify criteria for the management of water in plain environments. During a three year period the different components of the water balance were determined and analyzed in afforestation of Pinus radiata Don and Eucalyptus viminalis Labill in the rolling pampa and in Eucalyptus camaldulensis Dehnh and Eucalyptus viminalis Labill in the flooding pampa. With this purpose the following specific objectives were established: 1) To analyze the rain distribution under adult afforestation of Pinus radiata Don, Eucalyptus viminalis Labill and Eucalyptus camaldulensis Dehnh in two localities of the pampean prairie; 2) To model the runoff under current land use conditions and simulate possible scenarios considering a change in land use (conversion from pasture to afforestation); 3) To evaluate fluctuations in the water table at farm level to determine relationships of charge/discharge under the land uses considered in each studied site, and 4) To establish a simple methodology to estimate the crop coefficient in order to quantify the evapotranspiration of the considered afforestation.

The results obtained in relation to rainfall indicate that pines have a higher interception capacity than eucalyptus, which is directly related to the age of the stands. 
Using the methodology of the curve number by means of the hydrological model L-THIA NPS, an important reduction of the annual runoff in the conversion of pasture to afforestation was established. This model proved to be a powerful tool for the diagnosis of superficial water runoff behavior in hypothetical situations of land use. At an underground level, it was confirmed that the afforestation studied in the flooding pampa increased infiltration processes in periods with excess water, and also increased water deficit in periods with low rainfall because of increased phreatic water discharge. In contrast the afforestation of the rolling pampa decreased water discharge during dry seasons or low rainfall and increased infiltration processes in periods of excess water. It was observed that while some stands acted as preferential sites for discharge, others were able to facilitate or interrupt recharge when compared with other land uses or coverage. Finally, the methodology developed to calculate the evapotranspiration demonstrated that the conversion from pasture to fast growing afforestation generated an increase of the evapotranspiration of $51-87 \%$ when compared to the natural situation and turned the hydric performance from positive to strongly negative for most of the time. This represented an extra contribution of $35-67 \%$ above the median annual precipitation, establishing that the pine stand has a minor water yield (groundwater discharge) than eucalyptus, and within the latter, that the stands of $E$. viminalis have a higher water yield than $E$. camaldulensis.

Finally it is concluded that afforestation make a more exhaustive use of water when compared with pastures. The canopy intercepts more water and reduces the amount that reaches the soil, the water that reaches the soil does not drain superficially so easily because of the litter and tends to infiltrate in the soil. This infiltration, facilitated by an increase of the porosity and hydrophobicity of organic matter, is quickly absorbed by afforestation and released to the environment. The existence of a phreatic aquifer at less than $6 \mathrm{~m}$ from the surface constitutes an extra supply of water for afforestation that is used when needed, generating depressions of more than $2 \mathrm{~m}$ deep and turning natural sites of recharge in sites of net discharge. One of the main problems related to water consumption by plants is the possibility of the salinization of soil and water tables. This issue has been treated in local studies and there is a clear need to keep on studying this matter. 
Capítulo 1

Introducción 


\subsection{INTRODUCCIÓN GENERAL}

\subsubsection{Situación de los bosques en el mundo}

Los bosques desempeñan un papel fundamental para la vida en la tierra: forman parte esencial en el ciclo global del carbono, constituyen ambientes de amplia biodiversidad y desempeñan un rol importante en disponibilidad y calidad del agua. Históricamente, los bosques han acompañado al desarrollo de las comunidades por medio de una infinidad de funciones que van desde el aporte de abrigo, alimento y combustible; hasta su utilización en la industria maderera, productos forestales no madereros (medicinales; nutracéuticos; alimenticios; bioquímicos, etc. (FAO, 2001; FAO, 2002)) y servicios ambientales (sumideros de carbono, regulación hídrica).

En la última evaluación de los recursos forestales mundiales (FAO, 2010a), se señala que el $31 \%$ de la superficie emergente del mundo se encuentra ocupada por bosques. Esto representa algo más de 4.000 millones de hectáreas concentradas mayoritariamente en la Federación Rusa, Brasil, Canadá, Estados Unidos de América y China (53\%), y aún se les debe sumar las tierras clasificadas como "otras tierras boscosas", en las que Argentina se posiciona como uno de los cinco países más representativos de este rubro, y "otras tierras con cubiertas de arboles" que constituyen, en conjunto, más del $9 \%$ del total de tierras emergidas (1.179 millones de ha).

El ecosistema de bosques es considerado como el más extenso del mundo. La preocupación sobre su uso y deterioro ha hecho que los países promuevan su conservación a través de la implementación de un variado conjunto de medidas, entre las que se destacan: el incremento de las superficies forestadas (cambio de uso de tierras) y la ordenación de los bosques naturales bajo un enfoque de sustentabilidad. La actual demanda de productos forestales y servicios de los bosques es una combinación de una demanda estática o ligeramente al alza de la madera, una demanda estable pero en ligero ascenso de productos forestales no maderables (PFNM) y una demanda pujante pero en gran medida no monetizada de servicios ambientales (Leslie, 2005). Estos servicios, a su vez, se relacionan con las funciones protectoras de los bosques y mantienen una íntima vinculación con el ciclo hidrológico de los ecosistemas que ocupan (Eagleson, 2002).

Actualmente, el $30 \%$ de los bosques del mundo se destinan a la producción maderera y de productos forestales no maderables (PFNM) como producción primaria; el 
24\% está destinado a usos múltiples, sin una actividad predominante; el 12\% está dedicado a la conservación de la biodiversidad; el 8\% tiene funciones de protección del suelo y el agua; el $4 \%$ se destina a funciones sociales y el resto presenta funciones desconocidas (FAO, 2010a).

El aumento y creciente impulso de las extensiones forestadas -aquellas que se establecen en tierras no forestales (FAO, 2011)- para la fijación de carbono, suministro de energía y madera, y la rehabilitación del paisaje (Perlis, 2007), ha generado inquietudes en cuanto a su impacto en el ciclo hidrológico (Nisbet et al., 2011, Jobbágy, 2011) dado que, tanto a nivel de árbol como de forestaciones, realizan un consumo más intenso del agua en comparación con vegetación más baja (Nisbet, 2005; Hamilton et al., 2009) y por consiguiente, afectan fuertemente la dinámica de este recurso.

La deforestación -causada mayoritariamente por la conversión de bosques a tierras de cultivo- ha manifestado una notable disminución global con cambios netos de superficie de 8,3 (1990-2000) a 5,2 millones de hectáreas por año (2000-2010) (FAO, 2011). Estas tendencias, sin embargo, no son compartidas por todas las regiones. Sudamérica y África han experimentado las máximas pérdidas netas de forestación (FAO, 2011). Argentina, por su parte, en el informe nacional de los recursos forestales mundiales 2010, informó una superficie de bosques de 29,4 millones de ha (0,73\% del total mundial), de los cuales el $4,7 \%$ representa las plantaciones forestales (cuyo uso es meramente productivo), el 3,9\% es destinado a funciones de conservación de la biodiversidad, el 8,7\% a usos variados, y el $82,7 \%$ restante posee una función desconocida (FAO, 2010b). La superficie destinada a la protección del suelo y recursos hídricos no es incluida en estos porcentajes, y por lo tanto es inexistente o por lo menos desconocida, lo que constituye un buen parámetro del avance a nivel país en materia de la conservación del recurso agua y refleja un claro déficit en este aspecto.

Calder y colaboradores (Calder et al., 2007) indicaron la necesidad de acortar la brecha entre la investigación hidrológica forestal y el diseño de las políticas forestales, además de resaltar la importancia de fortalecer los vínculos políticos entre los sectores forestal e hídrico. La sobreexplotación, contaminación y mal uso de los recursos en varias regiones del mundo, amenazan fuertemente la disponibilidad y la calidad del agua potable, y hacen que la relación entre los bosques y el agua sea una cuestión crítica a la que se debe otorgar una gran prioridad (Hamilton et al., 2009). 


\subsubsection{El ciclo del agua y las forestaciones}

El concepto de Ciclo del Agua (Ciclo Hidrológico), hace referencia a la circulación del agua en sus diversas formas y sistemas de almacenamiento a nivel mundial. Custodio y Llamas (1996) lo definen como un proceso continuo e irregular, tanto en el espacio como en el tiempo, en el que una partícula de agua que se evapora del océano regresa a él luego de haber pasado por los procesos de precipitación y escurrimiento superficial o subterráneo. Tal vez, una de las definiciones más concretas del "ciclo hidrológico" es la que hacen Ven te Chow y colaboradores (Chow et al., 1994) al decir que "se trata de la circulación ininterrumpida del agua entre la tierra y la atmósfera". Estos autores señalan, además, que este ciclo -foco central de la hidrología- no presenta un principio ni un fin y sus diversos procesos ocurren en forma continua.

La magnitud que adoptan los procesos (según sea el sistema en consideración) se materializa a través de balances hidrológicos que, en el caso particular de los ecosistemas forestales, dejan su impronta en el componente de intercepción y transpiración. (Poore y Fries, 1987; Cantú y González, 2002; Nosetto et al., 2005; Jobbágy et al., 2006b; Licata et al., 2011).

En la figura I.1 se esquematiza el ciclo hidrológico con todos sus componentes y porcentajes relativos de agua. Se parte de una lluvia incidente sobre la superficie terrestre del 100\%, que luego se desagrega en los distintos componentes del balance hídrico. El proceso de generación de caudales se vincula al tiempo de permanencia del agua, referido a cuencas pequeñas con cobertura forestal de regiones de clima húmedo templado (Hewlett, 1982). En este esquema, el $67 \%$ de la precipitación anual retorna a la atmósfera por evapotranspiración mientras que el elevado porcentaje asignado a la infiltración (91\%) pone de manifiesto el papel regulador de las coberturas forestales. Luego de que el agua infiltrada es absorbida por las raíces (60\%), una parte (8\%) llega al flujo como escurrimiento subsuperficial y otra parte (23\%) alcanza el acuífero libre y alimenta el flujo base (23\%) (Giraldo, 2002). El análisis del flujo y almacenamiento de agua en el balance global de agua da una visión de la dinámica del ciclo hidrológico (Chow et al., 1994). 


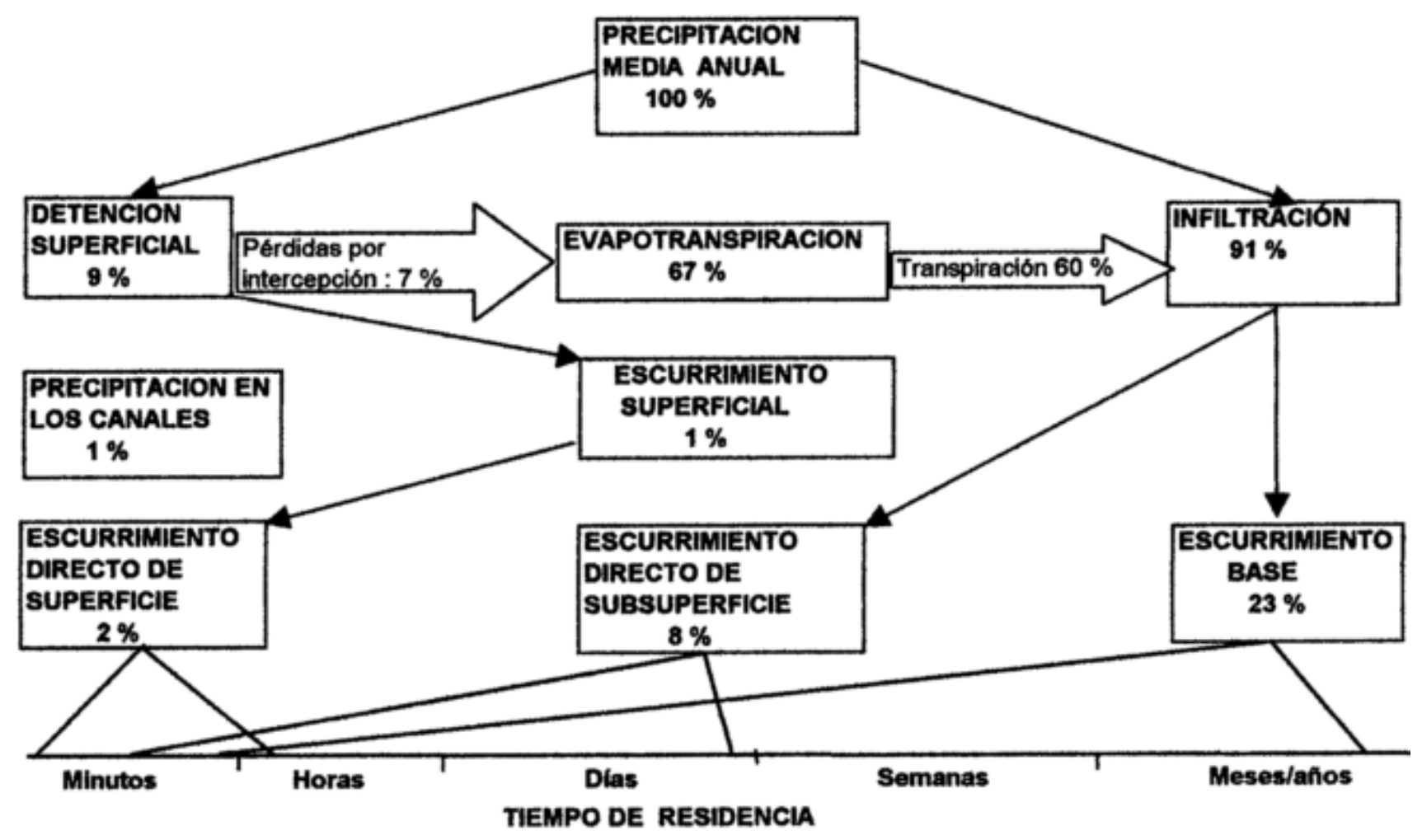

Figura I.1. Distribución porcentual de los componentes del balance hídrico junto con el tiempo de permanencia general indicada para cuencas hidrográficas pequeñas en buenas condiciones de cobertura forestal y en condiciones de clima templado. Extraído de Giraldo López (2002)

Si se considera que el sistema objetivo es un árbol individual en un suelo sin pendiente significativa -como es el caso de la pampa húmeda- (Figura I.2), los aportes de agua estarían dados principalmente por el agua proveniente de las precipitaciones (P). Además, los flujos horizontales -disminuidos por la baja energía morfológica del terreno-, podrían considerarse mínimos, más aún si se tratara de suelos con porosidades bajas y salino-sódicos, donde los flujos subsuperficial $\left(R_{s s}\right)$ y subterráneo $\left(R_{\text {subt }}\right)$ se verían muy reducidos. 


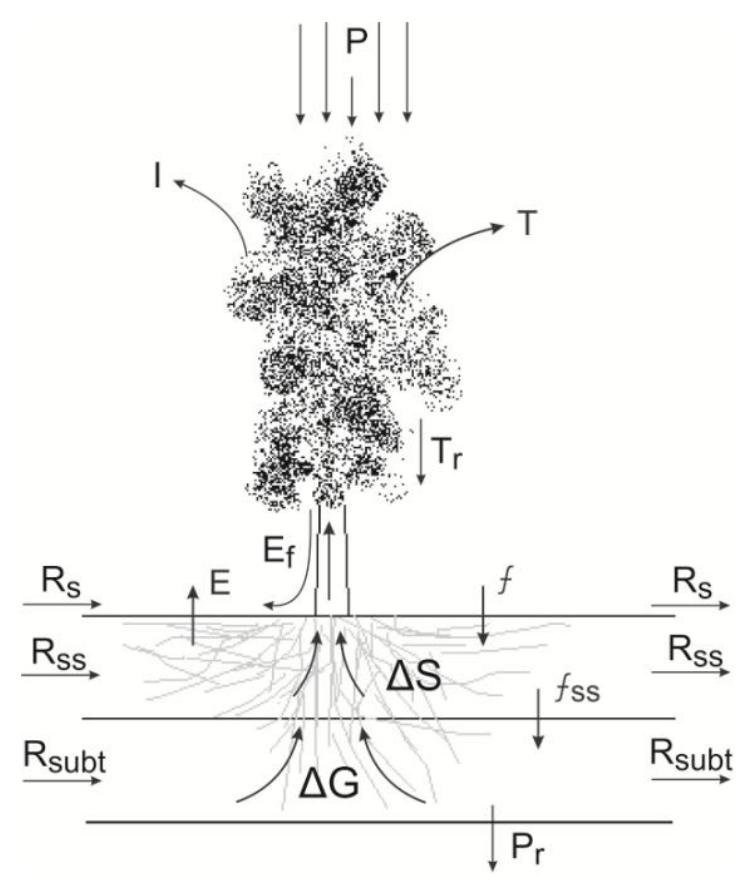

Figura I.2. Componentes del ciclo hidrológico para un árbol individual de la llanura pampeana tomado como sistema objetivo.

En este esquema, las pérdidas de agua se encuentran representadas esencialmente por los componentes de Intercepción (I), Transpiración (T), Evaporación (E) desde el suelo y Percolación profunda ${ }^{1}\left(\mathrm{P}_{\mathrm{r}}\right)$, que representa al agua que permea hasta acuíferos profundos sin formar parte de la descarga natural ${ }^{2}$. Complementariamente, los flujos verticales faltantes en este modelo están representados por el agua que atraviesa la canopea ${ }^{3}$ del árbol para llegar al suelo $\left(\mathrm{T}_{\mathrm{r}}\right)$-trascolación o throughfall-, el agua que escurre por los tallos de ramas y tronco $\left(\mathrm{E}_{\mathrm{f}}\right)$-escurrimiento fustal o stemflow-, la Infiltración (f) y la infiltración efectiva o recarga freática $\left(\mathrm{f}_{\mathrm{ss}}\right)$.

En la llanura pampeana, el agua de lluvia es de origen predominantemente convectivo (Sarochar et al., 2005) y representa la principal entrada al sistema (Usunoff et al., 1999). Esta, una vez que alcanza la canopea forestal, recorre tres caminos alternativos:

1 es el agua subterránea que fluye directamente al océano y evita, de esta manera, las aguas superficiales.

${ }_{2}^{2}$ La descarga natural corresponde al agua subterránea que alcanza la superficie (emerge por exfiltración) para conformar el flujo base.

3 Término proveniente del inglés "Canopy" y esta del latín "Canopus" (famosa ciudad egipcia conocida por sus grandes lujos), que sirve para indicar el hábitat que se encuentra en el dosel forestal. La canopea de un árbol individual se refiere a la capa superior de sus hojas (Colaboradores de Wikipedia, 2013a). 
atraviesa libremente el dosel forestal ${ }^{4}$ (trascolación), es interceptada por ramas y hojas y eventualmente se pierde a la atmósfera como vapor de agua (intercepción) o, superada la capacidad de retención de la planta, escurre por hojas y ramas hasta el suelo (escurrimiento fustal). Del conjunto de agua que alcanza el suelo -precipitación neta ${ }^{5}$-, una parte escurre por la superficie (escurrimiento superficial), otra parte se evapora (evaporación) y el resto penetra en el suelo para humedecerlo (infiltración), drena hasta la zona saturada (recarga o infiltración efectiva), o se pierde hacia capas más profundas (percolación profunda) fuera del alcance de las raíces donde no puede ser utilizada por el metabolismo del árbol (transpiración).

Otras vías de entrada de los sistemas forestales están dados por: la precipitación horizontal ${ }^{6}$ y el escurrimiento superficial (R). De estos, el primero constituye un fenómeno significativo en el caso de los bosques nublados de América central (FAO, 1995) o de Tenerife (España), donde ya los aborígenes hacían uso de él (Suárez, 2009), y el segundo es sumamente bajo en los sistemas llanos y, de ocurrir, es de tipo mantiforme, con largos períodos de permanencia en las depresiones del terreno (Fuschini Mejía, 1994; Usunoff et al., 1999).

Como se mencionó anteriormente, las pérdidas en los sistemas forestales se encuentran vinculadas con su mayor capacidad evapotranspirativa, mientras que las pérdidas por percolación profunda, si bien podrían estar ausentes bajo las forestaciones, representan la principal alimentación de los acuíferos profundos a nivel de paisaje (Auge, 2009).

Los ecosistemas forestales demandan grandes cantidades de agua, incluso más que casi todas las cubiertas de sustitución (incluidas la agricultura y el pastoreo), lo cual desestima la concepción hidrológica forestal que más árboles equivalen a más agua (Hamilton y King, 1983; Bruijnzeel, 1990; Kelliher et al., 1993; Zhang, 2001; Calder et al., 2007; Hamilton et al., 2009). Lee (1980), por su parte, sugiere que las diferentes clases de

${ }^{4}$ Capa aérea vegetal. Se define por el conglomerado de tallos, hojas, ramas, flores y frutos de las diferentes especies que crecen y se ubican en la parte aérea del bosque o copas de los árboles.

${ }^{5}$ Agua que efectivamente llega al suelo forestal (trascolación + escurrimiento fustal) y abastece al ciclo hídrico de un bosque (Huber y Oyarzún, 1983).

${ }^{6}$ En el interior de un bosque hay un aumento de precipitación que se escapa al pluviómetro corriente, pero que se comprueba directamente, por las gotitas de agua de la niebla condensada, que se mueven horizontalmente, se depositan en las copas y forman gotas que escurren al suelo. Este fenómeno ha sido llamado "precipitación horizontal y condensación oculta" (Giraldo López, 2002) 
plantas se ubican en el siguiente orden, de acuerdo a las cantidades de agua que interceptan: pinos > eucaliptos > otros árboles latifoliados > rastrojo > pastizales. Esta mayor demanda de agua por parte de las forestaciones, se debe a que, en general, presentan mayor área foliar, una mayor rugosidad de dosel y acceso a fuentes de agua más profundas que los pastos (Kelliher et al., 1993; Canadell et al., 1996; Calder, 1998; Jackson, 1999; Schenk y Jackson, 2002).

En general, las experiencias demuestran que el fenómeno de intercepción es mayor en precipitaciones débiles que en aguaceros fuertes, lo que indica que las especies de hoja caduca (frondosas) obtendrían un volumen menor de intercepción que las de hoja perenne (coníferas) (López Cadenas de Llano, 1998). Huber et al. (2010) afirman que los bosques en general, y las plantaciones forestales en particular, involucran una mayor cantidad de agua en la evapotranspiración y registran una superior pérdida de agua por intercepción del dosel en comparación a otros tipos de cubierta vegetal. Las cantidades relativas de este componente difieren entre especies en función de la arquitectura de los doseles y la intensidad y frecuencia de las precipitaciones. Así, se puede diferenciar especies latifoliadas como la teca y la caoba africana con valores de intercepción cercanas al $20 \%$ de la precipitación, mientras que las copas ralas del eucalipto interceptan cerca de 12\%, y rodales de rápido crecimiento con valores mayores de $40 \%$ para el caso de la Acacia mangium y $<25 \%$ para la coníferas en general (Bruijnzeel, 1997).

La precipitación neta, por otro lado, es la responsable de la recarga del volumen de humedad de los suelos. Esta se compone por la trascolación como el elemento más significativo, mientras que el escurrimiento fustal solo tendría relevancia porque penetra muy cerca a la base del tronco y de esta manera se pone en contacto inmediato con las raíces al infiltrar más rápida y efectivamente (Poore y Fries, 1987).

La tasa de fijación de carbono por parte de las forestaciones es muy variable y se encuentra íntimamente vinculada a su consumo de agua a través del proceso de transpiración, concebido como una consecuencia del control estomático que permite el ingreso del dióxido de carbono para la realización de la fotosíntesis (Winkler et al., 2009). Bruijnzeel (1997), señala estudios que reportan valores diarios de transpiración para a) rodales jóvenes a semimaduros y b) rodales adultos. En el primer caso, se tiene valores 3$5 \mathrm{~mm}$ frente a una situación sin limitaciones de agua en el suelo (Okali, 1980; Roberts y Rosier, 1993; Waterloo, 1994), mientras que en condiciones particulares de radiación y 
desfavorables de humedad edáfica se observan picos de 6-8mm/día (Kallarackal, 1992; Waterloo 1994). En el caso de plantaciones maduras, con defoliación estacional o con estrés hídrico, los valores usualmente decaen a 1-3mm/día (Monteny et al., 1985; Waterloo, 1994) o menos, bajo condiciones muy estacionales (Roberts y Rosier, 1993).

La posibilidad de acceso a fuentes subterráneas de agua y la capacidad de las raíces de aprovecharla, hacen que los árboles no sufran déficits hídricos, aún en climas secos, y utilicen tanto como necesiten (cantidad sujeta a la provisión de radiación solar y vientos) (Poore y Fries, 1987). La utilización de agua freática en la pampa deprimida ha sido documentada por Jobbágy y Jackson (2004) y presenta una serie de aspectos positivos como puede ser la mejora de la productividad y la atenuación de los riesgos de inundaciones al mantener los niveles freáticos más deprimidos, sin embargo, se evidencia una caída en el rendimiento hídrico y la posibilidad de una amenaza a la productividad por acumulación de sales (Jobbágy, 2011).

Por el contrario, la ausencia de un suministro subterráneo de agua, genera una dependencia sobre el reabastecimiento de la humedad del suelo, influenciado por el clima y en particular, por las fluctuaciones estacionales de la proporción entre precipitación y evapotranspiración potencial (Poore y Fries, 1987). Farley et al. (2005), en un estudio de la conversión de pastizales y arbustales por forestaciones alrededor del mundo, determinaron una caída promedio del rendimiento hidrológico del 39\% (167mm/año). A su vez, se advirtió que las reducciones causadas por las plantaciones de eucaliptos (50\%) superaban a las de pinos (30\%) y que, si se consideraba la proporción de los ingresos de agua de lluvia que llegan a los arroyos (fracción de rendimiento hidrológico) bajo cada par de pastizal o arbustal natural vs. forestación, esta fracción no se mantenía constante, por ello se tomó una reducción media de todos los pares del 15\% (porcentaje de la precipitación anual que deja de llegar a los cursos de agua). Esto se interpreta al considerar que un pastizal forestado, que antiguamente tenía un rendimiento hídrico del 15\%, ahora tendría posiblemente una reducción total de ese caudal (Jobbágy et al., 2006b).

La magnitud que toman todos estos flujos bajo las distintas condiciones climáticas, tipos de suelos y especies vegetales reviste gran importancia en la dinámica hídrica de los sistemas llanos. El estudio de estos flujos bajo plantaciones forestales, resulta entonces necesario para anticipar tanto sus efectos deletéreos como beneficios ecosistémicos. 


\subsubsection{Efecto de las forestaciones en el ciclo hidrológico}

La cobertura vegetal de los bosques influye sobre todos los procesos hidrológicos: intercepción de la lluvia (Huber y Oyarzun, 1984), variación en la evapotranspiración (Nosetto et al. 2008), retardo del escurrimiento y el aumento de la infiltración (Bruijnzeel, 1997). La acción de los sucesivos estratos sobre la circulación del agua, se evidencia en una modificación en las vías de escurrimiento hacia los cursos de agua o en su infiltración hacia el subsuelo (Mármol, 2006). Wooldridge (1970), por su parte, considera que el mantillo forestal es especialmente importante para mantener las tasas de infiltración rápidas y por lo tanto tiene influencia en las variaciones de los niveles freáticos. Por otra parte, la incorporación de la materia orgánica en los suelos minerales, de manera artificial o por medios naturales, aumenta su permeabilidad como resultado de una mayor porosidad (Pritchet, 1991).

En un análisis de los efectos que tienen a nivel mundial las forestaciones y reforestaciones, Farley et al. (2005) mencionan una disminución promedio del 44\% (+/$3 \%)$ en la escorrentía para zonas forestadas, y del $31 \%$ (+/- 2\%) para forestaciones donde previamente había pastos y arbustos. Menciona, además, al eucalipto como la especie de mayor impacto sobre el escurrimiento superficial en zonas en las que previamente había pastizales $(75 \%+/-10 \%)$, en comparación con el pino $(40 \%+/-3 \%)$. Indica que estas reducciones en las pérdidas por escorrentía de pastizales forestados pueden ser aún más severas en regiones secas que en húmedas. Cuando la escorrentía superficial es inferior al $10 \%$ de la precipitación media anual, las pérdidas en pastizales forestados se anulan completamente.

Jackson et al. (2005), a partir del estudio de más de 600 observaciones alrededor del mundo, afirman que las plantaciones provocan una disminución en el caudal de los cursos de agua equivalente a $227 \mathrm{~mm}$ por año globalmente (52\%), lo cual significa que un $13 \%$ de éstos permanezcan completamente secos por al menos un año.

Experiencias efectuadas en Uruguay, demuestran que las plantaciones forestales reducen el rendimiento hidrológico (escurrimiento superficial más infiltración) en aproximadamente un $70 \%$ con relación a la vegetación original (Panario et al., 2006).

A nivel regional, estas particularidades se verifican sobre extensos sectores de la llanura pampeana. La presencia de una capa freática poco profunda, resultante de un 
clima húmedo y un relieve muy plano con pobres redes de escurrimiento superficial, puede brindar un aporte adicional de agua para los cultivos y, en ciertas circunstancias, tornarse perjudicial cuando causa anegamiento y anoxia al cultivo (Jobbágy et al., 2007a).

En un estudio realizado sobre veinte pares de parcelas de pastizales en la región pampeana de Argentina (Jobbágy y Jackson, 2004), se obtuvo que el uso del agua subterránea por parte de las forestaciones puede mejorar la producción primaria, a la vez que provee una herramienta para el control de crecidas. Además, se estableció que las forestaciones poseen una mayor superficie foliar, una canopea más densa y un sistema radical con acceso más profundo a fuentes de agua. Estos cambios usualmente resultan en un aumento de pérdida de agua por evaporación, en un menor contenido de humedad en el suelo y zona de transición, y en una reducción de la recarga de agua subterránea.

Jobbágy et al. (2006b), indican además que la productividad primaria (ganancia de carbono o tasa de crecimiento), así como la acumulación de biomasa, son mayores en las plantaciones forestales que en el campo natural, y que este aumento de la productividad está acompañado por un mayor uso del agua por parte de los árboles, lo que aumenta la cantidad de agua evaporada y disminuye el rendimiento hidrológico. Asimismo, consignan que las disminuciones en el caudal de escurrimiento serían cercanas al 50\%, y que en situaciones donde el agua freática se encuentra cercana a la superficie, los árboles pueden aprovecharla, y al hacerlo, salinizar suelos y napas. Este fenómeno se verificaría en áreas con sedimentos de texturas medias (p. ej. materiales loéssicos) pero no en áreas de dunas o sedimentos muy arcillosos.

En suma, los procesos hidrológicos y las posibilidades de manejo del agua, vinculados a forestaciones, no pueden desvincularse de la problemática hidrológica de las grandes llanuras y requieren un cuidadoso tratamiento.

\subsubsection{Estado del conocimiento}

Los estudios sobre balances hidrológicos bajo forestaciones, pese a la importancia que posee la economía del agua y la alta influencia que ejercen las forestaciones en ella, no han sido tratados de forma extensa en Argentina. 
En lo que refiere a los bosques nativos, se puede nombrar el estudio llevado a cabo en Tierra del Fuego por Frangi y Richter (1994), donde se concluye que el agua no representaba una limitante para los bosques basales de Nothofagus y los componentes del ciclo hidrológico están asociados a variables de sitio como: regímenes de precipitación, relieve y suelos, y a factores estructurales de los bosques, como ser: estructura, fenofases foliares, biomasa, índice de área foliar y arquitectura, entre otras.

En la Patagonia se encuentran antecedentes referidos al uso plantaciones de Pinus ponderosa y su relación con pastizales y especies forestales nativas (Gyenge et al., 2002, 2003, 2011; Licata et al., 2008, 2011; Fernández et al., 2007). En ellos se demuestra que el consumo de agua por los pinos supera al de los pastizales y especies forestales nativas, aunque presentan valores de intercepción más bajos que estas últimas y un efecto benéfico sobre los pastos en meses con gran humedad edáfica. Además, resulta interesante que al analizar el efecto hidrológico del pino oregón en reemplazo de ñirantales y vegetación arbustiva nativa (Gyenge et al., 2009, 2011; Fernández et al., 2009), donde las diferencias entre las características fisiológicas y áreas foliares suponían intercepciones más elevadas y mayores consumos hídricos, no se hallaron diferencias significativas en los flujos de agua subterránea (causados por un mayor consumo de agua por parte de las especies exóticas). Sin embargo, en todos los casos de introducción de especies de rápido crecimiento (pino ponderosa y oregón) sobre sistemas nativos (pastizal, ciprés de la cordillera y bosque mixto de ñire), se verificó un aumento en la eficiencia del agua (Gyenge et al., 2011). Esto destaca la importancia de la continuidad de estos estudios para un correcto manejo del agua en estas zonas, particularmente en las más secas.

En Concordia, provincia de Entre Ríos, existen estudios que contrastan plantaciones de Eucalyptus grandis con los pastizales de la zona (Nosetto et al., 2005; Tesón, 2012) donde se verifica que la evapotranspiración de las plantaciones de eucaliptos duplicaría prácticamente a la de los pastizales mientras que reducen en un $80 \%$ el escurrimiento superficial.

En Santa Fe, desde el Instituto de Clima y Agua del INTA, se encuentran antecedentes sobre la contribución de plantaciones de Eucalyptus dunnii al balance hídrico regional, donde los consumos de agua con respecto al doble cultivo trigo-soja difieren en menos del $10 \%$ a la vez que cuadriplican la eficiencia en su uso (Rébori, 2004). 
En provincia de Buenos Aires Jobbágy y colaboradores (Jobbágy et al., 2006b, 2008; Jobbágy y Jackson, 2004, 2007; Engel et al., 2005) han estudiado el ciclo hidrológico de las plantaciones forestales con especial atención en el uso de agua subterránea y su relación con los pastizales. Estos autores observaron que las forestaciones hacen uso de las aguas subterráneas, para suplementar en un $25-50 \%$ a las precipitaciones ( $67 \%$ del consumo anual en E. camaldulensis), a la vez que ocasionan la salinización local de los suelos de porosidad intermedia $\left(6 \mathrm{~kg} / \mathrm{m}^{-2}\right.$ de sales bajo $E$ camaldulensis), al impedir la recarga de napas y lixiviación de sales. Esto se atribuye al mayor consumo de agua que hacen las especies forestales frente a los pastizales, que se traducen en aumentos del 40$80 \%$ de las pérdidas por evapotranspiración (Nosetto et al., 2005). Por otro lado, no descartan el uso de forestaciones para revertir el ascenso de napas freáticas (Jobbágy et al., 2006b; Jobbágy, 2011), problema severo en Australia, donde se sugiere un cubrimiento del $70 \%$ de las cuencas (George et al., 1999).

Estos estudios son indudablemente valiosos y, dada la acelerada demanda de productos forestales en el mundo y la dependencia que este tipo de actividad tiene con el agua, hacen necesaria su continuidad en la Argentina y particularmente en ambientes frágiles como la llanura pampeana.

\subsubsection{Ilanura pampeana}

La región pampeana, también conocida como pradera o llanura pampeana, se encuentra ubicada en las llanuras orientales de Argentina y constituye una de las praderas naturales más fértiles del mundo, dominada por una estepa de gramíneas y caracterizada por la ausencia o escasez de ejemplares arbóreos (León y Burkart, 1998; Morello et al., 2000; Batista et al., 2005; Szpeiner et al., 2007; Nuñez et al., 2007; PROSAP, 2010).

En ella se desarrolla la subregión húmeda pampeana, cuya explotación y creciente productividad de carnes y granos, se encuentra ligada a sucesivas transformaciones técnicas en el ámbito de la agricultura y la ganadería desde el siglo XIX (Viglizzo et al., 2002; Carlevari y Carlevari, 2007). Este fenómeno, acentuado en las últimas tres o cuatro décadas, se suma a la fuerte interrelación que existe entre aguas superficiales y subterráneas, establecida por el predominio de los movimientos verticales (evapotranspiración e infiltración) frente a los horizontales (escurrimiento) y a la escasa 
profundidad del nivel freático (Laurencena et al., 2005; Rojo et al., 2008; Jobbágy et al., 2007a; Vázquez et al., 2011). Esta situación conforma un área de suma fragilidad ante eventos hidrológicos extremos, de déficit o de excedentes hídricos (Montico, 2004), que genera un alto grado de incertidumbre frente a las consecuencias de estos cambios sobre el ambiente natural y su capacidad productiva a largo plazo.

De forma contemporánea al desarrollo productivo de la subregión húmeda pampeana, se manifiesta un creciente interés en la inclusión de especies forestales en estos sistemas productivos, atribuyéndoles cualidades únicas para modificar la dinámica hídrica de estos ambientes, al punto de ser consideradas verdaderas herramientas correctoras de los procesos naturales que lo degradan (Ameghino, 1884; Pritchet, 1991; Gottle y Sène, 1997; Mármol, 2006; Besteiro, 2010). Sin embargo, las distintas referencias a nivel nacional e internacional son poco frecuentes y carecen de un enfoque ecosistémico que integre las forestaciones en la fase superficial del ciclo hidrológico.

Por más de un siglo, los árboles han sido introducidos en chacras y estancias, y se han mantenido circunscriptos a sectores reducidos y aislados entre sí. Su efecto como reguladores de los problemas ocasionados por las secas e inundaciones a través de su incidencia en la carga y descarga de napas, control del escurrimiento hacia los arroyos, elevado consumo de agua y alto poder evapotranspirante, no ha sido dilucidado aún, lo que hace incipiente el estado de conocimiento al respecto.

El común acuerdo, indica que los ambientes planos como la llanura pampeana argentina, están caracterizados por escasas pendientes y capas subterráneas de agua muy superficiales y en ocasiones aflorantes (Laurencena et al., 2002; Vázquez, 2003; Auge et al., 2006; Jobbágy et al., 2007b; Nuñez et al., 2007). Constituyen, de esta manera, un ambiente afectado por largos períodos de sequías seguidos de inundaciones con severas consecuencias en la producción pecuaria, donde los procesos erosivos se encuentran relegados, en gran medida, a los cambios de uso del suelo y actividades productivas (Sala et al., 1981; León y Burkart, 1998; Vázquez et al., 2011).

El efecto de las forestaciones en estos ambientes, a pesar de ser consideradas como altas consumidoras de agua (Jobbágy et al., 2008), no es evidente. Esto se debe a la exigua presencia de forestaciones extensas, lo cual resalta la necesidad de realizar estudios de carácter local o puntual sobre los efectos de las forestaciones en el ciclo hidrológico de zonas llanas para comprender la influencia de las masas forestales en la 
interrelación aguas superficiales-aguas subterráneas, y que impulsen, ulteriormente, a la actividad forestal como una nueva actividad, complementaria a la actual y que es reconocida a nivel mundial por sus cualidades para modificar la dinámica hídrica de estos ambientes (Ameghino, 1884; Pritchet, 1991; Gottle y Sène, 1997; Mármol, 2006; Besteiro, 2010).

Un entendimiento adecuado de la incidencia de una forestación en este sistema hidrológico, puede favorecer la búsqueda de criterios que mejoren el manejo del agua y por ende, de la actividad productiva muchas veces significativamente afectada por problemas de anegamiento y sequías. 


\subsection{FUNDAMENTOS DE LA ELECCIÓN DEL TEMA}

La necesidad de explorar nuevos horizontes productivos frente a un crecimiento demográfico sostenido y la consecuente demanda de productos alimenticios, recursos naturales, tierras y manufacturas de todo tipo, ha generado una vertiginosa degradación de los recursos naturales a nivel mundial (McNeill, 2003). Contaminación, degradación y cambio climático, son ejemplos de la huella del hombre en nuestro planeta. Estos desequilibrios han llevado a la comunidad científica a realizar tangentes esfuerzos en dilucidar las causas, efectos y alternativas que permitan revertirlos. En este contexto, es posible reconocer al agua como el elemento esencial que vincula en mayor o menor medida el sinfín de procesos biológicos, físicos y químicos que hacen posible la vida (Sancho Sanz, 2007). Resulta sensato entonces, abocarse al estudio del agua y su correcta gestión. Sin embargo, esta problemática dista mucho de ser sencilla de resolver y requiriere del control de numerosas variables, en estudios prolongados en el tiempo y generalmente muy difíciles y costosos de implementar.

En el último siglo, los problemas vinculados con los excesos hídricos son enfrentados por medio del desarrollo de infraestructura hidráulica que, a pesar de ser necesaria en ciertos casos, no es suficiente para garantizar el uso sustentable del agua, la salud humana y el desarrollo económico.

El creciente interés en la instalación de masas forestales en la llanura pampeana, motivado por sus altos rendimientos y el apoyo fiscal (Jobbágy et al., 2006b), requiere necesariamente de una perspectiva que incorpore la dimensión ambiental, que conciba como un hecho irrefutable que el agua es un recurso natural esencial para mantener la vida en el planeta y que la única forma de seguir disfrutándolo es a través de su conocimiento y cuidado. Las forestaciones, como altos consumidores de este recurso, constituyen un ámbito de estudio prometedor y el hecho de presentar turnos largos y crecimiento retardado, las convierten en potenciales laboratorios biológicos.

Por estos motivos, se debe avanzar en el estudio del impacto hidrológico de las forestaciones de rápido crecimiento en la llanura pampeana, para lograr una correcta gestión del recurso agua. 


\subsection{ELECCIÓN DE LAS ÁREAS DE ESTUDIO}

Para la definición de las áreas de estudio se siguió una secuencia sencilla de criterios: en primer lugar, se identificaron aquellas forestaciones de la llanura pampeana cuya superficie en el terreno fuera suficientemente amplia como para provocar efectos identificables a nivel de carga y descarga de acuífero freático. Esta superficie se fijó en un mínimo de 5ha. Luego, se definieron aquellos sitios en los que fuera posible el libre acceso para la instalación y mantenimiento del instrumental de medición. Conjuntamente, al tratarse de mediciones semanales, se priorizaron aéreas cercanas y/o con personal de campo estable, dispuesto a ser capacitado para realizar las mediciones. Finalmente, se tomaron aquellos sitios en los que estuviera asegurada la permanencia de la extensión forestada por más de tres años y en donde fuera posible mantener la integridad del instrumental ante posibles hurtos y vandalismo.

El resultado de esta selección fue la adopción de dos sitos experimentales (áreas de estudio), ubicados en zonas características de la región pampeana: la pampa ondulada y la pampa deprimida. Las mismas, se las puede situar hidrológicamente en las cuencas de desagüe al Río de La Plata al Norte del Río Samborombón, correspondiente al sistema de la Región Noreste de la pampa húmeda, y la Zona de canales al Sur del Río Salado, perteneciente al sistema de la Región Atlántica Oriental de la pampa húmeda.

Con una extensión aproximada de $161.000 \mathrm{~km}^{2}$, estas subregiones se caracterizan por sus netas condiciones de llanura con redes hidrográficas restringidas por la exigua pendiente topográfica, la definición de cuencas hídricas de bordes difusos en donde abundan los cursos y cuerpos lacustres efluentes (Auge et al., 2006), y por la presencia de un acuífero libre muy cercano a la superficie en estrecha relación con las aguas superficiales. La descarga regional se produce en los ríos Paraná y de la Plata, y en el Océano Atlántico (Auge y Hernández, 1984).

El clima es templado húmedo con precipitaciones abundantes, en el orden de 700 a $1000 \mathrm{~mm} / a n ̃ o ~(N e w ~ e t ~ a l ., ~ 2002)$, distribuidas de manera más o menos homogénea a lo largo del año. Se reconocen, además, excesos hídricos de 0 a 250mm/año concentrados en el período otoño-invernal (Auge et al., 2006) y el predominio de los movimientos verticales del agua (evapotranspiración-infiltración) frente a los horizontales (escurrimiento) (Laurencena et al., 2005; Vázquez et al., 2011). 
Los sitios experimentales dentro de estas subregiones, poseen un carácter predial debido, básicamente, a la escasez de áreas amplias y densamente forestadas, suficientemente representativas de estas regiones. Éstos, serán referidos bajo la denominación de "Estancia El Centauro" (EEC) y "Predio Forestal Dolores"” (PFD) (Figura I.3).

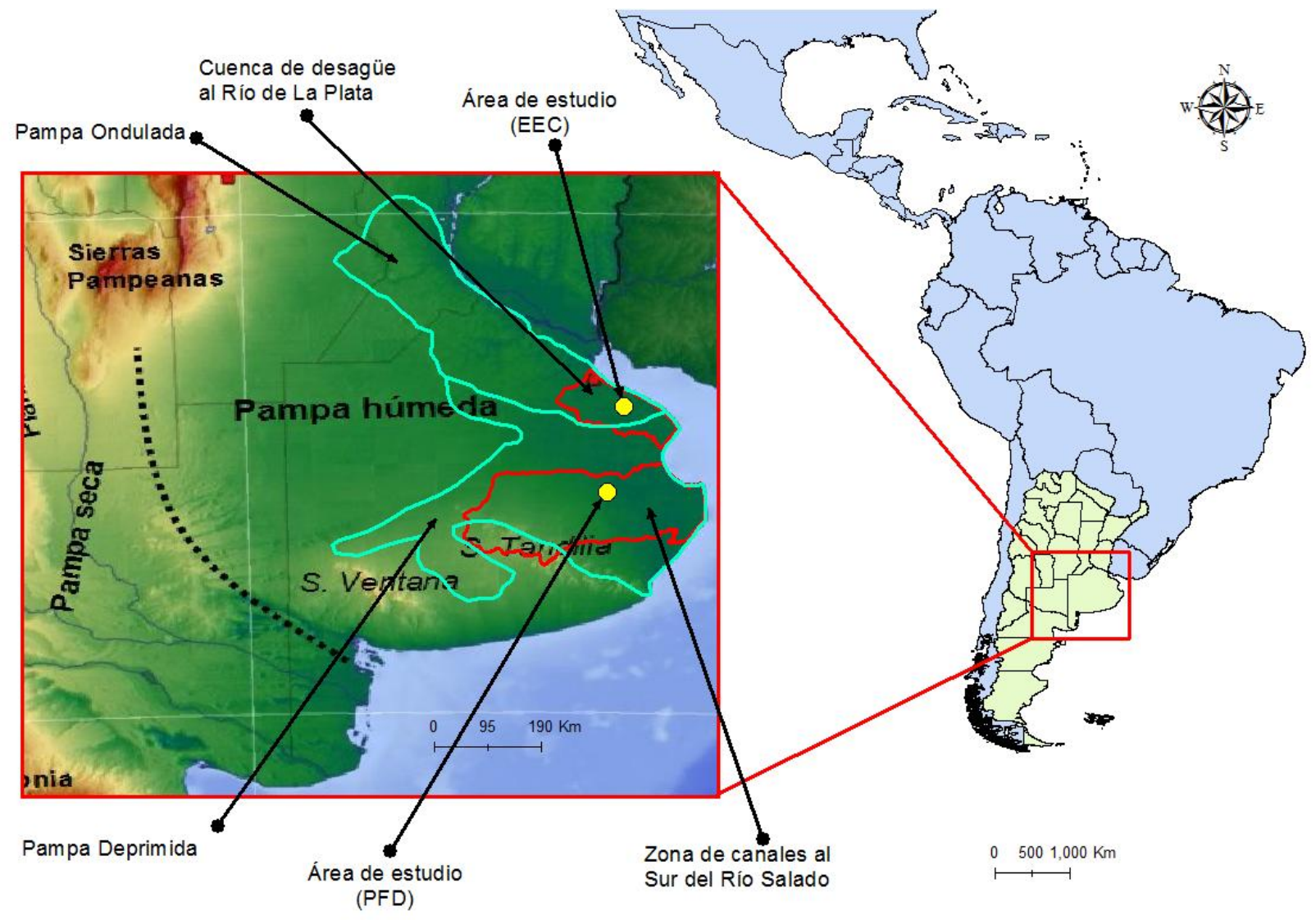

Figura 1.3. Ubicación geográfica de los sitios experimentales utilizados como áreas de estudio y señalados como EEC (Estancia El Centauro) y PFD (Predio Forestal Dolores) dentro de la provincia de Buenos Aires, Argentina. Se indican además las cuencas, regiones y subregiones a las cuales pertenecen estas áreas de estudio.

${ }^{7}$ Para trabajar en PFD se realizó un convenio marco entre la empresa Alto Paraná S.A., ex-Faplac, bajo el expediente $\mathrm{N}^{\circ} 200-820 / 09$ 


\subsubsection{Sistemas Ilanos en la pampa ondulada}

La pampa ondulada ocupa una angosta franja a lo largo del margen derecho de los ríos Paraná y de la Plata, con una suave ondulación del terreno resultante de la erosión fluvial (Pérez et al., 2009). Se encuentra limitada al norte con la Provincia de Santa Fe y al sudoeste con la pampa arenosa, y abarca una superficie del orden de los $3.200 .000 \mathrm{Ha}$ (PROSAP, 2010). Es considerada como uno de los territorios agroproductivos más ricos del mundo, con suelos fértiles, producto del depósito de las cenizas volcánicas del cuaternario, relieve suave, y la existencia general de abundante agua subterránea que solo hace poco comenzó a explotarse intensivamente para riego (Morello et al., 2000). Esta subregión se caracteriza por un régimen subhúmedo-húmedo (PROSAP, 2010), con precipitaciones anuales de $850 \mathrm{~mm}-1000 \mathrm{~mm}$ anuales, distribuidas en forma más o menos uniforme en las cuatro estaciones (Morello et al., 2000), las medias anuales son de $900 \mathrm{~mm}$, con mayor incidencia en el verano y menor en el invierno. Las temperaturas extremas alcanzan $-9^{\circ} \mathrm{C}$ en julio y $41,5^{\circ} \mathrm{C}$ en enero, con un período de heladas que comienza a fines de mayo y finaliza a principios de setiembre (PROSAP, 2010).

El paisaje es caracterizado como pastizal pampeano, y se encuentra profundamente modificado por el desarrollo de una vertiginosa actividad agropecuaria iniciada hace 400 años, e intensificada por el uso del alambrado y maquinaria agrícola a fines del siglo XIX y por los adelantos tecnológicos del siglo XX (León y Burkart, 1998), donde los pastos naturales fueron sustituidos por un mosaico de cultivos agrícolas (Szpeiner et al., 2007). Sólo en áreas con impedimentos serios para la agricultura, como sucede en la pampa deprimida, se conservan pastizales semi-naturales extensos (León et al. 1984; León, 1992). En el caso de la pampa ondulada, solo se encuentran escasos relictos de estos ambientes en áreas ferroviarias abandonadas y en parcelas que han sido aradas y cultivadas esporádicamente (León y Burkart, 1998).

En recientes décadas, se produjo una nueva serie de cambios sustanciales en los sistemas agrícolas pampeanos, sobre todo por la rápida expansión del cultivo de soja y, asociado con ella, la instalación masiva del procedimiento de siembra directa. Según datos de las últimas campañas agrícolas, argentina es la tercera productora mundial de soja, y agrupa el $84 \%$ de este cultivo en la pampa ondulada (Szpeiner et al., 2007).

Estos procesos, iniciados en 1970, engloban el concepto agriculturización, donde la pérdida de la estabilidad estructural en el horizonte de labranza se manifiesta como el 
principal factor de degradación de los suelos. Su consecuencia es una marcada disminución del porcentaje de materia orgánica en la capa arable, producto de excesivas labores (pulverización de los agregados) en las etapas de preparación de camas de siembra de los diferentes cultivos (manejo-monocultivo trigo-soja). Estos factores, sumados a las características de los suelos y las del paisaje, han determinado que una de las zonas potencialmente más productivas se encuentre actualmente con más del $75 \%$ de su superficie total afectada por diferentes problemas de degradación (PROSAP, 2010).

Es en este contexto, especialmente en áreas del hemisferio sur ocupadas inicialmente por pastizales naturales, donde las forestaciones plantean nuevas oportunidades productivas y compromisos con los servicios esenciales que estos ecosistemas brindan. Las plantaciones de especies forestales de rápido crecimiento como pinos y eucaliptos se transforman, en la actualidad, en un tipo de uso de la tierra localmente importante. Las transiciones entre sistemas dominados por pastos o árboles, suelen tener un gran impacto sobre el funcionamiento de los ecosistemas, debido al contraste que estos dos grandes grupos presentan en relación a la utilización de la energía, el agua y los nutrientes (Jobbágy et al., 2006b). El desarrollo de estudios tendientes a dilucidar estos impactos representa una necesidad inmediata dada la fragilidad de estos ambientes.

\subsubsection{Sistemas Ilanos en la pampa deprimida}

La pampa deprimida es una extensa llanura que se extiende hacia el noreste y sudoeste de las sierras de Tandilia en la provincia de Buenos Aires e incluye las áreas denominadas como la Depresión del Salado (Vervoorst, 1967) y la Región de Laprida (Etchevehere, 1961). La vegetación predominante es el pastizal natural, base forrajera de la actividad ganadera de cría, subdividido por alambrados y sometidos a un intenso pastoreo por ganado doméstico que mantiene, desde fines del siglo XIX, su fisonomía notablemente homogénea a través del paisaje. Esto conforma un mosaico formado por estepas graminosas y praderas con diferente cobertura y altura de pastos, hierbas y arbustos, donde se observan relictos de árboles nativos (Celtis tala o Jodina rhombifolia) y exóticos (Gleditsia triacanthos y Phoenix canariensis) restringidos a sitios de suelos profundos a lo largo de los alambrados (Batista et al., 2005). 
Se encuentra caracterizada por un clima sub-húmedo mesotérmico, con un régimen pluviométrico isohigro de lluvias distribuidas a lo largo de todo el año que oscilan entre $750 \mathrm{~mm}$ y $1000 \mathrm{~mm}$, con frecuentes períodos de inundaciones invernales o primaverales y de déficit hídrico estival (León y Burkart, 1998; Batista et al, 2005). Sus suelos son hidrohalomórficos del suborden Natracuoles y Natracualfes (Miaczynski, 1995; Soil Survey Staff, 2006), con un horizonte arcilloso, baja permeabilidad y alto contenido de sales sódicas (Salazar y Moscatelli, 1989; Lavado, 1992). La capacidad de infiltración de un horizonte Bt sódico típico alcanza valores de 0,001mm/día, con un techo cercano a los 10 $20 \mathrm{~cm}$ de profundidad, inferior a $17 \mathrm{~mm} / \mathrm{h}$ de infiltración básica (INTA, 1977; Vázquez et al., 2001). Esta situación explica el porqué varios autores (Sala et al., 1981; Lavado y Taboada, 1988), hayan desestimado la existencia de relaciones entre la altura del nivel freático y el agua acumulada en superficie, al detectar que en momentos húmedos y de nivel freático alto, la calidad del agua de la parte superior del acuífero ubicada a unos $40 \mathrm{~cm}$ de profundidad posee una composición química totalmente distinta a la superficial.

El relieve sumamente llano, con una pendiente promedio inferior al 0,1\%, llega en sectores próximos a la costa a valores cercanos al 0,001\% (Batista et al., 2005). Esto conforma un área de concentración de escurrimientos superficiales y subsuperficiales por excelencia (Vázquez et al., 2011), donde las aguas se estancan y forman lagunas y bañados (Pérez et al., 2009). El agua de escurrimiento no alcanza a modelar una red de drenaje desarrollada y por eso los sistemas fluviales son muy escasos (Etchevehere, 1961; Tricart, 1973). Los excesos de lluvia invernales y los déficits estivales, el drenaje lento, y el carácter salino sódico de los suelos determinan que, en gran parte de la pampa deprimida, sea frecuente la alternancia de anegamiento y sequía de variada intensidad (Sala et al., 1981; Batista et al., 2005). Esta situación se agrava por el diseño de la red vial, frecuentemente en dirección transversal al del flujo de agua y la construcción de numerosos canales clandestinos, sin un criterio integral sobre el funcionamiento hidrológico regional (Vázquez, 2003).

Más del $70 \%$ de las grandes inundaciones se han observado con eventos extraordinarios de otoño-invierno, con una duración media del período anegado de cinco meses (Vázquez et al., 2011). El resto ocurrieron durante la primavera, debido a una mayor demanda de la ET, con una duración media de tres meses o menos (Posadas, 1934; Barbagallo, 1983), lo que refuerza la idea que el principal componente vertical que controla el volumen de agua superficial es la ET (Vázquez et al., 2011). 
En virtud de los impedimentos que presentan estos ambientes para la agricultura, se reconocen extensos pastizales semi-naturales (León y Burkart, 1998) sujetos a situaciones de estrés periódico asociados a sequías e inundaciones, donde la dinámica del agua superficial y profunda responde, salvo en los períodos de inundación, a diferentes procesos y funcionan independientemente (Sala et al., 1981). En este escenario, los problemas vinculados al agua no sólo se refieren a ésta como recurso sino como peligro (Andrade y Scarpati, 2008). La actividad productiva de cría de ganado, regulada por la propia dinámica estacional, productividad y calidad de los pastizales naturales, se encuentra actualmente amenazada por cambios productivos y de uso de tierra que atentan contra el sostenimiento del sistema. Durante la última década la región registró un notable aumento de la carga animal por hectárea ganadera (Vázquez et al., 2008), acompañada por un avance de la frontera agrícola equivalente al $10 \%$ de la superficie ocupada por ganadería (Maresca, 2010), lo cual se traduce en el aumento y concentración de la actividad ganadera por el avance de la frontera agrícola sobre los suelos más productivos de la región y un aumento en la intensidad y concentración de la actividad ganadera.

En este contexto y como parte de las herramientas de promoción forestal nacional, surge desde la dirección de bosques y forestación del Ministerio de Asuntos Agrarios (http://www.maa.gba.gov.ar), el compromiso de incorporar a la forestación en el actual sistema productivo, con la pampa deprimida como área piloto para la implementación de un programa de instalación de forestaciones de servicio (Cortinas Forestales y principalmente Montes de Reparo). Este programa, al poseer carácter de política de estado, resulta potencialmente beneficioso debido a las cualidades mundialmente reconocidas de las forestaciones para modificar la dinámica hídrica de estos ambientes, al punto de ser consideradas verdaderas herramientas correctoras de los procesos naturales que lo degradan (Ameghino, 1884; Pritchet, 1991; Gottle y Sène, 1997; Mármol, 2006; Besteiro, 2010). Sin embargo, dada la utilización de especies de alto consumo hídrico y rápido crecimiento, como son los pinos y eucaliptos, resulta necesario profundizar los estudios sobre los costos y beneficios de estas acciones. 


\subsection{ORGANIZACIÓN DE LA TESIS}

La conformación estructural de esta tesis responde a una secuencia lógica de temas que han sido desarrollados individualmente, a fin de facilitar la lectura y comprensión de cada uno de ellos y posterior conexión y consulta.

Capítulo 1. Ofrece una introducción general al tema de estudio con énfasis en la situación de los bosques en el mundo y la relación que guardan las forestaciones con el ciclo hidrológico general. Se parte de la concepción de las existencias de bosques en el mundo y del incremento progresivo de las plantaciones en busca de abastecer la demanda de productos madereros y no madereros sin aumentar la presión sobre los bosques naturales. Se comenta la situación de las existencias argentinas y la importancia e interés de acortar la brecha de conocimiento respecto a las relaciones entre los bosques y plantaciones frente al recurso agua y su dinámica. Luego, desde una concepción de sistema, se presentan los flujos hídricos a un nivel de árbol individual, situado en una situación de pendiente mínima, para ingresar gradualmente en el estudio sobre el comportamiento hidrológico de las plantaciones en sitios llanos. Se hace mención, además, de los estudios más relevantes en materia del efecto de las plantaciones forestales en el balance hidrológico en Argentina y problemáticas referentes a la economía del agua y características productivas de la llanura pampeana. Se fundamenta brevemente la elección del tema de estudio y se definen los criterios seguidos para la elección de las áreas de estudio, junto con su ubicación general y una descripción regional de los sitios de estudio. Finalmente se plantea de forma abreviada la diagramación estructural de la tesis y se establecen los objetivos de la misma.

Capítulos 2 a 5. Se desarrollan los distintos componentes del balance hidrológico de forma individual para lograr una correcta interpretación de la tesis. Así, en el capítulo 2 se realiza un análisis de la distribución temporal de las precipitaciones y su redistribución bajo plantaciones forestales adultas de Pinus radiata (D. Don), Eucalyptus viminalis (Labill) y Eucalyptus camaldulensis (Dehnh) en las dos áreas de estudio. Se describen en detalle el comportamiento de 4 componentes verticales del ciclo hídrico bajo las plantaciones en estudio (precipitación, intercepción, trascolación y escurrimiento fustal) y se evalúa su valor relativo en el balance. En el capítulo 3 se desarrolla el componente de escurrimiento superficial por medio de la simulación con el modelo hidrológico L-THIA, basado en la metodología del número de curva, junto con proyecciones de los efectos del aumento o 
disminución de la superficie forestada. El Capítulo 4, titulado Infiltración y aguas subterráneas, trata del drenaje vertical de agua en el suelo con especial atención en la infiltración efectiva (recarga freática). Se inicia con la determinación de la infiltración bajo los distintos usos/coberturas del suelo y se concluye con el análisis de la dinámica de aguas subterráneas y la conformación de diagramas de flujo. Con esto se busca interpretar la incidencia de las forestaciones en la carga/descarga del acuífero libre inmediato (freática) e individualizar el componente de infiltración del balance. Finalmente, en el capítulo 5 se atiende el componente de evapotranspiración de referencia y de cultivo para cada una de las situaciones contempladas. Para esto se aplicó el método de la FAO Penman-Monteith y los procedimientos y recomendaciones estandarizados para la estimación de los datos climáticos faltantes. Se individualizan los componentes de evaporación y transpiración, por medio del cálculo de los coeficientes de cultivo ( $\mathrm{k}_{\mathrm{e}} \mathrm{y} \mathrm{k}_{\mathrm{cbaj}}$ ), y la evapotranspiración del cultivo $\left(\mathrm{ET}_{\mathrm{c}}\right)$ correspondiente a cada especie, cobertura y densidad considerada. En estos capítulos se trabajan los objetivos específicos de la tesis (apartado 1.5).

Parte de los resultados obtenidos en el capítulo 2, los correspondientes a la redistribución de las precipitaciones bajo forestaciones en la Estancia El Centauro, fueron utilizados para una publicación en la Revista de la Facultad de Agronomía, Tomo 111 (2) del 2012, bajo el título de "Redistribución de las precipitaciones sobre plantaciones forestales en un predio del partido de La Plata, Buenos Aires". Dicha publicación representa un requisito del reglamento de la carrera de doctorado de la Facultad de Ciencias Agrarias y Forestales de La Plata (Artículo 4b, Resolución CA Nro. 055/2010).

Capítulo 6. Se presentan pautas generales para la gestión del recurso agua en relación al uso y manejo de plantaciones forestales de rápido crecimiento en estas tierras.

Capítulo 7. Agrupa las discusiones parciales de cada capítulo para ser presentadas de forma integrada para una mejor comprensión de la dinámica hídrica de las plantaciones forestales en distintos ambientes la llanura pampeana. Se destacan los aspectos más importantes de la tesis para volcarlos en las conclusiones finales 


\subsection{OBJETIVOS}

El objetivo principal del presente estudio es evaluar la influencia hidrológica de forestaciones de rápido crecimiento en dos localidades de la llanura pampeana, como base para reconocer pautas de manejo del agua en ambientes de llanura. Para el logro del mismo, se fijaron los siguientes objetivos específicos:

1. Analizar la redistribución de las precipitaciones bajo plantaciones forestales adultas de Pinus radiata Don, Eucalyptus viminalis Labill y Eucalyptus camaldulensis Dehnh en los dos predios de la llanura pampeana.

2. Modelizar el componente de escurrimiento superficial bajo las condiciones de uso actual de los predios analizados y simular posibles escenarios de cambio de uso en la conversión pastizal-forestación.

3. Evaluar las fluctuaciones del nivel de capa freática a nivel predial, como base para determinar las relaciones de recarga/descarga bajo los usos/coberturas considerados en cada sitio de estudio.

4. Establecer una metodología sencilla para la estimación de los coeficientes de cultivo de las especies forestales a fin de cuantificar la evapotranspiración de los distintos cultivos evaluados.

Estos objetivos fueron trabajados individualmente en los distintos capítulos de la tesis bajo una serie de supuestos: la elevada capacidad de intercepción que caracteriza a las forestaciones, se manifiesta con mayor intensidad en los rodales de pino frente a los de eucalipto y, a su vez, aumenta en relación directa con la densidad de los rodales de este último genero (plantas por hectárea). Por otro lado, la conversión de pastizales por forestaciones genera una reducción sustancial del flujo de escurrimiento superficial al punto de llegar a anularlo. Asimismo, se sostiene que ante la existencia de períodos con excesos hídricos, las forestaciones estudiadas favorecen la infiltración y recarga freática bajo estas coberturas. Por el contrario, en esta conversión se acentuarán los procesos de descarga freática ante períodos con baja pluviometría. Por último, si se acepta que los sitios de estudio poseen características climáticas comparables, el rodal de pino presenta un menor rendimiento hídrico (descarga freática) frente a los de eucalipto y, dentro de 
estos, que el rendimiento hídrico de los rodales de E. viminalis superará a los de $E$. camaldulensis. 


\section{Capítulo 2}

\section{Intercepción de las}

precipitaciones 


\subsection{INTRODUCCIÓN}

Analizar el efecto de las forestaciones sobre el ciclo hidrológico no es algo sencillo y algunos autores consideran que las dificultades de obtener mediciones directas del uso del agua por parte de un bosque son insalvables (Novoa, 1998), por lo que se hace necesario agrupar al ciclo hidrológico en subsistemas, para su estudio individual (Chow et al., 1994). La intercepción, como componente más significativo de la redistribución de la precipitación en forestaciones (Poore y Fries, 1987; Cantú y González, 2002), se encuentra dentro del subsistema agua atmosférica junto a la precipitación, evaporación, y transpiración, pero además afecta a otras fases del ciclo, como la infiltración, la escorrentía y la evaporación del suelo (Belmonte y Romero, 1999).

La precipitación en forma de agua de lluvia, constituye el elemento primario del ciclo hidrológico y es, en sí misma, el componente que alimenta el ciclo -principal entrada del sistema en climas templados-. Se compone de aquellas precipitaciones generadas esencialmente por enfriamiento adiabático y que, según su origen, se las clasifica en: ciclónicas o estratiformes, convectivas u orográficas (Mármol, 2006). Estas últimas quedarían descartadas en la llanura pampeana, por la monotonía de su paisaje (Auge y Hernández, 1984), donde prevalecen las lluvias convectivas ${ }^{8}(75 \%)$ frente a las estratiformes (25\%) (Sarochar et al., 2005). Custodio y Llamas (1996), indican que las precipitaciones deben ser consideradas como un fenómeno discontinuo, dado que su distribución espacial y temporal es muy variable. A su vez, señalan que su formación proviene del vapor de agua contenido en las masas de aire que, a consecuencia de los cambios de presión y temperatura y el movimiento de las masas, ayudado, en ocasiones, por minúsculos núcleos de condensación y material sólido en suspensión, se reúne en gotas de agua o en cristales de hielo y cae venciendo las resistencias que se le oponen, hasta llegar a la superficie terrestre. Su correcta identificación supone considerar las características propias de los distintos tipos de precipitación: tamaño, velocidad, volumen, intensidad, duración, frecuencia y período de retorno o recurrencia (Mármol, 2006).

${ }^{8}$ Los eventos de tipo convectivo, si bien pueden ser menos frecuentes, traen asociada una mayor cantidad de precipitación, por lo que es muy razonable afirmar que estos fenómenos son responsables de una mayor proporción de los excesos de precipitación que se registran (Sarochar et al., 2005). Por el contrario, los eventos de tipo estratiformes afectan áreas más extensas y tienden a ser débiles y de larga duración. 
La intercepción, por su parte, constituye la porción de la precipitación que incide sobre el dosel forestal y queda retenido en él. En esta redistribución, la parte del agua de Iluvia que no es retenida, alcanza el suelo del bosque en forma de precipitación neta. A su vez, la precipitación neta se compone de dos vías: del agua que atraviesa libremente el dosel o gotea desde hojas y ramas en forma de precipitación directa (trascolación), y la que utiliza como senda de fluidos el fuste de los árboles para alcanzar la superficie el suelo o escurrimiento fustal (Huber, 2003). El valor de escurrimiento fustal representa una proporción muy baja de la precipitación total y adquiere relevancia al alcanzar la base de los troncos, donde se concentra la mayor cantidad de raíces de los árboles (Huber y Trecaman, 2000; Donoso et al., 2002), y donde muy seguramente se infiltrará más rápida y efectivamente (Poore y Fries, 1987).

\subsubsection{Antecedentes}

Los estudios de intercepción en forestaciones son profusos y sin embargo insuficientes para anticipar el comportamiento de este componente en situaciones locales o particulares. La intercepción no solo varía con la vegetación y características de las precipitaciones, sino que depende del clima, suelo y de las complejas interrelaciones entre estos elementos. Puede esperarse entonces, tantos valores de intercepción como combinaciones de estos elementos en la naturaleza. Sin embargo, es preciso conectar las distintas experiencias realizadas al respecto, a fin de aunar criterios e identificar patrones que nos lleven a un mejor y más completo entendimiento de los beneficios y costos hídricos de las forestaciones en ambientes llanos.

Con respecto a esto, puede señalarse un estudio llevado a cabo por la FAO, sobre los efectos ecológicos de los eucaliptos (Poore y Fries, 1987). En este estudio se exponen una serie de ensayos con eucaliptos (Lima, 1976; Smith, 1974; George, 1978; Dabral y Subba Rao, 1968, 1969), donde se observa que mantienen menores tasas de intercepción frente a otros tipos vegetales $(10,9-11,65 \%$ frente a $18,7 \%$ en $P$. radiata; $27,0 \%$ en $P$. roxburghii, $20,8 \%$ en Tectona grandis, $38,2 \%$ en Shorea robusta y $28,5 \%$ en Acacia catechu).

Por su parte, Bruijnzeel (1997), realizó una interesante evaluación de las experiencias sobre la hidrología de las plantaciones en los trópicos y concluyó que a pesar 
de que no existen evidencias para afirmar que el consumo de agua por las plantaciones excede al de los bosques naturales, si las hay para afirmar que las plantaciones de rápido crecimiento, establecidas en potreros, disminuyen fuertemente el flujo superficial al cerrarse las copas, particularmente en la estación seca. A su vez, este autor indica que los valores de intercepción adoptan valores cercanos al 12\% para eucaliptos, 20\% para latifoliadas y menores del $25 \%$ para coníferas. Esto último concuerda con lo observado por Poore y Fries (1987) al decir que los valores de intercepción tienden generalmente a ser mayores para pinos y quizás más bajos para árboles latifoliados, diferentes a los eucaliptos.

En Sudáfrica, Le Maitre et al. (1999) indican que un cambio en la cobertura vegetal (por ejemplo: pasturas por forestaciones), posee un significativo impacto en el volumen de agua interceptada y ulteriormente en la recarga del agua subterránea. Además, estos autores presentan antecedentes de bosques templados con pérdidas por intercepción de 20 a $40 \%$ de $\mathrm{P}$ en coníferas y de 10 a $20 \%$ en plantaciones de maderas duras (Zinke, 1967); Intercepciones de 10 a $20 \%$ de $P$ en rodales de $P$. radiata de 8 y 29 años respectivamente (Pienaar, 1964; Versfeld, 1988), e intercepciones de 13 y 4,1\% de P en rodales jóvenes de E. grandis y $P$. patura, respectivamente (Dye, 1993).

Giraldo (2002), en su libro de "Memorias: Hidrología Forestal", indica que las plantaciones de eucaliptos en Australia presentan intercepciones de $15-25 \%$ de la precipitación incidente. Además, menciona valores del $12 \%$ para plantaciones de $E$. grandis (CONIF, 1998) y del $21 \%$ en plantaciones de $P$. patula en Colombia (Tobón, 1989), y una revisión de estudios de Norte América, Europa y Rusia (Rakhmanov, 1966) donde se establecieron intercepciones inferiores al 35\% de $\mathrm{P}$ en bosques mixtos, del $20-22 \%$ en bosques de hoja ancha y de $25 \%$ en plantaciones de pino.

Del mismo modo, de Paula Lima (2008) realizó una presentación de distintos estudios sobre la intercepción de las lluvias por las forestaciones, e indicó intercepciones de 17 a $28 \%$ de $\mathrm{P}$ en plantaciones adultas de $P$. canariensis; $\mathrm{I}=19$ y $25 \%$ en bosques de pino y eucaliptos de Estados Unidos (Voigt, 1960); I=32\% y 12\% en rodales de $P$. sylvestris y latifoliadas mixtas de Inglaterra (Rutter, 1963; Dewalle y Pausell, 1969); I=38\% en forestaciones subtropicales de Brasil (Geiger,1966); I=14,6\% en plantaciones homogéneas de E. camaldulensis en Israel (Karschon y Heth, 1967), e intercepciones de 12,2 y 6,6\% para plantaciones jóvenes de E. saligna y P. caribaea de Brasil (Lima, 1976). 
Se observa que a lo largo de los años se han desarrollado numerosas experiencias y obtenido una respuesta muy variable con respecto al componente de intercepción para cada especie y lugar. Tal vez, un mejor enfoque puede ser tomado al ordenar estos antecedentes según la etapa de desarrollo de las especies forestales (juveniles, adultas) para luego volcarnos en la comparación directa de los pinos frente a los eucaliptos, y a las sustituciones de estas por especies nativas y praderas:

\section{a) Forestaciones juveniles}

En Murcia (España), Belmonte S. y Romero D. (1999) identificaron pérdidas por intercepción en plantaciones jóvenes de $P$. halepensis con oscilaciones de 26 a $28 \%$ para años pluviométricamente normales, pero que pueden alcanzar valores cercanos al $40 \%$ en años secos.

A su vez, en un estudio en el que se compara una plantación joven de Pinus radiata frente a un matorral de espinillo en la VII Región de Chile, Huber (2003) indicó que la mayor intercepción observada en los pinos (33\% de $\mathrm{P}=1054 \mathrm{~mm}$ ) -agua que no ingresa al sistema- no condicionó una menor ET ( $53 \%$ de P) frente al matorral ( $42 \%$ de P), cosa que atribuyó a un sistema radicular más profundo y, por lo tanto, un mayor volumen de suelo para extraer agua. Esto contrarresta en parte la mayor intercepción observada en pinos pero retrasa y disminuye la recarga freática.

Por otro lado, un estudio sobre plantaciones jóvenes de $P$. pinaster en Galicia, indica reducciones del $23,3 \%$ en la entrada de agua en el suelo (agua interceptada por la cubierta arbórea y devuelta a la atmósfera) y por lo tanto una disminución importante de la disponibilidad de este recurso en el suelo (Rodríguez et al., 2010).

Pareciera que los montos de intercepción en rodales juveniles son altos, como así también la capacidad de exploración de sus raíces. Esto condiciona fuertemente la disponibilidad hídrica de los suelos e indirectamente la recarga freática. Una posible explicación a los elevados valores de I en esta etapa puede encontrarse en las características de las lluvias. Los estudios presentados aquí, se situaron en sitios donde las precipitaciones anuales rondaron los 950mm (con excepción del desarrollado en Murcia donde $\mathrm{P} \leq 250 \mathrm{~mm} / \mathrm{año}$ ) y seguramente que han prevalecido aquellas de baja intensidad y corta duración. 


\section{b) Forestaciones adultas}

En un bosque adulto de Pinus radiata de Chile, donde las pendientes no superan el $7 \%$ y las precipitaciones anuales alcanzan los $2000 \mathrm{~mm}$, se identificaron intercepciones del $10,3 \%$ de $\mathrm{P}$, mientras que el agua que alcanza el suelo como precipitación neta, se conforma por un $13 \%$ de $\mathrm{E}_{\mathrm{f}}$ y un $87 \%$ de $\mathrm{T}_{\mathrm{r}}$ (Huber y Oyarzún, 1983). Resulta interesante resaltar, que estos autores atribuyen el comportamiento de estos componentes a las características de las precipitaciones y condiciones meteorológicas reinantes, al señalar que con aportes de lluvia inferiores a $20 \mathrm{~mm}$, discontinuadas o de baja intensidad, la retención de agua en copas es casi total $(\mathrm{I}=53,2 \%$ de $\mathrm{P}$ ), mientras que lluvias de más de $40 \mathrm{~mm}$ no permiten que el agua interceptada sea evaporada y escurre al suelo una vez saturado el dosel $(\mathrm{I}=4 \%$ de $\mathrm{P})$. Además, indican que la rugosidad de las cortezas de pinos adultos origina retenciones de $6 \mathrm{~mm}$, antes de que el agua de lluvia escurra libremente por el tronco, mientras que la capacidad de retención de las copas se fijó en 0,9mm.

Huber y Oyarzún (1984), sobre el mismo rodal anterior, identificaron una serie de factores que condicionan a la intercepción. Determinaron una correlación directa entre la intercepción y la intensidad y duración de las lluvias, mientras que la velocidad del viento impactó significativamente pero de forma inversa. Esto indica que velocidades altas del viento condicionan reducciones importantes en la intercepción, debido principalmente a que el viento sacude las copas de los árboles y el agua adherida a las acículas es removida de ellas y se reduce, de esta manera, el tiempo de exposición para una potencial evaporación.

Valores similares se reportaron en la cuenca de Candelario (sistema central español), donde se determinaron intercepciones de la precipitación del $9 \%$ sobre plantaciones de Pinus sylvestris L., mientras que del $91 \%$ del agua que llego al suelo, el $12 \%$ correspondió al $\mathrm{E}_{\mathrm{f}}$ y el $88 \%$ a la $\mathrm{T}_{\mathrm{r}}$ (mayor responsable del retorno de bioelementos al suelo) (Santa Regina et al., 1989).

A su vez, en un estudio realizado dentro del bosque experimental de la Universidad de Nuevo León, México (Cantú y González, 2002), se analizó la distribución de las precipitaciones sobre plantaciones adultas de encino (Quercus sp.), Pinus pseudostrobus Lindl y mixtas de 80 a 100 años. Estos autores hallaron intercepciones de 19,2; 13,6 y 23\% para pino, encino y mixto, respectivamente, por lo que sugieren el manejo sustentable del 
bosque de encino como mejor recurso para la conservación de los recursos hídricos en regiones semiáridas.

En su etapa adulta, los rodales alcanzan un estado de crecimiento menos acelerado y los consumos hídricos (ET) solo pueden incrementarse por un aumento gradual en su capacidad de intercepción.

\section{c) Pinus vs. Eucalyptus}

Con base en conceptos generales sobre morfología foliar y orientación, Poore y Fries (1987) afirman que bajo condiciones similares, es esperable una mayor interceptación en pinos frente a los eucaliptos y que estos últimos, además, interceptan cerca de una cuarta parte de la precipitación, que no alcanza a estar disponible para la recarga de la humedad del suelo o los acuíferos.

Las magnitudes que adoptan los componentes son variadas: 10,3\% de I, 78\% de $\mathrm{T}_{\mathrm{r}}$ y $11,7 \%$ de $E_{f}$ para un bosque de Pinus radiata D. Don (Huber y Oyarzún, 1983); valores de $6,5 \%$ de I, $91,2 \%$ de $\mathrm{T}_{\mathrm{r}}$ y $2,3 \%$ de $\mathrm{E}_{\mathrm{f}}$ en plantaciones de Eucalyptus globulus Labill, y de 22,8, 77 y 0,15\%, respectivamente, para plantaciones de Pinus pinea L. (González et al., 1993); y valores de intercepción de 11-20\% para un monte adulto de Eucalyptus (Leite et al., 1997).

En Chile, Oyarzún y Huber (1999) compararon el comportamiento hidrológico en los tres primeros años del establecimiento de plantaciones de Pinus radiata y Eucalyptus globulus para una precipitación promedio de 1932mm/año. Los resultados alcanzados fueron intercepciones bajas en ambas especies (3-7\% de P), producto de su baja cobertura; un especial incremento en el escurrimiento fustal de los pinos ( 3,5 a $5,9 \%$ de $\mathrm{P})$ frente a los eucaliptos $(0,1$ a $0,8 \%$ de $\mathrm{P})$, debido a su verticalidad y convergencia de ramas al tronco principal, y un notable incremento de la evapotranspiración del primer año (30\%) con respecto al tercero (55\%) para ambas especies. Esto evidencia un ávido consumo de la humedad del suelo en etapas tempranas del crecimiento de estas especies pero no una pérdida significativa de agua del sistema por intercepción, lo cual agravaría la situación, especialmente en zonas con escasas precipitaciones. 
Por otro lado, en su etapa adulta del desarrollo, Huber et al. (2010) identificaron intercepciones superiores en rodales de $P$. radiata (16,5\% de $\mathrm{P}$ ) frente a los de $E$. globulus (10,5\% de P), mientras que los valores de ET de los eucaliptos (73\% de P) superaron a la de los pinos $(64,5 \%$ de $\mathrm{P})$, lo que resulta de la mayor humedad edáfica que poseen los eucaliptos como consecuencia de poseer menores pérdidas por intercepción. Según estos autores, la menor cantidad de agua que involucran las plantaciones de pino en la evapotranspiración, influyen de forma inversa en los montos de escurrimiento superficial de estas cuencas, y por lo tanto en la carga de sedimentos.

De estos antecedentes se desprende que, con algunos rangos de variación, los pinos interceptan más agua de lluvia que los eucaliptos e incluso, casi llegan a duplicar la cantidad interceptada por estos.

\section{d) Forestación vs. Bosque nativo}

En la patagonia argentina, Licata et al. (2011) encontraron que los rangos de intercepción de los bosques nativos de Austrocedrus chilensis D. Don (35-44\% de P) superan a los de las plantaciones exóticas de Pinus ponderosa Doug (17-22\% de P) y esto compensaría el incremento en la transpiración que manifiesta el reemplazo de los bosques nativos por plantaciones de $P$. ponderosa (Licata et al., 2008). Además, se demuestra que la variación de la intercepción responde más a un cambio de especies que a un cambio de densidades de plantación (Licata et al., 2011), en contraposición a lo que ocurre con la transpiración (Licata et al., 2008).

Por otro lado, Iroume y Huber (2000) hallaron disminuciones potenciales en los caudales de crecida por la intercepción de las lluvias por parte de los bosques nativos de Roble-Raulí-Coihue y plantaciones adultas de pino Oregón ( $\mathrm{I}=26$ y $34 \%$ de $\mathrm{P}$, respectivamente). Mientras que Pizarro et al. (2005), al estudiar el cambio masivo de vegetación nativa por plantaciones de Pinus radiata en Chile, no observaron diferencias significativas en el comportamiento hidrológico de los dos tipos de bosques.

De estos antecedentes no es posible obtener más que la noción de que las especies nativas presentan un aparente estado de equilibrio hidrológico y que las especies forestales de rápido crecimiento, a pesar que muchas veces no se manifieste taxativamente, no parecen respetarlo. Al tratarse de una conversión entre especies del 
mismo tipo forestal (Por ejemplo: reemplazo de coníferas por coníferas o de latifoliadas por latifoliadas), puede esperarse que las variaciones en los consumos hídricos (ET) sean liderados por cambios el componente $\mathrm{T}$ más que por I. Sin embargo, al tratarse de situaciones más complejas (bosques mixtos y/o varios estratos vegetales, condiciones ambientales heterogéneas o extremas), la dificultad de mantener y realizar mediciones hidrológicas confiables bajo los sistemas forestales naturales se tornan aun más complejas que en las plantaciones forestaciones, y no es posible acertar ninguna generalización particular. Resulta necesario entonces, continuar los trabajos en este campo, en la medida que continúe la presión sobre los bosques nativos y su reemplazo por especies de rápido crecimiento.

\section{e) Forestación vs. Pastizales}

Kelliher et al. (1993) analizaron las características de la ET y canopea de los bosques de coníferas frente a las de pastizales. Estos autores señalaron que a pesar de las profundas diferencias que poseen ambos tipos vegetales, en cuanto a la arquitectura de sus canopeas, ellas comparten similares valores máximos de evaporación horaria y conductancia superficial $(0,46 \mathrm{~mm} / \mathrm{h}$ y $22 \mathrm{~mm} / \mathrm{s})$, y aun más, las forestaciones presentan menor valor de E máxima media $(4 \mathrm{~mm} / \mathrm{d})$ en comparación a los pastizales $(4,6 \mathrm{~mm} / \mathrm{d})$. Sin embargo, las pérdidas de agua por intercepción en forestaciones alcanzaron aproximadamente el $30 \%$ de $\mathrm{P}$-el doble que en pastizales (15\% de $\mathrm{P})$-, valor que atribuyeron a las diferencias en la conductancia de las canopeas de ambos tipos vegetales $(200 \mathrm{~mm} / \mathrm{s}$ en forestaciones frente a $25 \mathrm{~mm} / \mathrm{s}$ en pastizales).

Por su parte, Huber et al. (1998) estudiaron el efecto de la densidad de plantaciones de Eucalyptus nitens sobre el balance hídrico y hallaron una relación directa entre la intercepción y la densidad del rodal. Estas plantaciones se desarrollaron en reemplazo de cubiertas herbáceas, en una zona de bajas pendientes $(<5 \%)$, al norte de la IX Región de Chile y bajo tres densidades de plantación distintas (1560, 850 y 663pl/ha). Los resultados arrojaron valores de intercepción de 30, 26,8 y 23,9\% de la precipitación total, correspondientes a las mayor, intermedia y menor densidad, respectivamente. Por otro lado, Calder et al. (2003, en: Nisbet, 2005), encontraron que bajo un amplio rango de lluvias, se mantenían porcentajes de intercepción del 25 al $45 \%$ en rodales de coníferas frente a valores del 10 al $25 \%$ en cubiertas de hierbas de hoja ancha. 
En Uruguay, al comparar microcuencas con cobertura forestal (plantación adulta de E. globulus sp. Maidenni) de 895árb/ha frente a pasturas naturales de uso ganadero (Silveira et al., 2011), se observó que la intercepción de las masas forestales decrecían con el aumento de la precipitación y formaban una asíntota algo superior al $10 \%$ en términos diarios. En términos medios, el valor de I adoptado para las forestaciones fue del $17 \%$, por ello, los autores interpretaron que el incremento de ET, verificado entre las distintas cobertura, puede ser asignado en gran parte a la intercepción.

Por lo tanto, puede interpretarse que el aumento de ET -resultante de las conversiones de coberturas herbáceas por plantaciones forestales-, se explica mayormente por las variaciones del componente I, que en ocasiones representa un valor dos veces más grande en forestaciones que en coberturas herbáceas (Kelliher et al., 1993; Calder et al., 2003, en: Nisbet, 2005)

Para los casos considerados, se espera que la elevada capacidad de intercepción que caracteriza a las forestaciones, se manifieste con mayor intensidad en los rodales de pino frente a los de eucalipto y, a su vez, que esta capacidad aumente en relación directa con la densidad de los rodales de este último genero (plantas por hectárea). Además, como lo sugiere Bruijnzeel (1997), al tratarse de plantaciones adultas el componente de intercepción puede llegar a superar al de transpiración, constituyéndose en el principal responsable del alto consumo hídrico atribuido a las forestaciones. 


\subsection{MATERIALES Y MÉTODOS}

\subsection{1 Área de estudio}

\subsubsection{Estancia el Centauro (EEC)}

La EEC se encuentra situada sobre la Ruta Provincial Nro. 36, entre los kilómetros 65 y 66 , a $20 \mathrm{~km}$ al Sur de la Ciudad de La Plata, partido al cual pertenece. Hidrológicamente, se la puede ubicar dentro del área de influencia del Arroyo La Paloma, tributario de tercer orden del Arroyo El Pescado. (Figura II.1).

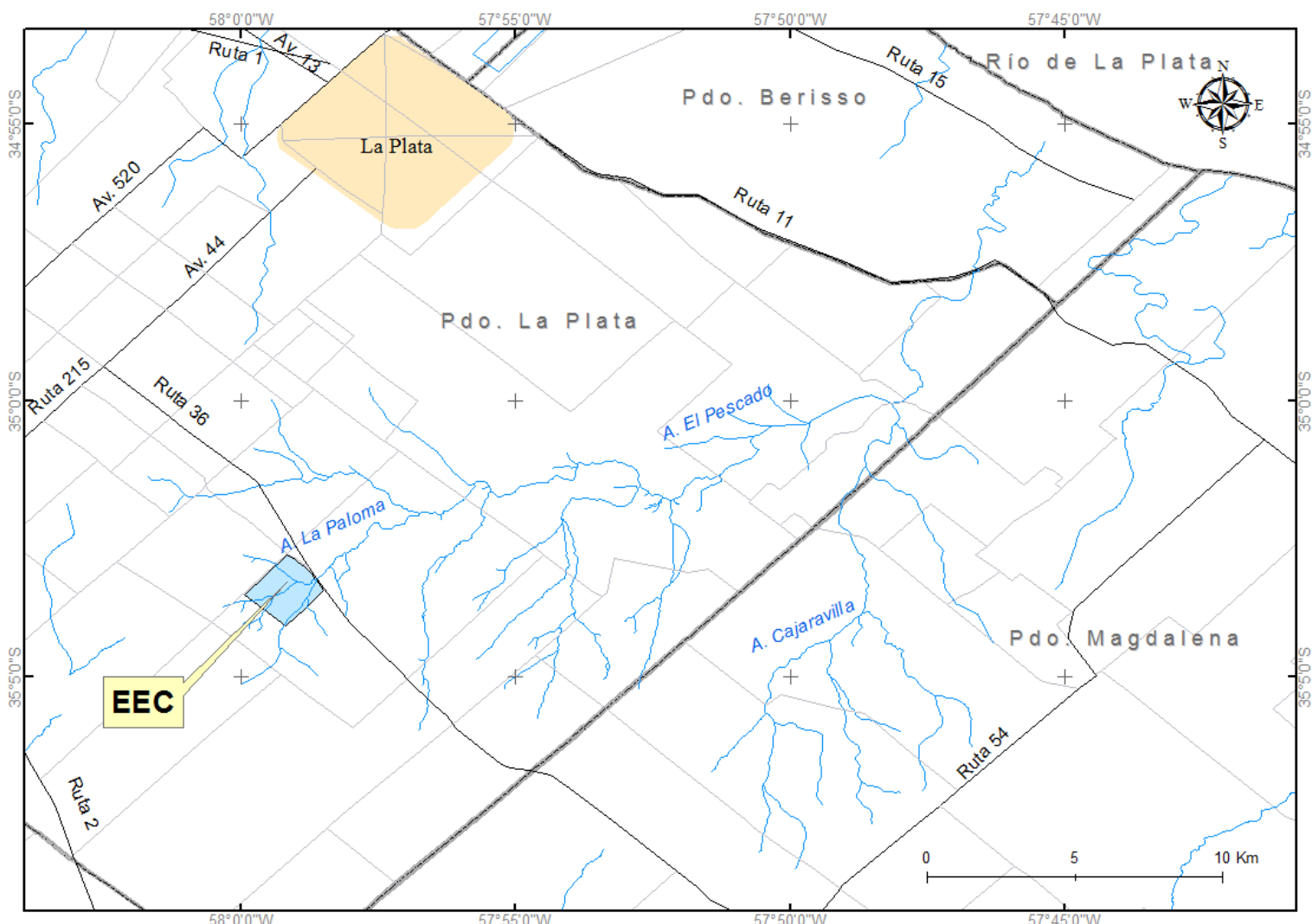

Figura II.1. Localización geográfica de la Estancia el Centauro (EEC), vías de acceso e hidrografía característica.

\section{a. Clima (EEC)}

Hurtado et al. (2006) realizaron una caracterización climática general, en el Centro de Investigaciones de Suelos y Aguas de Uso Agropecuario (CISAUA), para la ciudad de La Plata, que indica para el período 1909-2005, una precipitación media anual de 1040mm, 
siendo marzo el mes más lluvioso $(111 \mathrm{~mm})$ y junio el menos lluvioso (63mm). Así mismo, la distribución estacional de las lluvias fue caracterizada como regular (Tabla II.1).

Tabla II.1. Distribución estacional de las lluvias, en valores medios, para el período 19092005, partido de La Plata. Adaptado de (Hurtado et al., 2006)

\begin{tabular}{ccc}
\hline Período & Precipitación $(\mathrm{mm})$ & Porcentaje del período (\%) \\
\hline Verano (diciembre, enero, febrero) & 289 & 27,8 \\
Otoño (marzo, abril, mayo) & 289 & 27,8 \\
Invierno (junio, julio, agosto) & 196 & 18,8 \\
Primavera (septiembre, octubre, noviembre) & 266 & 25,6 \\
\hline
\end{tabular}

En la tabla II.2 se muestra el balance hídrico medio mensual realizado en este estudio para el Partido de La Plata. Para su confección, los autores definen una capacidad hídrica del suelo de 200mm (capacidad de campo) y obtienen un pequeño déficit de agua para los meses de verano $(7 \mathrm{~mm})$ y un exceso de mayor intensidad entre fines de otoño y principios de primavera $(241 \mathrm{~mm})$, que totaliza un balance positivo en donde las precipitaciones que superan el volumen de agua evapotranspirada, en parte son conducidas por la red de drenaje en forma de escorrentía y en parte, alimentan las reservas de agua subterránea (infiltración efectiva).

Tabla II.2. Balance hídrico medio mensual (1909-2005) para el partido de La Plata. Adaptado de Hurtado et al. (2006)

\begin{tabular}{|c|c|c|c|c|c|c|c|c|c|c|c|c|c|}
\hline & Ene & Feb & Mar & Abr & May & Jun & Jul & Ago & Sep & Oct & Nov & Dic & Año \\
\hline$P$ & 101 & 94 & 111 & 95 & 83 & 63 & 66 & 67 & 77 & 93 & 96 & 94 & 1040 \\
\hline$E T P$ & 129 & 103 & 92 & 56 & 40 & 25 & 23 & 28 & 42 & 64 & 88 & 116 & 806 \\
\hline$P-E T P$ & -28 & -9 & 19 & 39 & 43 & 38 & 43 & 39 & 35 & 29 & 8 & -22 & \\
\hline$E T R$ & 125 & 101 & 92 & 56 & 40 & 25 & 23 & 28 & 42 & 64 & 88 & 115 & 799 \\
\hline Alm & 155 & 148 & 167 & 200 & 200 & 200 & 200 & 200 & 200 & 200 & 200 & 179 & \\
\hline$V_{\text {Alm }}$ & -24 & -7 & 19 & 33 & 0 & 0 & 0 & 0 & 0 & 0 & 0 & -21 & \\
\hline Def & 4 & 2 & & & & & & & & & & 1 & 7 \\
\hline Exc & & & & 6 & 43 & 38 & 43 & 39 & 35 & 29 & 8 & & 241 \\
\hline
\end{tabular}

Donde: $E T P=$ evapotranspiración $(\mathrm{mm}) ; P=$ precipitación $(\mathrm{mm}) ; P-E T P=$ precipitación menos evapotranspiración $(\mathrm{mm}) ; A l m=$ almacenaje $(\mathrm{mm}) ; V_{A l m}=$ variación de almacenaje $(\mathrm{mm}) ; E T R=$ evapotranspiración real $(\mathrm{mm}) ; D e f=$, déficit $(\mathrm{mm})$, y $E x c=$ exceso $(\mathrm{mm})$. 
Para completar la caracterización climática, Hurtado et al. (2006) señalan que la temperatura media anual alcanza los $16,2^{\circ} \mathrm{C}$, reconocen a enero como el mes más cálido $\left(22,8^{\circ} \mathrm{C}\right.$ de media) y a julio como el más frío $\left(9,9^{\circ} \mathrm{C}\right.$ de media). Además, indican la existencia de vientos predominantes del Este, con una velocidad media anual de $12 \mathrm{~km} / \mathrm{h}$.

\section{b. Hidrología (EEC)}

La red hidrográfica correspondiente a la EEC y su área de influencia, se definió a partir de la digitalización en pantalla sobre imágenes procesadas del Google Earth@. Esta red hidrográfica digital se trabajó mediante comparación y solapamiento con toda la cartografía disponible y generada con la misma referencia, como ser: cartas topográficas digitalizadas y georreferenciadas provenientes del IGN (escala 1:50000), información digital de GeoINTA (www.geointa.gov.ar), Atlas de suelos de la República Argentina, SIG 250, fotografías aéreas e imágenes satelitales. Este procesamiento permitió delimitar la red hidrográfica en forma completa y definida geográficamente y puede ser representada fielmente en el terreno, como se expresa en la figura II.2.

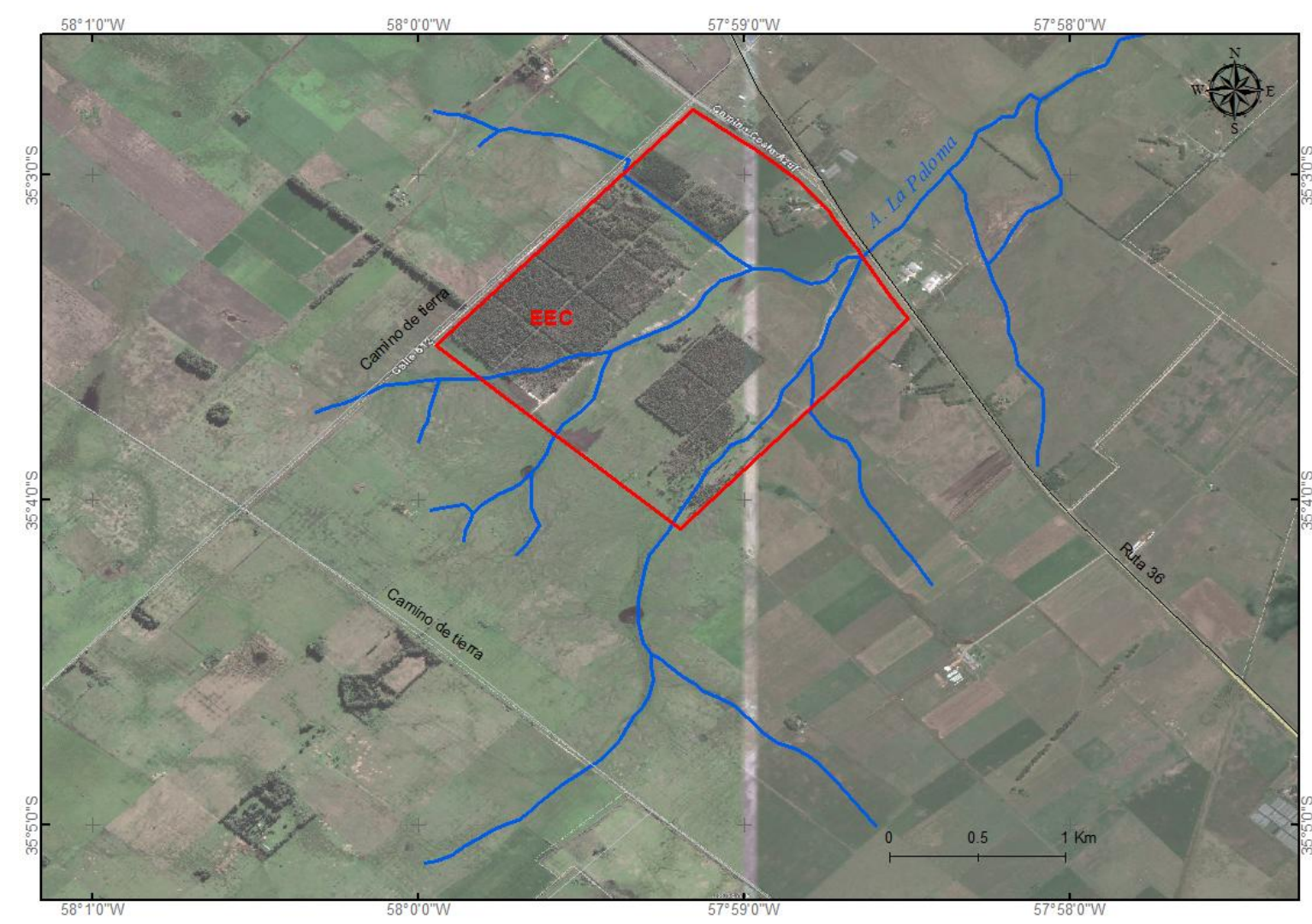

Figura II.2. Límites de la Estancia El Centauro junto con la red hidrográfica correspondiente al Arroyo La Paloma, montada sobre una imagen del Google Earth@ como fondo. 


\section{c. Uso y cobertura del suelo (EEC)}

El predio posee una superficie de $300 \mathrm{ha}$, de las cuales 6,5ha están ocupadas por plantaciones de Pinus radiata Don; 91 ha de Eucalyptus viminalis Labill y 3ha de Salix sp. Además, dispone de 57ha que están destinadas a la rotación de especies forrajeras (avena, maíz, sorgo), y el resto de la superficie corresponde a pastizal natural modificado (Figura II.3).

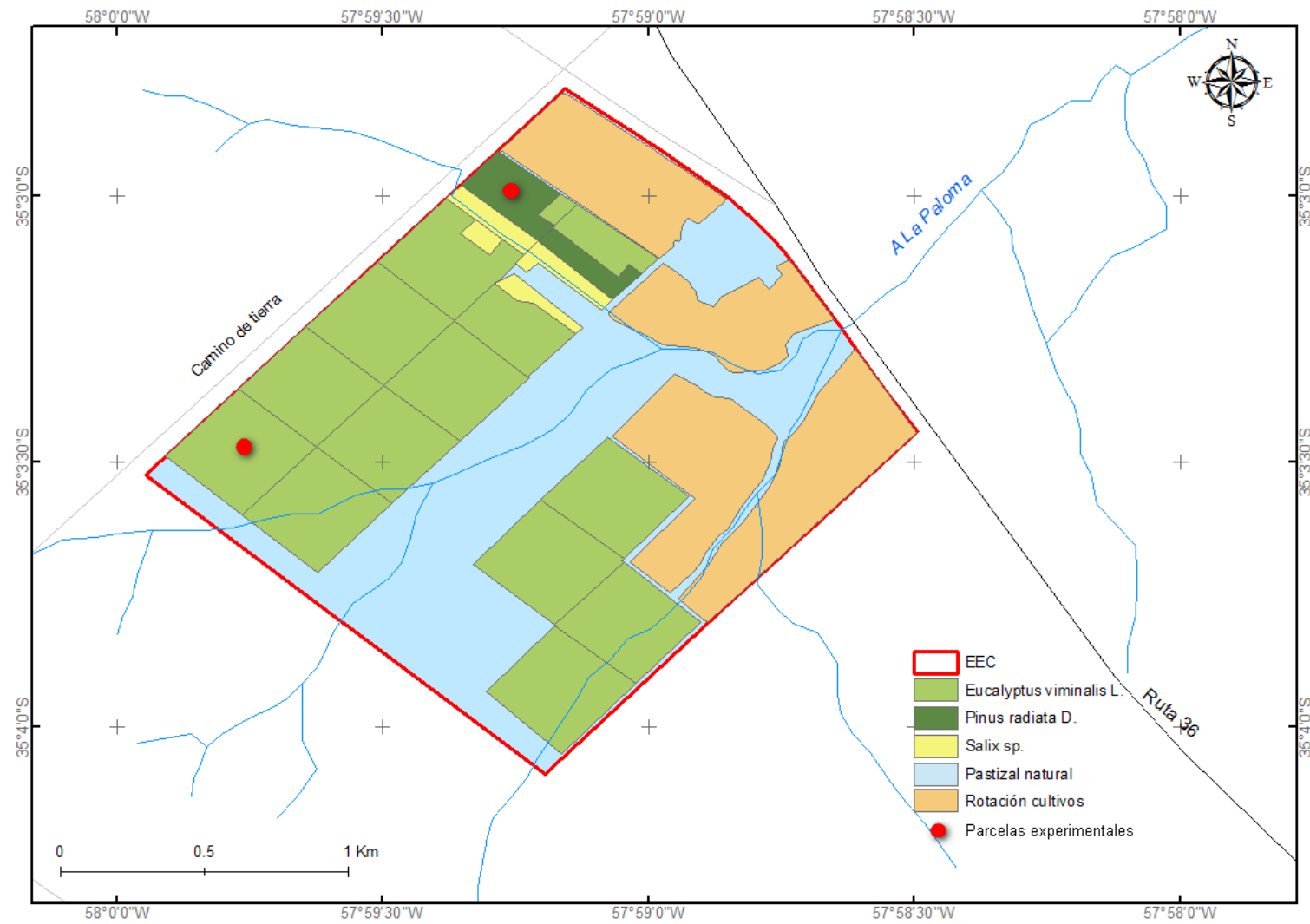

Figura II.3. Estancia El Centauro y zonificación del uso del suelo.

En función de las distintas coberturas señaladas en la figura II.3, se agruparon tres tipos de usos: forestal; ganadera extensiva y rotación de cultivos. A su vez, cabe aclarar que dentro del uso forestal, solo se estudiaron las plantaciones de pino $(6,6 \mathrm{ha})$ y las de eucalipto $(127,4 \mathrm{ha})$. A continuación se detallan las características más relevantes:

Forestación. La forestación de Pinus radiata Don posee una edad estimativa en 30 años (al inicio del estudio) y se encuentra plantada con un espaciamiento de $2,5 \mathrm{~m}$ por 2,5m (1600árb/ha), con un porcentaje de fallas actuales del 25\%. Carece de prácticas 
silvícolas como podas y raleos, y posee un 5\% de los individuos (árboles) suprimidos (muerto y/o caídos) por competencia. El diámetro a altura de pecho (DAP) promedio, al inicio de las experiencias, fue de $28,9 \mathrm{~cm}$ y la canopea se distribuye en un solo estrato de copas con una altura media de $22 \mathrm{~m}$, sin desarrollo de un estrato vegetal inferior.

El suelo se encuentra cubierto por un manto de acículas, ramas y conos de $13 \mathrm{~cm}$ de espesor. El seguimiento de los incrementos de DAP, altura y cobertura durante el período de estudio en las parcelas experimentales reveló un escaso desarrollo de los individuos respecto a la condición inicial, por lo que no fue considerado.

El porcentaje de cobertura de la forestación de pino se estimó en 53,5\%. Su cálculo proviene de una adaptación de la metodología seguida por De la Vega et al. (2010) y propuesta por Macfarlane et al. (2007). Se basa en el procesamiento digital, en ArcGis 9.2@, de imágenes del follaje, tomadas con una cámara Kodak de $5 \mathrm{Mb}$ desde el nivel del suelo y en forma ortogonal. Esas imágenes fueron transformadas a formato GRID $^{9}$ y reclasificadas con el fin de lograr dos valores de píxel ${ }^{10}$, uno que representa la cobertura y otro el cielo libre. Finalmente se contabilizaron, del total de pixeles de la imagen, los que representan la cobertura forestal, y mediante el promedio de ellas se obtuvo el valor medio de cubierta forestal del terreno. En la figura II.4 se muestra la imagen original y la procesada junto con los porcentajes de cobertura forestal del terreno.

${ }^{9}$ Formato de imágenes ráster nativo del programa ArcGis de Esri. Se trata de un mapa de distribución espacial en el que cada píxel posee un valor atributivo (Besteiro y Delgado, 2011)

${ }_{10}$ Acrónimo del inglés "picture element" (elemento de imagen). Representa la menor unidad homogénea en color que forma parte de una imagen digital (Colaboradores de Wikipedia, 2013b). 


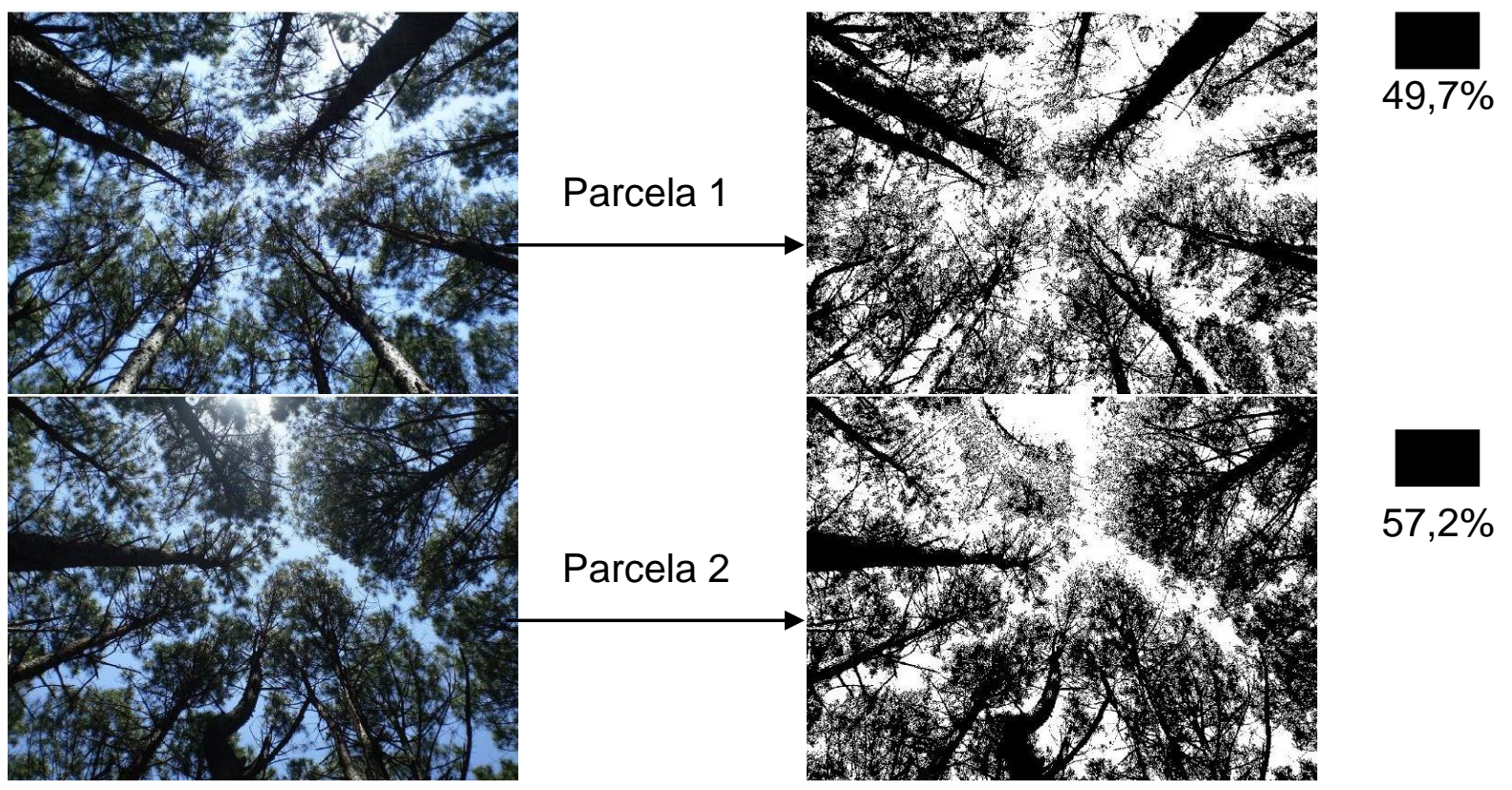

Figura II.4. Imágenes originales y procesadas para el cálculo de cobertura forestal de pino.

La forestación de Eucalyptus viminalis Labill está compuesta por rebrotes de 10 años (al inicio del estudio), en un número promedio de tres rebrotes por cepa. El distanciamiento de las cepas es de 2,5 por 2,5m (1600árb/ha) con un porcentaje de fallas actuales del 10\%. El DAP promedio al inicio de las experiencias fue de $8,85 \mathrm{~cm}$, encontrándose individuos con DAP desde $1 \mathrm{~cm}$ hasta $18,5 \mathrm{~cm}$.

El rodal carece de manejo silvícola y la canopea se distribuye en tres estratos de $20 \mathrm{~m}, 12 \mathrm{~m}$ y $7 \mathrm{~m}$ de altura, con un estrato herbáceo poco desarrollado. El suelo se encuentra cubierto de hojas y ramas que no llegan a formar un manto uniforme y superior al centímetro de espesor. El seguimiento de los incrementos de DAP, altura y cobertura durante el período de estudio en las parcelas experimentales reveló un escaso desarrollo de los individuos respecto a la condición inicial, por lo que no fue considerado.

El porcentaje de cobertura de la forestación de eucalipto se estimó en un 36,7\%. Al igual que en la forestación de pino, este valor surge del valor medio de las coberturas existentes por encima de los pluviómetros instalados para la medición de la trascolación y se calculó a través de la misma metodología antes señalada. En la figura II.5 se muestra la imagen original y la procesada junto con los porcentajes de cobertura forestal del terreno. 

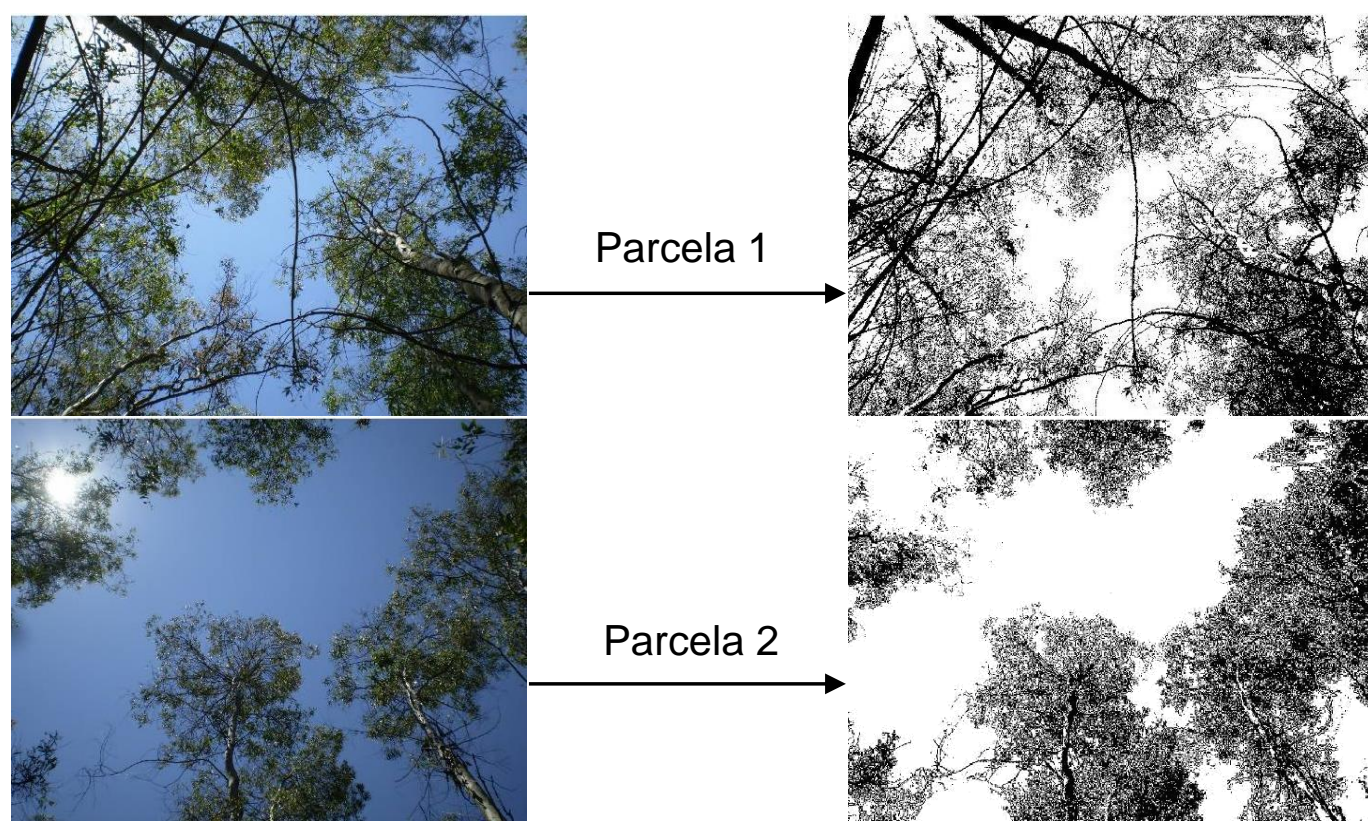

Figura II.5. Imágenes originales y procesadas para el cálculo de cobertura forestal de eucalipto en la EEC.

\begin{abstract}
Pastizal modificado: La denominación de pastizal natural modificado, responde a zonas cubiertas espontáneamente por pastizal y relegadas a la actividad ganadera extensiva. Esta cobertura se vincula con zonas bajas, imperfectamente drenadas y/o empobrecidas, que requieren grandes inversiones a fin de tornarlas productivas para otros usos. (Figura II.6)
\end{abstract}

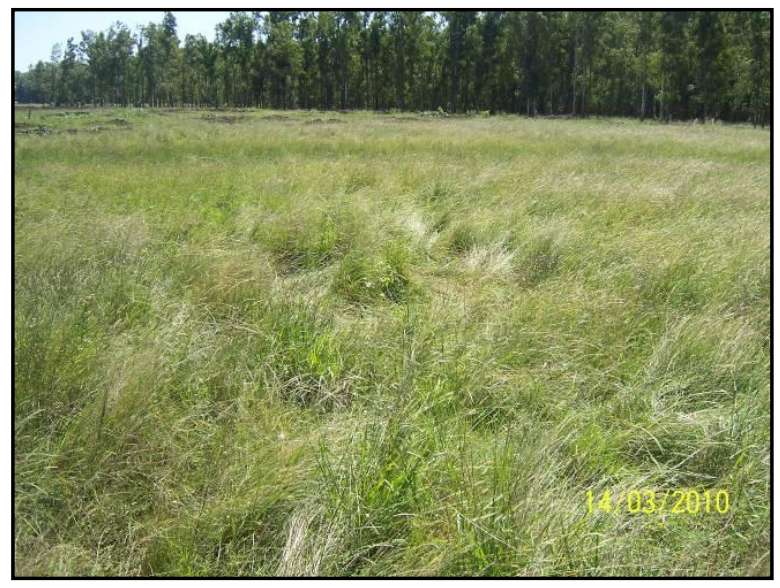

Figura II.6. Detalle fotográfico del pastizal natural modificado de la EEC.

Rotación de cultivos: Las gramíneas forrajeras cultivadas en rotación, a través de siembra directa en la EEC, son la Avena sativa (Avena), Zea mays (Maíz) y Sorghum bicolor (Sorgo).

En lo que refiere a las actividades productivas que se desarrollan en el área circundante al EEC (uso del suelo), se puede mencionar el uso agropecuario extensivo con un $93 \%$ de participación, el forestal con el $6 \%$ y el agrícola intensivo con el $1 \%$. El uso 
agropecuario extensivo, involucra cultivos extensivos (soja, trigo, maíz, girasol, lino), pasturas artificiales para ganadería, tambo, haras y cabañas; incluye además, el uso ganadero extensivo y los terrenos incultos a causa de antiguas decapitaciones con mínima recuperación, suelos degradados y planicies de inundación de arroyos. El uso forestal, por su parte, se encuentra poco desarrollado por falta de promoción e incentivos, pudiendo ser una alternativa para los suelos degradados o con limitaciones. El uso agrícola intensivo, incluye a la horticultura, floricultura, fruticultura, avicultura, apicultura y granja de pequeños animales. La horticultura es la actividad más importante en este último uso $\mathrm{y}$, a pesar de que no es muy representativa en el área de estudio, el partido de La Plata constituye uno de los grandes centros horticultores del país.

\subsubsection{Predio Forestal Dolores (PFD)}

EI PFD se encuentra a 50km de la Ruta Nacional número 2 (acceso Parravichini), a $65 \mathrm{~km}$ de la ciudad de Dolores y a 40km de la ruta 29 (acceso Udaquiola) (Figura II.7).

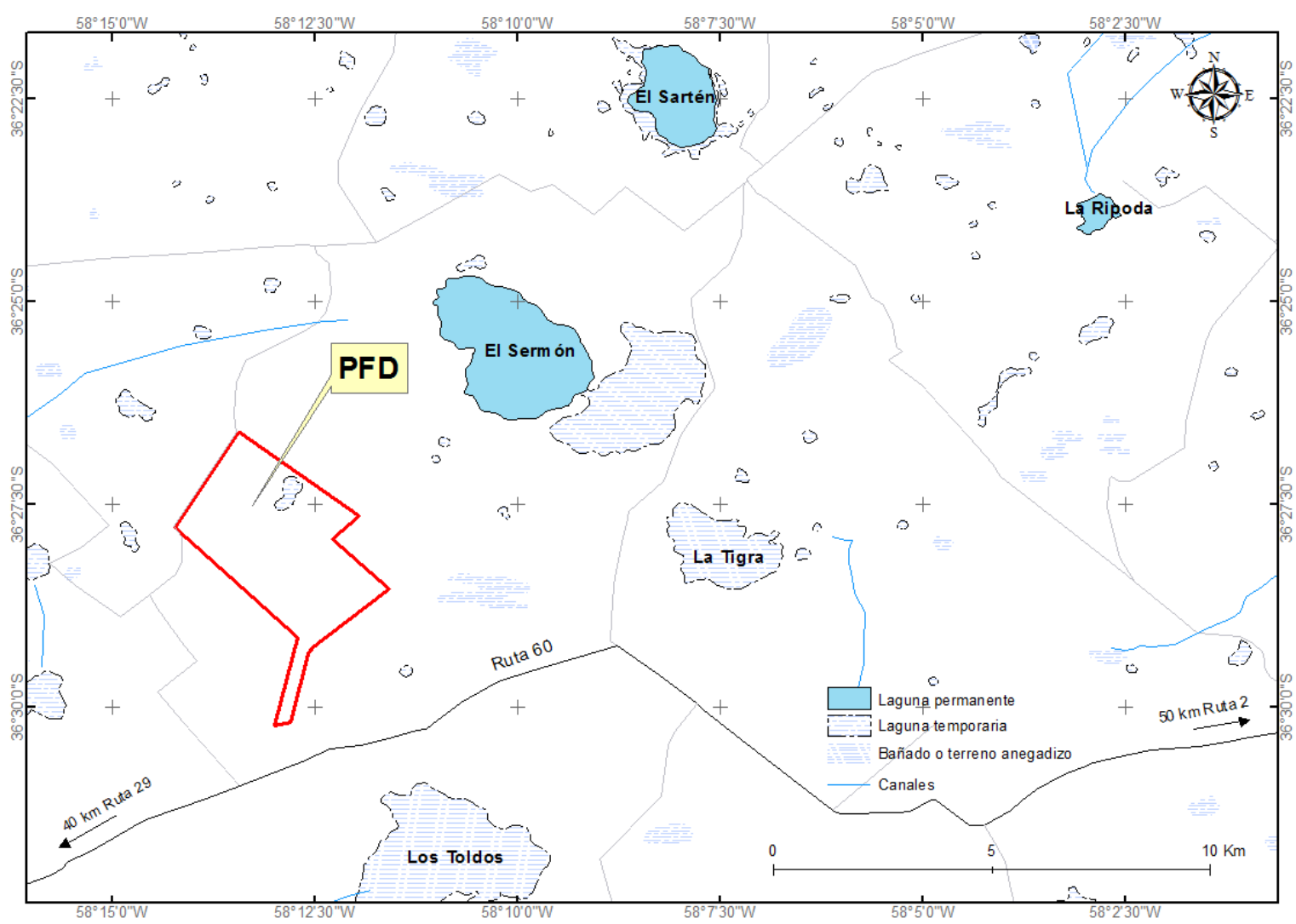

Figura II.7. Localización geográfica del Predio Forestal Dolores (PFD), con caminos de acceso e hidrografía característica. 


\section{a. Clima (PFD)}

La región en estudio se encuentra caracterizada por un clima sub-húmedo mesotérmico, con marcada variación estacional de la temperatura que aumentan en sentido sur-norte, con $21^{\circ} \mathrm{C}$ a $23^{\circ} \mathrm{C}$ en enero y $7^{\circ} \mathrm{C}$ a $9^{\circ} \mathrm{C}$ en julio, y una estación fría poco o nada notable con temperaturas medias anuales de $13^{\circ} \mathrm{C}$ a $16^{\circ} \mathrm{C}$ (Burgos y Vidal, 1951; Vervoorst, 1967; Walter, 1967; Laprida, 2006).

El régimen pluviométrico de esta región es isohigro, con lluvias distribuidas a lo largo de todo el año que oscilan entre $750 \mathrm{~mm}$ anuales en el sur y $1000 \mathrm{~mm}$ en el norte, con un gradiente negativo de este a oeste, con frecuentes períodos de inundaciones invernales o primaverales y de déficit hídrico estival (Sala, 1975; León y Burkart, 1998; Batista et al., 2005; Pérez et al., 2007). En PFD, y como se verá más adelante, se identifica una precipitación media anual de $941,7 \mathrm{~mm}$ y una ETP anual de $1235,3 \mathrm{~mm}$.

Los inviernos son húmedos con excesos hídricos del orden de los 0 a 250mm/año (Auge, 2006) y anegamientos frecuentes como consecuencia de la baja evapotranspiración (Laprida, 2006). Estos excesos disminuyen hacia el oeste y suroeste (Vega et al., 1995).

En los veranos, si bien la precipitación suele ser mayor, hay un pronunciado déficit de humedad del suelo como consecuencia de la mayor evapotranspiración y, en ciertos períodos, como consecuencia de las sequías (Laprida, 2006).

Más del $70 \%$ de las grandes inundaciones se han observado con eventos extraordinarios de otoño-invierno, con una duración media del período anegado de cinco meses (Vázquez et al., 2011). El resto ocurrieron durante la primavera, debido a una mayor demanda de la ET, con una duración media de tres meses o menos (Posadas, 1934; Barbagallo, 1983). Esto refuerza la idea que el principal componente vertical que controla el volumen de agua superficial es la ET (Vázquez et al., 2011).

\section{b. Hidrología (PFD)}

En la figura II.7 se muestran los distintos cuerpos de agua digitalizados en función de las cartas topográficas del IGN (escala 1:50000) y corroborados con información digital de GeoINTA (www.geointa.gov.ar), Atlas de suelos de la República Argentina, SIG 250, 
imágenes satelitales y mapa de suelos a nivel del Predio Forestal Dolores y su área de influencia.

Se trata de un área de concentración de los escurrimientos superficiales y subsuperficiales por excelencia (Vázquez et al., 2011), donde la respuesta a los eventos de Iluvia no pueden ser explicados por los conceptos clásicos de la hidrología de superficie, debido a que se trata de una extensa zona plana con alta densidad de cuerpos de agua y escasa energía morfométrica (Tricart, 1973), donde el agua de escurrimiento no alcanza a modelar una red de drenaje desarrollada (Batista et al., 2005).

La precipitación caída, al no ser evacuada por canales y arroyos, es captada por el sistema y convertido en expansión y disipación que ocupa todas las áreas deprimidas de primer orden (cubetas de deflación, áreas deprimidas aledañas a cuerpos de agua, vías de escurrimiento), para luego, una vez colmatadas éstas, avanzar en función de su altura relativa sobre las de segundo orden (áreas planas circundantes a las anteriores) (Vázquez et al., 2011). La capacidad de retención de este sistema fue estimado en 100-300mm (Posadas, 1934), superados los cuales, devienen en inundaciones.

Es evidente entonces que los procesos verticales (evapotranspiración e infiltración) dominan en la dinámica del agua acumulada superficialmente (Vázquez et al., 2011).

\section{c. Uso y cobertura del suelo (PFD)}

El predio posee una superficie de $1015,5 \mathrm{ha}$, de las cuales: un $66,1 \%$ se encuentra forestado con Eucalyptus camaldulensis Dehnh y Eucalyptus viminalis Labill. Además, el 6,7\% está destinado a un área protegida, a modo de reserva ecológica, donde se desarrolla una laguna temporaria; el 11,1\% está cubierto por pastizales naturales; el 9,4\% son áreas de tala rasa y el 6,7\% restante, corresponde a viviendas, galpones y caminos (Figura II.8). 


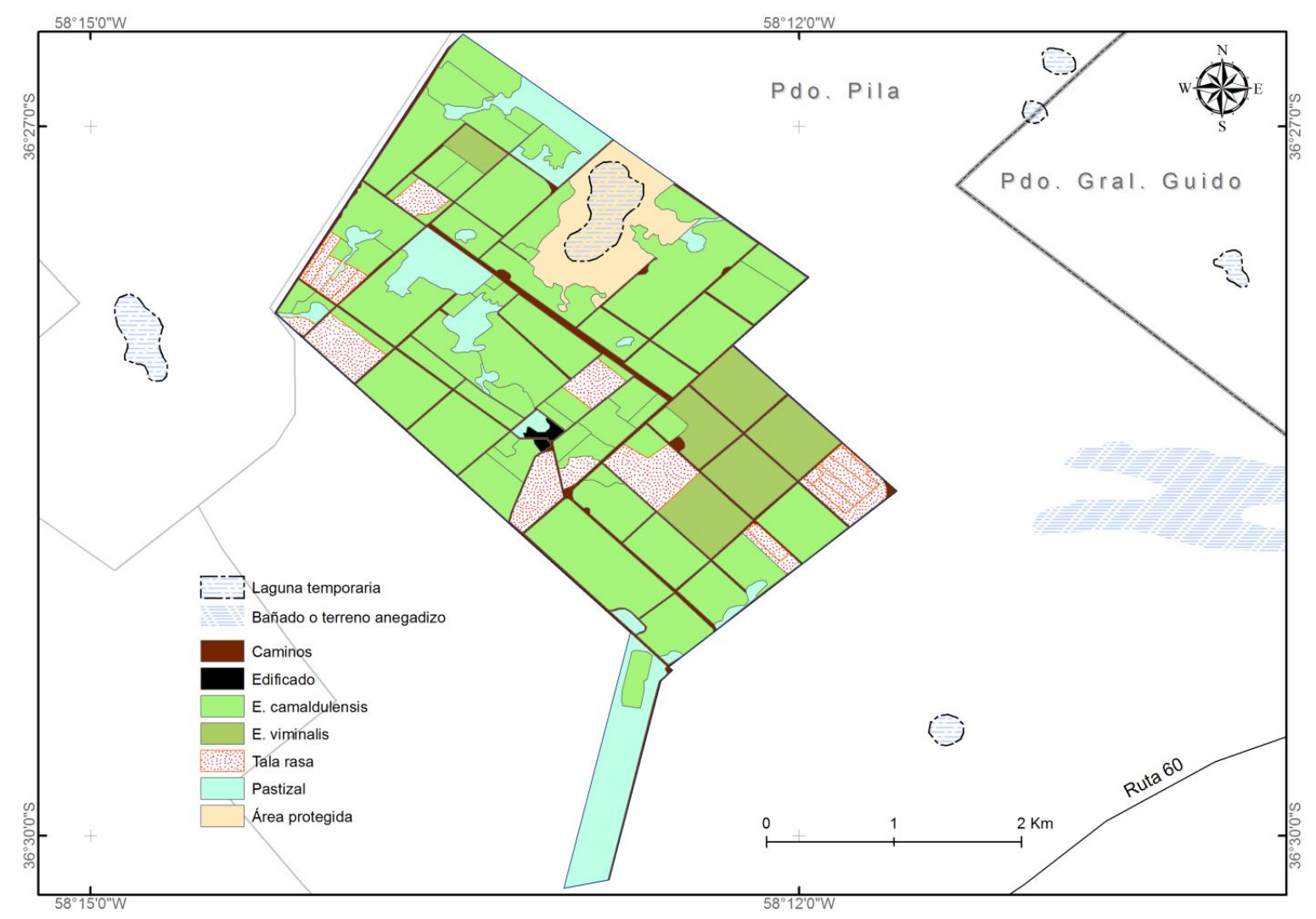

Figura II.8. Predio Forestal Dolores y tipos de coberturas y usos del suelo.

Se trata de un predio netamente forestal perteneciente a la empresa Alto Paraná, con más del $75 \%$ destinado a la actividad forestal y poco menos del $7 \%$ a caminos y viviendas. La superficie restante (poco menos del 18\%), corresponden a zonas bajas inundables donde se desarrolla pastizal nativo. Además, el suelo forestado se encuentra cubierto por un mantillo de hojas y ramas de espesor variable, que puede alcanzar los $15 \mathrm{~cm}$.

En la figura II.9 se muestra un mapa realizado por la empresa Alto Paraná, donde se indican con color verde, los lotes elegidos para la realización de las experiencias junto a una breve descripción de los mismos. 


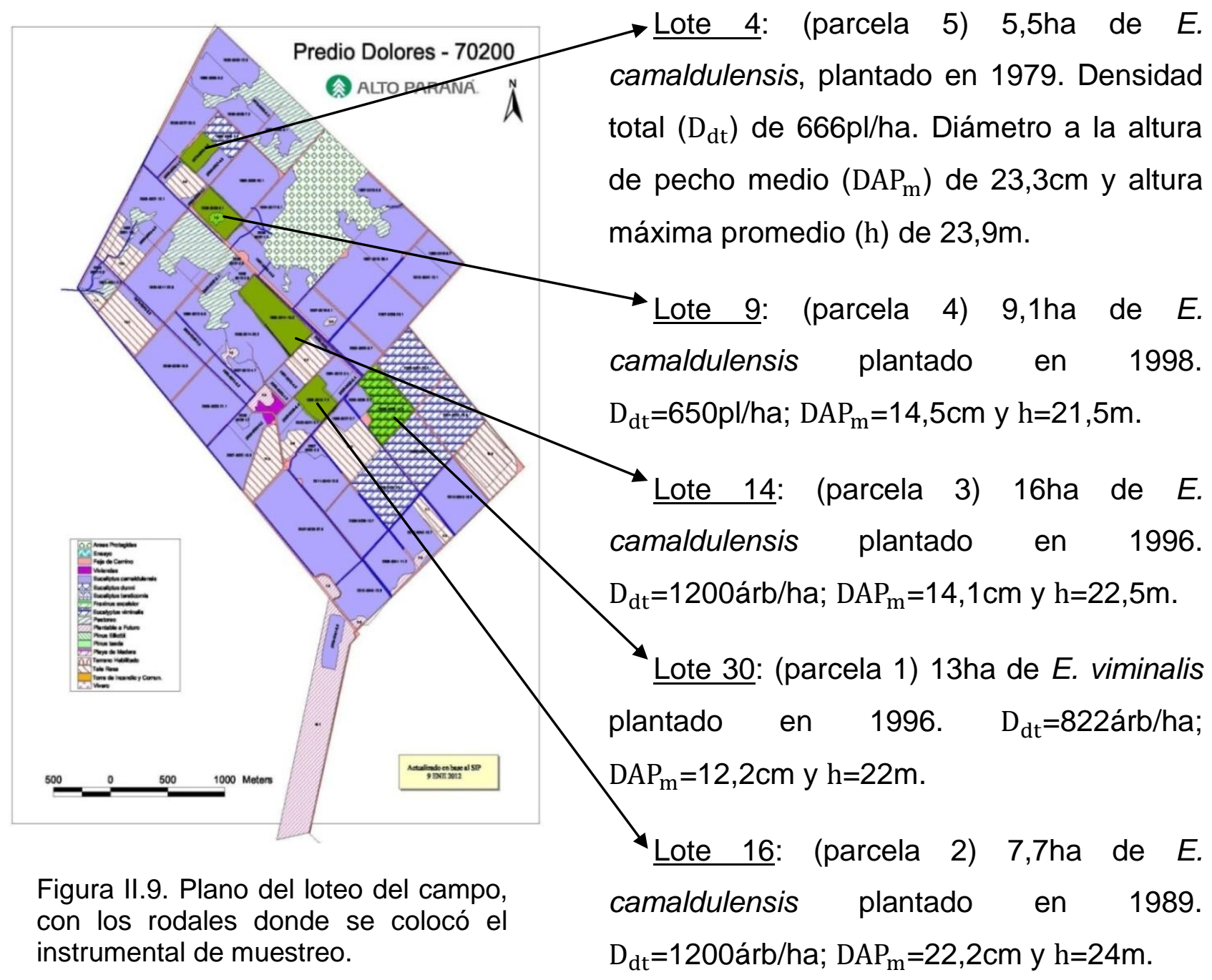

El porcentaje de cobertura de la forestaciones de eucalipto, correspondientes a cada parcela de muestreo, se muestran en la figura II.10., donde se observa la imagen cruda y la procesada junto con el porcentaje de cobertura. La metodología seguida para el cálculo de estas coberturas es la que se uso en EEC (apartado 2.2.1.1c). Se trata de una metodología de fácil y rápida aplicación, que permite obtener un valor estimativo de la cobertura forestal por medio de la reclasificación digital de las imágenes ortogonales de la cobertura y su posterior contabilización. 


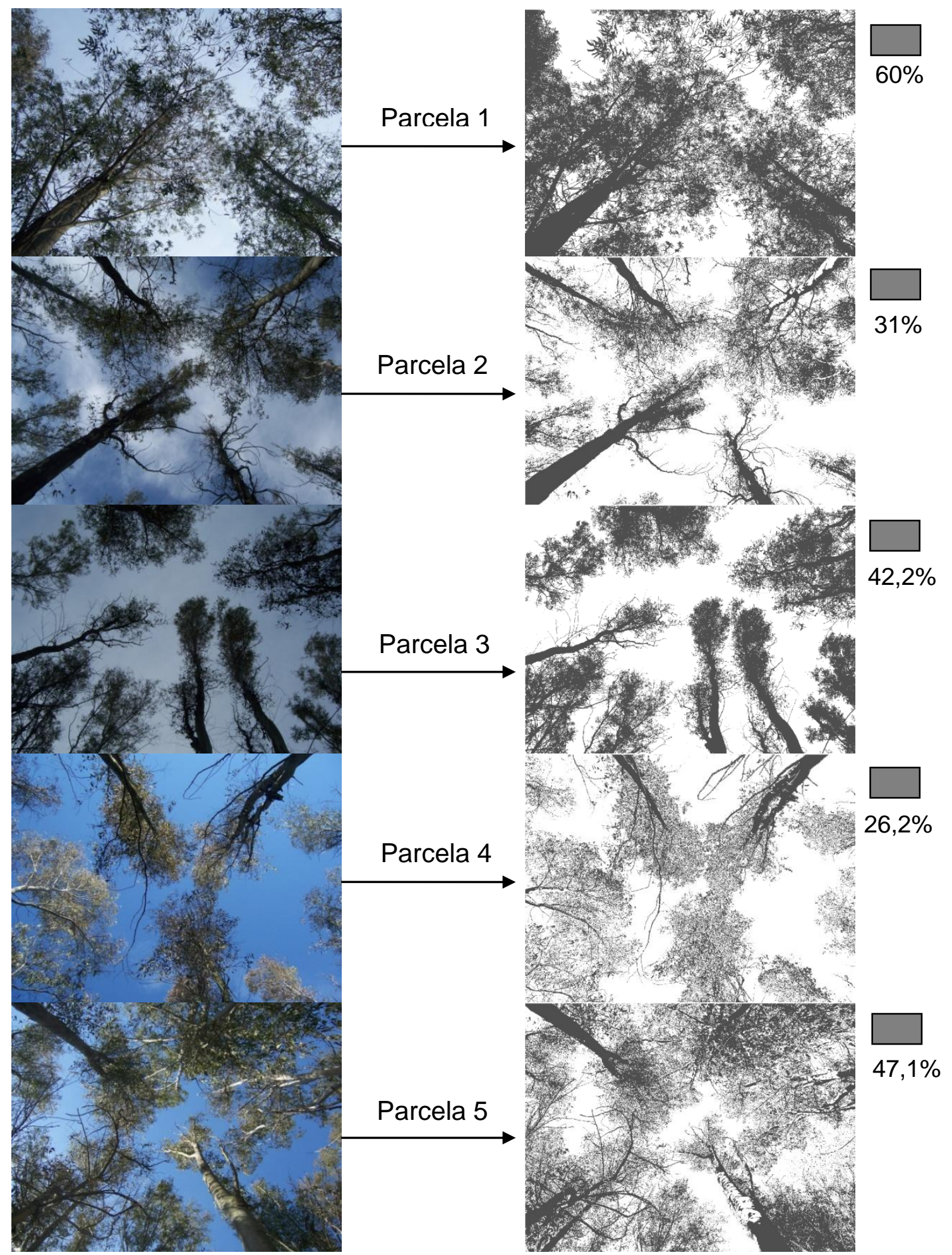

Figura II.10. Imágenes de la cobertura forestal en el PFD, ordenada de a pares por parcela de muestreo. Se muestra la imagen no procesada en color junto a la procesada en banco y gris.

En el área circundante al PFD, la vegetación predominante es el pastizal natural formado por un mosaico de estepas graminosas y praderas con diferente cobertura y altura 
de pastos, hierbas y arbustos. Los árboles nativos, en cambio, son muy escasos y su distribución restringida. Desde fines del siglo XIX, los pastizales de la pampa deprimida están subdivididos por alambrados y sometidos a un intenso pastoreo por ganado doméstico que mantiene su fisonomía notablemente homogénea a través del paisaje (Batista et al., 2005). 


\subsubsection{Precipitación}

En lo que refiere a la medición directa de la precipitación, se puede distinguir, a grandes rasgos, dos tipos de instrumentales de medida: los medidores con registro y los medidores sin registro. Los primeros, son aquellos aparatos que registran de forma automática la profundidad de la lámina de lluvia a intervalos reducidos de tiempo (Ejemplo: pluviógrafo tipo Canjilones); los segundos son aquellos que registran esa misma lámina de lluvia y se miden manualmente a intervalos mayores de tiempo.

Los datos de precipitación considerados en el análisis provinieron de varias fuentes. En la EEC (Figura II.11), se instalaron dos pluviómetros (pluviómetro de campo y pluviómetro testigo), y además, se dispuso de los datos pluviométricos diarios provenientes de la Estación Experimental Ing. Agr. Julio Hirschhorn de la Facultad de Ciencias Agrarias y Forestales de La Plata (FCAyF), UNLP. El primero de estos pluviómetros, el pluviómetro de campo, fue registrado diariamente por el personal del campo, y el segundo, denominado pluviómetro testigo, fue registrado personalmente de forma semanal, al igual que los datos de la red de monitoreo de pozos y las parcelas de muestreo.

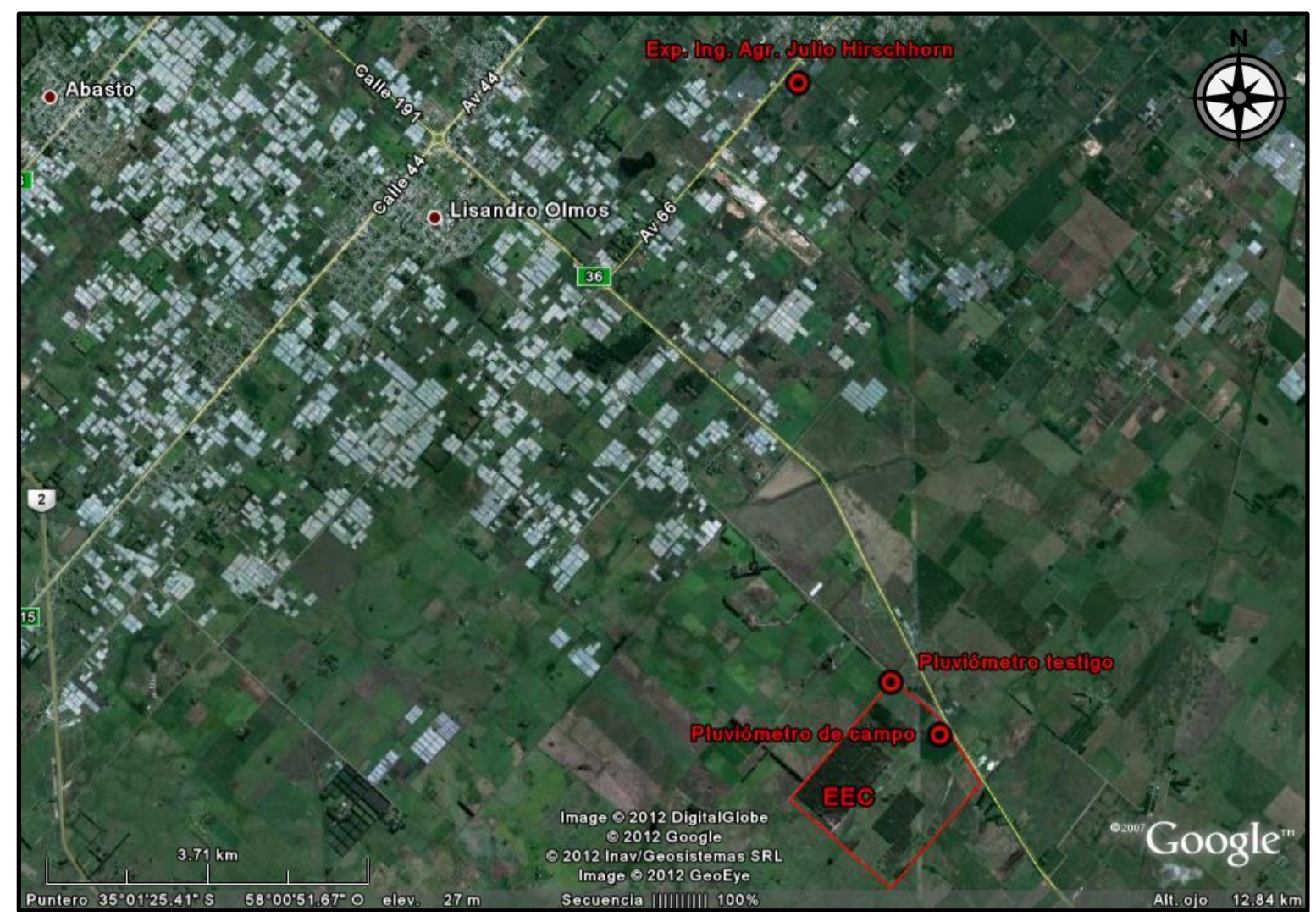

Figura II.11. Ubicación de estación experimental Ingeniero Julio Hirschhorn y pluviómetros de la Estancia El Centauro. De fondo se muestra un mosaico de imágenes Google Earth junto a la red caminera. 
En el PFD (Figura II.12), se instaló una estación meteorológica de registro continuo (estación testigo) y se contó con los datos de un pluviómetro perteneciente a la empresa Alto Paraná (pluviómetro campo) y con los registros de lluvias corregidas de la estación meteorológica del Servicio Meteorológico Nacional (SMN) denominada Aeródromo Dolores.

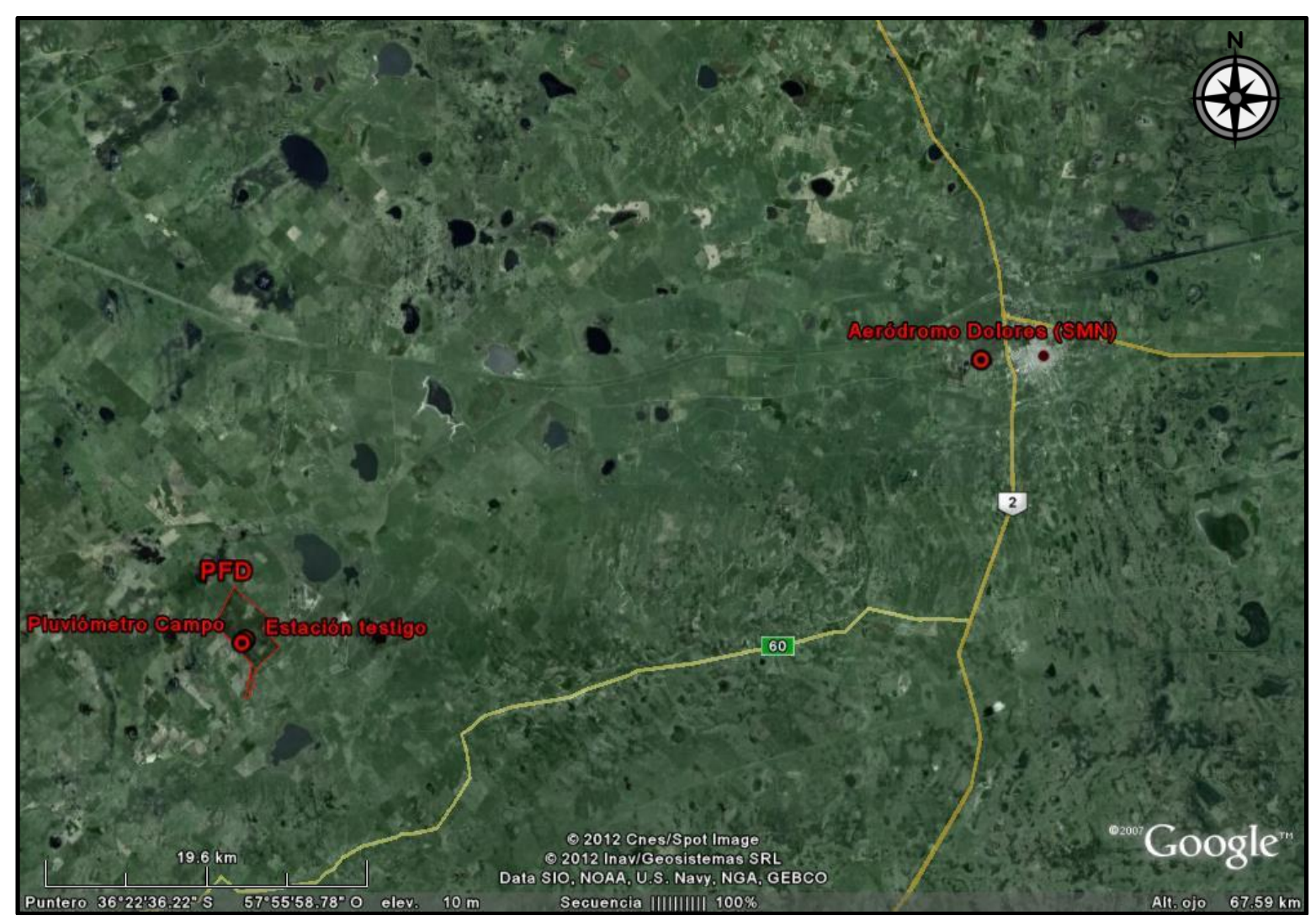

Figura II.12. Ubicación de la estación del Servicio Meteorológico Nacional, Aeródromo Dolores, y de la estación meteorológica y pluviómetro del Predio Forestal Dolores. De fondo se muestra un mosaico de imágenes Google Earth junto a la red caminera.

En la tabla II.3 se muestra un detalle de las distintas fuentes de datos pluviométricos, así como su ubicación, tipo y período considerado en el análisis. 
Tabla II.3. Fuente de datos pluviométricos, ubicación, frecuencia de datos y distancia de las estaciones meteorológicas de los sitios de estudio.

\begin{tabular}{ccccccc}
\hline Nombre & Lugar & Cercanía & Latitud & Longitud & Período & Datos \\
\hline Experimental Hirschhorn & EEC & $8 \mathrm{~km}$ & $-34^{\circ} 59,1^{\prime}$ & $-57^{\circ} 59,8^{\prime}$ & $1998-2011$ & Diarios \\
Experimental Hirschhorn & EEC & $8 \mathrm{~km}$ & $-34^{\circ} 59,1^{\prime}$ & $-57^{\circ} 59,8^{\prime}$ & $1918-2011$ & Mensuales \\
Pluviómetro testigo & EEC & 0 & $-35^{\circ} 02,8^{\prime}$ & $-57^{\circ} 59,2^{\prime}$ & $2008-2011$ & Semanales \\
Pluviómetro campo & EEC & 0 & $-35^{\circ} 03,1^{\prime}$ & $-57^{\circ} 58,8^{\prime}$ & $2008-2011$ & Diarios \\
Aeródromo Dolores (SMN) & PFD & $65 \mathrm{~km}$ & $-36^{\circ} 19,0^{\prime}$ & $-57^{\circ} 43,0^{\prime}$ & $1959-2012$ & Diarios \\
Estación testigo (Agromet) & PFD & 0 & $-36^{\circ} 28,2^{\prime}$ & $-58^{\circ} 12,9^{\prime}$ & $2009-2012$ & 1 1/2 Hora \\
Pluviómetro campo & PFD & 0 & $-36^{\circ} 28,4^{\prime}$ & $-58^{\circ} 13,1^{\prime}$ & $2009-2012$ & Diarios \\
\hline
\end{tabular}

El análisis y descripción de las distintas series se inició a través de la representación gráfica de las series anuales y el análisis estadístico a nivel anual, mensual y diario de los datos pluviométricos provenientes de las estaciones meteorológicas (EEJH y EMAD). Esta primera aproximación, tiene un carácter comparativo y busca obtener una visión regional de la situación hidrológica entre ambos sitios de estudio (EEC y PFD), sustentado en registros diarios reconocidos y extensamente utilizados.

El análisis estadístico para esta primera comparación (EEJH vs. EMAD), se realizó en las escalas anual y mensual, para los 53 años que estas series comparten (1959-2011), y diaria, para el período 1998-2011 (15 años completos). Se procedió a la evaluación gráfica de las precipitaciones acumuladas anuales de ambos sitios (EEJH y EMAD) y luego a la valoración analítica de los datos anuales, mensuales y diarios por medio de análisis de doble masa y la utilización de los coeficientes de consistencia e inconsistencia propuestos por Colotti et al. (2003) y utilizados por Gattinoni et al. (2011). Luego, para complementar el análisis gráfico, se evaluó la similaridad/disimilaridad de las series a través del coeficiente de correlación de Pearson y, finalmente, la significancia de las diferencias entre las precipitaciones medias anuales, mensuales y diarias por medio de la prueba $U$ de MannWhitney (Zar, 1999), consistente en una prueba no paramétrica para muestras independientes.

Concretado el análisis inicial, y con el fin de dar fortaleza a los valores de precipitación medidos, evaluar su consistencia y posibilitar extrapolaciones temporales; se procedió al contraste entre los datos procedentes de las estaciones meteorológicas (EEJH y EMAD) y los determinados in situ (pluviómetros testigos y de campo correspondientes a EEC y PFD). 
Se procedió a la realización de un análisis gráfico de cada uno de los pares de series mensuales (pares "EEJH-Testigo EEC" y "EMAD-Testigo PFD"), para identificar las tendencias y el grado de correlación de los mismos. Sin embargo, surge la necesidad de preguntarse si es correcto utilizar indistintamente los registros de lluvia provenientes de las estaciones meteorológicas y la de los testigos del campo y, de la misma manera, cuál sería el error que se comete al hacerlo. Para responder estas inquietudes, se procedió con las determinaciones analíticas, mediante la utilización de pruebas no paramétricas (U de Mann-Whitney), donde se buscó verificar la existencia de diferencias significativas entre valores medios mensuales de cada sitio de estudio. Luego, se realizaron análisis de doble masa sobre los pares analizados, para establecer el grado de heterogeneidad de los datos a lo largo de los tres años de mediciones y, finalmente, se determinaron los coeficientes de consistencia e inconsistencia de Colotti et al. (2003), con el fin de mensurar cuan consistentes son estos.

El análisis de doble masa es una metodología muy utilizada en el estudio de series pluviométricas, que permite determinar inconsistencias de la información (grado de heterogeneidad de datos pluviométricos) y corregirla. Analiza la consistencia de una serie de valores acumulados anuales o mensuales medidos en una estación ( $\mathrm{x}$ ) frente a los datos acumulados de otra estación o grupo de ellas (y) (Linsley et al., 1993). El gráfico de estas dos variables acumuladas (x e y) permite ajustar una recta, en la cual se pueden observar quiebres o cambios de pendiente que solo pueden deberse a causas ajenas al fenómeno meteorológico y que dan una idea de la consistencia u homogeneidad de los datos. Si la línea acumulada de los datos de las distintas estaciones no presenta quiebres apreciables, puede concluirse que no existe una fuerte heterogeneidad entre las estaciones.

De la misma manera, los coeficientes de consistencia e inconsistencia a utilizar son propuestos por Colotti et al. (2003) como los más apropiados para la comparación simultánea de dos sucesiones de medidas meteorológicas. Estos autores, proponen estos índices como elementos decisores al evaluar la necesidad de ajuste de un conjunto de nuevos datos meteorológicos automáticos que deben acoplarse a registros antiguos, medidos convencionalmente por distintos organismos que administran redes meteorológicas en Venezuela. En Argentina, estos índices fueron utilizados satisfactoriamente por Gattinoni et al. (2011) en el Instituto de Clima y Agua del INTA Castelar para evaluar el funcionamiento de dos estaciones meteorológicas automáticas, a 
través de los datos acumulados diarios y mensuales de precipitación. La obtención de estos coeficientes surge del desarrollo del error cuadrático medio $\left(\mathrm{E}_{\mathrm{CM}}\right)$, al demostrarse que $\mathrm{E}_{\mathrm{CM}}=\mathrm{V}(\mathrm{x})+\mathrm{V}(\mathrm{y})-2 \mathrm{C}(\mathrm{x}, \mathrm{y})$, donde: $\mathrm{E}_{\mathrm{CM}}=\mathrm{V}(\mathrm{x}-\mathrm{y})$, es la varianza de la razón entre muestras; $\mathrm{V}(\mathrm{x})$, es la varianza de la muestra $\mathrm{x} ; \mathrm{V}(\mathrm{y})$, es la varianza de la muestra $\mathrm{y}, \mathrm{y}$ $C(x, y)$, es la covarianza entre las muestras $x$ e $y$. Luego, bajo el supuesto de que la esperanza matemática de $\mathrm{x}$ es igual a la de $\mathrm{y}$, se obtiene el Coeficiente de Inconsistencia $\mathrm{C}_{\mathrm{I}}$ (Ecuación II.1).

$$
C_{I}=\frac{V(x-y)}{V(x)+V(y)}
$$

Este coeficiente varía entre 0 (muestras linealmente dependientes o perfectamente consistentes) y 1 (muestras totalmente independientes), suponiendo que no existe correlación lineal entre los dos conjuntos de mediciones. Los autores extienden el concepto de inconsistencia incorporando el de consistencia entre los datos y para ello definen el Coeficiente de Consistencia $\left(\mathrm{C}_{\mathrm{C}}\right)$ (Ecuación II.2).

$$
\mathrm{C}_{\mathrm{C}}=1-\mathrm{C}_{\mathrm{I}}
$$

Los modelos de planilla confeccionados para la toma de datos pluviométricos semanales en la EEC y PFD, se muestra en el apartado de anexos. 


\subsubsection{Intercepción}

La pérdida por intercepción fue calculada de forma indirecta a través de la medición del escurrimiento fustal o stemflow $\left(\mathrm{E}_{\mathrm{f}}\right)$ y la trascolación o throughfall $\left(\mathrm{T}_{\mathrm{r}}\right)$, según la ecuación II.3 (Pritchet, 1991):

$$
\mathrm{I}=\mathrm{P}-\left(\mathrm{T}_{\mathrm{r}}+\mathrm{E}_{\mathrm{f}}\right)
$$

Para la medición del $\mathrm{E}_{\mathrm{f}}$ se diseñaron e implantaron parcelas experimentales. La elección de los individuos (árboles) se realizó por medio de un relevamiento y caracterización general de los rodales en parcelas de $100 \mathrm{~m}^{2}$, donde se contabilizó el número de árboles en pie, árboles faltantes, densidad de plantación, altura media, diámetro medio y porcentaje de cobertura de copas. Esta última se realizó mediante una adaptación de la metodología propuesta por Macfarlane et al. (2007), mencionada en el apartado 2.2.1.1c. La misma consiste en el análisis de fotos planas ortogonales del dosel forestal, donde se contabiliza el número total de pixeles de cada imagen y los correspondientes a la vista libre del cielo (gT). La razón de estos valores, según la ecuación II.4, permite la obtención del porcentaje de cobertura de copas $\left(\mathrm{f}_{\mathrm{c}}\right)$.

$$
\mathrm{f}_{\mathrm{c}}=1-\frac{\mathrm{gT}}{\text { Pixeles totales }}
$$

En la EEC, se definieron dos parcelas experimentales (una en pino y otra en eucalipto) en las que se colocaron dos (2) colectores de $E_{f}$ en cada una de ellas. En el PFD se definieron 5 parcelas experimentales, con un número variable de colectores por parcela (de 4 a 9 ).

Los colectores de flujo consistieron, inicialmente, en una banda de papel aluminio sujeta a $1,7 \mathrm{~m}$ de altura alrededor de una sección en bisel de los árboles elegidos. Estas fueron moldeadas y forradas con masilla para evitar filtraciones. Luego, mediante tubos pasa-pared de nylon, fue posible vincular las canaletas con colectores calibrados 
(capacidad de 60lts en EEC y 200lts en PFD). A partir del año 2010, los collarines de aluminio fueron reemplazados por unos de polipropileno y goma sellados con pegamento siliconado (Figura II.14).

En la figura II.13, se muestra el proceso de instalación de un colector de escurrimiento fustal en un árbol de pino. El proceso se inició con una limpieza superficial de la corteza (imagen número 3 de la Figura II.13), a fin de minimizar la posibilidad de filtraciones (esto no fue necesario en eucalipto). Se continuó con la colocación de un cordón de masilla a modo de corte en bisel, con una mínima inclinación para que escurra el agua (imagen 4). Sobre la masilla, se colocó una banda de papel aluminio plegada (imagen 5), sujeta con hilo y posteriormente, doblada en sus bordes a modo de canaleta colectora (imagen 6, 7). En la imagen 7 a 10 se observa la colocación de los tubos pasa-pared de nylon y el forrado del interior de la canaleta colectora con masilla. Finalmente, se muestra la colocación de la manguera transparente que conecta al tambor graduado de 60lts, paralelo a la base del árbol y sobre una base fija horizontal (imagen 10 a 13).
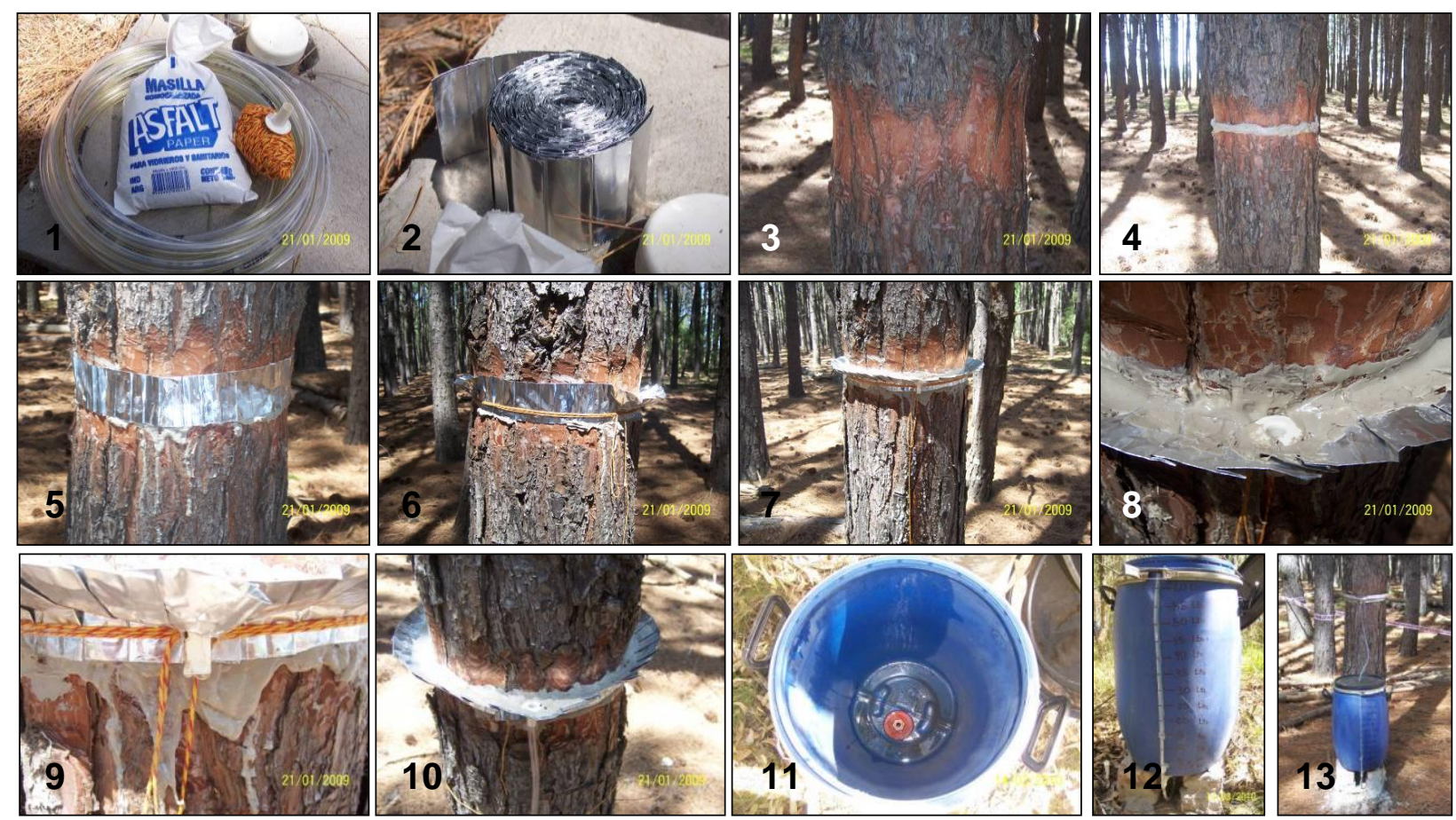

Figura II.13. Secuencia de imágenes (de izquierda a derecha y de arriba hacia abajo) indicando la instalación de un colector de escurrimiento fustal en un árbol de pino. 
El cálculo de la proyección de las copas de los árboles ensayados fue utilizado para los cálculos de la $\mathrm{ET}_{\mathrm{c}}$, presentados en el capítulo 5.

Los valores de trascolación $\left(\mathrm{T}_{\mathrm{r}}\right.$ ) en la $\mathrm{EEC}$, se obtuvieron por la instalación de pluviómetros de embudo en cada parcela (dos en pino y dos en eucalipto) a 1,3 metros de altura, con un diámetro de boca de $19,4 \mathrm{~cm}$ (superficie de captación $=295,44 \mathrm{~cm}^{2}$ ), y un recipiente contenedor de 2,4lts de capacidad aproximada. Estos pluviómetros fueron reubicados mensualmente para evitar errores de muestreo por captación en sitios preferenciales de escurrimiento. La trascolación o cantidad de agua que atraviesa el dosel y no queda retenido en él, se expresó como lámina acumulada en $\mathrm{mm}$ por medio de la razón del agua acumulada por la superficie de captación.

El método de "pluviómetro móvil" es considerado por ciertos autores (Lloyd y Marques, 1988, en: Bruijnzeel 1997) como una forma de sobrestimar la cantidad de lluvia que atraviesa el dosel, en comparación al método del "pluviómetro fijo". Estos autores aluden la eficiencia de estos métodos a su capacidad de representar de los "puntos de goteo". Sin embargo, otras investigaciones han demostrado la existencia de gradientes de trascolación bajo plantaciones (Mateos R. y Schnabel, 2002), al indicar zonas deprimidas próximas al tronco, donde el agua trascolada no alcanza el $20 \%$ de la precipitación bruta, y un aumento de la trascolación a medida que los colectores se alejan de los fustes hacia los extremos de las copas (130\% de la precipitación bruta). Esto último justificaría la utilización del método de pluviómetro móvil, dado que se busca captar todo el gradiente de trascolación sin la necesidad de contar con un número elevado de colectores.

En el caso de Predio Forestal Dolores (PFD), se instalaron un total de cinco colectores de agua bajo la canopea forestal (uno por cada parcela de muestreo), consistente en una canaleta de PVC de $0,435 \mathrm{~m}^{2}$ (14,5cm de ancho por $3 \mathrm{~m}$ de largo), colocada a 1,6 metros del suelo y provista de una leve inclinación (3\%) que permite el volcado del agua que atraviesa la canopea a un tanque colector graduado. Colectores semejantes han sido empleados por otros autores (Cantú y González, 2002), con resultados satisfactorios.

En la figura II.14 se muestra una secuencia de imágenes del procedimiento e instrumental de instalación de los pluviómetros de embudo en la Estancia El Centauro (EEC) y pluviómetros de canaleta y colectores de escurrimiento fustal en el Predio Forestal Dolores (PFD). 


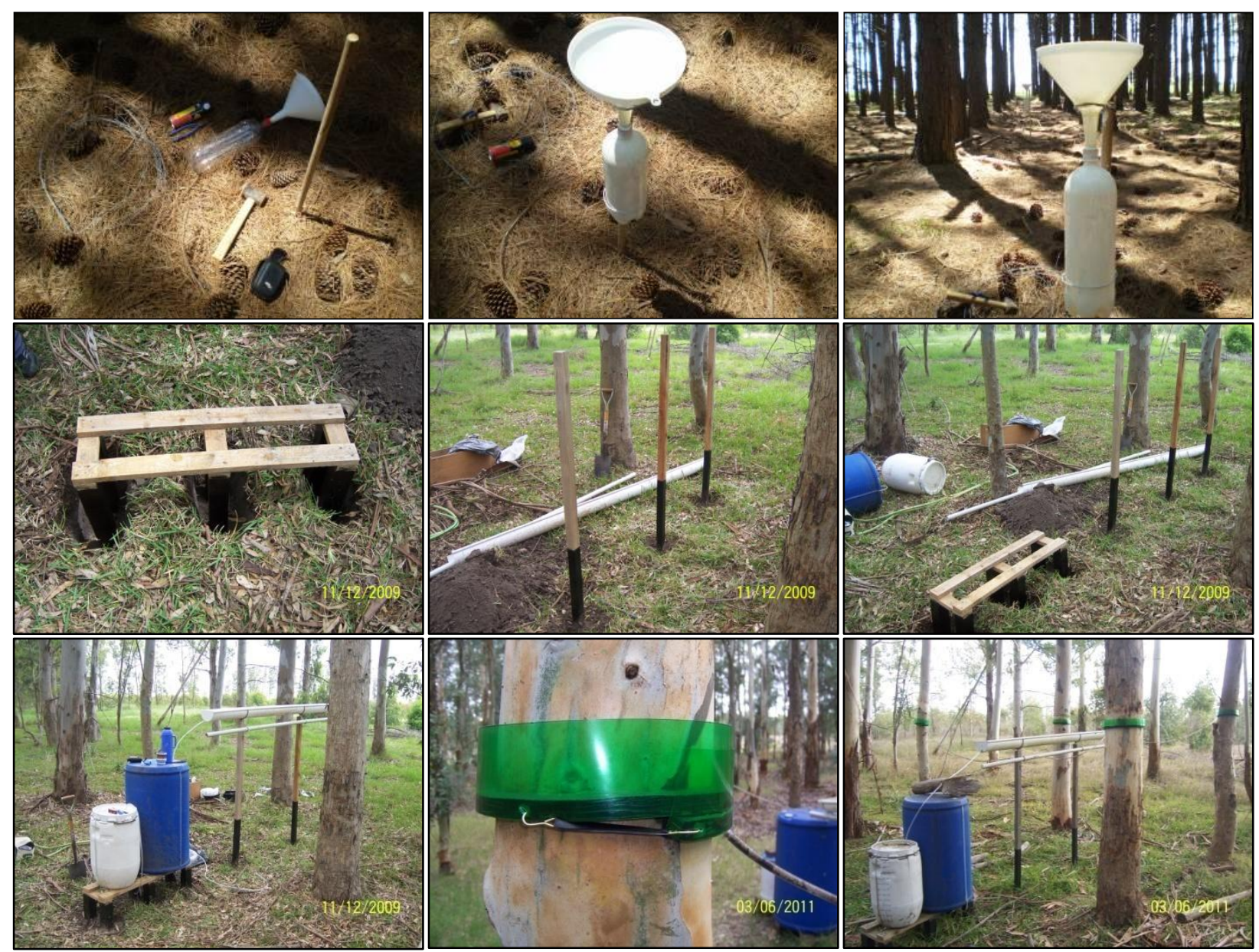

Figura II.14. Secuencia de imágenes mostrando el instrumental de fabricación y distintos pluviómetros instalados bajo la canopea forestal.

Las mediciones de escurrimiento fustal $\left(\mathrm{E}_{\mathrm{f}}\right)$ y trascolación $\left(\mathrm{T}_{\mathrm{r}}\right)$, en las parcelas de la EEC, se tomaron semanalmente a partir de julio del 2008, pero solo se lograron datos confiables, de ajuste y logística, a partir de enero del 2009 hasta diciembre del 2011. En el PFD, las mediciones comenzaron en septiembre de 2009 y el período de datos ajustados quedó comprendido entre abril del 2010 a septiembre de 2012.

El conjunto de componentes así obtenidos, permitió establecer relaciones entre variables por medio de análisis de regresión y la redistribución porcentual de la precipitación total en los diferentes componentes. 


\subsection{RESULTADOS}

\subsubsection{Precipitación}

En el gráfico II.1 se muestran los registros de lluvias anuales provenientes de la Estación Experimental Julio Hirschhorn (EEJH) y de la Estación Meteorológica Aeródromo Dolores (EMAD), junto con un par de rectas horizontales que indican los valores de precipitación media anual para cada estación. Estas series se exponen de forma pareada para los períodos 1918-2011 (EEJH) y 1959-2011 (EMAD), sin embargo, comparten 53 años y es sobre este período que se hace el análisis.

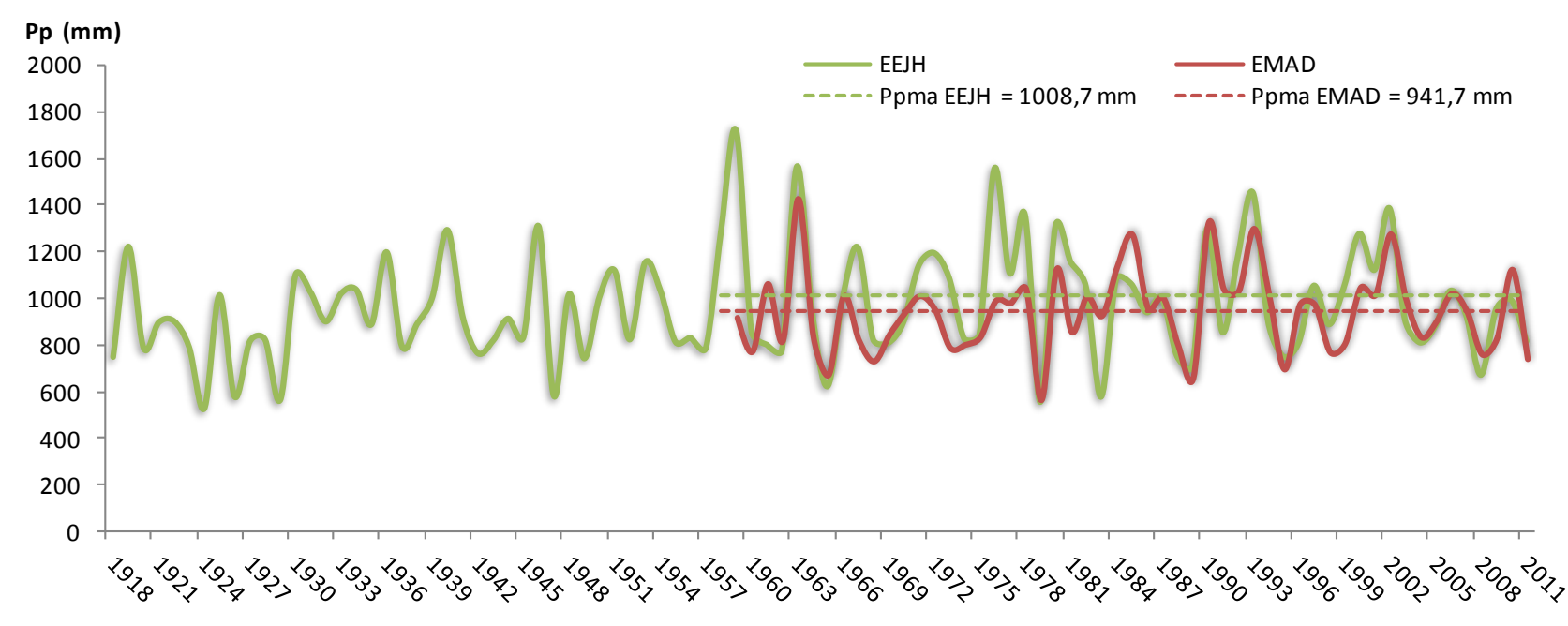

Gráfico II.1. Precipitaciones acumuladas anuales de la Experimental J. Hirschhorn (EEJH en verde) y del Aeródromo Dolores (EMAD en rojo) para las series 1918-2011 y 1959-2011 respectivamente. En líneas punteadas se muestra la precipitación media anual para el período 1959-2011, correspondiente a cada estación.

Del análisis gráfico II.1 resulta que los datos son consistentes y con una estrecha relación que se manifiesta con frecuencias de 3 a 4 años entre valores máximos. Esto se corrobora con el análisis de doble masa (Gráfico II.2), donde los valores acumulados anuales de ambas estaciones representan una recta sin quiebres considerables y con un ajuste muy elevado $\left(\mathrm{R}^{2}>0,99, C_{C}=0,61\right) \mathrm{y}$, por lo tanto, evidencia una buena homogeneidad de los datos pluviométricos. 


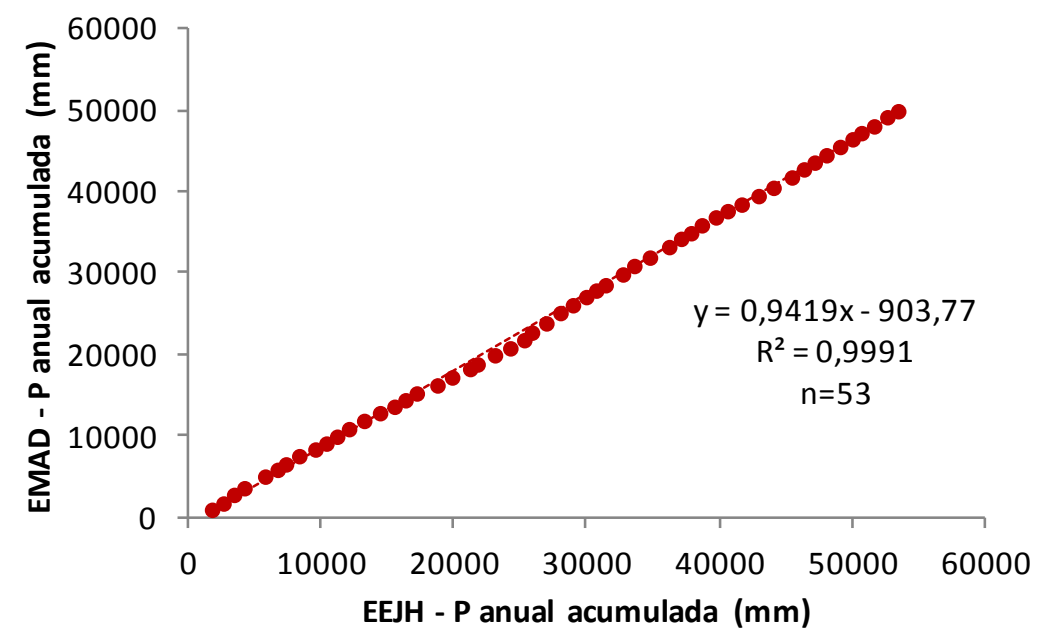

Gráfico II.2. Análisis de doble masa para una serie de 53 años (período 1959-2011), correspondiente a las estaciones EEJH y EMAD.

La relación detectada gráficamente entre variables, se corrobora con la obtención un valor alto en coeficiente de correlación de Pearson $(r=0,65)$ para un umbral de significación de $\alpha=0,05$. La prueba $U$ de Mann-Whitney, por otro lado, evidenció que los valores medios anuales no presentan diferencias significativas, expresados por una precipitación anual media en la EEJH $(1008,7 \mathrm{~mm} \pm 35,0 \mathrm{~mm})$ y la EMAD $(941,7 \mathrm{~mm} \pm 24,4 \mathrm{~mm})$, bajo un umbral de significación de $\alpha=0,05$.

El análisis de consistencia de datos a nivel mensual y diario, por medio de los gráficos de doble masa (Gráfico II.3 y II.4), muestra que los datos son también homogéneos. Sin embargo, al utilizar los coeficientes de consistencia/inconsistencia se observan valores de $C_{C}=0,63\left(C_{I}=0,37\right)$ a nivel mensual, en coincidencia con el anterior análisis, y una pequeña desviación o heterogeneidad entre los datos a nivel diaria $\left(C_{I}=0,67\right.$; $\left.C_{C}=0,33\right)$. 


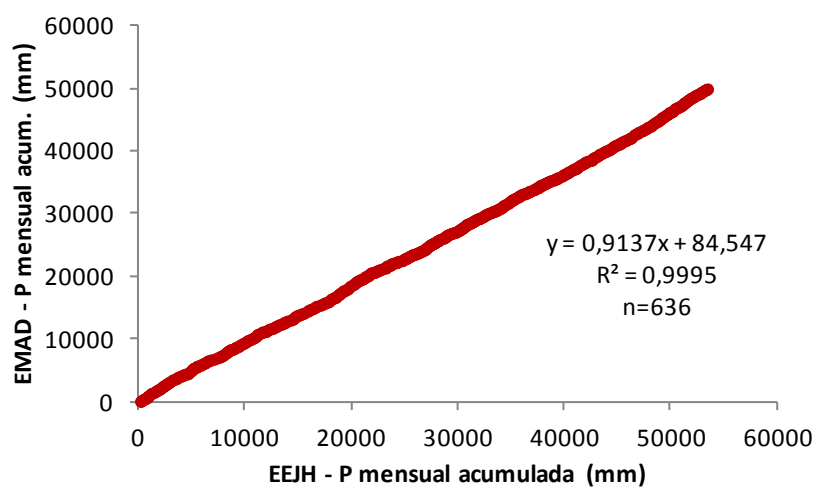

Gráfico II.3. Análisis de doble masa para las series de precipitaciones acumuladas mensuales de 53 años (1959-2011), correspondientes a la experimental Julio Hirschhorn (EEJH) y el Aeródromo Dolores (EMAD).

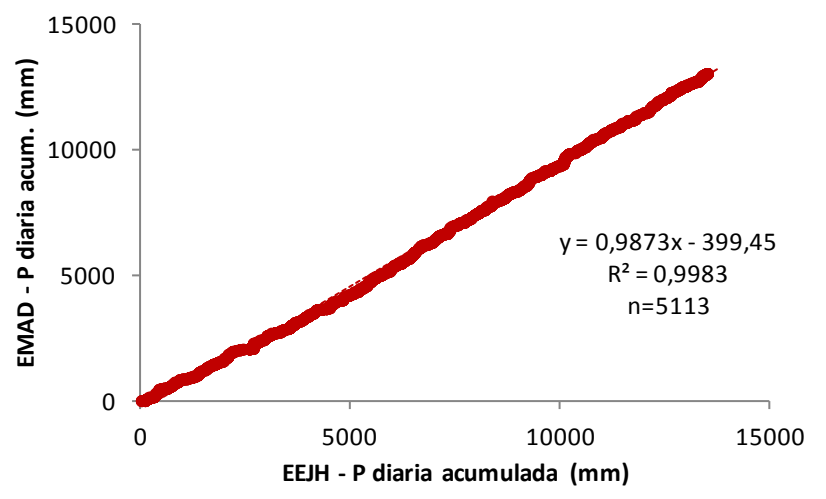

Gráfico II.4. Análisis de doble masa para una serie de precipitaciones diarias acumuladas de 14 años (1998-2011), correspondientes a EEJH y EMAD.

Por otro lado, la correlación entre las series mensuales es significativa $(r=0,64$; $\alpha=0,05)$ y $\sin$ diferencias entre medias (EEJH:84,1 mm $\pm 2,4 \mathrm{~mm}$; EMAD:78,5mm $\pm 2,2 \mathrm{~mm}$ ) para un nivel de significación de $\alpha=0,05$, mientras que los datos diarios arrojan bajos valores de coeficiente de correlación de Pearson $(0,33 ; \alpha=0,05)$ y su comparación por la prueba del $U$ de Mann-Whitney indica que la diferencia entre las muestras es significativa para un umbral de significancia de 0,05 (EEJH: 2,6mm $\pm 0,12 \mathrm{~mm}$; EMAD: 2,5mm $\pm 0,12 \mathrm{~mm}$ ).

A continuación, en los gráficos 11.5 y II.6, se comparan las precipitaciones mensuales de las estaciones EEJH y EMAD frente a la de los pluviómetros testigo de la EEC y PFD. Se indican, además, las tendencias polinómicas de las series para una mejor visualización. La finalidad de este contraste es establecer la representatividad que poseen las estaciones para los sitios de estudio y justificar, con cierto grado de certidumbre, el uso de los datos provenientes de las estaciones cuando sean requeridos para el análisis. Los períodos considerados son de tres años, entre enero de 2009 y diciembre de 2011 para el gráfico II.5 y entre septiembre de 2009 y agosto de 2012 para el gráfico II.6. 


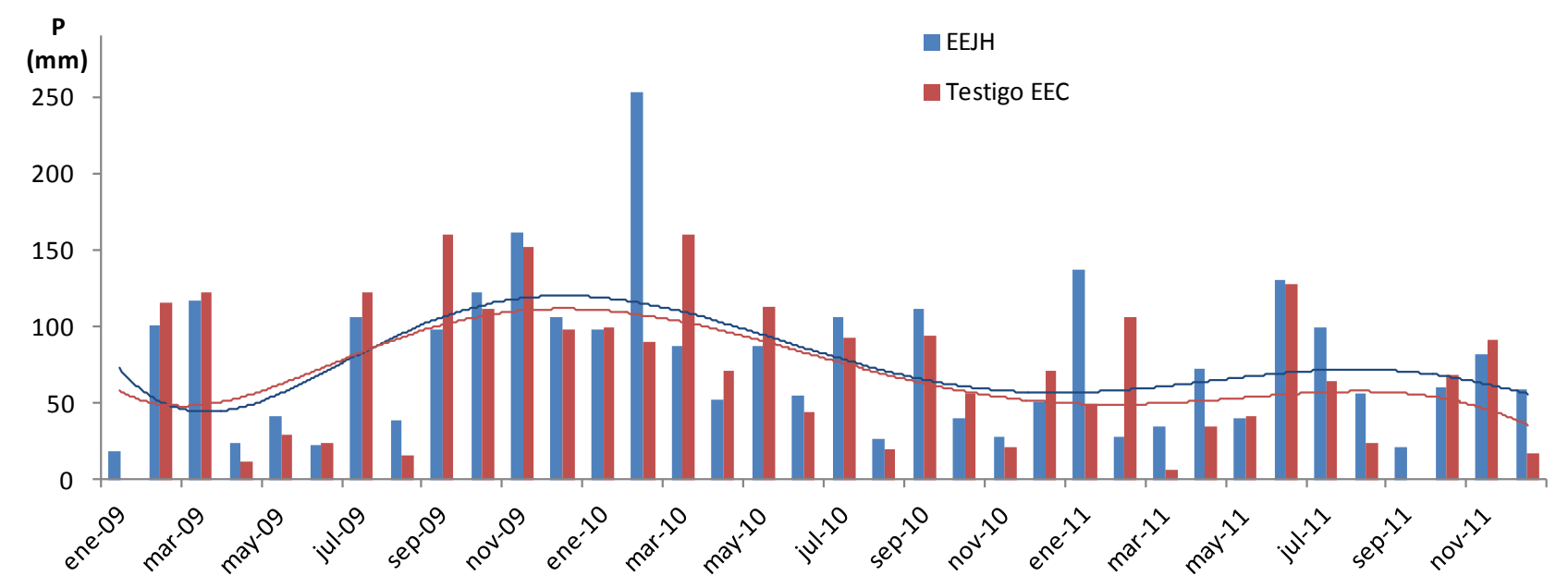

Gráfico II.5. Precipitaciones mensuales registradas en la EEJH (azul) y testigo EEC (rojo), para el período de tres años (36 meses).

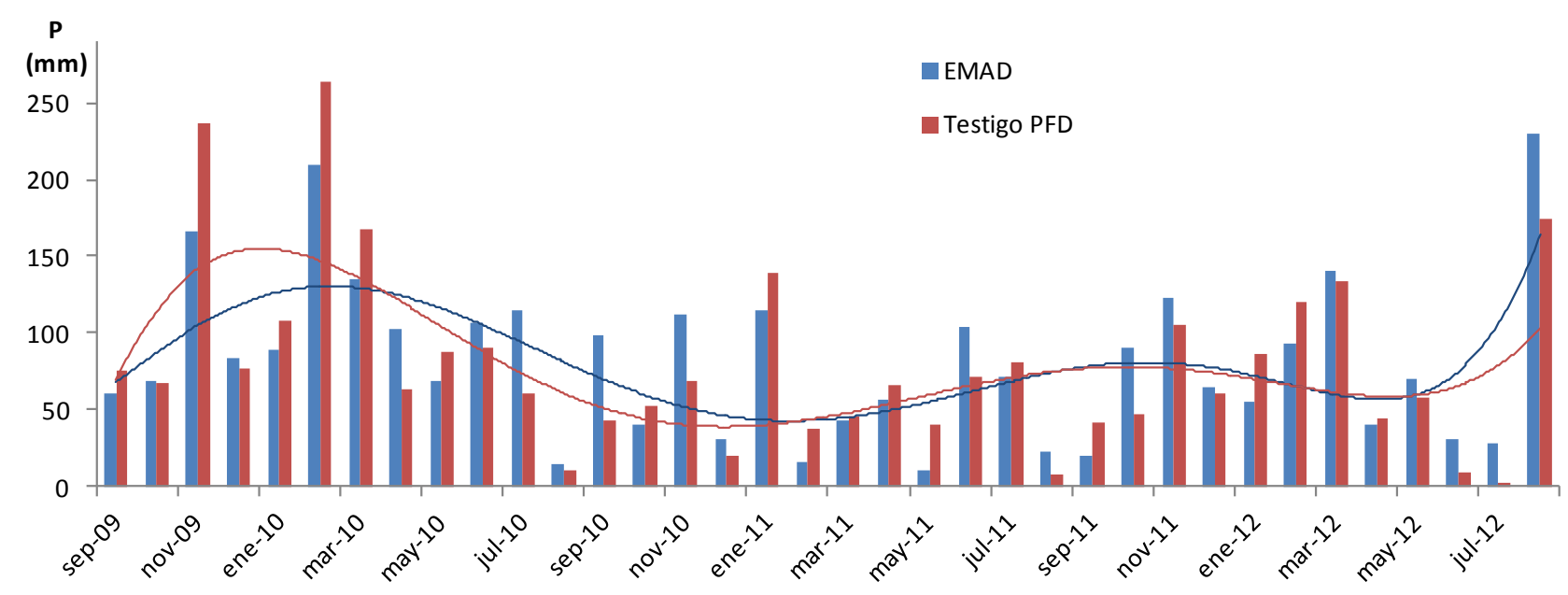

Gráfico II.6. Precipitaciones mensuales registradas en la EMAD (azul) y testigo PFD (rojo), para el período de tres años (36 meses).

Al analizar estos resultados de forma conjunta, es posible distinguir que las estaciones húmedas se desarrollan en los meses de noviembre a abril. Esto es más notable en los períodos nov09-abr10 y nov11-abr12. Resulta difícil, sin embargo, establecer una relación entre los pares comparados. La comparación de los pares de muestras por la prueba de Mann-Whitney, bajo un umbral de significancia de 0,05, indicó que no existen diferencias entre las lluvias de las estaciones meteorológicas frente a las registradas en los predios EEC y PFD por los pluviómetros testigos. 
En los gráficos II.7 y II.8 se muestran los análisis de doble masa efectuados. De ellos se puede interpretar que los datos se comportan de manera homogénea alrededor de la línea de tendencia, con valores de $\mathrm{R}^{2}$ muy elevados que indican que las precipitaciones mensuales tienden a variar de forma conjunta.

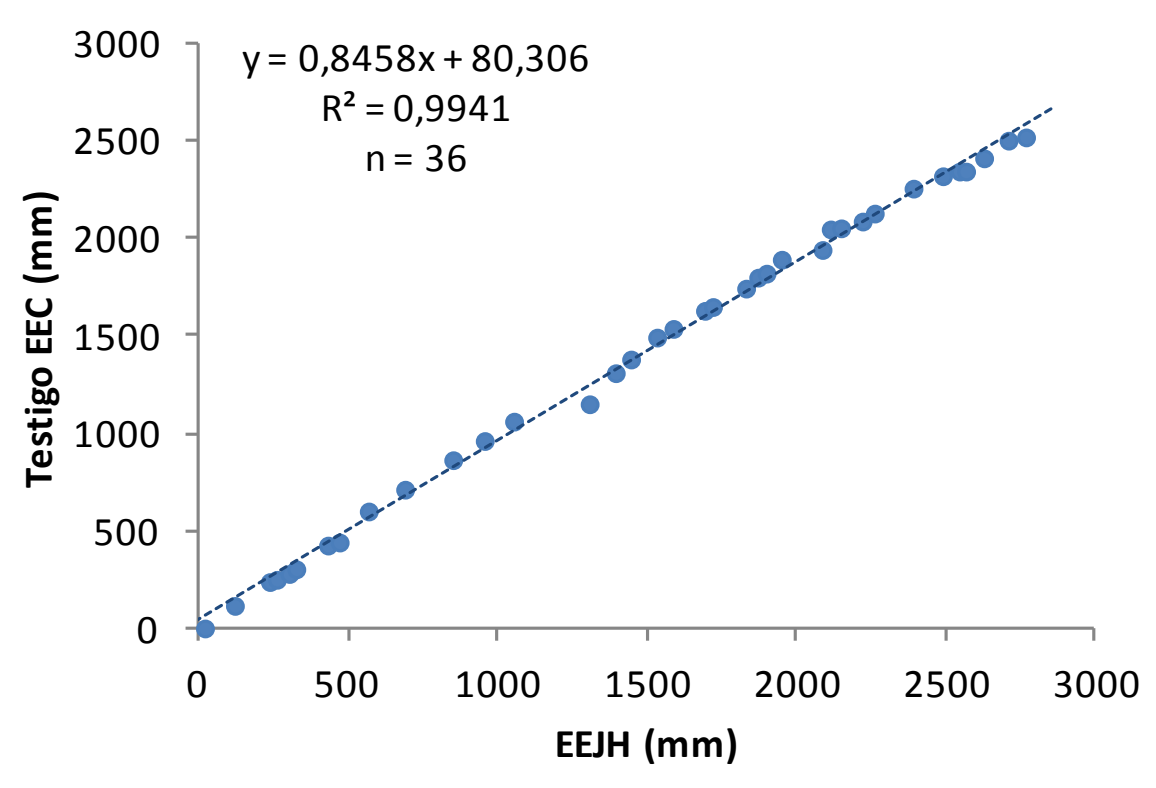

Gráfico II.7. Análisis de dobles masas acumuladas de las lluvias mensuales registradas en la EEJH y EEC, para el período de estudio de tres años (36 meses).

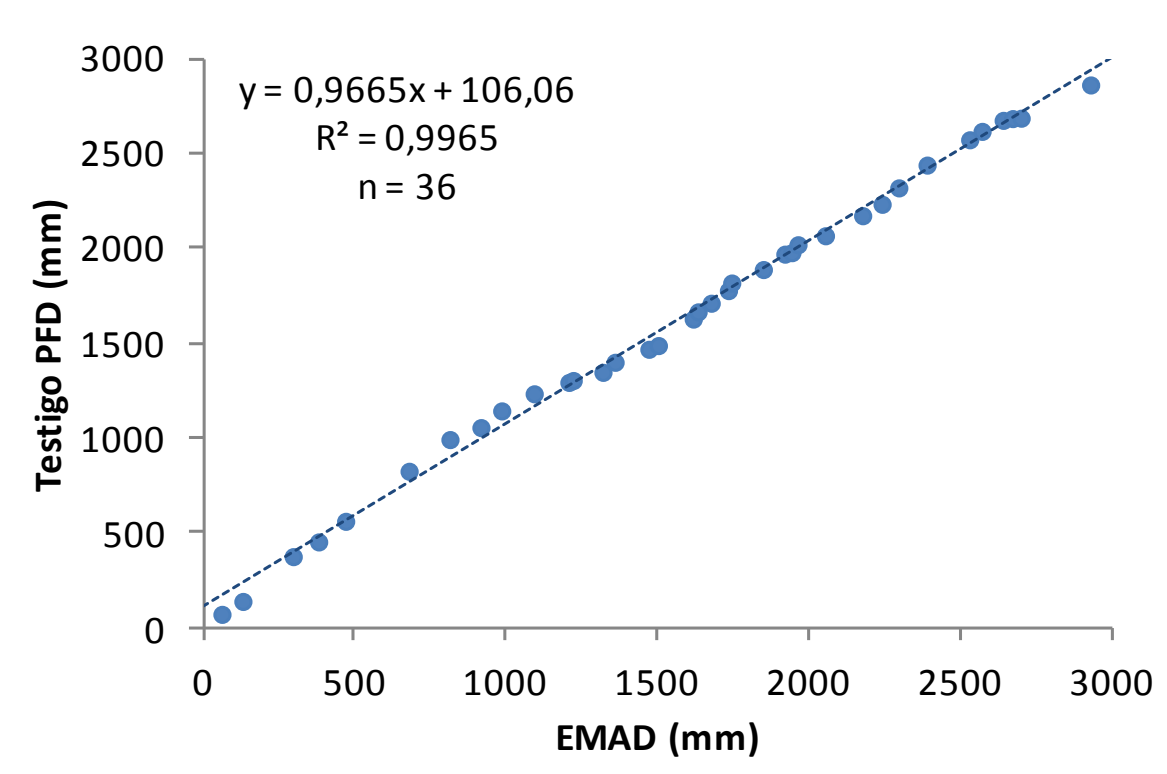

Gráfico II. 8. Análisis de dobles masas acumuladas de las lluvias mensuales registradas en la EMAD y PFD, para el período de estudio de tres años (36 meses). 
Finalmente se determinaron los valores de los coeficientes de consistenciainconsistencia de los pares analizados. De los mismos, se desprenden valores de $\mathrm{C}_{\mathrm{I}}=0,19$ y $C_{C}=0,81$ para el par "EEJH-Testigo EEC", y valores de $C_{I}=0,23$ y $C_{C}=0,73$ para el par “EMAD-Testigo PFD”.

Los registros de lluvia provenientes del pluviómetro de campo en la EEC y de la estación testigo en el PFD, fueron desechados por falta de datos e inconsistencias en los mismos, debido a fallas en el instrumental o negligencia de los operarios.

Para facilitar la interpretación de los datos obtenidos, en la tabla II.4 se muestran los valores de precipitación media anual junto con sus máximos y mínimos, para la Estancia El Centauro y Predio Forestal Dolores. Además, en la tabla II.5 se muestran los valores acumulados de P para los tres años de muestreo, junto con las precipitaciones mensuales medias, máximas y mínimas.

Tabla II.4. Precipitación anual media para la serie histórica (53 años) y serie de muestreos (3 años).

\begin{tabular}{|c|c|c|c|c|}
\hline \multirow{2}{*}{ Predio } & \multicolumn{3}{|c|}{$\mathrm{P}(\mathrm{mm})$ Serie histórica } & \multirow{2}{*}{$\begin{array}{c}\mathrm{P}(\mathrm{mm}) \text { Serie muestreos } \\
\text { Media }\end{array}$} \\
\hline & Media & Máx. & Mín. & \\
\hline EEC & 1008,7 & 1720,0 & 557,0 & 922,5 \\
\hline PFD & 941,7 & 1426,5 & 563,3 & 976,6 \\
\hline
\end{tabular}


Tabla II.5. Precipitaciones acumuladas mensuales y estacionales para la serie de muestreos (3 años), junto con el número de semanas con lluvia para el total de la serie de muestreos y los valores de precipitación mensual media, máxima y mínima.

\begin{tabular}{|c|c|c|c|c|c|c|c|c|c|c|}
\hline & \multicolumn{5}{|c|}{ EEC } & \multicolumn{5}{|c|}{ PFD } \\
\hline & \multirow{2}{*}{$\begin{array}{c}\mathbf{P} \\
\mathrm{mm}\end{array}$} & \multirow{2}{*}{$\begin{array}{c}\mathbf{N} \\
\text { semana }\end{array}$} & \multicolumn{3}{|c|}{$\mathbf{P}_{\text {mes }}(\mathrm{mm})$} & \multirow{2}{*}{$\begin{array}{c}P \\
\mathrm{~mm}\end{array}$} & \multirow{2}{*}{$\begin{array}{c}\mathbf{N} \\
\text { semana }\end{array}$} & \multicolumn{3}{|c|}{$\mathbf{P}_{\text {mes }}(\mathrm{mm})$} \\
\hline & & & Med. & Máx. & Mín. & & & Med. & Máx. & Mín. \\
\hline Dic. & 215,2 & 10 & 71,7 & 105,6 & 51,0 & 179,6 & 13 & 59,9 & 84,0 & 31,3 \\
\hline Ene. & 253,0 & 12 & 84,3 & 136,4 & 18,4 & 259,9 & 12 & 86,6 & 115,3 & 55,4 \\
\hline Feb. & 380,5 & 10 & 126,8 & 253,0 & 27,4 & 320,8 & 11 & 106,9 & 209,6 & 16,0 \\
\hline Verano & 848,7 & & & & & 760,3 & & & & \\
\hline Mar. & 239,8 & 14 & 79,9 & 117,2 & 35,2 & 316,9 & 10 & 105,6 & 138,7 & 43,2 \\
\hline Abr. & 147,0 & 11 & 49,0 & 71,8 & 23,8 & 200,2 & 10 & 66,7 & 102,3 & 40,9 \\
\hline May. & 169,2 & 11 & 56,4 & 87,2 & 40,4 & 149,3 & 9 & 49,8 & 69,9 & 10,8 \\
\hline Otoño & 556,0 & & & & & 666,3 & & & & \\
\hline Jun. & 207,4 & 12 & 69,1 & 129,8 & 23,0 & 242,8 & 11 & 80,9 & 107,3 & 31,0 \\
\hline Jul. & 310,5 & 10 & 103,5 & 106,2 & 98,7 & 219,0 & 8 & 73,0 & 114,7 & 33,3 \\
\hline Ago. & 121,8 & 11 & 40,6 & 56,0 & 26,8 & 262,1 & 8 & 87,4 & 224,6 & 14,2 \\
\hline Invierno & 639,7 & & & & & 723,8 & & & & \\
\hline Sep. & 229,8 & 9 & 76,6 & 111,0 & 21,4 & 178,5 & 10 & 59,5 & 98,2 & 20,0 \\
\hline Oct. & 222,6 & 9 & 74,2 & 121,8 & 40,4 & 199,9 & 11 & 66,6 & 90,7 & 40,0 \\
\hline Nov. & 270,8 & 13 & 90,3 & 161,0 & 28,0 & 400,8 & 13 & 133,6 & 166,2 & 111,7 \\
\hline Primavera & 723,2 & & & & & 779,2 & & & & \\
\hline Total & 2767,6 & 132 & & & & 2929,6 & 126 & & & \\
\hline
\end{tabular}

Se debe notar, sin embargo, que los tres años de muestreo en cada sitio de estudio, están desplazados unos 9 meses y comparten solo 28 meses de datos (Gráficos II.5 y II.6).

En ambos casos (EEJH y EMAD), fue necesario completar los datos faltantes de las series mediante métodos autoregresivos. Estos arreglos corresponden al 1,2\% de los datos de la serie EEJH y al 1,8\% de la EMAD. Algunos de estos arreglos, además, se realizaron sobre datos consecutivos, por lo que resulta incierto el efecto de los mismos en el análisis. 


\subsubsection{Intercepción}

Del total de datos medidos a lo largo de los tres años de muestreo, solo fueron considerados para el análisis aquellos que se presentaron completos $\left(\mathrm{P}, \mathrm{T}_{\mathrm{r}}\right.$ y $\left.\mathrm{E}_{\mathrm{f}}\right)$. Con la base de datos así establecida, se continuó con la depuración al descartar los conjuntos [P, $\mathrm{T}_{\mathrm{r}}$ y $\mathrm{E}_{\mathrm{f}}$ ] con $\mathrm{P}=0$ y aquellos en el que alguno de sus componentes resultara evidentemente dudoso por mal funcionamiento del instrumental, negligencia o vandalismo. Finalmente, de un total de 98 semanas de medidas completas en PFD y 102 en EEC, se utilizaron para el análisis un total de 254 conjuntos en el PFD y de 290 en EEC. Los datos descartados por ausencia de precipitaciones ( $\mathrm{P}=0$ ) conforman el $25,6 \%$ en PFD y el $8,8 \%$ en EEC, respecto al total de datos completos (490 en PFD y 408 en EEC), lo que equivale a 25 semanas sin lluvia en PFD y 9 semanas en EEC. El resto de los datos descartados responden a mediciones faltantes o anómalas por fallas del instrumental, vandalismo $\mathrm{y} / \mathrm{o}$ negligencia $(22,6 \%=111$ datos en PFD y $20,1 \%=82$ datos en EEC $)$.

En los gráficos II.9 al II.15 se muestran los análisis de regresión efectuados con los componentes $\mathrm{P}_{\mathrm{n}}, \mathrm{T}_{\mathrm{r}}$ y $\mathrm{E}_{\mathrm{f}}$, resultantes de la redistribución de las precipitaciones sobre las plantaciones de $P$. radiata y $E$. viminalis en EEC y de $E$. camaldulensis y $E$. viminalis en PFD.

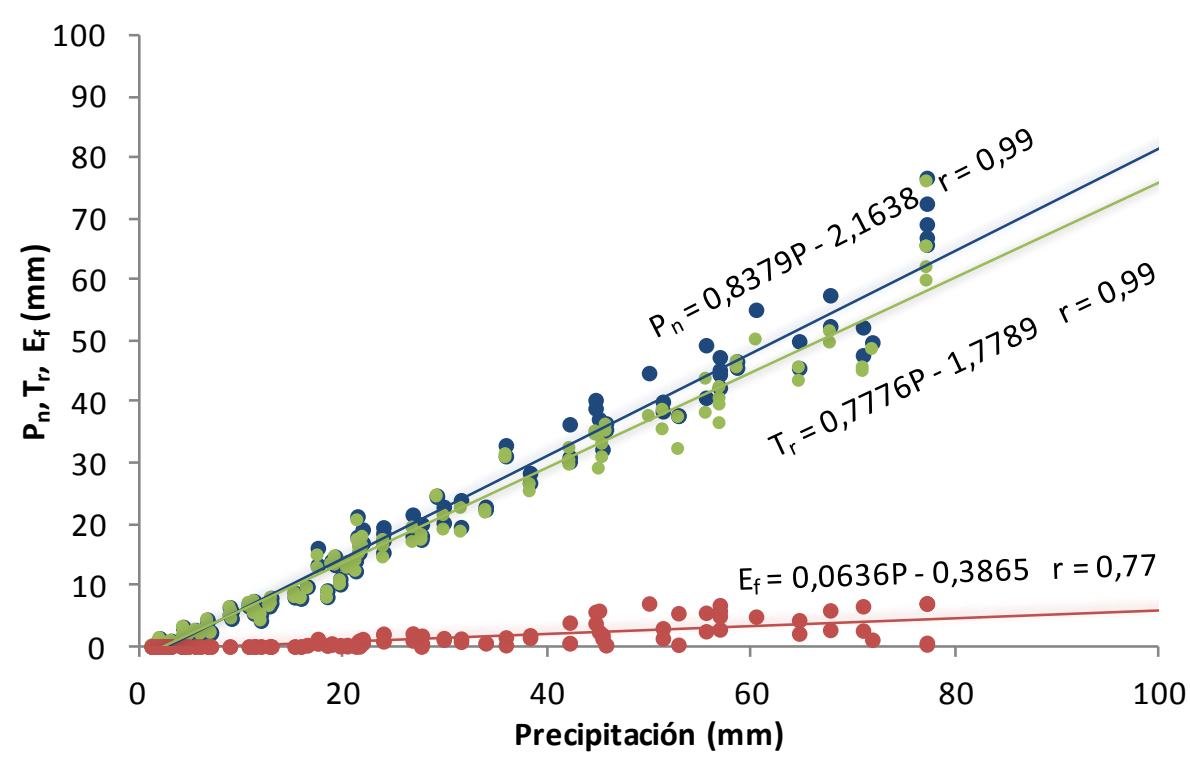

Gráfico II.9. Distribución de los componentes precipitación neta $\left(\mathrm{P}_{\mathrm{n}}\right)$, trascolación $\left(\mathrm{T}_{\mathrm{r}}\right)$ y escurrimiento fustal $\left(\mathrm{E}_{\mathrm{f}}\right)$ en relación de la precipitación que incide sobre una plantación de $P$. radiata en la EEC. Regresiones lineales junto a funciones y coeficientes de ajuste. Adaptado de Besteiro y Rodríguez (2012). 


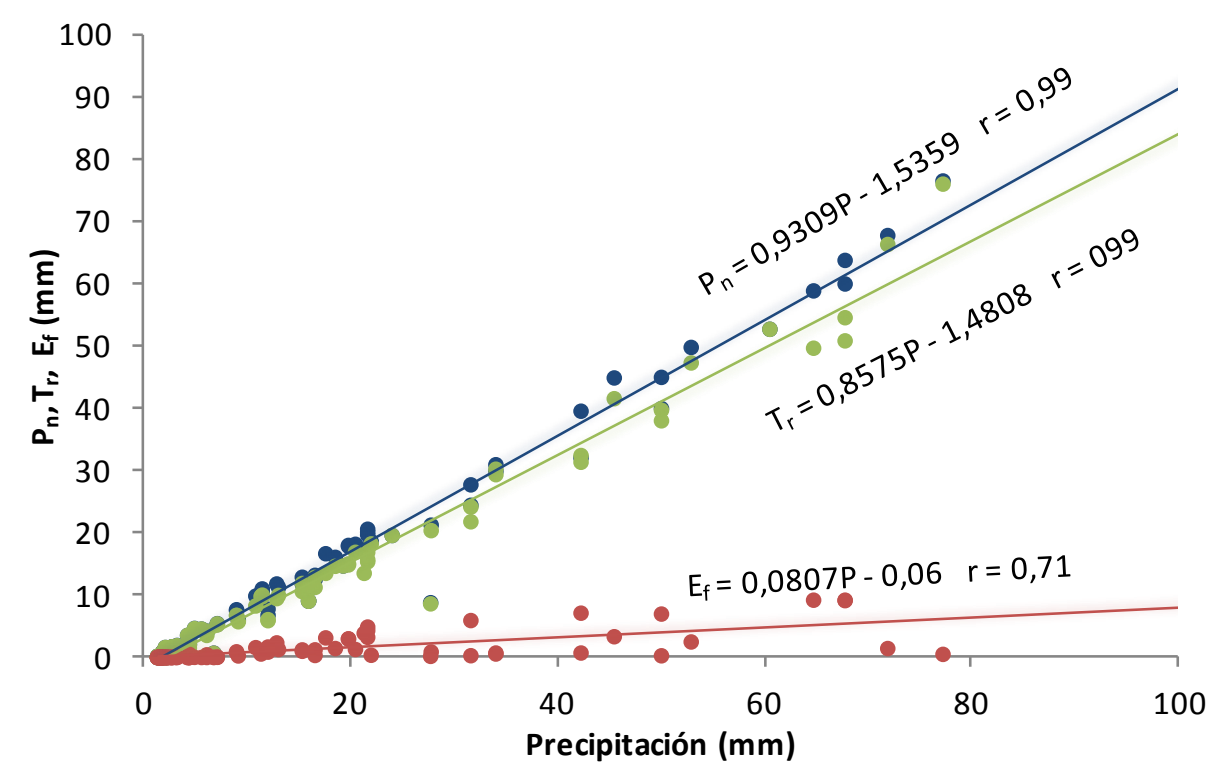

Gráfico II.10. Distribución de los componentes precipitación neta $\left(\mathrm{P}_{\mathrm{n}}\right)$, trascolación $\left(\mathrm{T}_{\mathrm{r}}\right)$ y escurrimiento fustal $\left(\mathrm{E}_{\mathrm{f}}\right)$ en relación de la precipitación que incide sobre una plantación de $E$. viminalis en la EEC. Regresiones lineales junto a funciones y coeficientes de ajuste. Adaptado de Besteiro y Rodríguez (2012).

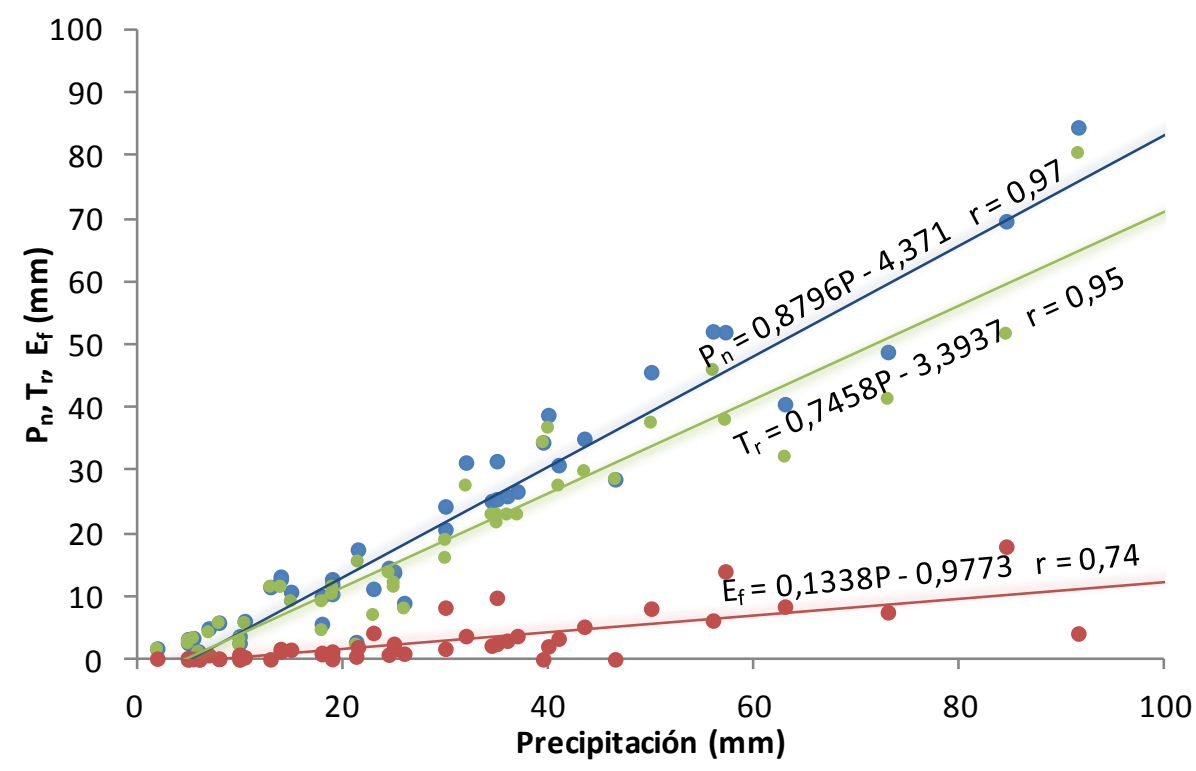

Gráfico II.11. Distribución de los componentes precipitación neta $\left(\mathrm{P}_{\mathrm{n}}\right)$, trascolación $\left(\mathrm{T}_{\mathrm{r}}\right)$ y escurrimiento fustal $\left(\mathrm{E}_{\mathrm{f}}\right)$ en relación de la precipitación que incide sobre una plantación de $E$. viminalis en el PFD (Parcela 1). Regresiones lineales junto a funciones y coeficientes de ajuste. 


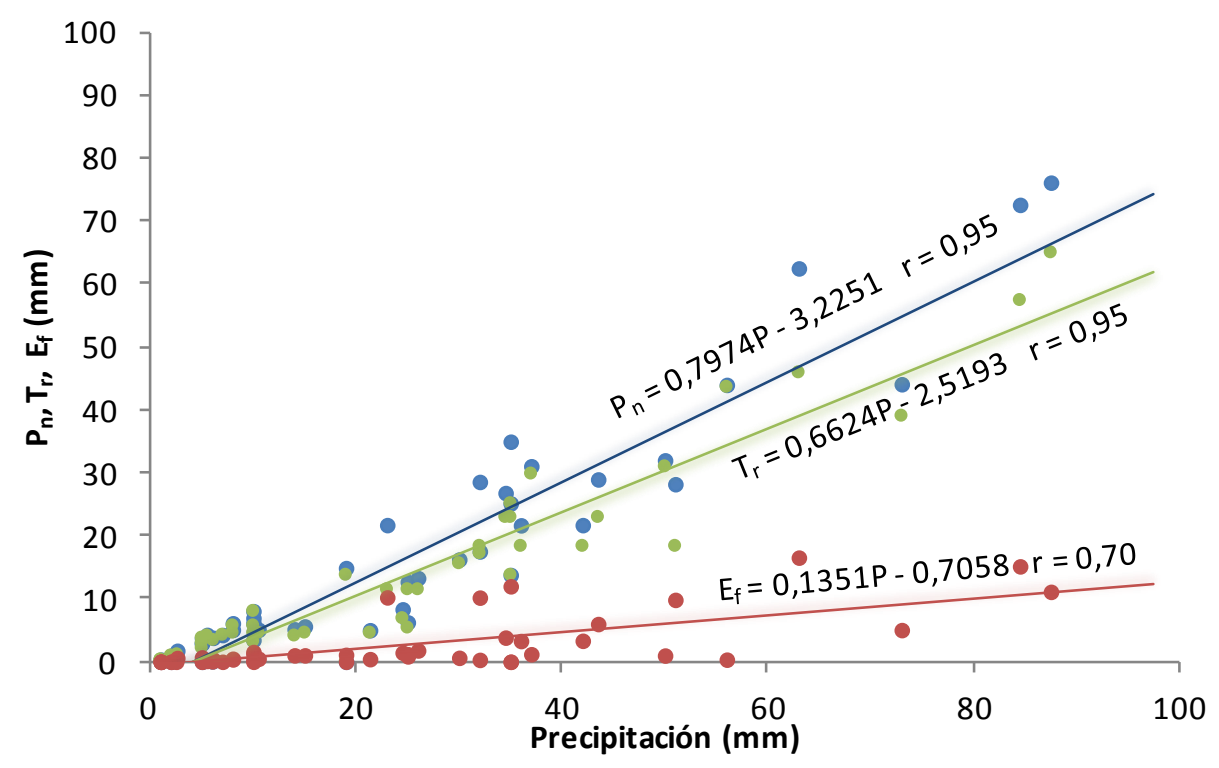

Gráfico II.12. Distribución de los componentes precipitación neta $\left(\mathrm{P}_{\mathrm{n}}\right)$, trascolación $\left(\mathrm{T}_{\mathrm{r}}\right)$ y escurrimiento fustal $\left(E_{\mathrm{f}}\right)$ en relación de la precipitación que incide sobre una plantación de $E$. camaldulensis en el PFD (Parcela 2). Regresiones lineales junto a funciones y coeficientes de ajuste.

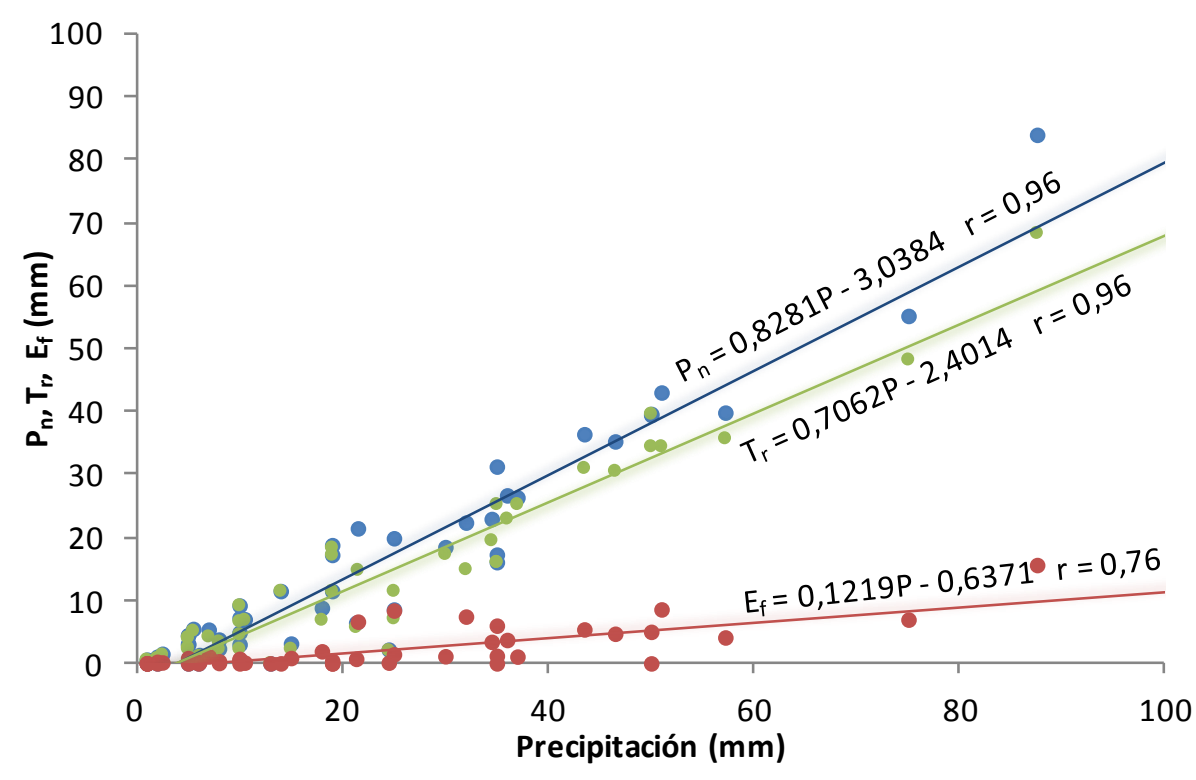

Gráfico II.13. Distribución de los componentes precipitación neta $\left(\mathrm{P}_{\mathrm{n}}\right)$, trascolación $\left(\mathrm{T}_{\mathrm{r}}\right)$ y escurrimiento fustal $\left(\mathrm{E}_{\mathrm{f}}\right)$ en relación de la precipitación que incide sobre una plantación de $E$. camaldulensis en el PFD (Parcela 3). Regresiones lineales junto a funciones y coeficientes de ajuste. 


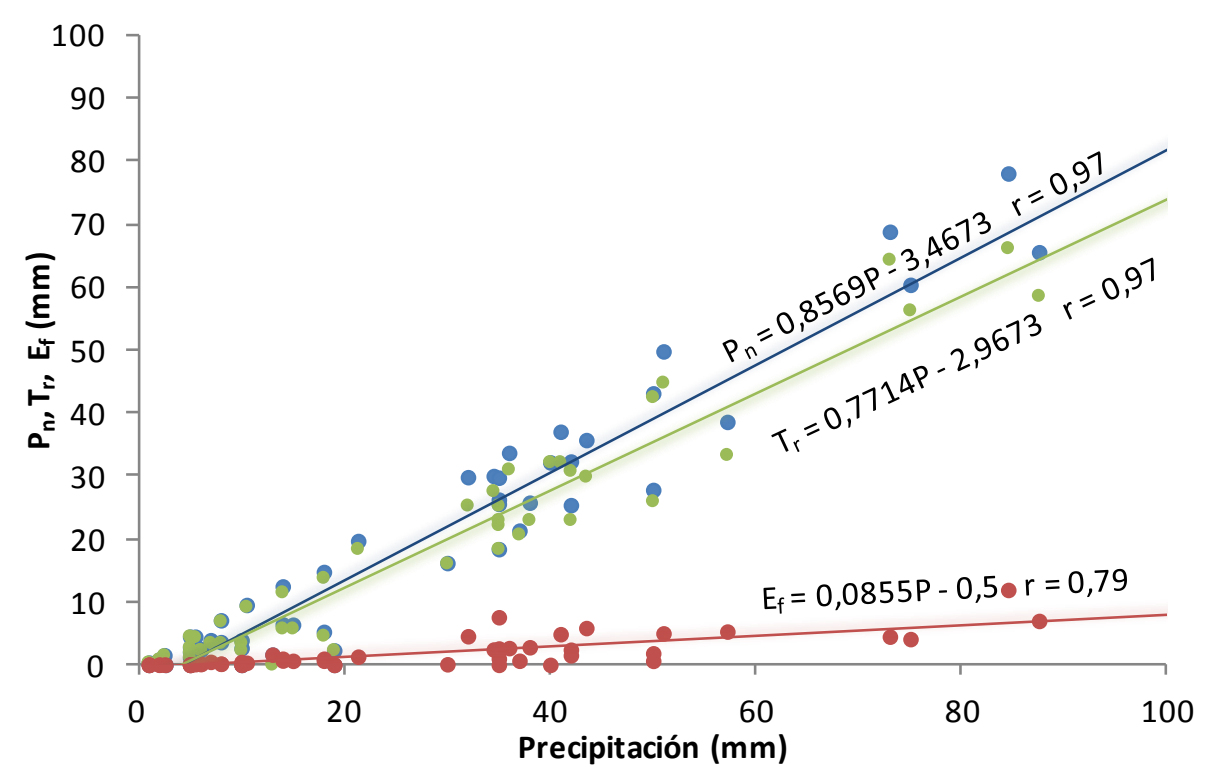

Gráfico II.14. Distribución de los componentes precipitación neta $\left(\mathrm{P}_{n}\right)$, trascolación $\left(\mathrm{T}_{\mathrm{r}}\right)$ y escurrimiento fustal $\left(\mathrm{E}_{\mathrm{f}}\right)$ en relación de la precipitación que incide sobre una plantación de $E$. camaldulensis en el PFD (Parcela 4). Regresiones lineales junto a funciones y coeficientes de ajuste.

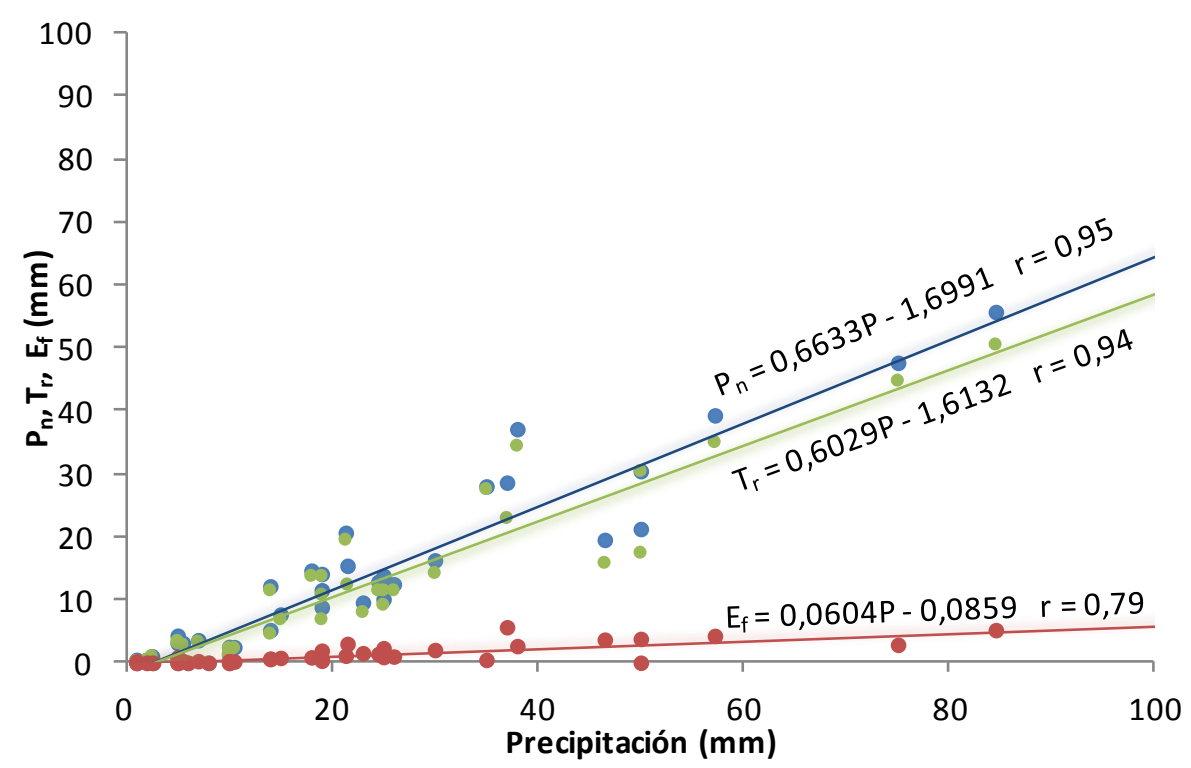

Gráfico II.15. Distribución de los componentes precipitación neta $\left(\mathrm{P}_{\mathrm{n}}\right)$, trascolación $\left(\mathrm{T}_{\mathrm{r}}\right)$ y escurrimiento fustal $\left(\mathrm{E}_{\mathrm{f}}\right)$ en relación de la precipitación que incide sobre una plantación de $E$. camaldulensis en el PFD (Parcela 5). Regresiones lineales junto a funciones y coeficientes de ajuste. 
Los datos analizados manifiestan altos grados de ajuste lineal $(r>0,7)$ que se traducen en una elevada correlación entre los componentes de trascolación $\left(\mathrm{T}_{\mathrm{r}}\right)$, escurrimiento fustal $\left(E_{\mathrm{f}}\right)$ y precipitación neta $\left(\mathrm{P}_{\mathrm{n}}\right)$.

Las ecuaciones resultantes de estos ajustes de regresión lineal, fueron aplicadas a las precipitaciones provenientes de la Estación Experimental Julio Hirschhorn (EEJH) y a la Estación Meteorológica Aeródromo Dolores (EMAD) a fin de disponer de un análisis completo de la redistribución de los componentes de las precipitaciones consideradas en el balance (apartado 5.2.3). En las tablas II.6 a II.12 se muestra el análisis temporal de los componentes de la redistribución de las lluvias sobre plantaciones forestales de pino y eucalipto en EEC y de eucalipto en PFD, respectivamente.

Tabla II.6. Redistribución de las precipitaciones mensuales y estacionales sobre una forestación de $P$. radiata de la pampa ondulada para el período: ene.2009-dic.2011. Adaptado de Besteiro y Rodríguez (2012).

\begin{tabular}{|c|c|c|c|c|c|c|c|}
\hline & \multirow{2}{*}{$\frac{\mathrm{P}}{\mathrm{mm}}$} & \multicolumn{2}{|c|}{$\mathrm{T}_{\mathrm{r}}$} & \multicolumn{2}{|c|}{$E_{f}$} & \multicolumn{2}{|c|}{ I } \\
\hline & & $\mathrm{mm}$ & $\%$ & $\mathrm{~mm}$ & $\%$ & $\mathrm{~mm}$ & $\%$ \\
\hline Dic. & 215,2 & 162,0 & 75,3 & 9,1 & 4,2 & 44,1 & 20,5 \\
\hline Ene. & 253,0 & 191,4 & 75,7 & 11,0 & 4,4 & 50,6 & 20,0 \\
\hline Feb. & 380,5 & 290,5 & 76,4 & 17,3 & 4,6 & 72,6 & 19,1 \\
\hline Verano & 848,7 & 643,9 & 75,9 & 37,5 & 4,4 & 167,3 & 19,7 \\
\hline Mar. & 239,8 & 181,1 & 75,5 & 10,4 & 4,3 & 48,3 & 20,1 \\
\hline Abr. & 147,0 & 109,0 & 74,1 & 5,8 & 3,9 & 32,3 & 21,9 \\
\hline May. & 169,2 & 126,2 & 74,6 & 6,9 & 4,1 & 36,1 & 21,3 \\
\hline Otoño & 556,0 & 416,3 & 74,9 & 23,0 & 4,1 & 116,7 & 21,0 \\
\hline Jun. & 207,4 & 155,9 & 75,2 & 8,8 & 4,2 & 42,7 & 20,6 \\
\hline Jul. & 310,5 & 236,1 & 76,0 & 13,9 & 4,5 & 60,5 & 19,5 \\
\hline Ago. & 121,8 & 89,4 & 73,4 & 4,5 & 3,7 & 27,9 & 22,9 \\
\hline Invierno & 639,7 & 481,4 & 75,3 & 27,1 & 4,2 & 131,1 & 20,5 \\
\hline Sep. & 229,8 & 173,4 & 75,4 & 9,9 & 4,3 & 46,6 & 20,3 \\
\hline Oct. & 222,6 & 167,8 & 75,4 & 9,5 & 4,3 & 45,3 & 20,4 \\
\hline Nov. & 270,8 & 205,2 & 75,8 & 11,9 & 4,4 & 53,7 & 19,8 \\
\hline Primavera & 723,2 & 546,4 & 75,5 & 31,3 & 4,3 & 145,6 & 20,1 \\
\hline Total & 2767,6 & 2088,0 & 75,4 & 118,9 & 4,3 & 560,7 & 20,3 \\
\hline
\end{tabular}

Donde: $\mathrm{P}=$ precipitación acumulada para los tres años considerados; $\mathrm{T}_{\mathrm{r}}=$ trascolación; $\mathrm{E}_{\mathrm{f}}=$ escurrimiento fustal, e I=intercepción. Los valores porcentuales son función de P. 
Tabla II.7. Redistribución de las precipitaciones mensuales y estacionales sobre una forestación de E. viminalis de la pampa ondulada para el período: ene.2009-dic.2011. Adaptado de Besteiro y Rodríguez (2012).

\begin{tabular}{|c|c|c|c|c|c|c|c|}
\hline & \multirow{2}{*}{$\begin{array}{c}\mathrm{P} \\
\mathrm{mm}\end{array}$} & \multicolumn{2}{|c|}{$\mathrm{T}_{\mathrm{r}}$} & \multicolumn{2}{|c|}{$E_{f}$} & \multicolumn{2}{|c|}{ I } \\
\hline & & $\mathrm{mm}$ & $\%$ & $\mathrm{~mm}$ & $\%$ & $\mathrm{~mm}$ & $\%$ \\
\hline Dic. & 215,2 & 180,1 & 83,7 & 14,4 & 6,7 & 20,8 & 9,6 \\
\hline Ene. & 253,0 & 212,5 & 84,0 & 17,0 & 6,7 & 23,5 & 9,3 \\
\hline Feb. & 380,5 & 321,8 & 84,6 & 25,8 & 6,8 & 32,9 & 8,6 \\
\hline Verano & 848,7 & 714,4 & 84,2 & 57,1 & 6,7 & 77,2 & 9,1 \\
\hline Mar. & 239,8 & 201,2 & 83,9 & 16,1 & 6,7 & 22,6 & 9,4 \\
\hline Abr. & 147,0 & 121,6 & 82,7 & 9,6 & 6,6 & 15,8 & 10,7 \\
\hline May. & 169,2 & 140,6 & 83,1 & 11,2 & 6,6 & 17,4 & 10,3 \\
\hline Otoño & 556,0 & 463,4 & 83,4 & 36,9 & 6,6 & 55,7 & 10,0 \\
\hline Jun. & 207,4 & 173,4 & 83,6 & 13,8 & 6,7 & 20,2 & 9,7 \\
\hline Jul. & 310,5 & 261,8 & 84,3 & 20,9 & 6,7 & 27,7 & 8,9 \\
\hline Ago. & 121,8 & 100,0 & 82,1 & 7,9 & 6,5 & 13,9 & 11,4 \\
\hline Invierno & 639,7 & 535,2 & 83,7 & 42,7 & 6,7 & 61,8 & 9,7 \\
\hline Sep. & 229,8 & 192,6 & 83,8 & 15,4 & 6,7 & 21,8 & 9,5 \\
\hline Oct. & 222,6 & 186,4 & 83,8 & 14,9 & 6,7 & 21,3 & 9,6 \\
\hline Nov. & 270,8 & 227,8 & 84,1 & 18,2 & 6,7 & 24,8 & 9,2 \\
\hline Primavera & 723,2 & 606,8 & 83,9 & 48,4 & 6,7 & 68,0 & 9,4 \\
\hline Total & 2767,6 & 2319,9 & 83,8 & 185,1 & 6,7 & 262,6 & 9,5 \\
\hline
\end{tabular}

Donde: $\mathrm{P}=$ precipitación acumulada para los tres años considerados; $\mathrm{T}_{\mathrm{r}}=$ trascolación; $\mathrm{E}_{\mathrm{f}}=$ escurrimiento fustal, e I=intercepción. Los valores porcentuales son función de $\mathrm{P}$.

Tabla II.8. Redistribución de las precipitaciones mensuales y estacionales sobre una forestación de E. viminalis de la pampa deprimida para el período: sep.2009-ago.2012.

\begin{tabular}{|c|c|c|c|c|c|c|c|}
\hline \multirow{2}{*}{ [Parcela 1] } & \multirow{2}{*}{$\begin{array}{c}\mathrm{P} \\
\mathrm{mm}\end{array}$} & \multicolumn{2}{|c|}{$\mathrm{T}_{\mathrm{r}}$} & \multicolumn{2}{|c|}{$E_{f}$} & \multicolumn{2}{|c|}{ I } \\
\hline & & $\mathrm{mm}$ & $\%$ & $\mathrm{~mm}$ & $\%$ & $\mathrm{~mm}$ & $\%$ \\
\hline Dic. & 179,6 & 123,7 & 68,9 & 13,6 & 7,6 & 42,2 & 23,5 \\
\hline Ene. & 259,9 & 183,6 & 70,7 & 21,6 & 8,3 & 54,6 & 21,0 \\
\hline Feb. & 320,8 & 229,1 & 71,4 & 27,7 & 8,6 & 64,0 & 20,0 \\
\hline Verano & 760,3 & 536,5 & 70,6 & 63,0 & 8,3 & 160,8 & 21,2 \\
\hline Mar. & 316,9 & 226,2 & 71,4 & 27,3 & 8,6 & 63,4 & 20,0 \\
\hline Abr. & 200,2 & 139,1 & 69,5 & 15,7 & 7,8 & 45,4 & 22,7 \\
\hline May. & 149,3 & 101,1 & 67,8 & 10,6 & 7,1 & 37,5 & 25,1 \\
\hline Otoño & 666,3 & 466,4 & 70,0 & 53,6 & 8,0 & 146,3 & 22,0 \\
\hline Jun. & 242,8 & 170,9 & 70,4 & 19,9 & 8,2 & 52,0 & 21,4 \\
\hline Jul. & 219,0 & 153,1 & 69,9 & 17,6 & 8,0 & 48,3 & 22,1 \\
\hline Ago. & 262,1 & 185,3 & 70,7 & 21,9 & 8,3 & 54,9 & 21,0 \\
\hline Invierno & 723,8 & 509,3 & 70,4 & 59,3 & 8,2 & 155,2 & 21,4 \\
\hline Sep. & 178,5 & 122,9 & 68,9 & 13,5 & 7,6 & 42,0 & 23,6 \\
\hline Oct. & 199,9 & 138,9 & 69,5 & 15,7 & 7,8 & 45,3 & 22,7 \\
\hline Nov. & 400,8 & 288,8 & 72,0 & 35,7 & 8,9 & 76,4 & 19,1 \\
\hline Primavera & 779,2 & 550,6 & 70,7 & 64,9 & 8,3 & 163,7 & 21,0 \\
\hline Total & 2929,6 & 2062,7 & 70,4 & 240,8 & 8,2 & 626,1 & 21,4 \\
\hline
\end{tabular}

Donde: $\mathrm{P}=$ precipitación acumulada para los tres años considerados; $\mathrm{T}_{\mathrm{r}}=$ trascolación; $\mathrm{E}_{\mathrm{f}}=$ escurrimiento fustal, e I=intercepción. Los valores porcentuales son función de $\mathrm{P}$. 
Tabla II.9. Redistribución de las precipitaciones mensuales y estacionales sobre una forestación de E. camaldulensis de la pampa deprimida para el período: sep.09-ago.12.

\begin{tabular}{|c|c|c|c|c|c|c|c|}
\hline \multirow{2}{*}{ [Parcela 2] } & \multirow{2}{*}{$\begin{array}{c}\mathrm{P} \\
\mathbf{m m}\end{array}$} & \multicolumn{2}{|c|}{$\mathrm{T}_{\mathrm{r}}$} & \multicolumn{2}{|c|}{$E_{f}$} & \multicolumn{2}{|c|}{ I } \\
\hline & & $\mathrm{mm}$ & $\%$ & $\mathrm{~mm}$ & $\%$ & $\mathrm{~mm}$ & $\%$ \\
\hline Dic. & 179,6 & 111,4 & 62,0 & 12,9 & 7,20 & 55,2 & 30,8 \\
\hline Ene. & 259,9 & 164,6 & 63,3 & 20,1 & 7,74 & 75,2 & 28,9 \\
\hline Feb. & 320,8 & 205,0 & 63,9 & 25,6 & 7,97 & 90,3 & 28,1 \\
\hline Verano & 760,3 & 480,9 & 63,3 & 58,6 & 7,71 & 220,7 & 29,0 \\
\hline Mar. & 316,9 & 202,4 & 63,9 & 25,2 & 7,96 & 89,3 & 28,2 \\
\hline Abr. & 200,2 & 125,0 & 62,5 & 14,8 & 7,38 & 60,4 & 30,2 \\
\hline May. & 149,3 & 91,3 & 61,2 & 10,2 & 6,85 & 47,7 & 32,0 \\
\hline Otoño & 666,3 & 418,7 & 62,8 & 50,2 & 7,54 & 197,4 & 29,6 \\
\hline Jun. & 242,8 & 153,3 & 63,1 & 18,6 & 7,66 & 70,9 & 29,2 \\
\hline Jul. & 219,0 & 137,5 & 62,8 & 16,5 & 7,52 & 65,0 & 29,7 \\
\hline Ago. & 262,1 & 166,0 & 63,4 & 20,3 & 7,75 & 75,7 & 28,9 \\
\hline Invierno & 723,8 & 456,8 & 63,1 & 55,4 & 7,65 & 211,7 & 29,2 \\
\hline Sep. & 178,5 & 110,7 & 62,0 & 12,8 & 7,19 & 55,0 & 30,8 \\
\hline Oct. & 199,9 & 124,8 & 62,5 & 14,7 & 7,38 & 60,3 & 30,2 \\
\hline Nov. & 400,8 & 258,0 & 64,4 & 32,7 & 8,17 & 110,1 & 27,5 \\
\hline Primavera & 779,2 & 493,5 & 63,3 & 60,3 & 7,74 & 225,4 & 28,9 \\
\hline Total & 2929,6 & 1849,9 & 63,1 & 224,5 & 7,7 & 855,2 & 29,2 \\
\hline
\end{tabular}

Donde: P=precipitación acumulada para los tres años considerados; $\mathrm{T}_{\mathrm{r}}=$ trascolación; $\mathrm{E}_{\mathrm{f}}=$ escurrimiento fustal, e I=intercepción. Los valores porcentuales son función de P.

Tabla II.10. Redistribución de las precipitaciones mensuales y estacionales sobre una forestación de E. camaldulensis de la pampa deprimida para el período: sep.09-ago.12.

\begin{tabular}{|c|c|c|c|c|c|c|c|}
\hline \multirow{2}{*}{ [Parcela 3] } & \multirow{2}{*}{$\begin{array}{c}P \\
\mathrm{~mm}\end{array}$} & \multicolumn{2}{|c|}{$T_{r}$} & \multicolumn{2}{|c|}{$E_{f}$} & \multicolumn{2}{|c|}{1} \\
\hline & & $\mathrm{mm}$ & $\%$ & $\mathrm{~mm}$ & $\%$ & $\mathrm{~mm}$ & $\%$ \\
\hline Dic. & 179,6 & 119,6 & 66,6 & 12,7 & 7,1 & 47,3 & 26,3 \\
\hline Ene. & 259,9 & 176,3 & 67,8 & 19,6 & 7,5 & 64,0 & 24,6 \\
\hline Feb. & 320,8 & 219,4 & 68,4 & 24,8 & 7,7 & 76,6 & 23,9 \\
\hline Verano & 760,3 & 515,3 & 67,8 & 57,1 & 7,5 & 187,9 & 24,7 \\
\hline Mar. & 316,9 & 216,6 & 68,3 & 24,5 & 7,7 & 75,8 & 23,9 \\
\hline Abr. & 200,2 & 134,2 & 67,0 & 14,4 & 7,2 & 51,6 & 25,8 \\
\hline May. & 149,3 & 98,2 & 65,8 & 10,1 & 6,7 & 41,0 & 27,5 \\
\hline Otoño & 666,3 & 448,9 & 67,4 & 49,0 & 7,4 & 168,4 & 25,3 \\
\hline Jun. & 242,8 & 164,3 & 67,7 & 18,1 & 7,5 & 60,4 & 24,9 \\
\hline Jul. & 219,0 & 147,4 & 67,3 & 16,1 & 7,3 & 55,5 & 25,3 \\
\hline Ago. & 262,1 & 177,9 & 67,9 & 19,8 & 7,5 & 64,4 & 24,6 \\
\hline Invierno & 723,8 & 489,5 & 67,6 & 53,9 & 7,5 & 180,3 & 24,9 \\
\hline Sep. & 178,5 & 118,8 & 66,6 & 12,6 & 7,0 & 47,1 & 26,4 \\
\hline Oct. & 199,9 & 134,0 & 67,0 & 14,4 & 7,2 & 51,5 & 25,8 \\
\hline Nov. & 400,8 & 275,9 & 68,8 & 31,7 & 7,9 & 93,3 & 23,3 \\
\hline Primavera & 779,2 & 528,7 & 67,8 & 58,7 & 7,5 & 191,8 & 24,6 \\
\hline Total & 2929,6 & 1982,4 & 67,7 & 218,7 & 7,5 & 728,4 & 24,9 \\
\hline
\end{tabular}

Donde: $\mathrm{P}=$ precipitación acumulada para los tres años considerados; $\mathrm{T}_{\mathrm{r}}=$ trascolación; $\mathrm{E}_{\mathrm{f}}=$ escurrimiento fustal, e I=intercepción. Los valores porcentuales son función de P. 
Tabla II.11. Redistribución de las precipitaciones mensuales y estacionales sobre una forestación de E. camaldulensis de la pampa deprimida para el período: sep.09-ago.12.

\begin{tabular}{|c|c|c|c|c|c|c|c|}
\hline \multirow{2}{*}{ [Parcela 4] } & \multirow{2}{*}{$\begin{array}{c}P \\
\mathrm{~mm}\end{array}$} & \multicolumn{2}{|c|}{$T_{r}$} & \multicolumn{2}{|c|}{$E_{f}$} & \multicolumn{2}{|c|}{ I } \\
\hline & & $\mathrm{mm}$ & $\%$ & $\mathrm{~mm}$ & $\%$ & $\mathrm{~mm}$ & $\%$ \\
\hline Dic. & 179,6 & 129,6 & 72,2 & 9,6 & 5,3 & 40,4 & 22,5 \\
\hline Ene. & 259,9 & 191,6 & 73,7 & 14,9 & 5,7 & 53,4 & 20,6 \\
\hline Feb. & 320,8 & 238,6 & 74,4 & 18,9 & 5,9 & 63,3 & 19,7 \\
\hline Verano & 760,3 & 559,8 & 73,6 & 43,4 & 5,7 & 157,1 & 20,7 \\
\hline Mar. & 316,9 & 235,5 & 74,3 & 18,6 & 5,9 & 62,7 & 19,8 \\
\hline Abr. & 200,2 & 145,5 & 72,7 & 10,9 & 5,5 & 43,7 & 21,8 \\
\hline May. & 149,3 & 106,2 & 71,2 & 7,6 & 5,1 & 35,4 & 23,7 \\
\hline Otoño & 666,3 & 487,3 & 73,1 & 37,2 & 5,6 & 141,9 & 21,3 \\
\hline Jun. & 242,8 & 178,4 & 73,5 & 13,8 & 5,7 & 50,7 & 20,9 \\
\hline Jul. & 219,0 & 160,0 & 73,1 & 12,2 & 5,6 & 46,8 & 21,4 \\
\hline Ago. & 262,1 & 193,2 & 73,7 & 15,0 & 5,7 & 53,8 & 20,5 \\
\hline Invierno & 723,8 & 531,6 & 73,5 & 41,0 & 5,7 & 151,2 & 20,9 \\
\hline Sep. & 178,5 & 128,8 & 72,2 & 9,5 & 5,3 & 40,2 & 22,5 \\
\hline Oct. & 199,9 & 145,3 & 72,7 & 10,9 & 5,5 & 43,7 & 21,8 \\
\hline Nov. & 400,8 & 300,3 & 74,9 & 24,2 & 6,0 & 76,4 & 19,0 \\
\hline Primavera & 779,2 & 574,4 & 73,7 & 44,6 & 5,7 & 160,2 & 20,6 \\
\hline Total & 2929,6 & 2153,1 & 73,5 & 166,1 & 5,7 & 610,4 & 20,8 \\
\hline
\end{tabular}

Donde: P=precipitación acumulada para los tres años considerados; $\mathrm{T}_{\mathrm{r}}=$ trascolación; $\mathrm{E}_{\mathrm{f}}=$ escurrimiento fustal, e I=intercepción. Los valores porcentuales son función de P.

Tabla II.12. Redistribución de las precipitaciones mensuales y estacionales sobre una forestación de E. camaldulensis de la pampa deprimida para el período: sep.09-ago.12.

\begin{tabular}{|c|c|c|c|c|c|c|c|}
\hline \multirow{2}{*}{ [Parcela 5] } & \multirow{2}{*}{$\begin{array}{c}\mathrm{P} \\
\mathrm{mm}\end{array}$} & \multicolumn{2}{|c|}{$T_{r}$} & \multicolumn{2}{|c|}{$E_{f}$} & \multicolumn{2}{|c|}{1} \\
\hline & & $\mathrm{mm}$ & $\%$ & $\mathrm{~mm}$ & $\%$ & $\mathrm{~mm}$ & $\%$ \\
\hline Dic. & 179,6 & 103,4 & 57,6 & 6,0 & 3,3 & 70,2 & 39,1 \\
\hline Ene. & 259,9 & 151,8 & 58,4 & 8,9 & 3,4 & 99,1 & 38,1 \\
\hline Feb. & 320,8 & 188,6 & 58,8 & 11,1 & 3,5 & 121,1 & 37,7 \\
\hline Verano & 760,3 & 443,8 & 58,4 & 26,0 & 3,4 & 290,4 & 38,2 \\
\hline Mar. & 316,9 & 186,2 & 58,8 & 11,0 & 3,5 & 119,7 & 37,8 \\
\hline Abr. & 200,2 & 115,9 & 57,9 & 6,7 & 3,4 & 77,6 & 38,8 \\
\hline May. & 149,3 & 85,1 & 57,0 & 4,9 & 3,3 & 59,2 & 39,7 \\
\hline Otoño & 666,3 & 387,2 & 58,1 & 22,6 & 3,4 & 256,5 & 38,5 \\
\hline Jun. & 242,8 & 141,5 & 58,3 & 8,3 & 3,4 & 93,0 & 38,3 \\
\hline Jul. & 219,0 & 127,2 & 58,1 & 7,4 & 3,4 & 84,4 & 38,5 \\
\hline Ago. & 262,1 & 153,2 & 58,4 & 9,0 & 3,4 & 99,9 & 38,1 \\
\hline Invierno & 723,8 & 421,9 & 58,3 & 24,7 & 3,4 & 277,2 & 38,3 \\
\hline Sep. & 178,5 & 102,8 & 57,6 & 5,9 & 3,3 & 69,8 & 39,1 \\
\hline Oct. & 199,9 & 115,7 & 57,9 & 6,7 & 3,4 & 77,5 & 38,8 \\
\hline Nov. & 400,8 & 236,8 & 59,1 & 14,0 & 3,5 & 150,0 & 37,4 \\
\hline Primavera & 779,2 & 455,3 & 58,4 & 26,7 & 3,4 & 297,2 & 38,1 \\
\hline Total & 2929,6 & 1708,2 & 58,3 & 100,1 & 3,4 & 1121,3 & 38,3 \\
\hline
\end{tabular}

Donde: $\mathrm{P}=$ precipitación acumulada para los tres años considerados; $\mathrm{T}_{\mathrm{r}}=$ trascolación; $\mathrm{E}_{\mathrm{f}}=$ escurrimiento fustal, e I=intercepción. Los valores porcentuales son función de P. 
La precipitación neta o agua que alcanza el suelo bajo las forestaciones de ambos sitios, se encuentra constituida principalmente por la trascolación, cuyos montos mensuales varían en relación a la precipitación total mensual. El rango de variación de este componente es inferior al 3,0\% y $2,5 \%$ en las plantaciones de pino y eucalipto de EEC (Tabla II.6 y II.7) y no superan el 4,3\% en los rodales de eucalipto de PFD (Tablas II.8 a II.12). Además, es posible verificar que los porcentajes máximos y mínimos de $\mathrm{T}_{\mathrm{r}}$ hallados en EEC ocurren a fines de verano e invierno respectivamente, mientras que en PFD se ubican a fines de otoño y primavera. Es interesante notar, sin embargo, que la proporción de los componentes $\mathrm{T}_{\mathrm{r}}-\mathrm{E}_{\mathrm{f}}$-I se mantienen prácticamente invariables a nivel estacional $\mathrm{y}$ mensual en ambas áreas de estudio (Tablas II.6 a II.12). Esto permite marcar que, tanto a nivel anual como mensual, la intercepción observada en el lote de pinos en EEC duplica a la del lote eucaliptos (Tablas II.6 y II.7). Al mismo tiempo, en PFD, los valores de I en $E$. viminalis duplican a los encontrados en EEC para la misma especie (Tablas II.7 y II.8), y es posible distinguir un amplio rango de variación de I en los rodales de E. camaldulensis (de $20,8 \%$ a 38,3\%), que no parecerían estar directamente relacionados con la densidad de árboles por hectárea, el DAP, la altura o el porcentaje de cobertura de los mismos (Tablas II.9 a II.12).

Por otro lado, se observa que las plantaciones de E. viminalis de ambos sitios de estudio (EEC y PFD) comparten similares valores de $E_{f}$, superiores a los encontrados en el lote de pinos, mientras que los distintos rodales de E. camaldulensis manifiestan amplias variaciones respecto a este componente que guardan relación con la densidad de árboles por hectárea.

El comportamiento de los componentes $\mathrm{T}_{\mathrm{r}}-\mathrm{E}_{\mathrm{f}}-\mathrm{I}$, se visualiza claramente en gráficos de tipo acumulados (Gráficos II.16 a II.22), donde son necesarios 1,6mm y 2,6mm de lluvia para saturar la capacidad de retención de agua en las copas de eucalipto y pino ensayados en EEC, y 5,0mm; 3,6mm; 3,7mm; 4,0 mm y 2,6mm para saturar las copas en cada una de las parcelas de PFD (parcela 1, 2, 3, 4 y 5, respectivamente). Por encima de estas cantidades, toda lluvia pasa a formar parte de la precipitación neta y a estar disponible para ser absorbida por la forestación o recargar el acuífero inmediato. 


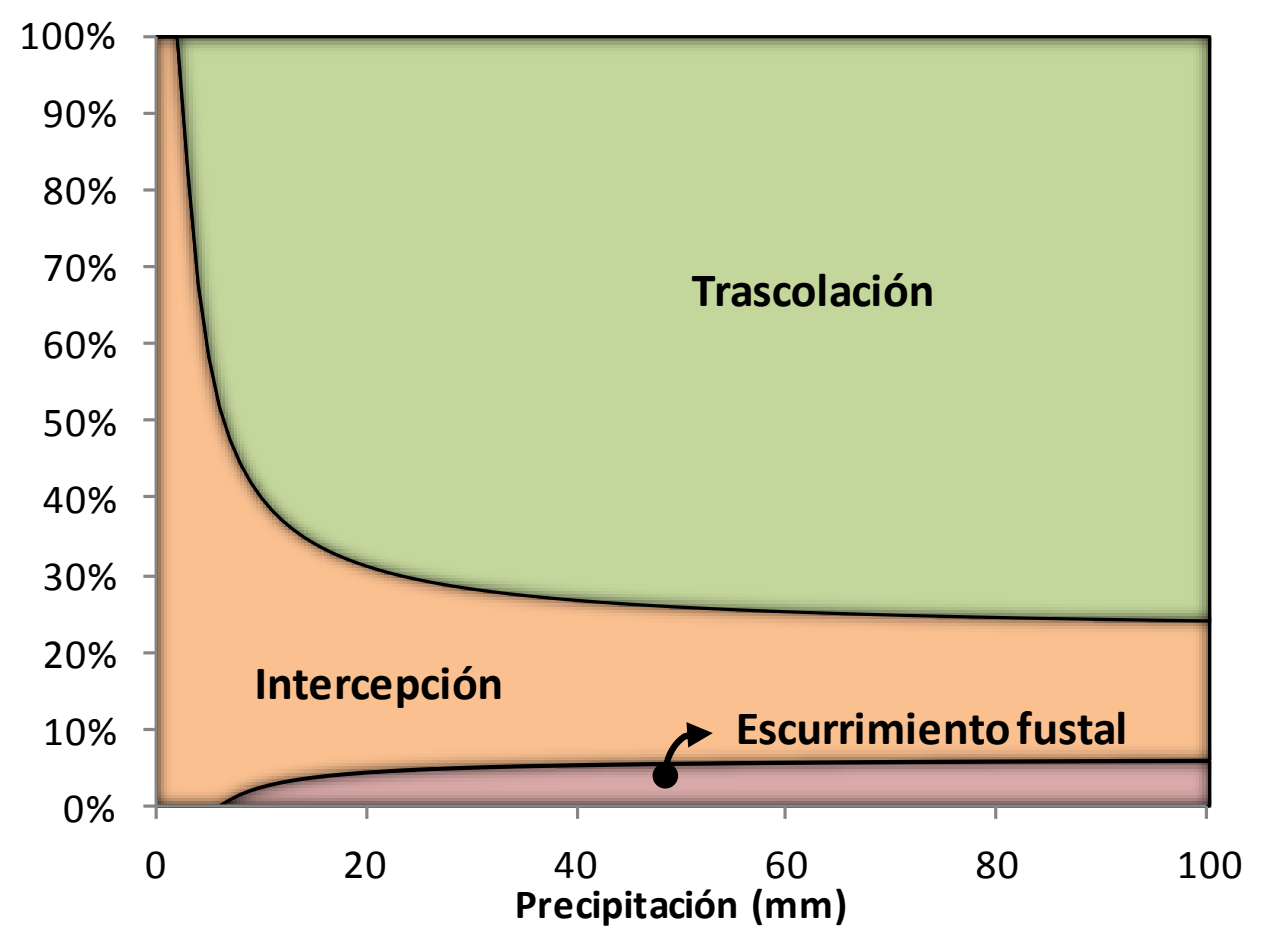

Gráfico II.16. Redistribución porcentual de las distintas láminas de lluvia acumulada que inciden sobre en una plantación de $P$. radiata de la pampa ondulada.

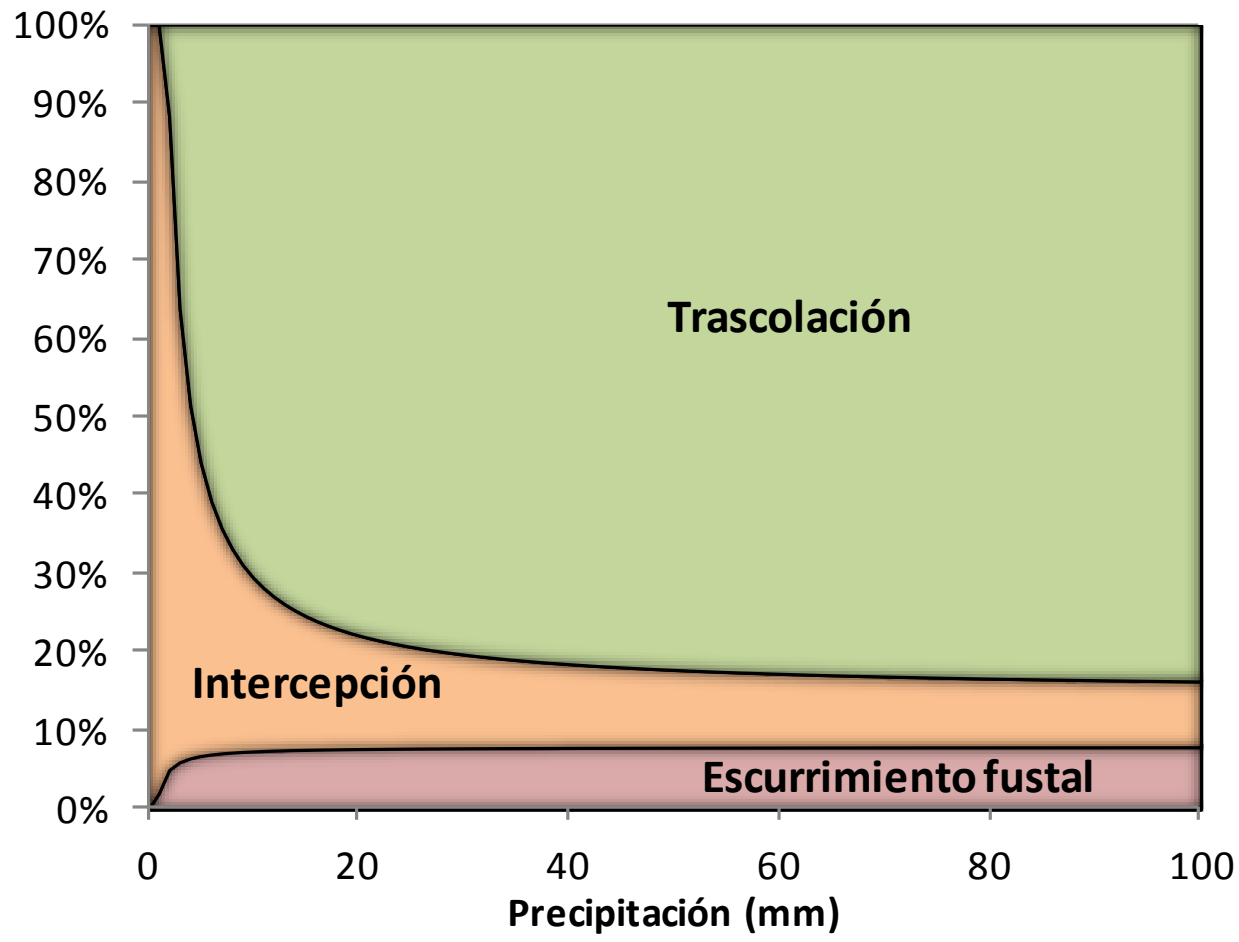

Gráfico II.17. Redistribución porcentual de las distintas láminas de lluvia acumulada que inciden sobre en una plantación de E. viminalis de la pampa ondulada. 


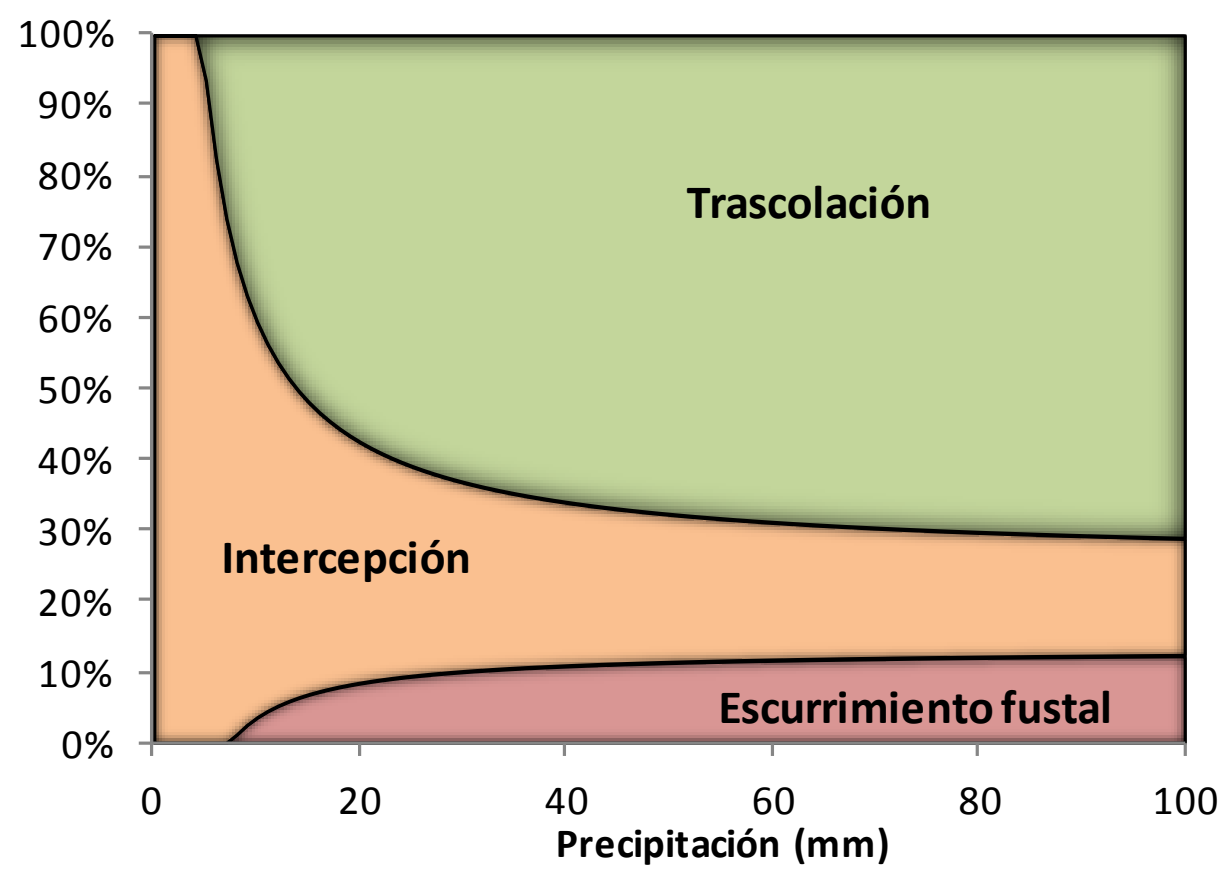

Gráfico II.18. Redistribución porcentual de las distintas láminas de lluvia acumulada que inciden sobre en una plantación de E. viminalis de la pampa deprimida (Parcela 1).

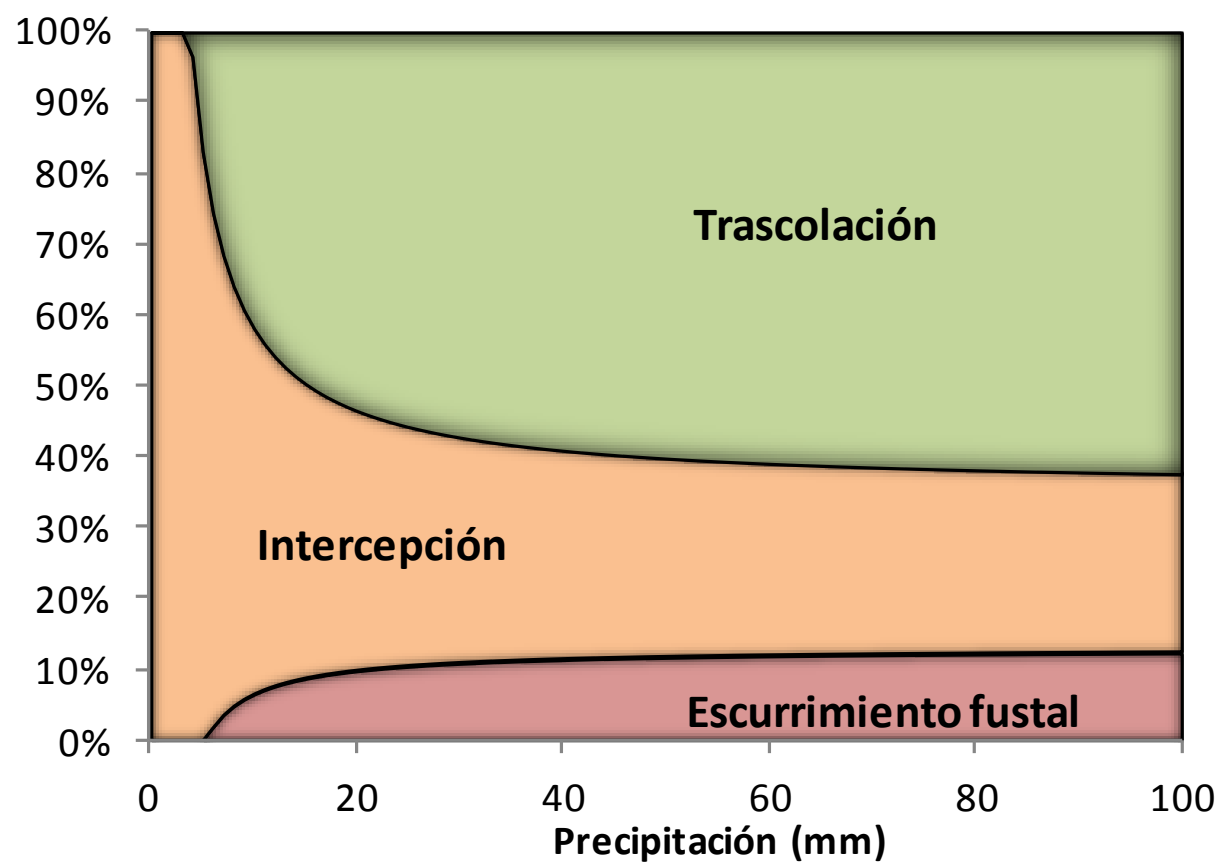

Gráfico II.19. Redistribución porcentual de las distintas láminas de lluvia acumulada que inciden sobre en una plantación de E. camaldulensis de la pampa deprimida (Parcela 2). 


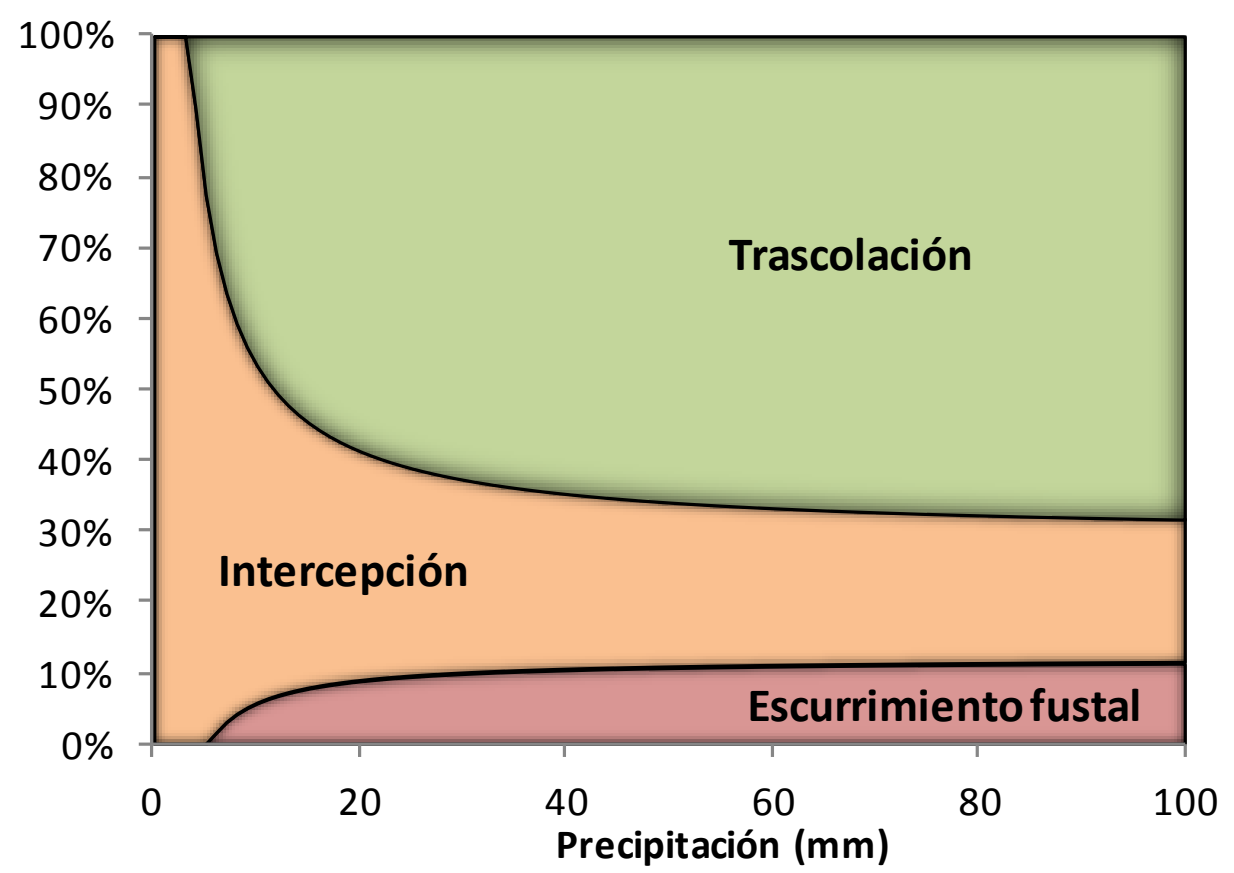

Gráfico II.20. Redistribución porcentual de las distintas láminas de lluvia acumulada que inciden sobre en una plantación de E. camaldulensis de la pampa deprimida (Parcela 3).

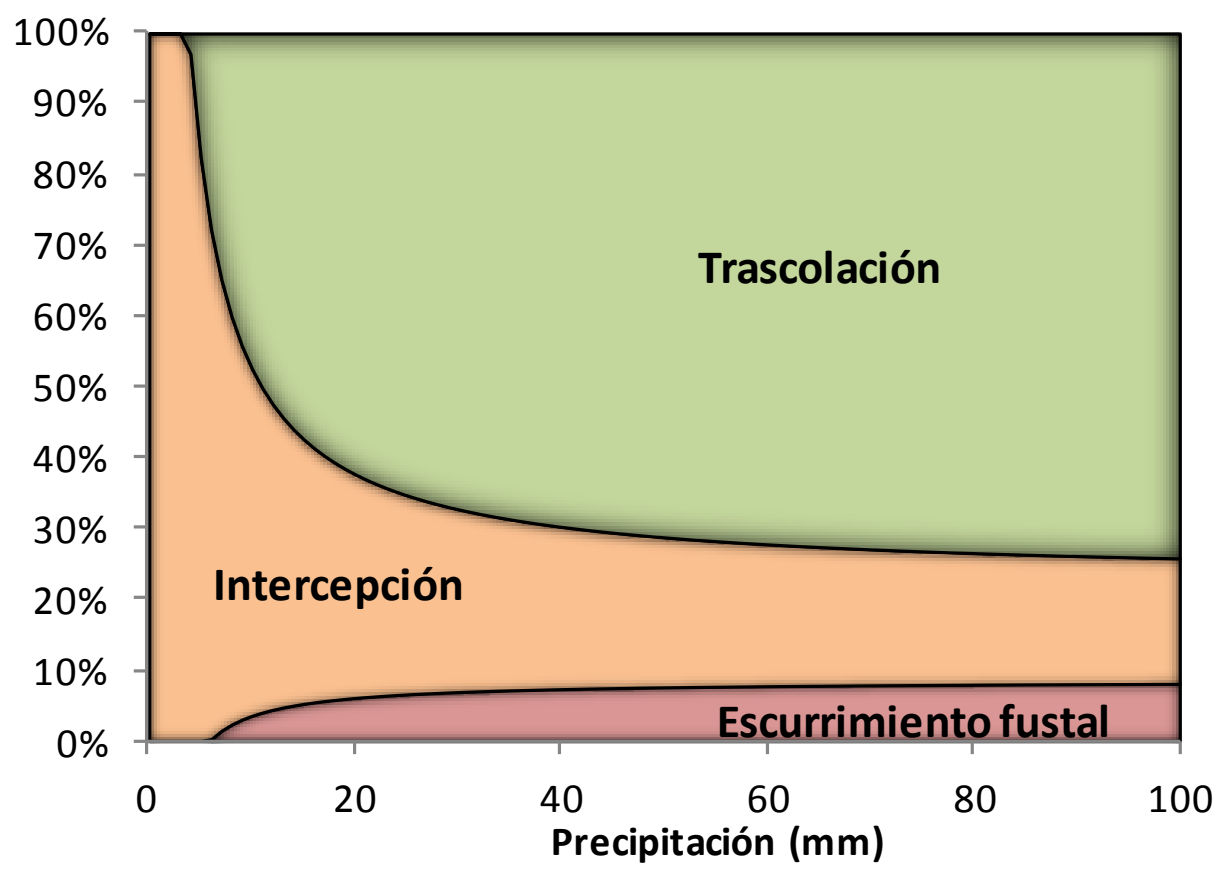

Gráfico II.21. Redistribución porcentual de las distintas láminas de lluvia acumulada que inciden sobre en una plantación de E. camaldulensis de la pampa deprimida (Parcela 4). 


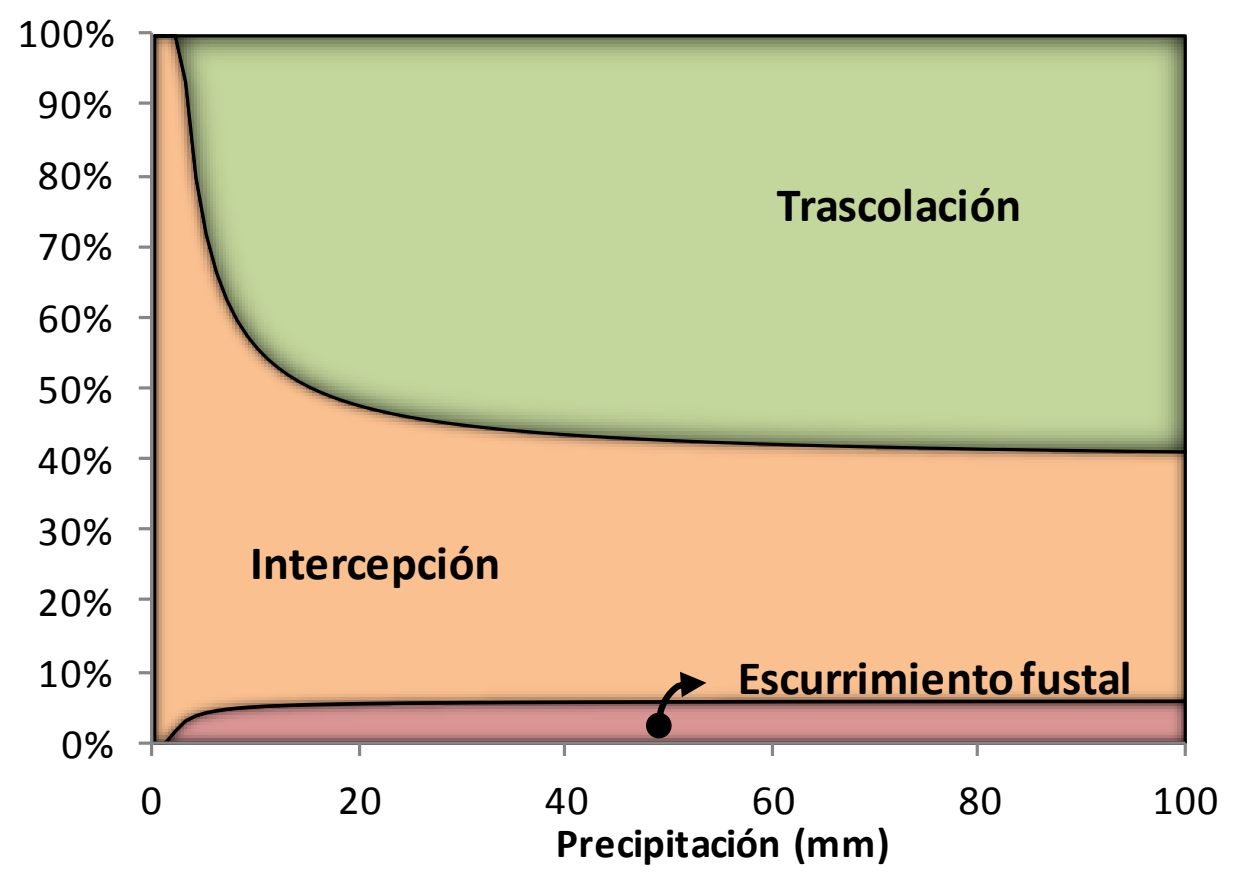

Gráfico II.22. Redistribución porcentual de las distintas láminas de lluvia acumulada que inciden sobre en una plantación de E. camaldulensis de la pampa deprimida (Parcela 5).

Este tipo de gráficos (Gráficos II.16 al II.22) representan el comportamiento de la trascolación, intercepción y escurrimiento fustal (variables respuesta o dependientes) frente a distintos eventos de lluvia sobre las forestaciones (variable de control o independiente). Además, es posible observar que el $E_{\mathrm{f}}$ se manifiesta superados los 6,1 y $0,7 \mathrm{~mm}$ de precipitación en los rodales de $P$. radiata y $E$. viminalis (EEC), mientras que en PFD lo hace superados los $7,3 \mathrm{~mm}$ de $P$ en $E$. viminalis, y en un rango de 1,4 a $5,8 \mathrm{~mm}$ en los rodales de E. camaldulensis.

En La Tabla Il.13 se reúnen algunas características de los rodales estudiados a fin de facilitar la interpretación de los resultados. 
Tabla II.13. Características dasométricas de los rodales estudiados, junto a los componentes porcentuales de la redistribución de las lluvias que inciden sobre ellos y capacidad máxima de retención de agua en troncos y dosel forestal.

\begin{tabular}{|c|c|c|c|c|c|c|c|c|c|c|c|c|}
\hline Sitio & Sp & $\begin{array}{c}\mathrm{D}_{\mathrm{dt}} \\
\text { (árb/ha) }\end{array}$ & $\begin{array}{l}\text { Edad } \\
\text { (años) }\end{array}$ & $\begin{array}{c}\mathrm{h} \\
(\mathrm{m})\end{array}$ & $\begin{array}{l}\text { DAP } \\
(\mathrm{cm})\end{array}$ & $\begin{array}{c}\mathrm{AB} \\
\left(\mathrm{m}^{2} / \mathrm{ha}\right)\end{array}$ & $\mathrm{f}_{\mathrm{c}} \cdot(\%)$ & $\begin{array}{c}\mathrm{T}_{\mathrm{r}} \\
(\%)\end{array}$ & $E_{f}(\%)$ & $\begin{array}{c}\mathrm{I} \\
(\%)\end{array}$ & $\begin{array}{c}\mathrm{E}_{\mathrm{f0}} \\
(\mathrm{mm})\end{array}$ & $\begin{array}{c}\mathrm{I}_{0} \\
(\mathrm{~mm})\end{array}$ \\
\hline \multirow{2}{*}{ EEC } & P. rad. & 1120 & 33 & 22,0 & 28,9 & 73,47 & 53,5 & 75,4 & 4,3 & 20,3 & 6,1 & 2,6 \\
\hline & E. vim. & 1440 & $33(13)^{*}$ & 20,0 & 8,85 & 8,86 & 36,7 & 83,8 & 6,7 & 9,5 & 0,7 & 1,6 \\
\hline \multirow{5}{*}{ PFD } & E. $\operatorname{vim}_{1}$ & 822 & 17 & 22,0 & 12,2 & 9,61 & 60,0 & 70,4 & 8,2 & 21,4 & 7,3 & 5,0 \\
\hline & E. cam 2 & 1200 & 24 & 22,2 & 24,0 & 54,29 & 31,0 & 63,1 & 7,7 & 29,2 & 5,2 & 3,6 \\
\hline & E. $\mathrm{cam}_{3}$ & 1200 & 17 & 22,5 & 14,1 & 18,74 & 42,2 & 67,7 & 7,5 & 24,9 & 5,2 & 3,7 \\
\hline & E. $\mathrm{cam}_{4}$ & 650 & 15 & 21,5 & 14,5 & 10,73 & 26,2 & 73,5 & 5,7 & 20,8 & 5,8 & 4,0 \\
\hline & E. cam $_{5}$ & 666 & 34 & 23,9 & 23,3 & 28,40 & 47,1 & 58,3 & 3,4 & 38,3 & 1,4 & 2,6 \\
\hline
\end{tabular}

Donde: Sp.=especie; $\mathrm{P}$. rad.=P. radiata; $\mathrm{E}$. vim. $=E$. viminalis; $\mathrm{D}_{\mathrm{dt}}=\mathrm{densidad}$ total del rodal; $\mathrm{h}=$ altura máxima promedio; $\mathrm{DAP}=$ diámetro a $1,3 \mathrm{~m}$ de altura, $\mathrm{AB}=a$ rea basal del rodal, $\mathrm{f}_{\mathrm{c}}=$ cobertura forestal; $\mathrm{T}_{\mathrm{r}}=$ trascolación; $\mathrm{E}_{\mathrm{f}}=$ escurrimiento fustal; I=intercepción; $\mathrm{E}_{\mathrm{f} 0}=$ cantidad de lluvia por encima de la cual comienza el escurrimiento fustal, y $\mathrm{I}_{0}=$ cantidad de lluvia necesaria para saturar la capacidad de retención del dosel forestal. Los subíndices $1,2, \ldots 5$, representan las parcelas de muestreo en PFD y $33(13)^{*}$ indica que los pies son de 33 años con rebrotes de 13 años. Los valores porcentuales son función de P 


\subsection{DISCUSIÓN}

Del análisis de las distintas series de datos pluviográficos se corrobora una buena correlación entre los valores anuales y mensuales correspondientes a las estaciones meteorológicas Julio Hirschhorn y Aeródromo Dolores (EEJH y EMAD). Los valores de precipitación anual son similares a los presentados por Hurtado et al. (2006) y Batista et al. (2005), sin embargo, el análisis de la consistencia de los datos mensuales y diarios indican diferencias entre las lluvias. Esto sugiere que la semejanza entre ambas series, a pesar de la distancia a la que se hallan las estaciones, se debe a que comparten las mismas isohietas regionales, con valores acumulados anuales de precipitación muy similares. A medida que se reducen los intervalos de análisis (intervalos mensuales y diarios), es posible verificar diferencias en la intensidad y duración de las lluvias, donde la correlación entre series se reduce gradualmente y la diferencia entre medias resulta significativa. Esta primera aproximación, tiene un carácter comparativo y busca obtener una visión regional de la situación hidrológica entre ambos sitios de estudio (EEC y PFD), sustentado en registros diarios reconocidos y extensamente utilizados.

Del contraste entre los registros de lluvias mensuales de las estaciones (EEJH y EMAD) frente a los pluviómetros testigo de EEC y PFD (Gráficos II.5 y II.6), se observa un elevado grado de correlación para cada uno de los pares ("EEJH-Testigo EEC" y "EMADTestigo PFD"). El análisis de doble masa sobre los pares analizados, por otro lado, demuestra una buena homogeneidad de los datos. La valoración de estas relaciones se concreta con el cálculo de los coeficientes de consistencia de Colotti et al. (2003) y el análisis de medias, que indican que cada par analizado posee una buena consistencia entre series y no presenta diferencias significativas entre medias. Esto habilita a utilizar indistintamente tanto los datos pluviométricos de las estaciones meteorológicas, como los de los pluviómetros testigo, a fin de posibilitar extrapolaciones temporales. El no encontrar datos perfectamente consistentes o linealmente dependientes al utilizar los coeficientes de consistencia-inconsistencia $\left(\mathrm{C}_{\mathrm{I}}=0 \circ \mathrm{C}_{\mathrm{C}}=1\right)$ es esperable y se justifica por el distanciamiento existente entre las estaciones meteorológicas y los pluviómetros testigos. Así, se cuenta con valores más elevados en el par "EEJH-Testigo EEC" $\left(C_{C}=0,81\right)$ frente al par "EMADTestigo PFD" $\left(C_{C}=0,73\right)$, que como puede verse en la figura II.11 y II.12 (Tabla II.3) difieren en el distanciamiento de los pares. Este razonamiento se verifica al calcular el coeficiente de consistencia entre las lluvias mensuales registradas en los pluviómetros testigo de los predios EEC y PFD, con valores de $\mathrm{C}_{\mathrm{C}}=0,5$ y donde los distanciamientos son aún mayores. 
En lo que respecta al análisis de la redistribución de las lluvias en los componentes de trascolación, escurrimiento fustal (Gráficos II.6 al II.12), pueden observarse altos grados de ajuste lineal $(r>0,7)$ que expresan una elevada correlación entre los componentes de trascolación $\left(\mathrm{T}_{\mathrm{r}}\right)$, escurrimiento fustal $\left(\mathrm{E}_{\mathrm{f}}\right)$ y precipitación neta $\left(\mathrm{P}_{\mathrm{n}}\right)$ tal como lo presenta Huber y Oyarzún (1983). Es posible distinguir, además, la importancia parcial de los componentes $\mathrm{T}_{\mathrm{r}}$ y $\mathrm{E}_{\mathrm{f}}$ con respecto a la precipitación neta, considerada como la principal fuente que abastece de agua al ciclo hidrológico en un bosque (Chu-san Lin, 1968 y Schmaltz, 1969, en: Huber y Oyarzún, 1983). Así, el aporte de agua por $\mathrm{T}_{\mathrm{r}}$ predomina ampliamente sobre el $\mathrm{E}_{\mathrm{f}}$, en coincidencia con lo expuesto por numerosos autores del mundo (Leite et al., 1997 en Brasil; Oyarzún y Huber, 1999 en Chile y Rodríguez et al., 2010 en España), mientras que el $E_{f}$, en principio despreciable, cobra importancia en períodos de escasas precipitaciones por tratarse de un flujo concentrado alrededor del tronco donde se localiza la mayor densidad de raíces (Giordano, 1969 y Poupon, 1972, en: Poore y Fries, 1987). A este respecto, es oportuno mencionar el concepto de agua fácilmente aprovechable o AFA, que involucra a la fracción total de agua que las plantas pueden extraer del suelo sin experimentar estrés hídrico (Allen et al., 2006). Esta concepción surge de que el suelo húmedo es capaz de satisfacer los requerimientos de agua de las plantas en función de la demanda atmosférica, sin embargo, esta capacidad disminuye en la medida que el suelo pierde humedad y el agua en él es retenida más fuertemente. De esta manera, la posibilidad que tendrían las plantas de utilizar el agua del suelo hasta su punto de marchitez permanente, solo es posible a través de una reducción sustancial en la cantidad consumida.

Al interpretar los resultados del análisis temporal, de los componentes de la redistribución de las lluvias sobre las plantaciones forestales de pino y eucalipto en EEC (Tablas II.6 y II.7), se observa que los rangos de valores obtenidos (variación intraespecífica) son muy similares a los publicados para pinos y eucaliptos (Huber y Oyarzún, 1983; González et al., 1993; Leite et al., 1997; Bruijnzeel, 1997; Soares y Almeida, 2001; Teixeira Días, 2004), y se explican por las características de las precipitaciones y las condiciones meteorológicas predominantes en los períodos considerados. Las variaciones interespecíficas (entre distintas especies), en cambio, responden a la fisonomía y estructura de cada especie (Besteiro y Rodríguez, 2012) y permiten distinguir una notable diferencia en los porcentajes de intercepción entre especies, donde los valores observados en pinos duplican a los determinados en 
eucaliptos. Esta diferencia resulta esperable, sin embargo, por la arquitectura característica de esta especie, rugosidad de corteza, y tipo y disposición de ramas y hojas y confirma la hipótesis de que la capacidad de intercepción de los pinos estudiados supera a la de los eucaliptos.

Los resultados obtenidos para el PFD (Tablas II.8 a II.12), al igual que en el caso de EEC, se presentan sin grandes variaciones a nivel mensual y estacional, sin embargo evidencian un considerable aumento en el porcentaje de agua interceptada muy por encima de los valores informados para este género y aún también para los pinos (Poore y Fries, 1987; Bruijnzeel, 1997; Le Maitre et al., 1999; Giraldo, 2002; de Paula Lima, 2008). Esto representa un conflicto frente a la aceptación de la hipótesis formulada de que los pinos interceptan más agua de lluvia que los eucaliptos. La explicación que se encuentra para este comportamiento podría estar relacionada con alguna de las siguientes reflexiones:

1) La cercanía de la napa freática permite un abastecimiento de agua permanente, por lo que las plantas se mantienen en producción constante a lo largo del año (crecimiento ininterrumpido), que las mantiene en un estado fisiológico activo, con un follaje pleno y su capacidad de intercepción al máximo todo el año. Esto no sucedería en EEC y repercute en el grado de intercepción de estos rodales.

2) Los rodales de PFD se encuentran manejados para la producción de fibra y pulpa, donde se busca maximizar el crecimiento en volumen de madera y no en diámetro de fustes. Esto provoca que los fustes, en su competencia por luz solar, se elongen al punto que la superposición de copas provocaría un incremento sustancial en la capacidad de intercepción del agua de lluvia.

3) Se trata de un campo aislado de cualquier estructura natural o artificial elevada, donde la brisa es constante y genera una remoción permanente de la capa límite de humedad adherida en hojas y ramas, que provoca que el agua interceptada se evapore rápidamente sin llegar a saturar la capacidad de almacenamiento de las mismas y así lograr elevados porcentajes de intercepción.

La ausencia de repeticiones en las situaciones analizadas y el no contar con repeticiones de las coberturas de pino en PFD convierte este punteo en especulaciones sin sustento estadístico. Se advierte por lo tanto, la necesidad de realizar un estudio más 
minucioso al respecto. No obstante, es posible establecer que el rango de intercepción determinado en PFD para E. camaldulensis no presenta una relación directa con la densidad de árboles por hectárea, el DAP, la altura máxima promedio, el porcentaje de cobertura o el área basal de los rodales; en contradicción a lo expuesto por Hofstede (1998), quien sostiene que el área basal es una de las características estructurales de mayor importancia en las pérdidas de agua por intercepción. En cambio, es posible establecer, tanto para los rodales de E. camaldulensis como para los otros rodales del mismo género, una relación directa entre el porcentaje anual de intercepción y la edad de los rodales. Así, a mayor edad de los rodales se estableció un mayor porcentaje anual de intercepción del agua de lluvia. Esta evidencia coincide con lo expresado por FAO (1962) y habilita a rechazar la hipótesis de que la capacidad de intercepción de estos rodales aumente con la densidad de los mismos.

El escurrimiento fustal resultante de los rodales de pino y eucaliptos en estudio (Tablas II.6 a II.12), presentó una baja proporción respecto a la precipitación total acumulada de EEC (3,7-4,6\%/año en $P$. radiata y $6,5-6,8 \%$ /año en $E$. viminalis) y PFD (7,18,9\%/año en E. viminalis y 3,3-8,2\%/año en E. camaldulensis). Estos valores, considerados como despreciables por algunos autores (Díaz y Rébori, 2003), presentan un importante rango de variación mensual de 4,5-17,3mm y 7,9-25,8mm para $P$. radiata y $E$. viminalis en EEC, y de $10,6-35,7 \mathrm{~mm}$ y $4,9-32,7 \mathrm{~mm}$ en plantaciones de E. viminalis y E. camaldulensis en PFD (Tablas II.6 a II.12). Esta variación indica un rango de valores totales anuales de $44,4-55,2 \mathrm{~mm}$ para el rodal de $P$. radiata, un rango de $78,0-81,6 \mathrm{~mm}$ para $E$. viminalis en EEC; un rango de 85,2-106,8mm para E. viminalis en PFD, y un rango de $\mathrm{E}_{\mathrm{f}}$ total anual de 39,6-98,4mm para E. camaldulensis. Además, en el caso de los rodales de Eucalyptus de PFD y ECC (particularmente los de E. viminalis), se observa que los valores de $E_{f}$ en PFD se equiparan prácticamente con el componente de intercepción en EEC, que es considerado como el componente más significativo de la redistribución de la precipitación en forestaciones (Cantú y González, 2002).

Al igual que lo expuesto por Huber y Oyarzún (1983), el inicio del escurrimiento fustal en pino se manifiesta superados los 6,1 mm de precipitación (Gráfico II.16, Tabla II.13), debido en parte a las características de absorción y rugosidad de su corteza, mientras que en los eucaliptos lo hace al superar un rango de precipitaciones acumuladas de 0,7 a 7,3mm (Gráficos II.17 a II.22, Tabla II.13). 
En el caso de los eucaliptos, es necesario diferenciar al E. viminalis de EEC del resto, ya que el valor de saturación $(0,7 \mathrm{~mm})$ se puede explicar por el estado más bien juvenil de los rebrotes y/o el tipo de variedad, caracterizados por un tallo muy liso sin restos de corteza adheridos donde el agua escurre fácilmente prácticamente desde el inició de las precipitaciones. En PFD, donde los rodales son más viejos y además existe un manejo silvícola que promueve la existencia de individuos monopodiales y de mayor diámetro, los fustes mantienen las cortezas adheridas por largo tiempo, al punto de generar una gran rugosidad en los troncos que justificaría en parte los valores presentados de 1,4 a 7,3mm de $\mathrm{E}_{\mathrm{f} 0}$.

Como ya fue mencionado, los gráficos II.16 al II.22, representan el comportamiento de la intercepción y escurrimiento fustal (variables respuesta o dependientes) frente a distintos eventos de lluvia sobre las forestaciones (variable de control o independiente). Esto, no solo es importante porque permite inferir o proyectar el comportamiento de estos valores ante cambios climáticos de largo plazo, sino que posee especial trascendencia en la llanura pampeana por la evidencia un significativo incremento de las precipitaciones anuales a lo largo de los años (Magrin et al., 2005) y que según Forte lay et al. (2008) solo forma parte de un ciclo climático, que podría devenir en grandes pérdidas para la agricultura una vez que se vuelva a los registros de lluvia propios de la década del 70'. 


\section{Capítulo 3}

\section{Escurrimiento superficial}




\subsection{INTRODUCCIÓN}

El escurrimiento se define como el agua proveniente de la precipitación que circula sobre o bajo de la superficie terrestre y llega a una corriente para finalmente ser drenada hasta la salida de la cuenca (Mijares, 1994).

El camino que sigue el agua una vez que cae en la superficie terrestre (descontando el agua interceptada y evaporada), hasta que alcanza el cauce es muy variable y se puede separar en tres componentes: escurrimiento superficial, escurrimiento subsuperficial y escurrimiento subterráneo.

De los tres tipos de escurrimiento, el superficial es el que llega primero a la salida de una cuenca y abarca tanto el flujo por la superficie del terreno como el que sigue el curso de agua. Se lo considera relacionado directamente con la precipitación y se dice que proviene de la precipitación en exceso o efectiva, constituyendo el escurrimiento directo. Del agua que infiltra, una parte puede moverse lateralmente hacia los cauces en las capas próximas a la superficie constituyendo, de esta manera, el escurrimiento subsuperficial o epidérmico, y otra parte puede llegar hasta el nivel freático aumentando el agua subterránea que eventualmente puede descargarse en los cauces como escurrimiento subterráneo, flujo base o descarga de estiaje.

Existe un cuarto componente de la escorrentía total, la fracción que cae directamente sobre la superficie libre del agua (ríos, lagos, embalses), pero su valor es de escasa importancia (Mármol, 2006).

El valor real de la escorrentía superficial directa que circula hacia los cauces solo puede determinarse de forma experimental, mediante la instalación de una red de pluviómetros y aforos en la red de drenaje. Estos datos son raros en cuencas pequeñas e inexistentes a nivel predial, por lo que es habitual recurrir a métodos paramétricos 0 al método analítico del número de curva, para la determinación de escorrentías anuales con cierta rigurosidad (López Cadenas de Llano, 1998). 


\subsubsection{Sistemas hidrológicos atípicos}

Las cuencas de llanura poseen características particulares que las distinguen de las que tradicionalmente se ocupa la hidrología clásica.

Mientras que el concepto clásico reconoce a la cuenca como una unidad física delimitada por las divisorias de agua, donde los excedentes hídricos drenan siempre por un determinado punto (Chow et al., 1994), las cuencas de llanura se desarrollan sobre rocas sedimentarias de estructura aclinal (Gaspari et al., 2009), donde la escasa energía morfogenética hace que los excesos hídricos no estén necesariamente encausados ni drenando hacia un mismo sitio. Inclusive, ante excesos hídricos prolongados, pueden acumularse grandes volúmenes de agua capases de desbordar por sobre las divisorias de aguas pobremente definidas (Giraut, 2006).

La escasa pendiente de las cuencas de llanura condiciona gradientes hidráulicos extremadamente bajos y condicionan que el flujo horizontal del agua en el suelo sea muy lento. De esta manera, el agua que se infiltra en el terreno es prácticamente incapaz de escurrir horizontalmente, acumulándose hasta alcanzar un equilibrio entre la infiltración a través de la zona vadosa y la evapotranspiración. El balance de agua en el suelo es por lo tanto principalmente vertical (Fuschini Mejía, 1994, en: Badano, 2010).

En estas condiciones, los cambios de uso del suelo y las características de la cobertura vegetal, tendrán una incidencia directa en el balance hídrico vertical. El escurrimiento general será inferior al $5 \%$ de la precipitación y, cuando las precipitaciones superan la capacidad de almacenamiento de los suelo, se producirá el llenado secuencial de los bajos y lagunas, la elevación de los niveles freáticos, interconexión de cauces indefinidos, escurrimiento mantiforme y ocasionalmente en inundaciones (Sallies, 1999).

Por todo lo anterior, es posible identificar a la llanura pampeana como un "Sistema hidrológico no típico" (Fertonani y Prendes, 1983; Giraut, 2006), cuyas características más sobresalientes fueron señaladas por Sallies (1999) de la siguiente manera:

1) Predominan los movimientos verticales del agua por no tener el terreno suficiente pendiente (menor del 1\%).

2) Mucha retención superficial en bajos, esteros y lagunas. 
3) No se puede relacionar en forma estrecha la precipitación con el caudal de los cursos.

4) Tributarios mal definidos y tendencia a la paralelización de los cauces con el principal, si es que existe. Generalmente no llegan al mismo, solamente en las grandes crecientes se integra la red hidrológica.

5) Los arroyos son interrumpidos por lagunas y llevan agua de la napa en general muy cercana a la superficie.

6) Divisorias de agua mal definidas.

7) Poca o nula erosión hídrica.

\subsubsection{Escurrimiento bajo forestaciones}

La información referida al escurrimiento superficial bajo plantaciones resulta escasa, posiblemente por lo dificultoso de su implementación y seguimiento. Sin embargo existen numerosas relaciones obtenidas de la medición de caudales.

Al tratar con sitios de pendientes pronunciadas, es esperable la presencia de coeficientes de escurrimiento elevados, acompañados con el acarreo de materiales por arrastre o suspensión. Casos como este, con pendientes del 20\%, se advierten en Chile por ejemplo, donde los valores de escurrimiento se distribuyen entre el $33 \%$ y $23 \%$ en plantaciones de Pinus radiata y Eucalyptus globulus respectivamente (Huber et al., 2010). Sin embargo, en el caso de sistemas atípicos como la llanura pampeana, los valores de escurrimiento se definen como el $6 \%$ de la precipitación (Auge, 2005), por consiguiente, los procesos erosivos derivados del agua de escurrimiento son excepcionales y, si los hay, son de carácter muy puntual.

Un importante conjunto de experiencias sobre el fenómeno de escurrimiento bajo forestaciones, fue sintetizado por Poore y Fries (1987). Entre ellas, pueden mencionarse: 1) valores de escurrimiento del $1 \%$ de $P$ para plantaciones de Eucalyptus globulus e insignificantes para pastos en el sur de la India (Chinnamani et al., 1965; Samraj et al., 1977); 2) reducciones del escurrimiento superficial del $28 \%$ para microcuencas forestadas con E. grandis y E. camaldulensis, y del $73 \%$ en los picos de descarga (Mathur et al., 
1976); y 3) la obtención de menores porcentajes de flujo base total y coeficientes de escorrentía (4-19\%), y de mayores caudales de inundación (21\% más altos) en microcuencas forestadas con $E$. robusta frente a una con bosque nativo de montaña y dos con bosque secundario (Bailly et al., 1974).

Casos extremos, como el presentado por Scott y Lesch (1997) para pastizales de Sudáfrica, muestran que cuencas cuyo escurrimiento natural era de $236 \mathrm{~mm}$ presentaban un descenso significativo de este flujo al tercer año de ser forestadas con eucaliptos y que al noveno año se secaban completamente los arroyos. Otro tanto ocurrió en cuencas forestadas con pinos, donde escurrimientos de $217 \mathrm{~mm}$ sufrieron una reducción significativa al cuarto año de instalada la plantación y el secado de arroyos en el doceavo año.

Valores generales ampliamente aceptados, son los obtenidos por Farley et al. (2005) como resultado del estudio de datos recopilados de 26 cuencas alrededor del mundo. Estos autores coincidieron en que la instalación de forestaciones sobre pastizales y matorrales reduce en un 31 y $44 \%$ el escurrimiento superficial -efecto que se manifiesta con mayor intensidad en eucaliptos (75\%) que en plantaciones de pino (40\%)-. Además, indicaron que el efecto de estas conversiones es similar e incluso más intenso a nivel de los flujos subterráneos y sugieren que las regiones con valores de escurrimiento inferiores al $10 \%$ de la precipitación media anual, pueden manifestar una interrupción total de este flujo al forestar.

En el caso de cuencas atípicas como los sitios de estudio (EEC y PFD), y en función de lo antedicho, los escasos porcentajes de escurrimiento podrían ser anulados tras la instalación de forestaciones. Sin embargo, es necesario mensurar este fenómeno al punto de poder integrarlo al modelo de comportamiento de las forestaciones y su incidencia hidrológica. 


\subsection{MATERIALES Y MÉTODOS}

\subsubsection{Morfometría}

El funcionamiento de una cuenca se asemeja al de un colector que recibe la precipitación y la convierte en escurrimiento (Gaspari et al., 2009). Por tanto, el análisis morfométrico de estas unidades, resulta esencial a la hora para evaluar su comportamiento morfodinámico e hidrológico y permitirá predecir o comprender su comportamiento ante la ocurrencia de externalidades tales como una lluvia extrema (Méndez y Marcucci, 2006).

La caracterización morfométrica fue establecida a través de la determinación de parámetros de forma, de relieve y relativos a la red hidrográfica. Estos parámetros, desempeñan un papel fundamental en el estudio y comportamiento en los componentes del ciclo hidrológico y, comúnmente, comprenden parámetros de entrada de modelos hidrológicos.

A continuación se listan los parámetros calculados junto con una breve explicación extraída mayormente de Gaspari et al. (2009):

1) Área de una cuenca $(A)$. Es un parámetro relativo a la forma de una cuenca y corresponde a la superficie encerrada por la divisoria de aguas. Su unidad de medida es el $\mathrm{km}^{2}$. A partir de este parámetro se puede definir el tamaño de la cuenca y establecer un nombre para su caracterización.

2) Perímetro de la cuenca $(P)$. Es un parámetro relativo a la forma de una cuenca y representa la longitud de la línea envolvente de la misma, expresada en km, trazada por la divisoria de aguas.

3) Longitud axial (La). Es la distancia existente entre la desembocadura y el punto más lejano de la cuenca. Es el mismo eje de la cuenca y su unidad es el km.

4) Factor de forma o de Gravelius (Ff). Responde a la relación entre el ancho promedio (Ap) y la longitud axial de la cuenca (La). Permite apreciar la tendencia de la cuenca a las crecientes y varía entre valores cercanos a 1 (cuencas de forma redondeada propensas acrecientes de mayor magnitud) y menores a 1 (cuencas de forma alargada, menos propensas a tener lluvias intensas y simultáneas sobre la superficie). 


$$
\mathrm{Ff}=\frac{\mathrm{Ap}}{\mathrm{La}}
$$

Donde: la longitud axial (La) representa la longitud, expresada en $\mathrm{km}$, desde el punto más alejado de la cuenca (coincidente con el punto más alto del cauce principal) hasta la desembocadura, y el ancho promedio (Ap), es igual a la razón entre la superficie de la cuenca $(A)$ y la longitud axial de la misma (La).

5) Índice de compacidad o de Gravelius (Kc). Es un índice adimensional que relaciona el perímetro de la cuenca con el perímetro de un círculo de igual superficie. Según el valor que adopta, se lo puede relacionar con distintas formas y estas a su vez, tendrán influencia sobre los escurrimientos y tiempos de concentración que definen la marcha de los hidrogramas ${ }^{11}$. En la ecuación III.2 se muestra la secuencia metodológica para la obtención de la ecuación para el cálculo de Kc y en la tabla III.1, se muestra las formas asociadas a distintos valores de Kc.

$$
\left.\begin{array}{c}
\mathrm{A}=\pi * \mathrm{r}^{2} \Rightarrow \mathrm{r}=\sqrt{\frac{\mathrm{A}}{\pi}} \\
\mathrm{p}=2 * \pi * \mathrm{r}=2 * \pi * \sqrt{\frac{\mathrm{A}}{\pi}}=2 * \sqrt{\mathrm{A} * \pi}
\end{array}\right\} \mathrm{Kc}=\frac{\mathrm{P}_{\text {cuenca }}}{\mathrm{P}_{\text {circulo }}}=\frac{\mathrm{P}}{2 * \sqrt{\mathrm{A} * \pi}}=0,28 * \frac{\mathrm{P}}{\sqrt{\mathrm{A}}}
$$

Donde: $\mathrm{r}$, es el radio en $\mathrm{km}$; $\mathrm{A}$, el área en $\mathrm{km}^{2}$ y $\mathrm{P}$ el perímetro en $\mathrm{km}$.

Tabla III.1. Cuadro de clases de formas correspondientes a distintos rangos del índice de compacidad adaptado de Mármol (2006)

\begin{tabular}{|c|l|}
\hline $\mathbf{K c}$ & \multicolumn{1}{c|}{ Clase de forma } \\
\hline $1-1,25$ & Casi redonda a oval redonda (compacta) \\
\hline $1,25-1,50$ & a oval oblonga \\
\hline $1,50-1,75$ & a rectangular oblonga \\
\hline$>1,75$ & a casi rectangular (alargada) \\
\hline
\end{tabular}

6) Curva hipsométrica. La generación de la curva hipsométrica en un área fue sugerida por Langbein, para proporcionar información sintetizada sobre la altitud de la

${ }^{11}$ Representación gráfica de las descargas instantáneas de un curso de agua en función del tiempo. Chow et al. (1994) los consideran como gráficos o tablas que muestran la tasa de flujo como función del tiempo en un lugar dado de la corriente. De la misma manera, indican que se trata de una expresión integral de las características fisiográficas y climáticas que rigen las relaciones entre la lluvia y el escurrimiento en una cuenca de drenaje particular. 
cuenca, que representa gráficamente la distribución de la cuenca vertiente por tramos de altura. Se expresa a través de una curva de doble eje de coordenadas, donde la ordenada es la cota de altura expresada en metros sobre el nivel del mar (msnm) y la abscisa es el área por encima de una cota dada $\left(\%-\mathrm{km}^{2}\right)$.

7) Curva hipsométrica relativa. Permite comparar el relieve de la microcuenca en estudio, con las curvas hipsométricas características del ciclo de erosión según Strahler (Gráfico III.1). Estas últimas, se definen de la siguiente manera: la curva superior (A) refleja una cuenca con un gran potencial erosivo y por lo tanto su fase juvenil; la curva intermedia (B) expresa una cuenca en equilibrio, indicativa de una fase de madurez y la curva inferior (C), representa una típica cuenca sedimentaria en su fase de vejez.

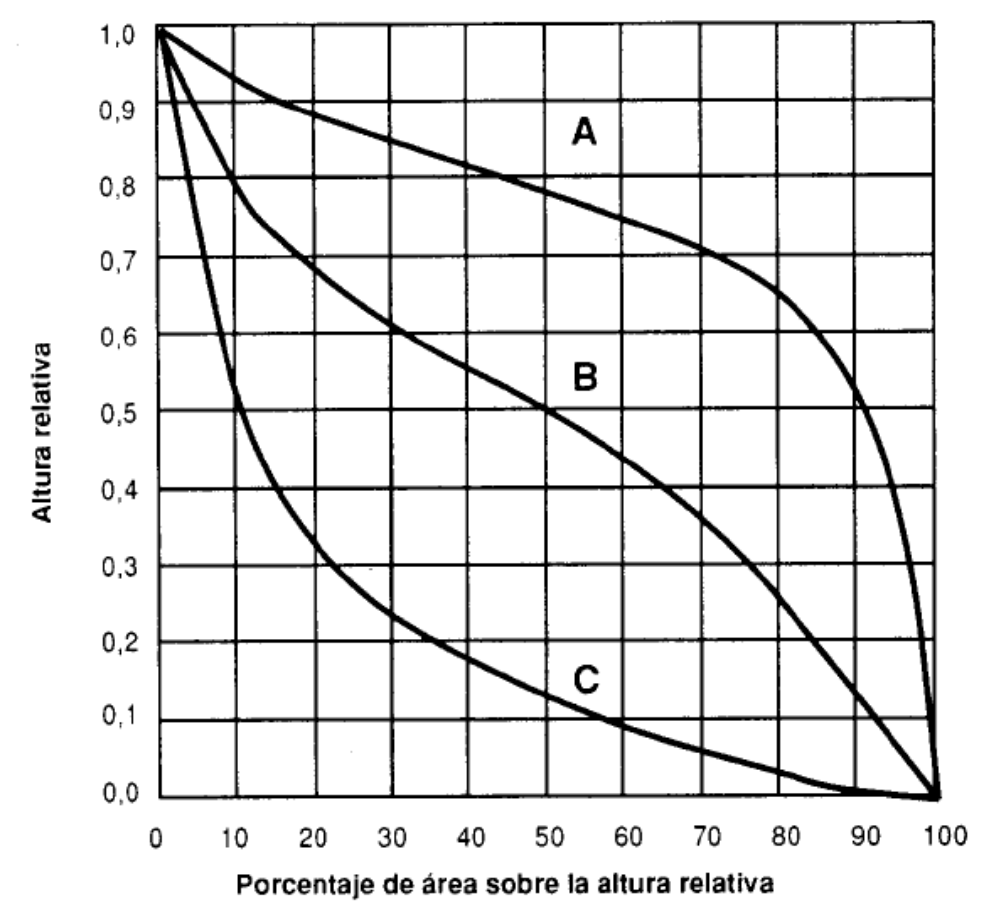

Gráfico III.1 Curvas hipsométricas características del ciclo de erosión de Strahler. Adaptado de Gaspari et al., 2009

8) Relación hipsométrica (Rh). Deriva del análisis de la curva hipsométrica (Ecuación III.3) y representa el estado de equilibrio dinámico de la misma. El cual será máximo cuando se alcance el valor unitario de $R h(R h=1)$. 


$$
\mathrm{Rh}=\frac{\mathrm{Ss}}{\mathrm{Si}}
$$

Donde: Ss y Si son el área sobre y bajo la curva hipsométrica, respectivamente.

9) Altura media $(\mathrm{Hm})$. Es un factor físico que facilita el estudio del movimiento de agua en la cuenca, a través del estudio de la distribución de las alturas en el terreno. Para su determinación se toma como referencia el nivel medio del mar.

$$
\mathrm{Hm}=\frac{\sum(\mathrm{ai} * \mathrm{hi})}{\mathrm{A}}
$$

Donde: $\mathrm{Hm}$ es la altitud media $(\mathrm{m})$; ai, el área entre par de cotas $\left(\mathrm{m}^{2}\right)$; hi, la altitud media entre dicho par $(\mathrm{m})$ y $\mathrm{A}$, el área de la cuenca $\left(\mathrm{m}^{2}\right)$. (Mármol, 2006)

10) Orientación de la cuenca. Se entiende como la dirección geográfica según la resultante de la pendiente general de las laderas (Llamas, 1993).

11) Pendiente media (PM). Se define como la media de las pendientes de las superficies elementales del terreno, o más exactamente, el promedio ponderado de las superficies elementales en las que la línea de máxima pendiente es constante. Se trata de un valor importante ya que incide directamente en la velocidad que toman las corrientes y la consecuente capacidad de erosión y arrastre de sedimentos (Mármol, 2006).

$$
\mathrm{PM}=\frac{\mathrm{H} * \mathrm{~L}}{\mathrm{~A}} * 100
$$

Donde: PM, es la pendiente media (\%); $\mathrm{H}$, la equidistancia entre las curvas de nivel $(\mathrm{km}) ; \mathrm{L}$, la longitud total de las curvas de nivel $(\mathrm{km})$ y $\mathrm{A}$, el área de la cuenca $\left(\mathrm{km}^{2}\right)$.

12) Coeficiente de rugosidad ( $\mathrm{Ra}$ ). Es la relación existente entre el desnivel de la cuenca y su densidad de drenaje. 
Donde: $\mathrm{Ra}$, es el coeficiente de rugosidad (adimensional); $\mathrm{H}$, la diferencia de altura entre el punto más alto y el más bajo $(\mathrm{km})$ y Dd, es la densidad de drenaje $\left(\mathrm{km}^{*} \mathrm{~km}^{-2}\right)$.

13) Densidad de drenaje (Dd). Determina cuán rápido será el tiempo de respuesta de una cuenca ante una tormenta. Densidades altas estarán asociadas con una evacuación más rápida del agua de lluvia, debido a que una gota deberá recorrer una longitud de ladera pequeña para terminar su recorrido sobre los cauces, donde la velocidad del escurrimiento es mayor, lo cual condiciona hidrogramas con un tiempo de concentración más corto.

Se define como la relación entre la suma de las longitudes de todos los cursos de agua que drenan en la cuenca con respecto al área de la misma (López Cadenas de Llano, 1998) y su determinación, permite caracterizar cuantitativamente la red hidrográfica de la cuenca y definir el grado de relación entre el tipo de red y la clase de material predominante -condicionantes del escurrimiento- (Henaos, 1988; López Cadenas de Llano, 1998; Gaspari, 2002).

$$
\mathrm{Dd}=\frac{\mathrm{Ln}}{\mathrm{A}}
$$

Donde Dd es la densidad de drenaje $\left(\mathrm{km}^{\mathrm{km}} \mathrm{km}^{-2}\right)$; Ln, es la sumatoria de las longitudes de todos los cursos de agua que drenan por la cuenca $(\mathrm{km})$, y $\mathrm{A}$, es el área total de la cuenca $\left(\mathrm{km}^{2}\right)$.

14) Pendiente media del cauce (J). La pendiente media del cauce se deduce a partir del desnivel topográfico sobre el cauce principal y la longitud del mismo. Se expresa en porcentaje, según la siguiente fórmula:

$$
\mathrm{J}=\left[\left(\frac{\mathrm{H}_{\max }-\mathrm{H}_{\min }}{\mathrm{L}}\right)\right] * 100
$$

Donde: $\mathrm{J}$ es la pendiente media del cauce (\%), Hmáx, es la cota máxima sobre el curso de agua (m); Hmín, es la cota mínima sobre el curso de agua $(m)$, y $L$, es la longitud del río más largo $(\mathrm{m})$. 
15) Tiempo de concentración (Tc). Es el tiempo que toma la partícula, hidráulicamente más lejana, en viajar hasta el punto emisor. Para ello se supone que el tiempo de duración de la lluvia es por lo menos igual al tiempo de concentración y que se distribuye uniformemente en toda la cuenca. Su estimación empírica posee varias expresiones, pero la más completa se expresa en la siguiente ecuación:

$$
\mathrm{Tc}=0,3 *\left(\frac{\mathrm{L}}{\mathrm{J}^{1 / 4}}\right)^{0,76}
$$

Donde: Tc es el tiempo de concentración (hs); L, es la longitud del cauce $(\mathrm{km})$, y J, la pendiente media del cauce (\%)

16) Número de orden de los cursos de agua. Es un número que tiene una relación estrecha con el número de ramificaciones de la red de drenaje. A mayor número de orden, es mayor el potencial erosivo, mayor el transporte de sedimentos y por tanto mayor también el componente de escurrimiento directo que en otra cuenca de similar área. Existen dos metodologías para determinar el orden de una cuenca, el criterio de Schumn y el criterio de Horton. El primero se determina al asignar el primer orden 1 a todos los cauces que no tienen tributarios y, en general, la unión de dos cauces de igual orden determinan o dan origen a otro de orden inmediatamente superior y dos de diferente orden dan origen a otro de igual orden que el de orden mayor y así sucesivamente hasta llegar al orden de la cuenca. El cauce principal tiene el orden más elevado, que es el orden de la cuenca. El criterio de Horton, sin embargo, sólo permite asignar el orden 1 a uno de los tributarios simples confluyentes, por lo que el orden inmediatamente superior conforma un menor ángulo con la dirección del flujo en el punto de confluencia. Luego, se siguen los pasos de la ley anterior hasta obtener el número de orden de la cuenca.

\subsubsection{Escurrimiento superficial}

El escurrimiento superficial es calculado por la aplicación del modelo hidrológico LTHIA NPS (Long-Term Hydrologic Impact Assessment and Non Point Source Pollutant Model) (Engel et al., 2003). Éste modelo se basa en la metodología del número de la curva (NC) del Soil Conservation Service (SCS) de los Estados Unidos y se utiliza para 
cuantificar el escurrimiento superficial mediante la transformación de la precipitación total en precipitación efectiva. Se considera como una herramienta de gran valor para la práctica hidrológica y su aplicación requiere del conocimiento del tipo y uso de suelo, de las características edáficas del lugar de estudio y de los registros de precipitación diaria.

La metodología involucra el procesamiento de información referente al suelo y geología de la EEC y PFD bajo el entorno informático del GIS ArcView 3.2. Esta información de base, se digitalizó y corroboró por fotointerpretación y experiencias a campo. Luego, se determinó el uso del suelo y tipos de cobertura, adaptándolos a los requerimientos del modelo. El procesamiento digital de la base de datos vectorial (usos del suelo y grupos hidrológicos), permitió obtener un mapa de valores de NC para las áreas de estudio y finalmente uno de lámina media anual de escurrimiento.

Las series de lluvias diarias utilizadas para la confección del mapa de escurrimiento, provinieron de la Estación Experimental J. Hirschhorn (EEJH) y la Estación Meteorológica del Aeródromo Dolores (EMAD) y corresponden a los tres años de toma de muestras (ene09-dic11 para EEC y sep09-ago12 para PFD). El mapa de grupos hidrológicos, se obtuvo de la digitalización de los mapas de suelos 1:50000 del INTA (INTA, 2010; INTA, 2011), cuyas características se encuentran en el apartado 4.2.1.1 y 4.2.1.2.

El método del número de curva (NC) o curva número, fue desarrollado por el Servicio de Conservación de Suelos de los Estados Unidos en 1972 (Mintegui Aguirre y López Unzú, 1990) como un método sencillo para calcular la lluvia efectiva (escurrimiento superficial) en aquellos casos en los que no se tienen datos de aforo. Es función de la lluvia acumulada, la cobertura del suelo, el uso del suelo y las condiciones de humedad antecedente y establece, en función de sus condiciones texturales y comportamiento frente a la infiltración, cuatro complejos denominados grupos hidrológicos (GH). Además, considera las distintas coberturas vegetales, los usos del suelo y los tratamientos culturales. Finalmente, la integración de las características edáficas y las de cobertura vegetal, generan los denominados complejos suelo-vegetación. Estos complejos, en relación a las condiciones de humedad antecedente del suelo, permiten asignar distintos valores de número de curva (NC) como se indica en la tabla III.2. 
Tabla III.2. Valores de número de curva para suelos con diferentes usos. Adaptado de Gaspari et al. (2009).

\begin{tabular}{cccccc}
\hline Uso Suelo & Condición Hidrológica & $\mathrm{A}$ & $\mathrm{B}$ & $\mathrm{C}$ & $\mathrm{D}$ \\
\hline Pastura, Pastizal o & Pobre & 68 & 79 & 86 & 89 \\
rango de forrajes continuo para pastoreo & Medio & 49 & 69 & 79 & 84 \\
& Bueno & 39 & 61 & 74 & 80 \\
\hline Bosque & Pobre & 45 & 66 & 77 & 83 \\
& Medio & 36 & 60 & 73 & 79 \\
& Bueno & 30 & 55 & 70 & 77 \\
\hline Granjas, construcciones, caminos, lotes & - & 59 & 74 & 82 & 86 \\
circundantes & - & & & \\
\end{tabular}

En la tabla III.3 se muestra la clasificación de la condición de humedad antecedente del suelo en función de la precipitación acumulada ocurrida con una anterioridad de cinco días. La misma, es de gran importancia y debe tenerse en cuenta para la aplicación de este método.

Tabla III.3. Condiciones de humedad antecedente en función de la precipitación acumulada de 5 días. Adaptado de Gaspari et al. (2009).

\begin{tabular}{ccc}
\hline Condición & Humedad antecedente del suelo & Lluvia antecedente total de 5 días (mm) \\
\hline I & Suelo seco & $0-12,7$ \\
II & Suelo medio & $12,7-38,1$ \\
III & Suelo húmedo (saturado debido a lluvias & $>38,1$ \\
\hline
\end{tabular}

El procedimiento matemático que usa el L-THIA para la determinación del escurrimiento superficial por el método del SCS, se presenta en las ecuaciones III.10 a III.16, donde se expone la secuencia de cálculo (USDA-SCS, 1964).

$$
\begin{aligned}
& \frac{\mathrm{F}}{\mathrm{S}}=\frac{\mathrm{Q}}{\mathrm{Po}} \\
& \frac{\mathrm{P}-\mathrm{Io}-\mathrm{Q}}{\mathrm{S}}=\frac{\mathrm{Q}}{\mathrm{P}-\mathrm{IO}}
\end{aligned}
$$




$$
\begin{aligned}
& P=Q+I o+F \\
& Q=\frac{(P-I o)^{2}}{P-I o+S} \\
& I o=0,2 \times S \\
& Q=\frac{(P-I o)^{2}}{P+4 \times I o}=\frac{(P-0,2 \times S)^{2}}{P+0,8 \times S} \\
& S=254\left(\frac{100}{N C}-1\right)
\end{aligned}
$$

En el gráfico III.2 se observa cómo se descompone la precipitación en el tiempo, lo que permite inferir analíticamente cada una de las ecuaciones antes expuestas. En este gráfico, $\mathrm{P}_{0}$ se lee como la precipitación efectiva; $\mathrm{P}$ responde a la precipitación total; $\mathrm{Q}$ es el escurrimiento; F la infiltración establecida como abstracciones; Io son las pérdidas iniciales y $\mathrm{S}$ es la abstracción potencial (máxima) de una cuenca luego de producirse el exceso de Iluvia.

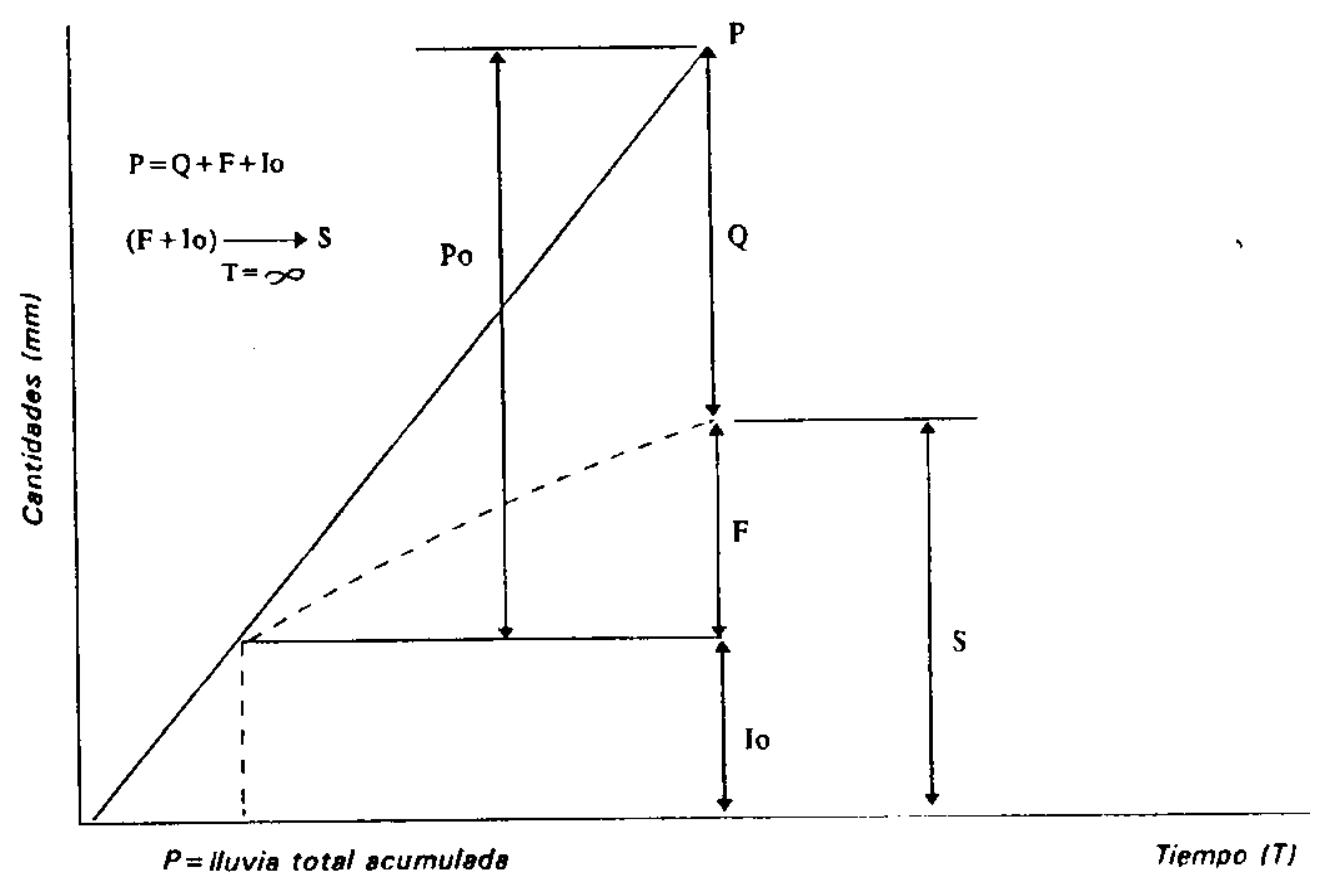

Gráfico III.2. Descomposición de la precipitación en el tiempo. Fuente: López Cadenas del Llano (1998). 


\subsection{RESULTADOS}

\subsubsection{Morfometría de la Estancia El Centauro (EEC)}

A continuación se presentan los resultados del análisis de las características morfométricas y funcionales de la Microcuenca del Arroyo La Paloma (MALP) (Figura III.1), la cual contiene el área de estudio ( $14 \%$ de la cuenca) en el cierre o salida de la misma. Este apartado deriva del estudio de Maestría inédito, realizado para el informe final de tesis en el año 2010 (Besteiro, 2010).

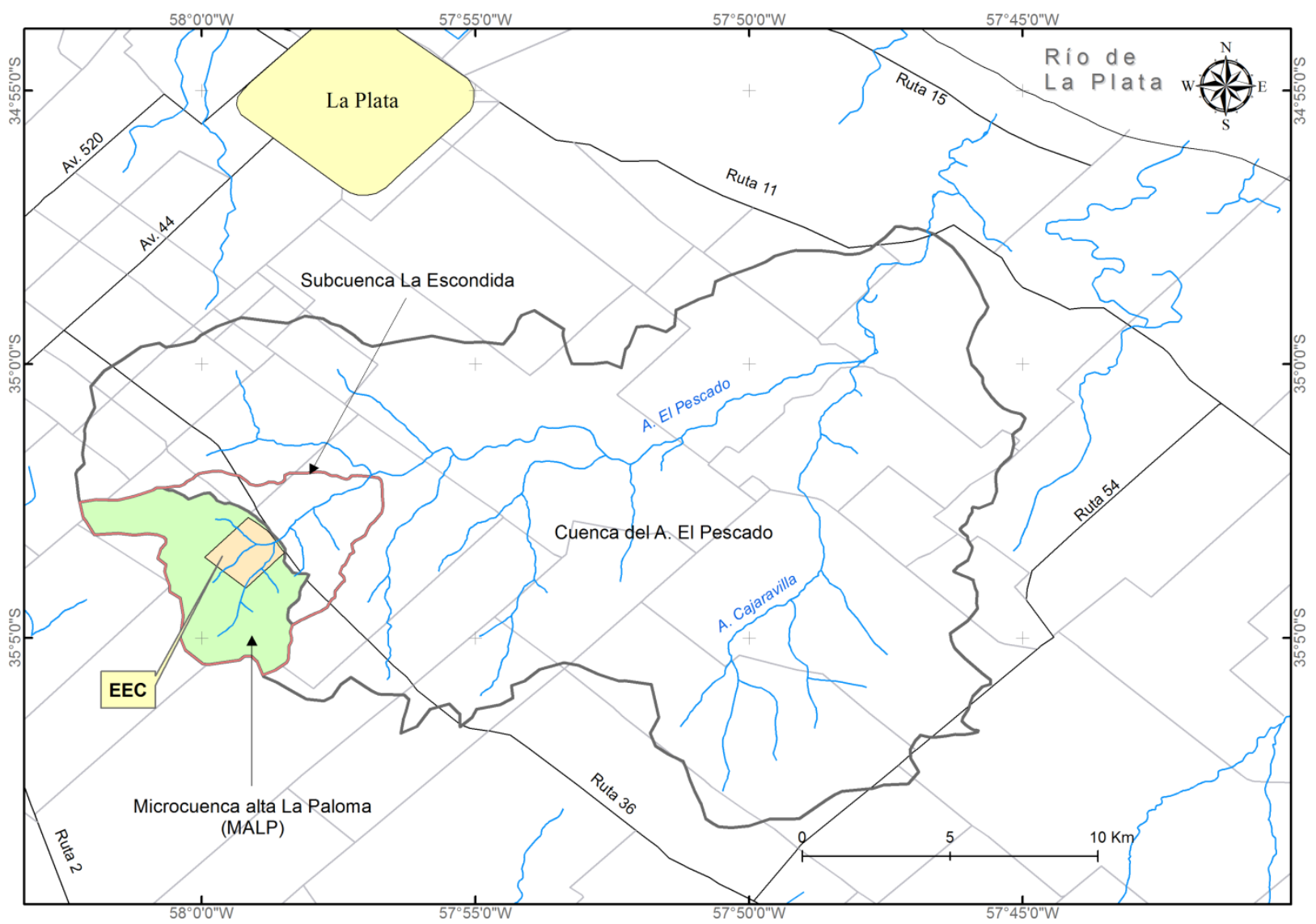

Figura III.1. Localización geográfica de la MALP.

En lo que respecta a la forma de la cuenca, puede indicarse que la misma posee un área $(A)$ de $21,41 \mathrm{~km}^{2}$, un Perímetro $(P)$ de $22,74 \mathrm{~km}$ y una Longitud axial $(\mathrm{La})=5,66 \mathrm{~km}$. Estas dimensiones, sumadas a un Factor de forma $(\mathrm{Ff})$ de 0,668 y un Índice de compacidad $(\mathrm{Kc})$ de 1,382, permitieron definir la influencia de la forma de la cuenca en el 
movimiento y captación del agua de lluvia. Estos resultados indican una concentración del escurrimiento característico de una cuenca oval-oblonga, con sus tributarios dispuestos radialmente y que desembocan en un punto central.

El relieve de la cuenca queda representado en parte por la Curva hipsométrica (Gráfico III.3) y la Curva hipsométrica relativa (Gráfico III.4). La primera de ellas permite establecer las áreas comprendidas entre distintas cotas, y puede leerse como que el 100\% de la cuenca se distribuye en cotas superiores a los 16 msnm; el 50\% sobre los 23 msnm, y el $5 \%$ sobre los 26 msnm. De esta, se deriva la Relación hipsométrica (Rh), cuyo valor $(0,67)$ es un indicador del estado de equilibrio dinámico de la cuenca con máximo en 1 . La Curva hipsométrica relativa, a su vez, permite comparar el relieve de la microcuenca con las curvas hipsométricas características del ciclo de erosión según Strahler (Gaspari et al., 2009). De esta comparación, se resuelve asignar al Arroyo La Paloma la fase de vida B o intermedia, indicativa de una cuenca en equilibrio o estado de madurez de la misma.

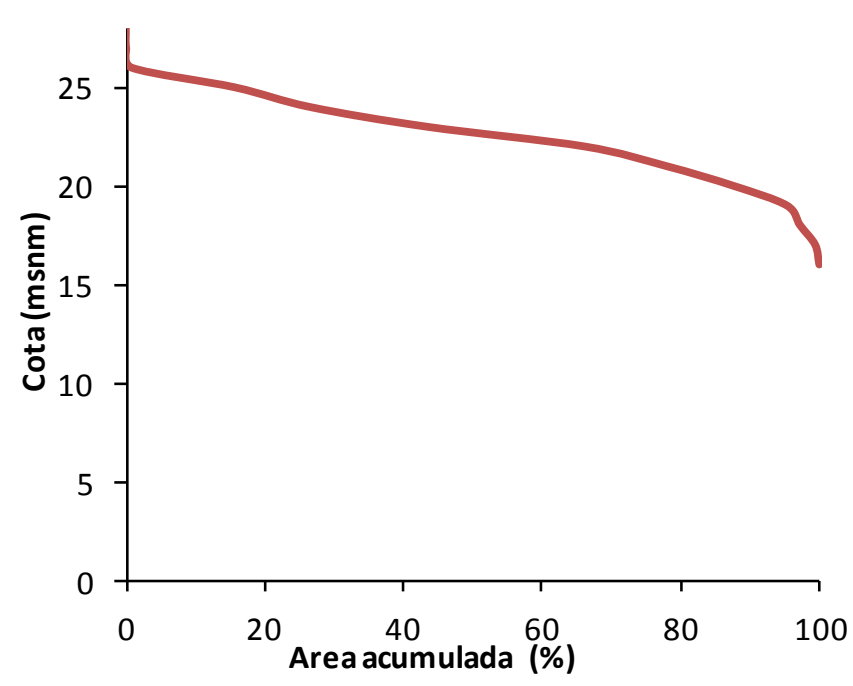

Gráfico III.3. Curva hipsométrica correspondiente a la MALP.

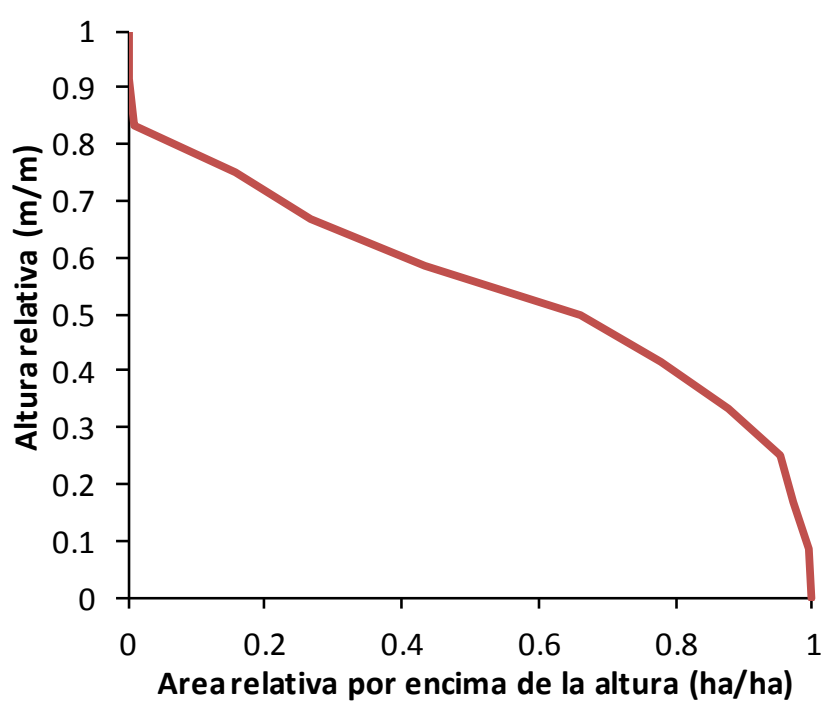

Gráfico III.4. Curva hipsométrica relativa correspondiente a la MALP.

Para completar los parámetros morfométricos relativos al relieve, se determinó la Altura media de la MALP $(\mathrm{Hm})$ de $21,55 \mathrm{~m}$ con orientación Noreste-Este y pendiente natural hacia el Río de La Plata. Ésta pendiente, corresponde a un 0,5\% de Pendiente media (PM), 
atribuible a un paisaje de tipo plano a muy plano según López Cadenas de Llano (1998), al cual se le suma un bajo Coeficiente de rugosidad (Ra) igual a 0,32.

En relación a los parámetros relativos a la red hidrográfica, la MALP exhibe una densidad de drenaje (Dd) media, igual a $0,68 \mathrm{~km}^{-1}$, con pendientes medias bajas $(\mathrm{J}=0,18 \%)$ y alto tiempo de concentración ( $\mathrm{Tc}=9,61 \mathrm{hs}$.). Esto determina caudales picos más atenuados y por lo tanto mayor tiempo de permanencia de agua en el campo (mayor tiempo de recesión). En la figura III.2, se define el orden de los cursos según la metodología de Horton.

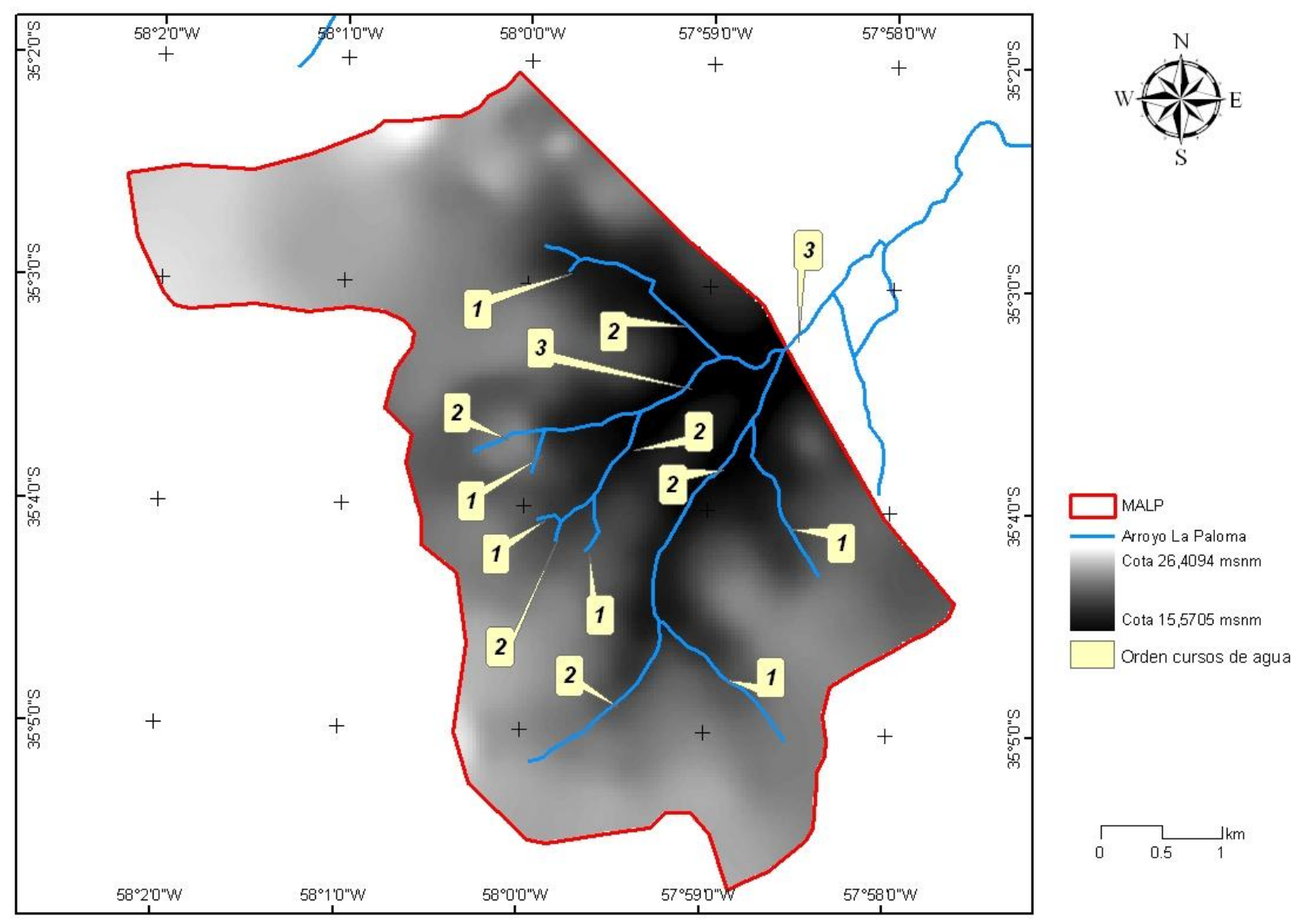

Figura III.2. Orden de los cursos de agua correspondiente a la Microcuenca Arroyo La Paloma según la metodología de Horton. De fondo se muestra el modelo de elevación del terreno (dem). 


\subsubsection{Morfometría del Predio Forestal Dolores (PFD)}

Las características del área de estudio y en particular su exigua pendiente, impiden la correcta definición de los límites de una cuenca convencional o típica. Estos ambientes conforman sistemas atípicos, donde los movimientos del agua son casi exclusivamente verticales y los limites de cuenca son difusos.

El comportamiento arreico de estas cuencas, donde las aguas se evaporan o infiltran en el terreno antes de encauzarse en una red de drenaje, condiciona su tradicional análisis. Por lo tanto, el estudio de las características morfológicas y funcionales a través de distintos parámetros de forma, relieve y red hidrográfica se vuelve inconsistente y solo posee importancia a nivel comparativo.

En la figura III.3 se muestra la delimitación de la Cuenca del Arroyo Langueyú, propuesta por la Subsecretaría de Recursos Hídricos de la Nación (SSRH) en el Atlas 2010 de Cuencas y Regiones Hídricas la República Argentina ( $\underline{\text { www.hidricosargentina.gov.ar) }}$. La misma, presenta una superficie de $10.073 \mathrm{~km}^{2}$ con bordes difusos y una pendiente general hacia el Noreste-Este que desemboca en la bahía Samborombón y encierra en su parte baja al PFD. La cuenca baja, a su vez, corresponde a la zona donde el Arroyo Langueyú se une con el Arroyo El Perdido y luego es canalizado hasta la Bahía de Samborombón por el Canal 1. Esta canalización atraviesa un terreno extremadamente llano donde prevalece un sistema de lagunas permanentes, transitorias y zonas anegadizas vinculadas por canales clandestinos, que no siempre siguen la dirección de los canales 1 y 9 , impiden notablemente la descarga de los excesos hídricos al mar, como también lo hacen las rutas 2 y 11, al actuar como verdaderos diques de contención. 


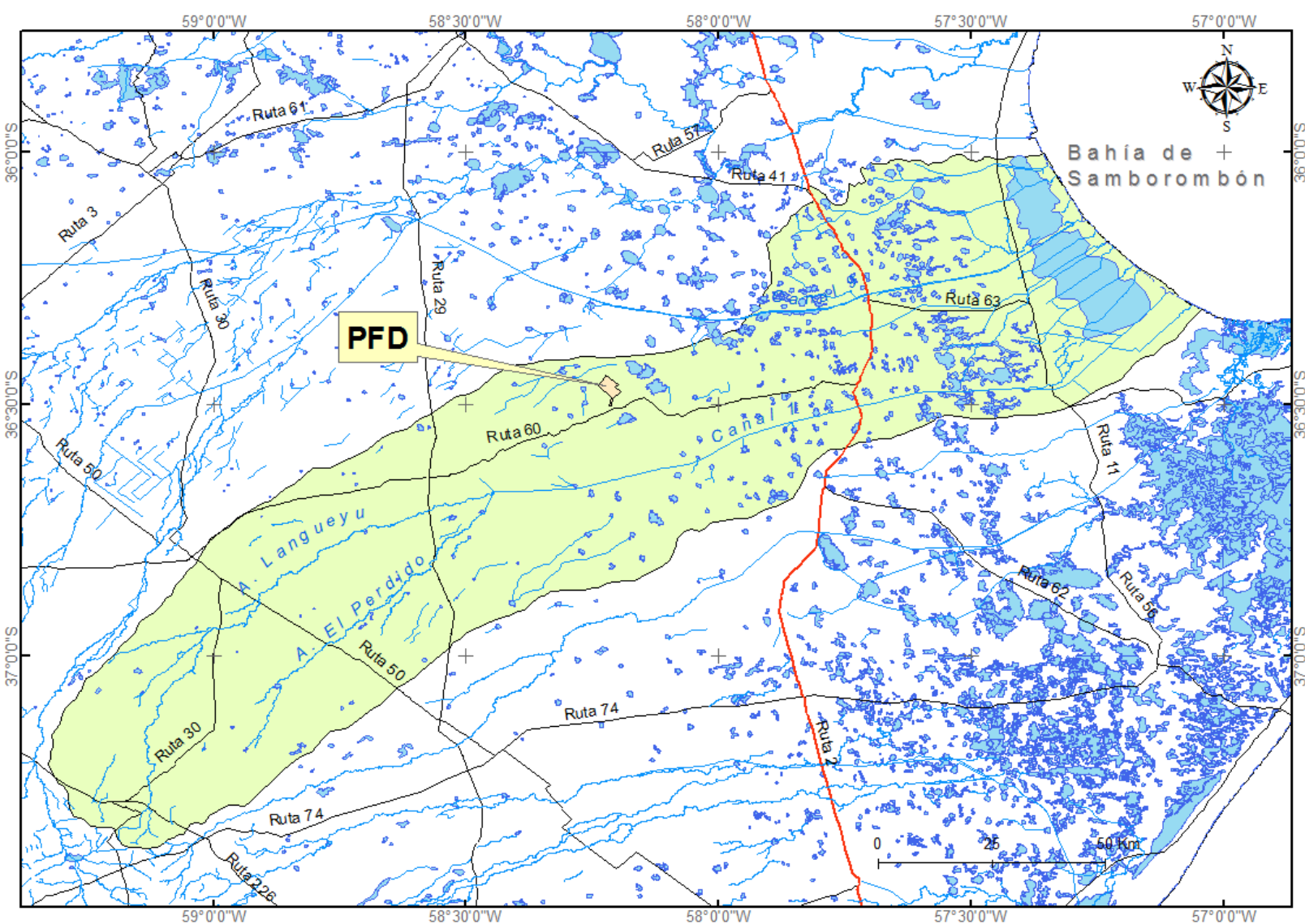

Figura III.3. Localización de la Cuenca del Arroyo Langueyú. Adaptado del Atlas 2010 de Cuencas y Regiones Hídricas la República Argentina.

A continuación se indican los parámetros de forma, relieve y de la red de drenaje de la cuenca que encierra al PFD y que, como fuera mencionado, deben ser tomados con cierta reserva al tratarse de un sistema no típico.

En lo referente a su forma, solo resta apuntar la magnitud de su perímetro $(P)$, igual a $573 \mathrm{~km}$, y los valores de longitud axial (La) y ancho promedio (Ap), de $223 \mathrm{~km}$ y $45,2 \mathrm{~km}$ respectivamente, puesto que la superficie (A) ya fue mencionada. Estos parámetros conforman una cuenca de tipo acintada o alargada y ancho más o menos constante, en correspondencia con el factor de forma (Ff) igual a 0,2 .

El relieve de la cuenca presenta una orientación Noreste-Este hacia la Bahía Samborombón, fácilmente observable en la figura III.3, y valores de altura media ( $\mathrm{Hm})$ y pendiente media (PM) iguales a $46,8 \mathrm{~m}$ y al $0,25 \%$ respectivamente. Estos valores permiten suponer que las altas pendientes, concentradas en la cabecera de la cuenca, no llegan a ser representativas en este análisis ya que la pendiente media de la cuenca la define como 
una cuenca muy plana (López Cadenas de Llano, 1998), con pendiente natural hacia el mar. La relación hipsométrica da cuenta de una cuenca que se encuentra lejana al equilibrio morfológico $(\mathrm{Rh}=1)$, por lo que resulta necesario complementar estos parámetros con la curva hipsométrica (Gráfico III.5) e hipsométrica relativa (Gráfico III.6) para un mejor entendimiento de su relieve.

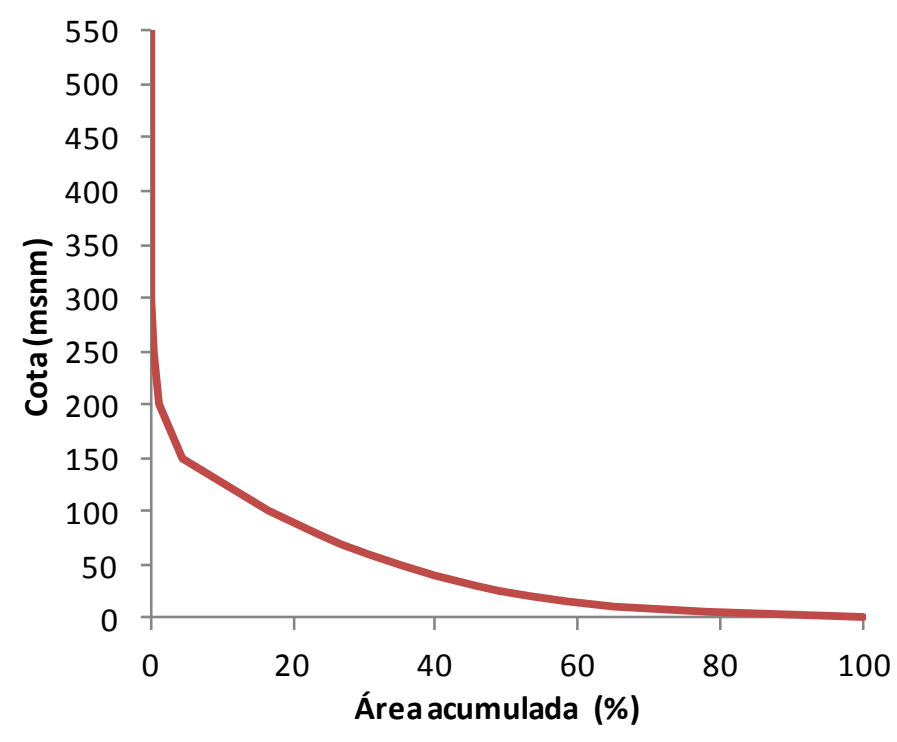

Gráfico III.5. Curva hipsométrica correspondiente a la Cuenca Langueyú.

La forma particular de estas curvas se debe a que la cuenca del Arroyo Langueyú desemboca hacia el mar en la cota cero. La lectura de la curva hipsométrica permite establecer que menos del $20 \%$ de la superficie de la cuenca se desarrolla en cotas superiores a los $100 \mathrm{msnm}$ (zona de cabecera con pendientes elevadas) y solo el $44 \%$ de la cuenca se desarrolla sobre los $30 \mathrm{~m}$ de cota. Esto determina que el resto de la cuenca mantenga un desnivel cercano al $0,003 \%$, coincidente con la parte baja de la misma (zona canalizada). A su vez, la relación hipsométrica (Rh) que deriva de esta curva, arroja un valor de 0,1 y por tanto un elevado estado de fragilidad o desequilibrio de la misma. 


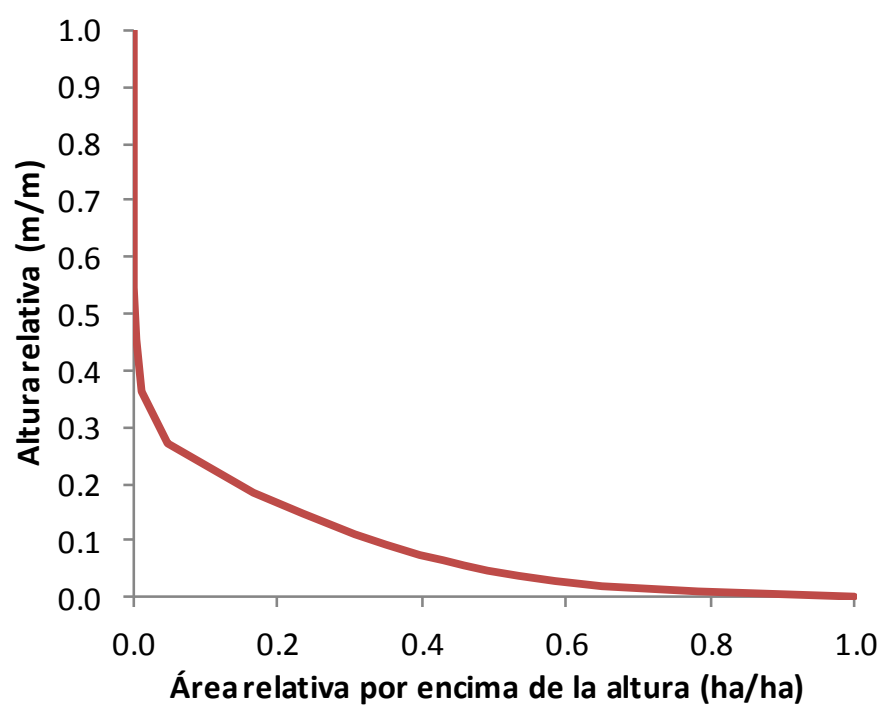

Gráfico III.6. Curva hipsométrica relativa correspondiente a la Cuenca Langueyú.

El análisis de la curva hipsométrica relativa, muestra que la Cuenca del Arroyo Langueyú se asocia con una cuenca en fase de vejez, típicamente sedimentaria.

Con respecto a los parámetros relativos a la red de drenaje, en los que se consideran las canalizaciones, puede establecerse una densidad de drenaje muy reducida $\left(\mathrm{Dd}=0,0004 \mathrm{~km}^{-1}\right)$, al igual que la pendiente media del cauce, con valores de $\mathrm{J}=0,12 \%$. Esto último explica el tiempo de concentración calculado ( $\mathrm{Tc}=191 \mathrm{hs})$, característico de ambientes donde las aguas permanecen en superficie grandes períodos hasta que infiltran o evaporan. Esta situación se agrava por las dunas existentes en la bahía Samborombón que dificultan aún más el desagüe de los excesos hídricos.

\subsubsection{Escurrimiento superficial}

El cálculo de escurrimiento superficial (R), por medio del modelo hidrológico L-THIA, precisó la confección de los mapas de usos del suelo y de grupos hidrológicos, trabajados en formato vectorial y georreferenciados en coordenadas planas (Posgar 1998, faja 5). A estos, se sumó la elaboración de dos tipos de archivos: uno de lluvias diarias para las series anuales disponibles y el otro, correspondiente a la base de datos del modelo, con NC adaptados a las zonas de estudio. 
Al analizar la situación edáfica (apartado 4.2.1) para la obtención de los mapas de Grupos Hidrológicos (Figura III.4), se vislumbra una situación hidrológica comprometida para la actividad agrícola ganadera. Esto se verifica por el deficiente escurrimiento y la disminuida capacidad de infiltración que presentan los suelos, debido a la presencia de alcalinidad sódica, horizontes Bt sódicos a menos de $50 \mathrm{~cm}$ de profundidad y un paisaje de escasas pendientes que facilita situaciones de anegamientos prolongados (INTA, 1989, 2010, 2011). Esta situación se encuentra agravada en el PFD, donde el paisaje posee pendientes inferiores al 0,1\% (Vázquez, 2003), mientras que en la EEC no superan el 1\% (Laurencena et al., 2002). La cubeta de deflación en la que se halla el PFD (Movia y Burkart, 1976), define un paisaje en extremo plano, sin una dirección de flujo evidente, y donde los problemas de anegamiento por impermeabilización del suelo son intensificados, donde prevalece un ambiente típicamente lacunar.
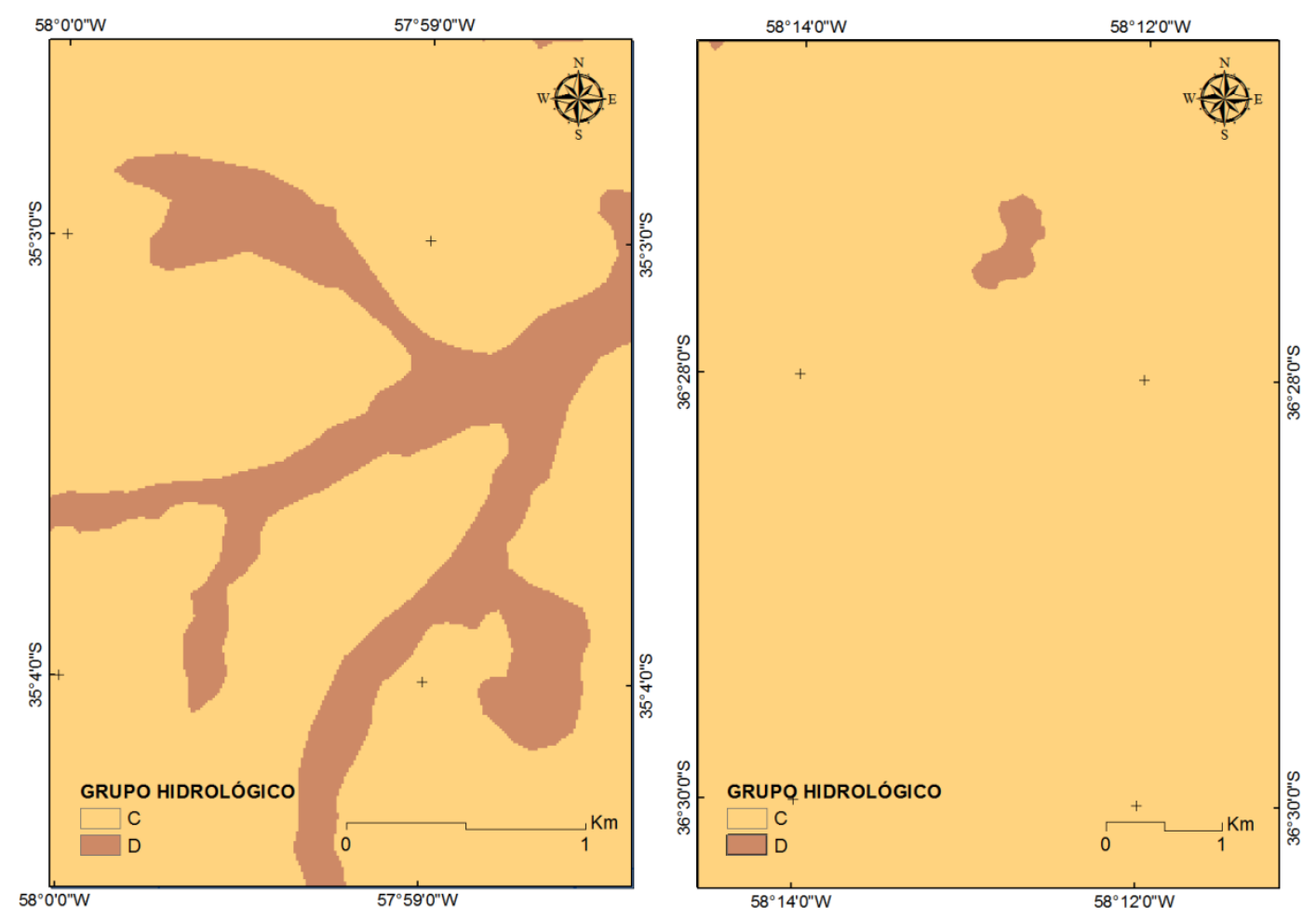

Figura III.4. Mapas de Grupo Hidrológico adaptados al modelo L-THIA, correspondientes a la EEC (izquierda) y PFD (derecha).

En relación a los mapas de uso del suelo (Figura III.5), es posible distinguir que la EEC se ubica a la salida de la Microcuenca del Arroyo La Paloma y que las plantaciones 
están concentradas donde se perciben los mayores problemas de impermeabilidad del suelo (coincidente con el Grupo Hidrológico D). Esta disposición responde a un esfuerzo de reducir los excesos hídricos y permitir que la actividad agrícola cubra la mayor cantidad de superficie sobre zonas de baja productividad, ocupadas por pastizal natural modificado. Esto no ocurre en el PFD, donde la actividad forestal es la predominante y solo queda sin forestar los lugares que se encuentran anegados gran parte del año y admiten únicamente el desarrollo de pastizal natural.
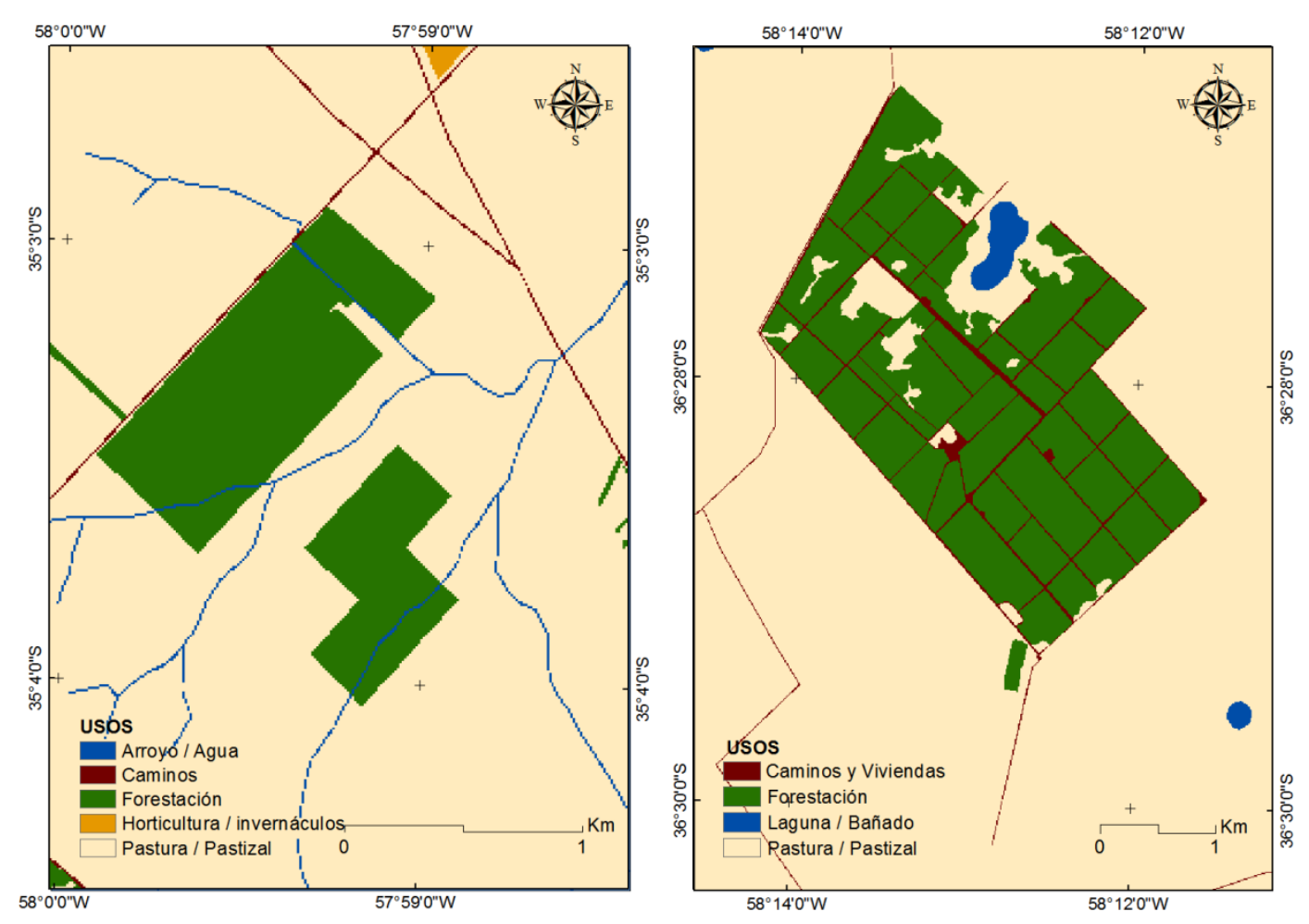

Figura III.5. Mapas base de usos del suelo para las áreas de estudio, correspondientes a la EEC (izquierda) y PFD (derecha).

En la figura III.6 se presenta el producto obtenido del modelo L-THIA. Se expresan los números de curva resultantes del cruce de los mapas base (Figura III.4 y III.5) y las láminas medias anuales de escurrimiento superficial, que devienen de la interacción entre estos valores y las series de precipitación computadas para cada sitio. 

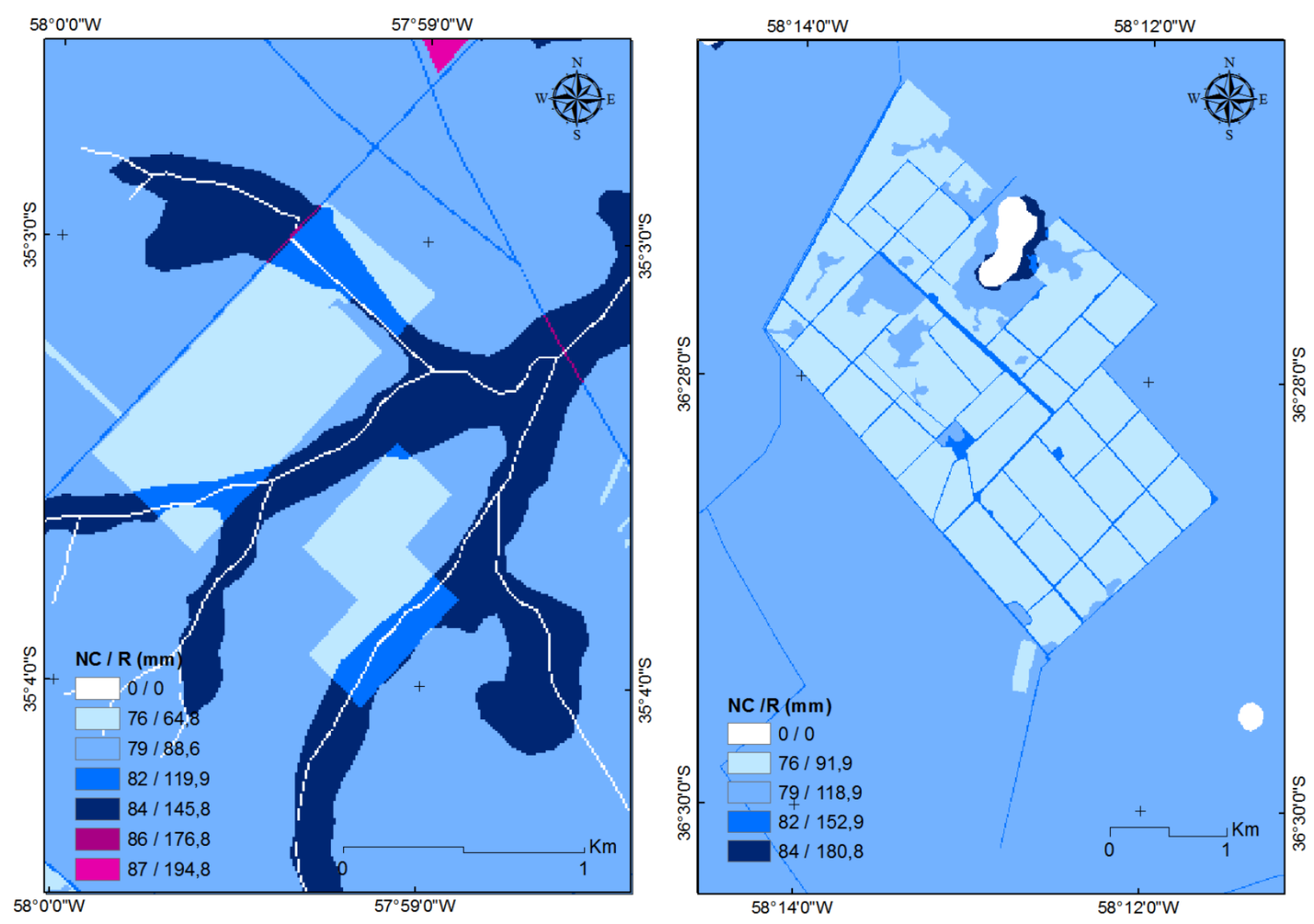

Figura III.6. Mapa de NC y precipitación efectiva o escurrimiento superficial en $\mathrm{mm}(\mathrm{R})$, obtenido por procesamiento automático con L-THIA, de la base de datos vectorial y lluvias diarias, correspondientes a la EEC (izquierda) y PFD (derecha).

La interacción entre los distintos usos del suelo y las características edáficas queda reflejada en la magnitud de los números de curva, muy variables para las situaciones que se contemplan (de 76 a 84). Estos valores de NC representan escurrimientos superficiales que varían de 64,8 a 145,8mm en EEC y de 91,9 a 180,8mm anuales en PFD, para una precipitación promedio anual de 922,5mm en EEC y de 976,6mm en PFD. Los valores 0, se corresponden con áreas tomadas como "sin dato", equivalentes a lagunas y cauces.

En la tabla III.4 se muestran los porcentajes de ocupación de los valores de NC y escurrimiento superficial $(\mathrm{R})$ para cada uno de los predios. Además, se incluye la precipitación promedio anual de los tres años de muestreo (P) junto con el valor de escurrimiento ponderado anual correspondiente a la situación real de cada predio $\left(\mathrm{R}_{\mathrm{a}}\right)$, para el período considerado en cada caso. 
Tabla III.4. Porcentajes de ocupación de los valores de NC y escurrimiento superficial en los sitios de estudio.

\begin{tabular}{cccccc}
\hline Predio & $\mathrm{NC}$ & Ocupación $(\%)$ & $\mathrm{R}(\mathrm{mm})$ & $\mathrm{P}(\mathrm{mm})$ & $\mathrm{R}_{\mathrm{a}}(\mathrm{mm})$ \\
\hline \multirow{4}{*}{ EEC } & 0 & 1,8 & 0 & & \\
& 76 & 34,7 & 64,8 & & 94,2 \\
& 79 & 32,3 & 88,6 & 922,5 & \\
& 82 & 9,1 & 119,9 & & \\
\multirow{4}{*}{ PFD } & 84 & 22,1 & 145,8 & & 98,9 \\
& 76 & 2,1 & 0 & & \\
& 79 & 75,4 & 91,9 & & \\
& 82 & 15,0 & 118,9 & 976,6 & \\
\hline
\end{tabular}

Donde: NC es el número de curva; R la lámina de escurrimiento superficial anual por complejo suelo-vegetación; P la precipitación promedio anual para las series consideradas, y $R_{a}$ es la lámina ponderada de escurrimiento superficial anual actual (con forestaciones).

La lámina de escurrimiento anual ponderado obtenida para ambos predios, representa un 10,1 y 10,2\% de la precipitación media anual registrada en EEC y PFD respectivamente. Se estima que el valor de escurrimiento anual bajo las forestaciones es de $76,3 \mathrm{~mm}$ para EEC y $92,0 \mathrm{~mm}$ para PFD. A su vez, varía entre 64,8 y $119,9 \mathrm{~mm}$ para la EEC y entre 91,9 y $152,9 \mathrm{~mm}$ para el PFD, que equivale a un $\mathrm{R}=7,0-13,0 \%$ de la precipitación media anual en EEC y 9,5-15,8\% en el PFD. El pastizal en cambio, arroja valores de escurrimiento superficial anual de $111,8 \mathrm{~mm}$ para EEC y de $122,4 \mathrm{~mm}$ para PFD.

La conversión de pastizal por forestaciones representa una disminución en el escurrimiento superficial del 17,8 al $26,9 \%$ en EEC, mientras que en PFD, estos valores alcanzan reducciones del 15,4 al $22,7 \%$. 


\subsection{DISCUSIÓN}

Los valores de escurrimiento obtenidos por esta metodología son superiores a los publicados por Sallies (1999) y Auge (2005) para la llanura pampeana (5-6\%), especialmente en PFD, donde se evidencia una menor pendiente topográfica que supone valores aun más bajos que en EEC. Una posible explicación se hallaría en que el modelo del Número de Curva, a pesar de estar ajustado para esta zona y ser ampliamente utilizado, requiere de calibraciones que no han sido realizadas y por tanto puede resultar en sobreestimaciones. En este sentido, es importante recordar que los tres años analizados presentaron una pluviometría atípica con un período muy seco en 2008 y uno muy lluvioso a fines de 2009 y principios de 2010. Esto dificulta mucho las comparaciones con otras investigaciones ya que no es posible discernir hasta qué punto tienen influencia las condiciones climáticas particulares y las debidas a la falta de calibración del modelo.

A pesar de esto, es posible apreciar en los resultados alcanzados, una importante reducción del escurrimiento superficial anual en la conversión de pastizales por forestaciones, cercanas a las documentadas por Farley et al. (2005) a nivel global y Mathur et al. (1976) para microcuencas forestadas con E. grandis y E. camaldulensis en el norte de la India. No obstante, esta metodología no permite discriminar entre los valores de escurrimiento bajo las distintas especies forestales ya que no existen valores de Número de Curva ajustados para dichas condiciones.

En el caso de EEC, se encuentra una capa superficial de hojas y ramas que recubre el suelo bajo la forestación de pino, que genera reducciones del escurrimiento y podría llegar a anular este componente, en coincidencia con lo mencionado por Wooldridge (1970). Esta situación, se presenta también en las forestaciones de eucalipto aunque no de forma tan homogénea. Sin embargo, las reducciones máximas del escurrimiento obtenidas para la conversión de pastizales por forestaciones no superaron los $25,9 \mathrm{~mm}$ del escurrimiento superficial anual en EEC y los $27,9 \mathrm{~mm}$ en PFD. En suma, las reducciones del escurrimiento superficial, calculadas en la conversión de pastizales por plantaciones forestales de rápido crecimiento en los sitios de estudio, fueron insuficientes para anular este componente. Estos productos hacen imposible aceptar la hipótesis de que las forestaciones anulan el componente de escurrimiento superficial, pero permiten identificar una clara reducción del mismo. 
Pese a las dudas que pueden existir a la hora de optar por la utilización de esta metodología, resulta indiscutible su practicidad como primera aproximación en el estudio del escurrimiento superficial y se constituye en una poderosa herramienta para la modelización de situaciones hipotéticas. Por ejemplo: si se quiere saber el efecto de reemplazar las superficies forestadas por la actividad dominante (pastura-pastizal), se podrían diferenciar incrementos del escurrimiento superficial a nivel predial. Esto se logra al contrastar la situación actual (parcialmente forestado) con una hipotética (sin forestaciones). Estos incrementos en el escurrimiento superficial anual, por el reemplazo de la forestación a nivel predial, alcanzarían valores absolutos de $+10,6 \mathrm{~mm}$ en la EEC y $+20,3 \mathrm{~mm}$ en el PFD (Tabla III.5).

Tabla III.5. Porcentajes de ocupación de los valores de NC y escurrimiento superficial en los sitios de estudio, para una situación hipotética donde las forestaciones son reemplazadas por la actividad predominante en la zona.

\begin{tabular}{cccccc}
\hline Predio & $\mathrm{NC}$ & Ocupación $(\%)$ & $\mathrm{R}(\mathrm{mm})$ & $\mathrm{P}(\mathrm{mm})$ & $\mathrm{R}_{\mathrm{h} 1}(\mathrm{~mm})$ \\
\hline \multirow{3}{*}{ EEC } & 0 & 1,8 & 0 & & \\
& 79 & 67,0 & 88,6 & 922,5 & 104,8 \\
& 84 & 31,2 & 145,8 & & \\
\multirow{2}{*}{ PFD } & 0 & 2,1 & 0 & & 119,2 \\
& 79 & 90,3 & 118,9 & 976,6 & \\
& 82 & 6,7 & 152,9 & & \\
\hline
\end{tabular}

Donde: $\mathrm{R}_{\mathrm{h} 1}$ es la lámina de escurrimiento ponderada para una situación sin forestaciones, donde predomina el uso catalogado como "Pastura, pastizal o cultivo de forrajeras continuo para ganado".

Si ahora se buscara indagar sobre el efecto de reemplazar las pasturas por forestaciones, el contraste de la situación actual (parcialmente forestado) por la hipotética (totalmente forestado) resultaría en una reducción en el escurrimiento superficial anual de $24,85 \pm 1,05 \mathrm{~mm}$ para la EEC y de $27,45 \pm 0,45 \mathrm{~mm}$ para el PFD. Este efecto se muestra en la Tabla III.6, donde las reducciones absolutas de escurrimiento a nivel predial, adoptan valores de $-13,4 \mathrm{~mm}$ en EEC y $-4,0 \mathrm{~mm}$ en PFD. 
Tabla III.6. Porcentajes de ocupación de los valores de NC y escurrimiento superficial en los sitios de estudio, para una situación hipotética donde los pastizales son reemplazados por forestaciones de rápido crecimiento.

\begin{tabular}{cccccc}
\hline Predio & $\mathrm{NC}$ & Ocupación $(\%)$ & $\mathrm{R}(\mathrm{mm})$ & $\mathrm{P}(\mathrm{mm})$ & $\mathrm{R}_{\mathrm{h} 2}(\mathrm{~mm})$ \\
\hline \multirow{3}{*}{ EEC } & 0 & 1,8 & 0 & & \\
& 76 & 67,0 & 64,8 & 922,5 & 80,8 \\
& 82 & 31,2 & 119,9 & & \\
\multirow{3}{*}{ PFD } & 0 & 2,1 & 0 & & 94,9 \\
& 76 & 90,3 & 91,9 & 976,6 & \\
& 82 & 6,7 & 152,9 & & \\
\hline
\end{tabular}

Donde: $\mathrm{R}_{\mathrm{h} 2}$ es la lámina de escurrimiento ponderada para una situación de ocupación completa con forestaciones.

De estas simulaciones se desprende que la instalación de forestaciones de rápido crecimiento en pastizales sin especies arbóreas, generaría reducciones de 20 a $23 \%$ a nivel predial. Esto se encuentra en línea con lo modelado para los 3 años de estudio y constituye una herramienta de diagnóstico rápida del efecto de las forestaciones en el escurrimiento superficial, que facilita la construcción de posibles escenarios de uso del suelo y su efecto sobre el componente de escurrimiento superficial. La magnitud de los resultados alcanzados refuerza la necesidad de realizar calibraciones sobre esta metodología a fin de obtener valores específicos de NC para cada especie y situación estudiada. 


\section{Capítulo 4}

\section{Infiltración y aguas}

\section{subterráneas}




\subsection{INTRODUCCIÓN}

\subsubsection{Infiltración y recarga freática}

Como ya fue indicado en el apartado 1.3, en los suelos de la llanura Chacopampeana se reconocen excesos hídricos de 0 a $250 \mathrm{~mm} /$ año, concentrados en el período otoño-invernal (Auge et al., 2006), y el predominio de los movimientos verticales del agua (evapotranspiración-infiltración) frente a los horizontales (escurrimiento) (Laurencena et al., 2005; Vázquez et al., 2011). De esta manera, pese a que en la mayor parte de estas tierras predominan suelos de granulometría fina (limo y arcilla), la infiltración (10 a 15\% de la lluvia), supera a la escorrentía (5 a 10\% de la lluvia), debido a la escasísima pendiente topográfica (cm a m/km) (Auge, 2005).

La infiltración (f) puede considerarse entonces como un componente de significativa importancia en la dinámica hídrica de sistemas llanos, y, aunque este término posee muchas acepciones, previamente definidas pueden ser tomadas como ciertas por las distintas disciplinas e investigadores. Por lo tanto, resulta necesario diferenciar a la infiltración del concepto hidrogeológico de infiltración eficaz $\left(\mathrm{f}_{\mathrm{ss}}\right)$, que es el que comúnmente se adopta para el estudio de la recarga/descarga de aguas subterráneas (Nuñez et al., 2007; Aragón et al., 2011).

Mientras que la infiltración responde al proceso por el cual el agua pasa de la superficie al subsuelo (SSSA, 2001), la infiltración eficaz o efectiva constituye el agua infiltrada que, superada la zona de aireación del suelo, alcanza la superficie freática (Auge, 2005) y es considerada como la única fuente de recarga del acuífero freático (Laurencena et al., 2002).

Por otro lado, es preciso identificar a la infiltración instantánea real ${ }^{12}$ (f) como la expresión del agua que penetra en el suelo por unidad de superficie y que, cuando el suelo se encuentra encharcado, pasa a llamarse infiltración potencial o capacidad de infiltración ${ }^{13}$ $\left(f_{p}\right)$. Los valores acumulados de ambas expresiones (Infiltración acumulada real e

${ }^{12}$ Infiltración instantánea real (f). Se define como el flujo de agua que entra en el suelo por unidad de superficie. Es por tanto el valor que $q$, flujo en medio poroso, alcanza en la superficie del suelo $(f=q)$ y sus dimensiones son de velocidad $\left[\mathrm{LT}^{-1}\right]$. La Infiltración acumulada real (F) tiene unidades de longitud $[\mathrm{L}]$. (Muñoz y Ritter, 2005)

${ }_{3}$ Infiltración potencial o capacidad de infiltración (fp). Velocidad de infiltración que se produce cuando el suelo esta encharcado con una lámina de agua pequeña en superficie $\left[\mathrm{LT}^{-1}\right]$. La Infiltración acumulada bajo encharcamiento (Fp) tiene unidades de longitud [L]. (Muñoz y Ritter, 2005) 
infiltración acumulada bajo encharcamiento), tienen unidades de longitud (Muñoz y Ritter, 2005).

En el gráfico IV.1 se observa el comportamiento general de la infiltración en el tiempo. En la situación inicial (acumulación de agua superficial por comienzo de una precipitación), el gradiente hidráulico ${ }^{14}$ en las capas superficiales es muy grande y como consecuencia, la velocidad de infiltración máxima. A medida que el agua penetra en el perfil, el gradiente hidráulico disminuye hasta hacerse constante e igual, en teoría, al de conductividad hidráulica ${ }^{15}(\mathrm{k})$ en suelo saturado.

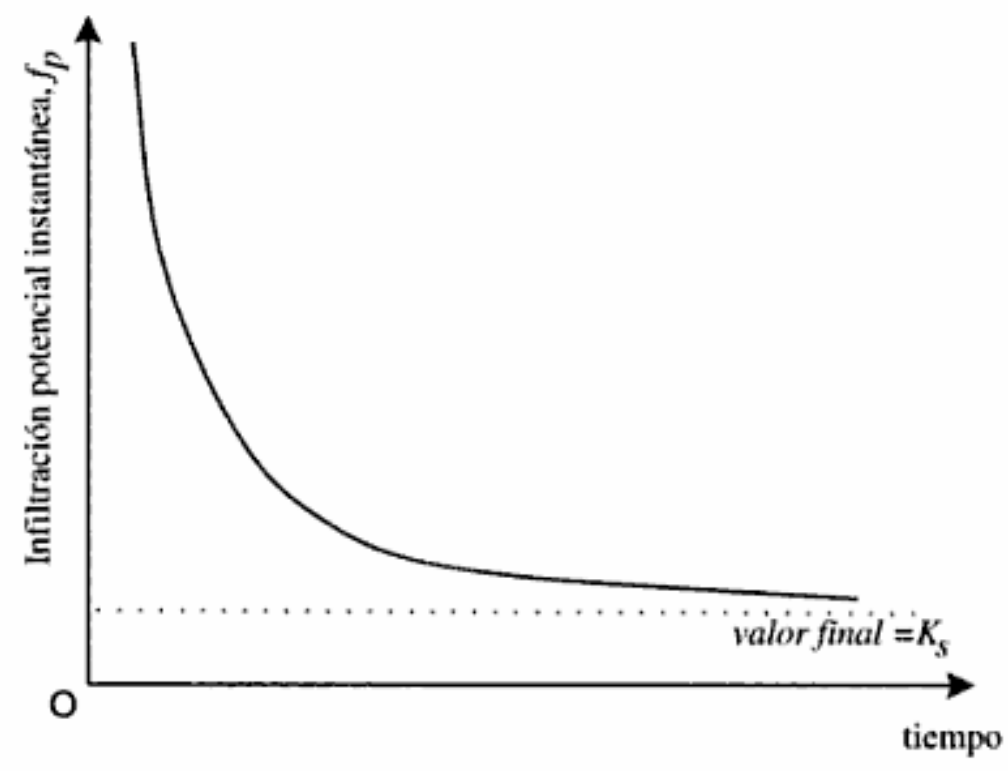

Gráfico IV.1. Curva de infiltración potencial instantánea en un suelo encharcado. Fuente: Muñoz y Ritter (2005).

Mijares (1994) indica que los factores que condicionan la capacidad de infiltración son numerosos y expone una lista de los que más se destacan en este sentido: textura del suelo, contenido de humedad inicial, contenido de humedad de saturación, cobertura vegetal, usos del suelo, aire atrapado en el suelo, lavado del material fino, compactación,

\footnotetext{
${ }^{14}$ Magnitud vectorial determinada por el incremento de potencial de agua por unidad de distancia. Es igual a la pendiente de la superficie piezométrica entre dos puntos de un acuífero.

${ }_{15}$ Concepto común que indica la facilidad que un cuerpo ofrece a ser atravesado por un fluido (Permeabilidad). En hidrogeología, la permeabilidad o conductividad hidráulica es la constante de proporcionalidad lineal entre el caudal y el gradiente hidráulico (Sánchez, 2012)
} 
temperatura, sus cambios y diferencias. Por su parte, Linsley et al. (1993), consignan que de aquellas características del suelo que afectan a la infiltración, la porosidad ${ }^{16}$ es posiblemente la más importante, ya que determina la capacidad de almacenamiento y también afecta la resistencia al flujo. De esta manera, a mayor porosidad corresponde un aumento de la infiltración. A la vez, argumenta que el aumento en el contenido de materia orgánica también tiende a aumentar la capacidad de infiltración, debido en gran parte al aumento de la porosidad.

Es importante recordar que los suelos de las áreas de estudio están afectados por inundaciones periódicas, acompañadas con problemas de salinidad-sodicidad. Estas características, propias de los sistemas llanos, hacen que la calidad de los excesos de agua sean los que dictan las características del proceso de salinización.

En la pampa deprimida, se reconoce que aproximadamente el $90 \%$ de los problemas de salinidad y sodicidad en los suelos se asocian con ascensos de agua subterránea, cuya carga de sales es superior al agua superficial (Nuñez et al., 2007). De todas maneras, cualquiera sea el contenido de sales en el agua, la escasa energía potencial del terreno y el predominio de las pérdidas evapotranspirativas del sistema, condicionan procesos de salinización. Esto genera distintos problemas: toxicidad y estrés hídrico por falta de agua (salinidad), o pérdida de estabilidad e impermeabilización de los suelos.

La modificación del ciclo hidrológico y la captación de estos flujos salinos mediante estrategias de bio-drenaje ${ }^{17}$, cambian el valor relativo de las tierras (Isidoro, 2011) y son reconocidas como una buena alternativa de aplicación tanto en la provincia de Buenos Aires como en muchas partes del mundo (Alconada et al., 2009).

${ }^{16}$ Variable adimensional que expresa el volumen de huecos (poros) sobre el volumen total de un material poroso (porosidad total), o bien, el volumen de agua drenada por gravedad (poros vaciados) sobre el volumen total del material poroso (porosidad eficaz). La diferencia entre estos dos parámetros es la retención específica (Sánchez, 2012)

${ }^{17}$ técnica que utiliza la vegetación para manejar el flujo de agua subterránea en un paisaje, mediante la evapotranspiración, con buen resultado en diversos países para el control de: inundación, salinización del suelo y elevación de la superficie freática (Alconada et al., 2009). 


\subsubsection{Métodos de estimación}

El cómputo de la infiltración representa un paso fundamental para el estudio de la dinámica del agua en el ciclo hidrológico de tierras llanas. Laurencena et al. (2002), reconoce su importancia y señala además, que resulta un elemento básico para la evaluación de la recarga y consecuentemente de las reservas de aguas subterráneas.

Los instrumentos utilizados para medir el volumen o flujo de agua que ingresa al suelo se denominan infiltrómetros y se los puede hallar de distintos tipos según sean de tensión, aspersión, surcos, de alturas variables o de anillo.

Otra posibilidad para la descripción del proceso de infiltración es la utilización de modelos empíricos (Tabla IV.1). El modelo de Green y Ampt es posiblemente uno de los más utilizados

Tabla IV.1. Algunos modelos empíricos para la determinación de la infiltración. Adaptado de Martín de Santa Olalla et al. (2005).

\begin{tabular}{|c|c|}
\hline Modelo & Autores \\
\hline$i=i_{c}+\frac{b}{I}$ & Green y Ampt, 1911 \\
\hline$i=B t^{-n}$ & Kostiakov, 1932 \\
\hline$i=i_{c}+\left(i_{0}-i_{c}\right) e^{-k t}$ & Horton, 1933 \\
\hline$i=i_{c}+\frac{S}{2 \sqrt{t}}$ & Philip, 1957 \\
\hline$i=i_{c}+a(M-I)^{n}$ & Holtan, 1961 \\
\hline
\end{tabular}

Donde: $\mathrm{i}$ = infiltración; I = infiltración acumulada; ic = flujo de infiltración que se alcanza en un período de tiempo largo o conductividad hidráulica y b, B, n, S, a, M y k = constantes.

Por su parte, Kelliher et al., (1993) señala la posibilidad de estimar la capacidad de almacenamiento de agua en cada capa del suelo a partir del conocimiento de su textura y contenido de piedra. A este respecto, Damiano y Taboada (2000) indican que los cultivos agrícolas dependen no solo de los aportes de agua de lluvia y riego, sino también de la capacidad de agua disponible en los suelos (retención de humedad entre los potenciales $33 \mathrm{kPa}$ y $-1500 \mathrm{kPa}$ ). Su determinación a campo y laboratorio, sin embargo, es costosa y demanda gran número de muestras, por lo que estos autores manifiestan la conveniencia de su estimación mediante funciones de pedotransferencia. 
Un ejemplo de estas funciones, con resultados satisfactorios en la pampa húmeda (Landini et al., 2007), es el programa "Soil Water Characteristics" de Saxton y Rawls (2006), cuyo manejo es sumamente sencillo y solo precisa datos de textura, contenido de materia orgánica, salinidad y grado de compactación para obtener las relaciones del contenido hídrico y tensión (punto de marchitez, capacidad de campo y saturación) y conductividad hidráulica saturada y no saturada.

Con respecto al cálculo de la infiltración, tomada desde una visión geomorfológica (infiltración efectiva o eficaz), puede considerarse que toda fracción de la precipitación que produce un aumento o un descenso de la capa freática es considerada como infiltración (Nuñez et al., 2007). Esto queda representado mediante una ecuación básica de balance hidrológico utilizada por Risiga para la pampa bonaerense. Aquí, la infiltración del agua de lluvia es considerada como la principal fuente de recarga del acuífero y la evapotranspiración, es el elemento predominante en lo que a salidas de agua del acuífero se refiere $(\mathrm{I}=\mathrm{P}-\mathrm{ETP})$.

Este autor, menciona que en la pampa bonaerense no existen datos de lisímetros que permitan hacer una comparación entre las diferencias de precipitaciónevapotranspiración potencial y los valores reales de infiltración. Esto hace que todo ascenso de la capa freática sea tomado como infiltración eficaz y los descensos como infiltración "negativa" (Nuñez et al., 2007). Esta última acepción, sin embargo, no es más que el proceso de descarga del acuífero, producto de que las entradas de agua al sistema son inferiores a las salidas. Por lo tanto, debe entenderse que la denominación "Infiltración negativa" está representada principalmente por los procesos de evapotranspiración y el ascenso capilar sobre la zona no saturada del suelo.

\subsubsection{Aguas subterráneas y las forestaciones}

La llanura pampeana exhibe una dinámica hídrica circunscripta a un estricto control ambiental que, sumado a la fisonomía del paisaje, conforman un ambiente de suma fragilidad ante cualquier cambio de uso. La sucesión de períodos de sequías e inundaciones, salinización y ascensos de napas, responden a procesos naturales de estos ambientes, muchas veces acelerados por malas prácticas productivas. En este escenario, cualquier cambio de uso tendrá un impacto de mayor o menor intensidad que, en el caso 
de la sustitución de pastos por forestaciones, estarán vinculados a un mayor consumo de agua por parte de las forestaciones y a su capacidad de acceder a fuentes de agua más profundas.

En un estudio de la FAO sobre los efectos ecológicos de los eucaliptos (Poore y Fries, 1987), se menciona que cualquier tipo de vegetación arbórea transpira con rapidez cuando sus raíces permanecen en contacto continuo con la capa freática y en consecuencia utilizan grandes cantidades de humedad. Además, indican como evidente, que bajo iguales circunstancias, una parcela de suelo desnudo aportará cantidades de agua al suelo y subsuelo significativamente más importantes que una parcela cubierta con Eucalyptus.

Por su parte, Kelliher et al. (1993) realizaron una revisión bibliográfica que concluyó que las raíces de coníferas en pastizales de Norte América se hallaban predominantemente en los primeros $3 \mathrm{~m}$ de profundidad (Sims et al. 1978), mientras que otros estudios observaron profundidades de 5m (Whitehead y Jarvis, 1981; Schulze et al., 1987; Whitehead et al., 1993) y 6m (Eastham et al., 1988). Además, explicaron que el 40\% del agua absorbida por raíces proviene del $20 \%$ más superficial de la zona radicular, mientras que el 33, 20 y 7\% restante proviene de raíces más profundas. Estas relaciones remarcan el hecho de que la demanda hídrica de las forestaciones se encuentra vinculada al balance entre la demanda atmosférica y la capacidad de absorción de agua por parte de las raíces.

En el caso de la llanura pampeana, se han determinado profundidades de raíces de hasta $6 \mathrm{~m}$ en plantaciones de E. camaldulensis, con un descenso promedio de los niveles de capa freática de $19 \mathrm{~cm}$, con respecto a la vegetación herbácea, y máximos de 1,7m en Chascomús (aprox. 55km de EEC) y 0,6m en Castelli (aprox. 55km de PFD) (Jobbágy y Jackson, 2004). Esto corrobora la existencia de un mayor consumo de agua por parte de las forestaciones, producto de un sistema radicular profundo que le permite utilizar el agua subterránea.

De la misma manera, observaciones detalladas de los niveles de capas freáticas en la pampa húmeda (Jobbágy et al., 2006a), permitieron identificar: desniveles de más de $0,5 \%$ entre plantaciones forestadas y pastizales, y fluctuaciones diarias bajo forestaciones (descensos diurnos y ascensos nocturnos de nivel), que alcanzaron los $10 \mathrm{~cm}$. La primera observación responde al consumo diferencial de las forestaciones (profundización de 
napas desde el centro de los rodales hacia afuera), mientras que las variaciones diarias son atribuidas a un aporte horizontal de agua desde las áreas circundantes a la forestación (pastizal).

Resulta interesante destacar que existen antecedentes en la pampa deprimida, que indican que no existe una relación evidente entre la altura del nivel freático y el agua acumulada en superficie (Vázquez et al., 2011). Se observa poca coincidencia entre los valores de profundidad de la capa freática y los de potencial agua del suelo en los primeros $15 \mathrm{~cm}$ de profundidad (Sala et al., 1981), además, períodos húmedos con un nivel freático alto han mostrado que la calidad del agua de la parte superior del acuífero (ubicada a unos $40 \mathrm{~cm}$ de profundidad) poseía una composición química totalmente distinta a la superficial (Lavado y Taboada, 1988). Este comportamiento es atribuible al horizonte $\mathrm{Bt}$, característico de estas tierras, cuya reducida permeabilidad desestima la relación existente entre la altura de la freática y el estado hídrico de las distintas comunidades vegetales del pastizal y advierte un potencial efecto perjudicial por parte de las forestaciones, las cuales, por la capacidad de exploración de sus raíces, actuarían sobre esta capa impermeable posibilitando el flujo de agua y sales.

Hamilton et al., (2009) mencionan la existencia de informes a nivel mundial que indican que 77 millones de hectáreas sufren salinización producida por actividades humanas (salinización secundaria) y que estas responden a modificaciones de la cubierta vegetal (41\%) y a excesos de irrigación (59\%).

El influjo de las forestaciones sobre las aguas subterráneas, apunta a que la conversión de pastizales en forestaciones estimula un aumento de la intercepción del agua de lluvia y la transpiración de las plantas, con la consecuente disminución del escurrimiento superficial e infiltración de agua en el suelo. Esto determina un descenso del nivel de capa freática y un incremento en la acumulación de sales en el suelo.

La experiencia Australiana sugiere que la explotación forestal o deforestación eleva los niveles freáticos y provoca un acarreo de sales en el perfil del suelo. Esto incita a pensar que la implantación de bosques en terrenos abiertos, donde las capas freáticas están cerca de la superficie, bajaría los niveles freáticos y mejoraría el drenaje (Hamilton et al., 2009). 
En relación a esto existe un estudio realizado por Vertessy et al., (2000) en la región centro-norte de Victoria (Australia), caracterizada por una topografía plana y una capa freática poco profunda $(2 \mathrm{~m})$, donde se concluyó que cuando la densidad de las plantaciones era suficiente alta (al punto que la demanda evapotranspirativa excede la infiltración del agua de lluvia en el suelo), los árboles utilizaban agua de la napa freática. Estos autores, indicaron que en estas condiciones, hay una acumulación de sales en la zona radicular de las plantaciones, cuya magnitud está en relación directa con la descarga neta de aguas subterráneas (diferencia entre la transpiración y la infiltración) y la concentración de sales del agua freática. A su vez, señalaron que la captación de aguas subterráneas disminuiría en la medida que aumenta la acumulación de sales, a menos que procesos como la lixiviación y difusión de sales sean capaces de equilibrar este incremento. Por otro lado, afirman que aún en las condiciones en que la plantación ya no haga uso del agua subterránea por acumulación de sales, logran negar efectivamente la recarga freática.

Si se destaca ahora el consumo de agua subterránea de las forestaciones -dado que los procesos de salinización involucrados exceden esta tesis-, se pueden mencionar autores que sugieren que plantaciones juveniles de pino y eucalipto poseen el mismo efecto sobre las reservas de agua del suelo (Oyarzún y Huber, 1999).

Al respecto, un estudio sobre el contenido de humedad del suelo bajo plantaciones de E. grandis y $P$. taeda en la provincia de Entre Ríos, reportó que mientras los suelos bajo eucalipto se presentaban con más humedad, la amplitud o variaciones bajo cada rodal eran similares. Esto último, se verificó tanto en función de la distancia del centro a la frontera de las plantaciones (capa freática se profundiza hacia el centro de las plantaciones) como en la profundidad y época del año (Torrán y Piter, 2009).

Por otro lado, Poore y Fries (1987) señalan estudios en la Planicie Costera Central de Israel donde se hizo la comparación de una plantación de E. camaldulensis (de $11 \mathrm{~m}$. de altura) con un terreno descubierto (Karschon y Heth, 1967). En este estudio, los eucaliptos utilizaron toda el agua disponible durante la estación húmeda, mientras que en la estación seca, disminuyeron el consumo. Esto generó reducciones del $20 \%$ en la producción de agua frente a un terreno descubierto y, aunque se estableció que la plantación nunca permitió un sobrante de agua de lluvia para escurrimiento o drenaje, la disminución de consumo detectada fue atribuida únicamente a la imposibilidad de los eucaliptos para 
acceder a fuentes de agua subterránea. Si bien no se hicieron experiencias con otras especies, Karschon y Heth (1967) señalaron que valores y comportamientos similares fueron registrados para pinos.

Por último, Silveira et al. (2006), determinaron que el contenido de agua del suelo bajo plantaciones de eucalipto era inferior al de una pastura natural durante el invierno. Estas diferencias, sin embargo, no se atribuyeron al mayor consumo de las plantaciones sino a una menor capacidad de retención de agua bajo el suelo forestal (fruto de un mayor porcentaje de macro-mesoporos) y al efecto de hidrofobicidad de la materia orgánica (producida por los Eucaliptos). Esto llevó a la conclusión de que en invierno, es esperable que las plantaciones de eucalipto promuevan el drenaje profundo y la recarga de acuíferos, dado que causan la disminución de la retención y el escurrimiento.

Todos los antecedentes mencionados hasta este punto del capítulo, permiten suponer que ante la existencia de períodos con excesos hídricos, las forestaciones estudiadas favorecerán la infiltración y recarga freática bajo estas coberturas. Por el contrario, acentuarán los procesos de descarga freática ante períodos con baja pluviometría. 


\subsection{MATERIALES Y MÉTODOS}

\subsection{1 Área de estudio}

\subsubsection{Estancia El Centauro (EEC)}

\section{a. Características edáficas (EEC)}

La EEC se encuentra situada en el Dominio Edáfico 9 (INTA, 1989). El paisaje está representado por planicies muy suavemente onduladas que presentan, como característica particular, un complejo edáfico compuesto por los tipos de suelos Natracualf típico, fino, y Cromudert acuéntico, muy fino, con limitaciones de alcalinidad sódica a menos de $50 \mathrm{~cm}$ de profundidad y drenaje deficiente por impermeabilidad.

El principal factor de degradación que afecta a los suelos de esta región, y por tanto a la actividad agrícola-ganadera, está dado por la pérdida de estabilidad estructural del horizonte superficial del suelo. Esto provoca una importante disminución del porcentaje de materia orgánica en la capa arable y se encuentra vinculado a excesivas labores productivas (pulverización de los agregados) de un proceso originado en 1970 y conocido como agriculturización (PROSAP, 2010).

Laurencena et al. (2002), indican que el área de estudio se localiza en un ambiente de llanura con suaves ondulaciones y pendiente regional hacia el noreste. Además señalan que la misma no supera el 1\%, por lo que predominan los procesos de infiltración frente a los de escurrimiento superficial.

En la figura IV.1 se muestra un mapa de los suelos correspondientes al área de influencia de la EEC, digitalizado sobre las cartas de suelos 1:50000 de la provincia de Buenos Aires (INTA, 2010). 


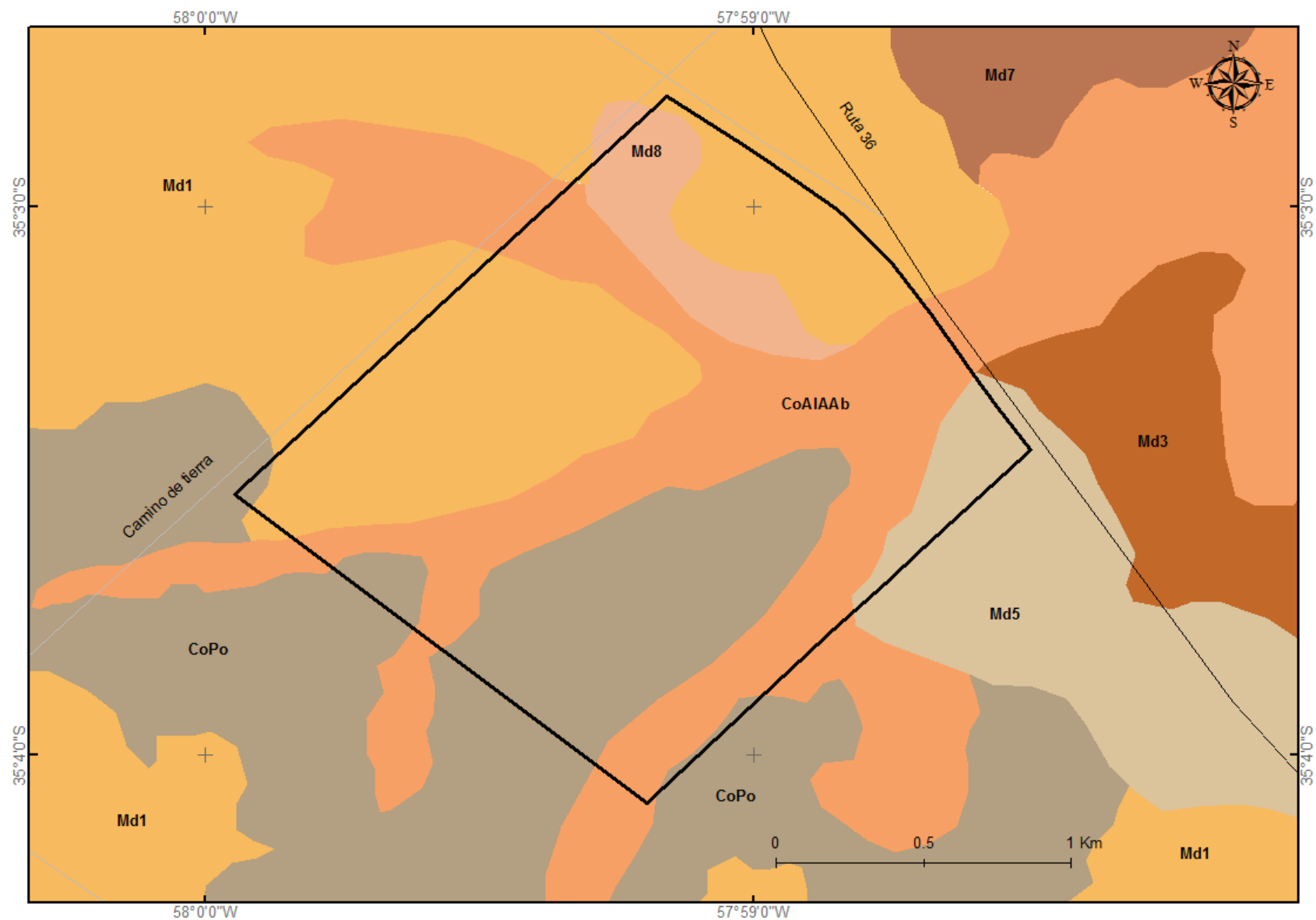

Figura IV.1. Mapa de unidades cartográficas de suelos en la EEC y área de influencia. Adaptado de INTA (2010).

El detalle de los códigos utilizados para la diferenciación de los tipos de suelo se muestra en formato de tabla (Tabla IV.2). En ella se presenta una reseña de los tipos de suelo correspondientes a la EEC, donde se señalan los complejos que componen cada unidad cartográfica, el tipo de paisaje y la clasificación según uso y productividad desarrollada por INTA (2010) y que se explica a continuación:

Clasificación de las tierras por su capacidad de uso: El sistema de clasificación utilizado en las cartas de suelos de la República Argentina Provincia de Buenos Aires, distingue ocho clases (I a VIII) que indican un aumento progresivo de las limitaciones que presentan los suelos para el desarrollo de los cultivos. Las cuatro primeras clases incluyen los suelos aptos para los cultivos agrícolas. La clase I requiere poco o ningún tratamiento de manejo o conservación especial. Las clases II, III y IV necesitan grados crecientes de cuidado y protección. Las clases $\mathrm{V}$ a VII por lo general no son aptas para los cultivos y precisan cuidados progresivamente más intensos, aún al ser destinadas para pasturas o 
forestación. Finalmente la clase VIII no tiene aplicación agrícola ni ganadera; sólo sirve para la recreación o para conservación de la fauna silvestre. Las subclases "e", "w", "s" o "c" indican los principales riegos o limitaciones de los suelos, siendo: "e"= susceptibilidad a la erosión; "w"= exceso de agua por drenaje pobre, humedad excesiva, capa de agua alta (freática o suspendida) y anegabilidad; "s"= limitaciones del suelo dentro de la zona radical por escasa profundidad, baja capacidad de retención de humedad, salinidad o alcalinidad y bajo nivel de fertilidad difícil de corregir; y por último la subclase "c"= limitaciones climáticas.

Índice de Productividad: La determinación del Índice de Productividad (IP) tiene como objetivo establecer una valoración numérica de la capacidad productiva de las tierras de una región. Se trata de un método paramétrico multiplicativo adoptado y modificado por el Instituto de Suelos del INTA-CIRN (INTA, 2010). El mismo considera los siguientes parámetros: Índice de Productividad de la unidad taxonómica; Disponibilidad de agua; Drenaje; Profundidad efectiva; Textura del horizonte superficial; Textura del horizonte subsuperficial; Contenido de sales solubles dentro de los primeros $75 \mathrm{~cm}$; Alcalinidad sódica (considerada hasta $1 \mathrm{~m}$ ); Contenido de materia orgánica; Capacidad de intercambio catiónico y Erosión.

Tabla IV.2. Detalle de las unidades taxonómicas correspondientes a los suelos de la Estancia El Centauro y alrededores.

\begin{tabular}{|c|l|}
\hline Unidad cartográfica & \multicolumn{1}{|c|}{ Unidad taxonómica } \\
\hline CoAIAAb & $\begin{array}{l}\text { Complejo de suelos alcalinos del Arroyo Abascay en bajos. Paisaje de } \\
\text { planos cóncavos. Uso VII ws. Productividad 4 }\end{array}$ \\
\hline CoPo & $\begin{array}{l}\text { Complejo de suelos hidromórficos-alcalinos Poblet (100\%) en bajos. Paisaje } \\
\text { de planos cóncavos. Uso VII ws. Productividad 4 }\end{array}$ \\
\hline Md1 & $\begin{array}{l}\text { Asociación Magdalena (75\%) en tendidos altos y Poblet (25\%) en } \\
\text { microdepresiones. Paisaje de planicies muy suavemente onduladas. Uso IV } \\
\text { ws. Productividad 48,9_A }\end{array}$ \\
\hline Md5 & $\begin{array}{l}\text { Consociación Magdalena (100\%) en tendidos altos. Paisaje de tendidos } \\
\text { amplios. Uso III w. Productividad 63,0_A }\end{array}$ \\
\hline Md8 & $\begin{array}{l}\text { Complejo Magdalena (60\%) en tendidos altos y Vieytes (40\%) en } \\
\text { microdepresiones. Paisaje de amplias pendientes con poco gradiente, con } \\
\text { lomadas planas y microdepresiones. Uso IV ew. Productividad 40,1_A }\end{array}$ \\
\hline
\end{tabular}




\section{b. Descripción de series de suelos (EEC)}

Poblet. Es un suelo pardo muy oscuro, de poco espesor, su aptitud es ganadera y se encuentra en un paisaje de planicies bajas amplias en el interfluvio de los ríos Salado y Samborombón, en posición de bajo, en la "subregión pampa ondulada baja", transición al sector de las llanuras marinas, bahía Samborombón, pobremente drenado, formado sobre sedimentos loéssicos de origen eólico, con fuerte alcalinidad sódica desde superficie y levemente salino, con pendientes de 0,5-1\%.

Magdalena. Es un suelo profundo, de aptitud agrícola, se encuentra en la cuenca del Río Samborombón, en la "subregión geomorfológica llanura marina de la Bahía de Samborombón", algo pobremente drenado, desarrollado a partir de sedimentos loéssicos finos, del Postplatense, Postquerandinense y Pampeano Superior (Tricart), no alcalino, no sódico, con pendientes que no superan el $0-0,5 \%$.

Vieytes. Es un suelo profundo, de aptitud ganadera, que se encuentra en los planos llanos del divorcio entre la margen izquierda del río Samborombón y los arroyos que vierten sus aguas directamente al Río de La Plata, en microdepresiones de la "subregión geomorfológica llanura marina del Río Samborombón", pobremente drenado, evolucionado sobre sedimentos limosos fluvio-lacustres y el Finipampeano (Tricart), con fuerte alcalinidad después de los $11 \mathrm{~cm}$ de profundidad, levemente salino desde los $52 \mathrm{~cm}$, con pendientes de 0 a $0,5 \%$.

Los suelos se presentan, en la gran mayoría de los casos $(67,9 \%)$, como suelos con moderadas limitaciones para el uso agrícola, con texturas finas, imperfectamente drenados y ubicados en vías de escurrimiento incipiente o depresiones que permanecen anegadas durante períodos significativos. El resto de estos suelos, se presentan como no aptos para cultivos, siendo posible el uso pecuario y forestal (Hurtado et al., 2006).

\section{c. Características geológicas (EEC)}

De Francesco et al. (2001), indican que la geología superficial está integrada por unidades litológicas de génesis fundamentalmente continental del Cenozoico Superior, que incluyen a los "Sedimentos Pampeanos" (Fidalgo et al., 1975), Formación La Postrera, 
Formación Luján y Aluvio (Fidalgo et al., 1973; De Francesco et al., 1999). A continuación se presenta una breve caracterización de cada una de estas unidades:

- Sedimentos Pampeanos. Origen esencialmente eólico y naturaleza limo arcillosa a arcillo limosa, con concentraciones y pulverulencias de $\mathrm{CO}_{3} \mathrm{Ca}$ y color castaño, se encuentran ampliamente distribuidos, constituyendo, en gran medida, el horizonte $\mathrm{C}$ de los suelos en este ámbito, aunque en ocasiones subyacen a otros depósitos eólicos y fluvio/lacustres. Presenta espesores que varían entre los 35 y $45 \mathrm{~m}$. Su edad es Pleistoceno medio-superior.

- Formación La Postrera. Integrada por limos a limos arenosos eólicos, homogéneos y friables, de color castaño amarillento a grisáceo y espesores entre 0,50-0,90m, se ubica, mayormente, en los sectores culminantes del relieve. Su edad es Pleistoceno superiorHoloceno.

- Formación Luján. Ubicada en los valles principales, está integrada por limos arenosos a limos arcillosos, de color verde-verde grisáceo a castaño amarillento en su base y gris castaño hacia el techo. Es cubierta por la Formación La Postrera y el Aluvio. La edad de esta unidad es Pleistoceno Superior-Holoceno.

- Aluvio. Constituido por sedimentos areno arcillosos a arcillosos, de color gris a gris verdosos, generados por acción fluvial y sedimentación en cuerpos de aguas estancadas, que ocupan amplias áreas deprimidas.

\section{d. Variables de interés (EEC)}

A continuación se presenta un listado de variables extraídas de la bibliografía específica (Tabla IV.3). Estas variables son las que dominan, de alguna manera, el comportamiento del agua en el suelo y constituyen herramientas importantes para entender su dinámica. 
Tabla IV.3. Variables edáficas e hidrogeológicas de la Estancia El Centauro y alrededores.

\begin{tabular}{|c|c|c|c|}
\hline Variable & Valores & Unidades & Autores \\
\hline Infiltración & 55 & mm/año & \multirow{2}{*}{ EASNE, 1972} \\
\hline Infiltración como porcentaje de la precipitación & 6 & $\%$ & \\
\hline Porosidad efectiva & 0,08 & $\mathrm{~m}^{3} / \mathrm{m}^{3}$ & \multirow{3}{*}{ Auge, 1995} \\
\hline Infiltración & 241 & $\mathrm{~mm} / \mathrm{año}$ & \\
\hline Infiltración como porcentaje de la precipitación & 24 & $\%$ & \\
\hline Infiltración & 224 & $\mathrm{~mm} / \mathrm{año}$ & \multirow{7}{*}{$\begin{array}{l}\text { Laurencena et al., } \\
\qquad 2005\end{array}$} \\
\hline Escurrimiento superficial & 53 & $\mathrm{~mm} / \mathrm{año}$ & \\
\hline $\begin{array}{l}\text { Capacidad de infiltración del Pampeano (incluye a la } \\
\text { capa freática) }\end{array}$ & $5-10$ & m/día & \\
\hline $\begin{array}{l}\text { Coeficiente de transmisividad del Pampeano (incluye } \\
\text { a la capa freática) }\end{array}$ & 200 & $\mathrm{~m}^{2} /$ día & \\
\hline Gradiente hidráulico (Ilanura alta) & 1,8 & $\mathrm{~m} / \mathrm{km}$ & \\
\hline Gradiente hidráulico (Ilanura baja) & 0,5 & $\mathrm{~m} / \mathrm{km}$ & \\
\hline Porosidad eficaz & 0,1 & & \\
\hline Coeficiente de almacenamiento del acuífero freático & $0,05-0,3$ & $\mathrm{~m}^{3} / \mathrm{m}^{3}$ & \multirow{4}{*}{ Auge, 2005} \\
\hline Porosidad efectiva del acuífero freático & $0,05-0,3$ & $\mathrm{~m}^{3} / \mathrm{m}^{3}$ & \\
\hline Infiltración como porcentaje de la precipitación & $10-15$ & $\%$ & \\
\hline Escorrentía como porcentaje de la precipitación & $5-10$ & $\%$ & \\
\hline Porosidad efectiva & 0,11 & $\mathrm{~m}^{3} / \mathrm{m}^{3}$ & González et al., 1997 \\
\hline
\end{tabular}

Es necesario recordar que la capa freática es un acuífero libre (sección superior del Pampeano), compuesta de una superficie hidráulica que actúa como techo del mismo y hace que la capa freática se encuentre en contacto directo con la atmósfera y por lo tanto a la misma presión (Auge, 2005). Como consecuencia de esto, el coeficiente de almacenamiento $^{18}(\mathrm{~S})$ de este acuífero es igual a la porosidad eficaz ${ }^{19}(\mathrm{Sy})$, a diferencia de los acuíferos confinados, donde $S$ varía entre $10^{-3}$ y $10^{-5}$.

${ }^{18}$ Volumen de agua que puede liberar un prisma de sección unitaria del acuífero al descender en una unidad el nivel piezométrico. Es igual al volumen de agua liberado por el volumen total que ha bajado la superficie piezométrica. En el caso de los acuíferos libres, el valor de S es igual a la Porosidad eficaz (OMM, 2011).

${ }^{19}$ Representa el volumen de agua contenido en una roca (suelo en este caso) que es liberada por la acción de la gravedad. Es reconocida como agua libre o gravífica (Custodio y Llamas, 1996). 


\subsubsection{Predio Forestal Dolores (PFD)}

\section{a. Características edáficas (PFD)}

El PFD se ubica en el dominio edáfico 24 (INTA, 1989), donde predomina un paisaje de planicies con algunas lomas alargadas y lagunas intercomunicadas por vías de escurrimiento poco definidas. Los suelos se presentan con asociaciones de Natracuol típico, fino, ocupando los planos; Hapludol tapto-nátrico, en lomas, y Natracualf típico en las márgenes de lagunas y vías de escurrimiento. El escurrimiento deficiente y el alto contenido de sodio a menos de $50 \mathrm{~cm}$ de profundidad constituyen las principales limitaciones.

Según Vázquez (2003), al área de estudio se ubica en un relieve sumamente llano, con una pendiente promedio inferior al $0,1 \%$, llegando en sectores próximos a la costa a valores cercanos al 0,001\%. Esta situación, sumada al hecho de que los suelos poseen distintos grados de alcalinidad, salinidad e hidromorfismo, distribuidos en forma de mosaico por toda el área, son los responsables de las frecuentes inundaciones y anegamientos a la que está sujeta la región.

Factores tales como el diseño de la red vial, frecuentemente en dirección transversal al del flujo de agua, y la construcción de numerosos canales clandestinos, sin un criterio integral sobre el funcionamiento hidrológico, solo profundizan la problemática regional (Rang et al., 1999).

Los suelos característicos son de tipo hidrohalomórficos del suborden Natracuoles, en asociaciones con Natracualfes y Natralboles (Vázquez et al., 2011). Estos suelos tienen típicamente un horizonte arcilloso, baja permeabilidad y alto contenido de sales sódicas (Salazar Lea Plaza y Moscatelli, 1989; Lavado, 1992).

En la figura IV.2 se muestra un mapa georreferenciado de los suelos correspondientes a un sector de la cuenca baja del Arroyo Langueyú en escala 1:50000 (INTA, 2011). Un detalle de los códigos utilizados para la diferenciación de los tipos de suelo, junto con el porcentaje de ocupación ellos en la cuenca, se muestran en la tabla IV.4. 


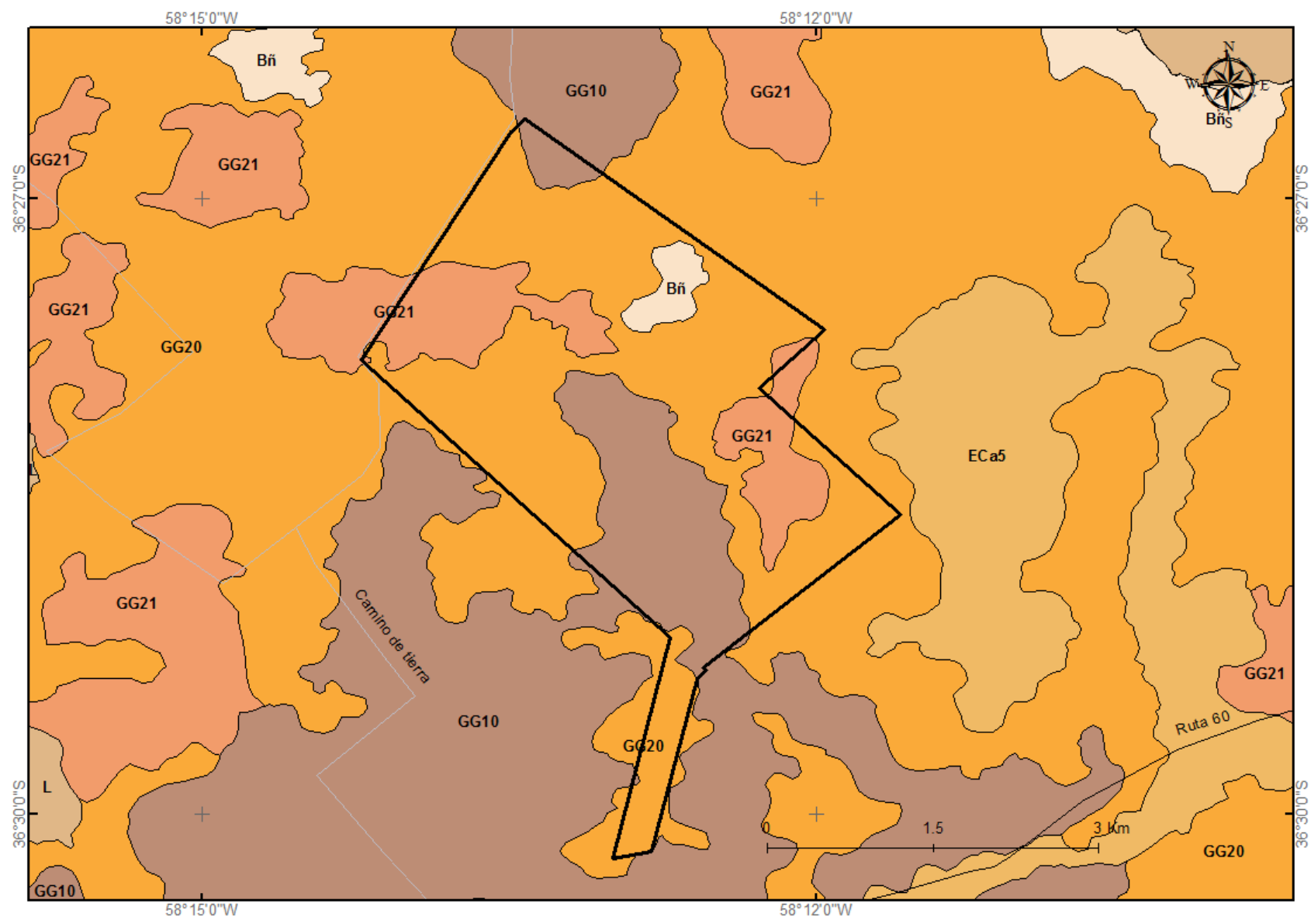

Figura IV.2. Mapa de suelos del Predio Forestal Dolores. Adaptado de INTA (2011).

Tabla IV.4. Detalle de las unidades taxonómicas presentes en el Predio Forestal Dolores y alrededores. Adaptado de INTA (2011).

\begin{tabular}{|c|l|}
\hline $\begin{array}{c}\text { Unidad } \\
\text { cartográfica }\end{array}$ & \multicolumn{1}{|c|}{ Unidad taxonómica } \\
\hline Bñ & $\begin{array}{l}\text { Grupo no diferenciado de Bañados (100\%) en bajos. Paisaje de bajos cóncavos } \\
\text { anegados con o sin curso de agua, generalmente pantanosos con agua de poca } \\
\text { profundidad. Uso VIII. Productividad 1. }\end{array}$ \\
\hline GG10 & $\begin{array}{l}\text { Asociación General Guido (70\%) en tendidos altos y Ayacucho (30\%) en lomas } \\
\text { bajas. Paisaje ligeramente ondulado. Uso VI ws. Productividad 25,0_B }\end{array}$ \\
\hline GG20 & $\begin{array}{l}\text { Asociación General Guido, pobremente drenado (50\%), en tendidos bajos y/o vías } \\
\text { de agua; General Guido (20\%) en tendidos altos; Castelli, pobremente drenado } \\
\text { (15\%), en tendidos bajos,y Suelos indiferenciados (15\%) en bajos cóncavos. } \\
\text { Paisaje con áreas planas bajas que en ocasiones funcionan como vías de agua. } \\
\text { Uso VI ws. Productividad 14,8_B }\end{array}$ \\
\hline GG21 & $\begin{array}{l}\text { Consociación General Guido (80\%) en tendidos altos; Castelli (10\%) en tendidos } \\
\text { bajos,y Ayacucho (10\%) en lomas bajas. Paisaje de planicies. Uso VI ws. } \\
\text { Productividad 20,0_B }\end{array}$ \\
\hline
\end{tabular}




\section{b. Descripción de series de suelos (PFD)}

General Guido. Es un suelo gris muy oscuro, profundo, con aptitud ganadera que se encuentran en los tendidos de la subregión pampa deprimida sector oriental, algo pobremente drenado, con rasgos hidromórficos, desarrollado sobre sedimentos finos, no salino a débilmente salino, con fuerte alcalinidad sódica desde los $14 \mathrm{~cm}$ de profundidad con pendientes que no superan el $0-0,5 \%$.

Ayacucho. Es un suelo negro a pardo oscuro, profundo, de aptitud agrícolaganadero, que se encuentra en un paisaje plano a muy suavemente ondulado en posición loma baja o tendidos altos, en la subregión de la pampa deprimida, moderadamente bien drenado, formado sobre sedimentos finos loéssicos y costra calcárea, alcalino sódico desde los $39 \mathrm{~cm}$ de profundidad, no salino, con pendientes de $0-1 \%$.

Castelli. Es un suelo gris muy oscuro, profundo, con aptitud ganadera que se encuentra en los tendidos de la subregión pampa deprimida sector oriental, en transición a la llanura marina de la Bahía de Samborombón; algo pobremente drenado, desarrollado sobre sedimentos eólicos finos, débilmente a moderadamente salino, con fuerte alcalinidad sódica desde superficie, con pendientes que no superan el 0-0,5\%.

Los excesos de lluvia invernales y los déficits estivales, el drenaje lento, y el carácter salino sódico de los suelos, con la presencia de un horizonte Bt sódico típico de $0,001 \mathrm{~mm} /$ día de capacidad de infiltración y un techo del mismo a los $10-20 \mathrm{~cm}$ de profundidad con una velocidad de infiltración básica inferior a $10517 \mathrm{~mm} / \mathrm{h}$, determinan que sea frecuente la alternancia de anegamiento y sequía. (INTA, 1977; Vázquez et al., 2001; Batista et al., 2005).

\section{c. Características geológicas (PFD)}

La región presenta una marcada monotonía en su condición geológica superficial, característica que tipifica a los ambientes llanos (Auge y Hernández, 1984).

El paisaje del área de trabajo, al igual que el resto de la pampa deprimida, se desarrolla sobre el relleno sedimentario de una gran fosa de hundimiento tectónico, modelada por sucesivas ingresiones del Océano Atlántico y por la acción eólica que actuó durante los períodos de clima desértico asociados con las glaciaciones (Vervoorst, 1967; 
Tricart, 1973). Estos agentes geomorfológicos dejaron formas residuales de relieve costero, como cordones de conchilla y acantilados, y de relieve eólico, como médanos y cubetas de deflación, que no corresponden a la humedad del clima actual (Tricart, 1973; Movia Y Burkart, 1976).

En la figura IV.3 se muestra un perfil del área de estudio junto con la denominación estratigráfica.

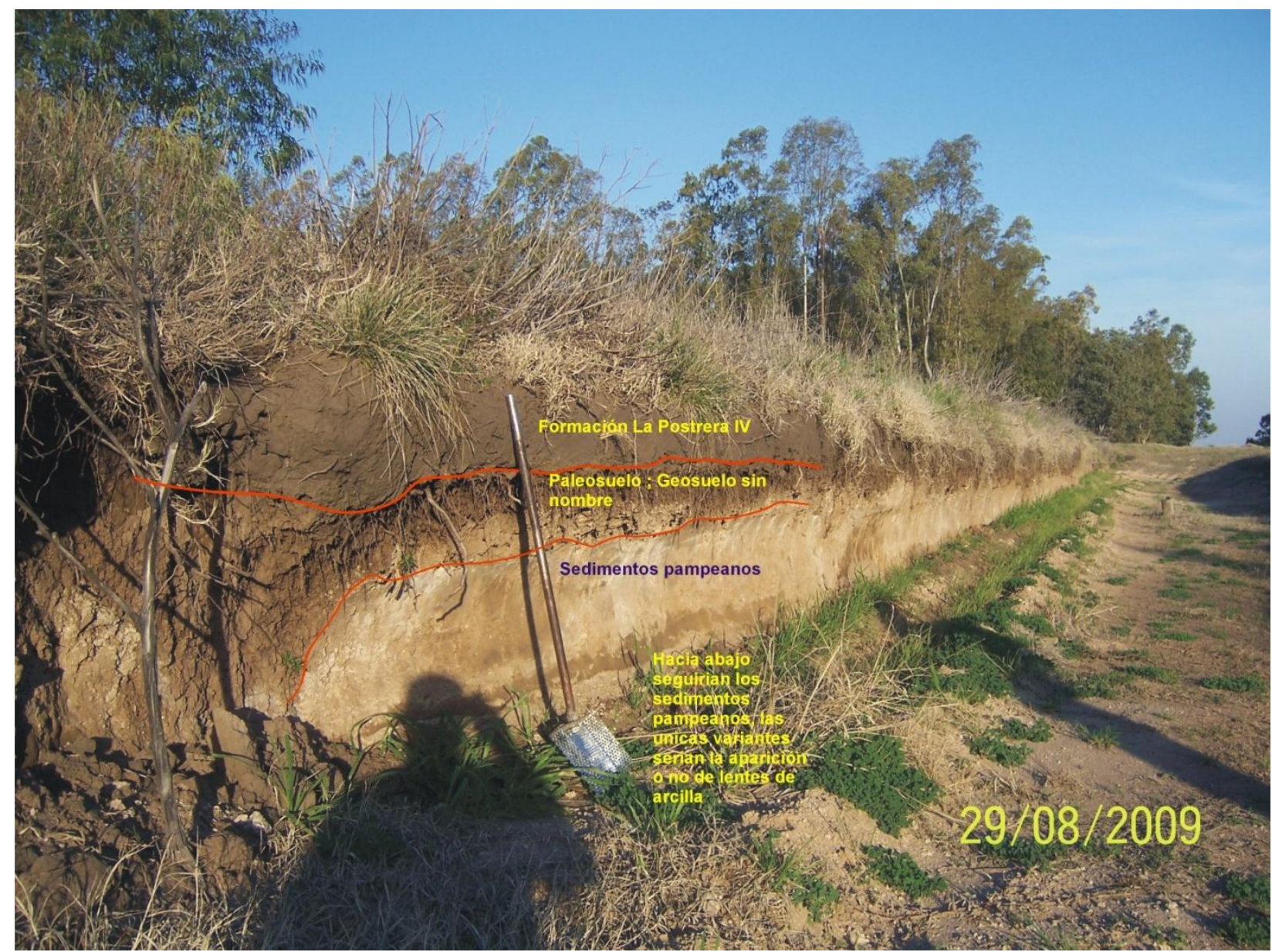

Figura IV.3. Estratigrafía del Predio Forestal Dolores.

Formación La Postrera IV. Sedimento mantiforme que corona la columna estratigráfica. Se trata de un depósito eólico, en cuyo seno se están desarrollando los suelos actuales, constituido por sedimentos edafizados de aspecto loéssico y espesor de $30 \mathrm{a} 50 \mathrm{~cm}$. Se compone de limos arenosos friables castaños grisáceos muy oscuros. Su 
estructura es granular, la materia orgánica y la bioturbación es abundante, y carece de carbonatos. Se le ha asignado la edad Holoceno tardío-tardío.

Geosuelo Sin Nombre. Se tratan de horizontes Bt y Bc de pocos $\mathrm{cm}$ de espesor (30 a 40). Es su parte inferior se notan carbonatos en posición horizontal.

Sedimentos Pampeanos. Se compone de limonitas arenosas de color castaño oscuro que en la parte superior se hace castaño amarillento. Estos depósitos loéssicos se presentan desde macizos a estratificados, leve a bien consolidados y cementados por carbonato de calcio en forma de septos subverticales a verticales. De edad pleistoceno medio a tardío.

\section{d. Variables de interés (PFD)}

En la tabla IV.5 Se muestra un conjunto de variables que, al igual que en EEC, permitirá construir una visión más acabada del medio para relacionarlo con las mediciones y determinaciones hidrológicas de esta tesis.

Tabla IV.5. Variables edáficas e hidrogeológicas del Predio Forestal Dolores y alrededores.

\begin{tabular}{|c|c|c|c|}
\hline Variable & Valores & Unidades & Autores \\
\hline Conductividad hidráulica & $1,0 \pm 0,12$ & m/día & Engel et al., 2005 \\
\hline Conductividad hidráulica & $2 \times 10^{-7}$ & $\mathrm{~m} / \mathrm{s}$ & \multirow{3}{*}{ Sallies, 1999} \\
\hline Pendiente & $0,5-0,1$ & $\%$ & \\
\hline Profundidad de suelos & poca & & \\
\hline $\begin{array}{l}\text { Capacidad de infiltración de un horizonte Bt } \\
\text { sódico típico }\end{array}$ & $\leq 0,001$ & mm/día & \multirow{3}{*}{ Vázquez et al., 2011} \\
\hline Profundidad del Bt sódico & $10-20$ & $\mathrm{~cm}$ & \\
\hline Velocidad de infiltración básica & $<17$ & $\mathrm{~mm} / \mathrm{h}$ & \\
\hline Porosidad eficaz & 0,1 & $\mathrm{~m}^{3} / \mathrm{m}^{3}$ & Nuñez et al., 2007 \\
\hline Porosidad eficaz & 0,2 & $\mathrm{~m}^{3} / \mathrm{m}^{3}$ & Aragón et al., 2011 \\
\hline
\end{tabular}




\subsubsection{Infiltración}

La estimación del almacenamiento del agua en el suelo, por medio del estudio de las variaciones del nivel freático, es una práctica habitual en la confección de balances hidrológicos y el estudio de la dinámica hídrica en tierras llanas con freática poco profunda (Farrington et al., 1990; Laurencena et al., 2002, 2005; Nuñez et al., 2007; Aragón et al., 2011). Los balances hídricos, sin embargo, adoptan expresiones variadas según el grado de detalle que se quiera alcanzar o la disponibilidad de información obtenida.

En el presente estudio, al no disponer de datos de humedad del suelo para el período considerado, se adoptó la metodología de Risiga (Nuñez et al., 2007), en la cual se considera como infiltración a toda aquella parte de la precipitación que produce un aumento en el nivel de la capa freática (infiltración eficaz) ó un descenso de la misma (infiltración "negativa").

De esta manera, para la determinación de la infiltración, tomada como infiltración eficaz $\left(f_{s s}\right)$, se instaló una red de monitoreo de niveles freáticos consistente en perforaciones de profundidades variables (Tabla IV.6), en número de seis para la EEC y siete en el PFD (Figura IV.4). En la EEC, además, se completó la red de monitoreo con una perforación abandonada de extracción de agua para ganado.

Tabla IV.6. Red de monitoreo freático de las áreas de estudio, indicando los códigos, profundidad y cota.

\begin{tabular}{|c|c|c|c|c|}
\hline \multirow{2}{*}{ Pozo } & \multicolumn{2}{|c|}{ Profundidad (mbnt) } & \multicolumn{2}{|c|}{ Cota terreno (msnm) } \\
\hline & EEC & PFD & EEC & PFD \\
\hline 1 & 12 & 6,1 & 24,66 & 18,00 \\
\hline 2 & 12 & 5 & 26,13 & 18,09 \\
\hline 3 & 11,75 & 4,8 & 23,30 & 16,98 \\
\hline 4 & 10,10 & 6 & 25,29 & 17,70 \\
\hline 5 & 11,5 & 6 & 24,36 & 17,84 \\
\hline 6 & 11,5 & 5,9 & 23,88 & 18,29 \\
\hline 7 & 100 & 5 & 24,87 & 19,09 \\
\hline
\end{tabular}



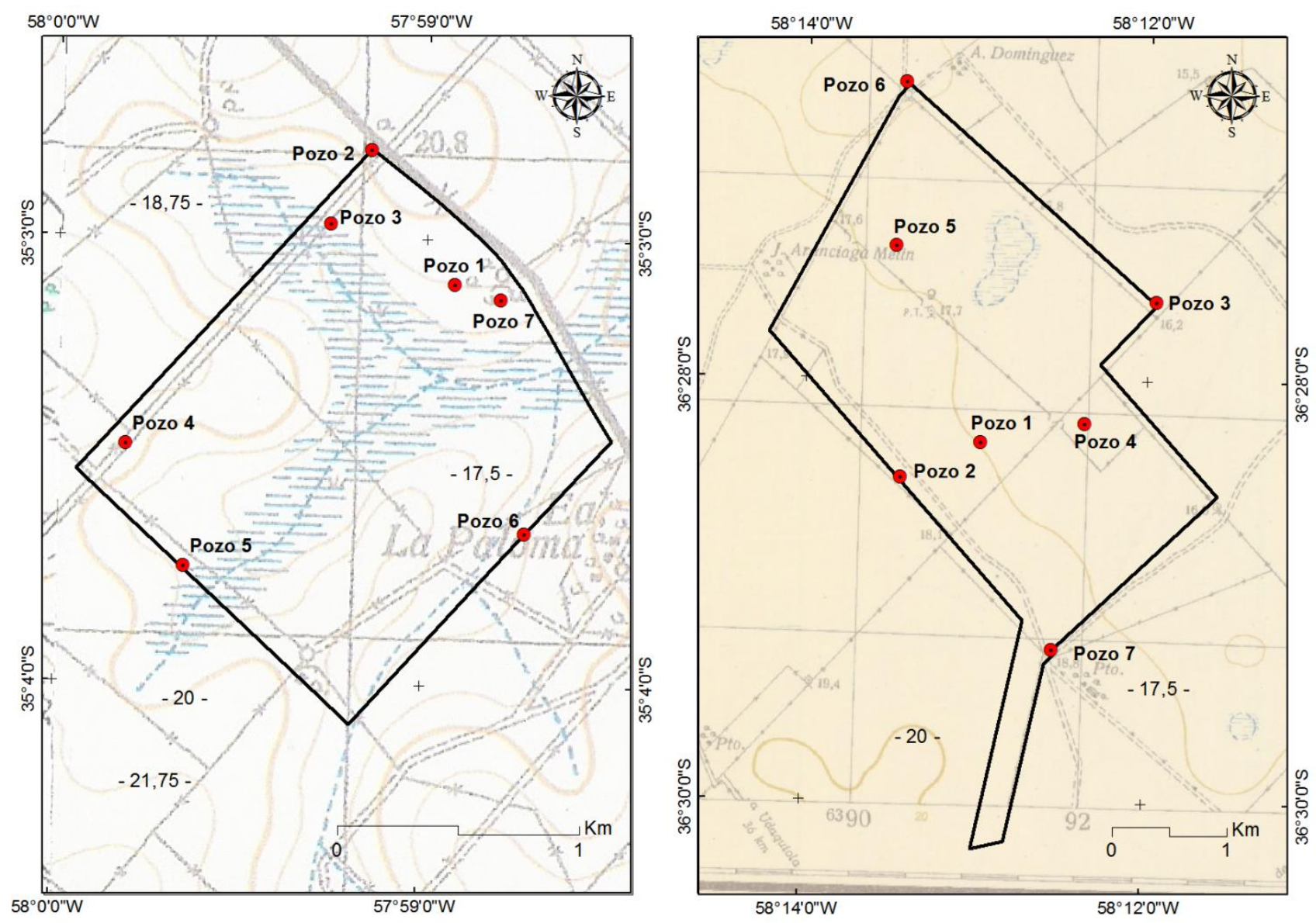

Figura IV.4. Ubicación de la red de monitoreo de niveles freáticos en la Estancia El Centauro (izquierda) y Predio Forestal Dolores (derecha). De fondo de observa las cartas topográficas correspondientes a la hojas Ignacio Correas (EEC) y Estancia El Sermón (PFD).

El período de muestreo fue de tres años (EEC: ene2009-dic2011; PFD: sep2009ago2012) y bajo una recurrencia de registro semanal a fin de poder homologarlo con el resto de las determinaciones.

Es necesario aclarar que las perforaciones, en adelante pozos, no se hallan todas bajo las forestaciones. Solo los pozos 3 y 4 de la EEC y los pozos 4 y 5 del PFD cumplen esta condición. El resto de los pozos se encuentran en las cercanías de las plantaciones sobre terrenos cubiertos por pastos. Además, todos los pozos que se hallan bajo las forestaciones comparten lugar con parcelas experimentales, donde se registraron los flujos de trascolación y escurrimiento fustal (apartado 2.2.3). Esto últimos, permitieron asignar un valor de infiltración a cada especie estudiada y, a su vez, comparar estos valores con la vegetación herbácea cercana. 
La confección de los pozos fue realizada con una torre de perforación móvil confeccionada para ese fin. La misma, cuenta con tramos de hierro huecos de $2 \mathrm{~m}$ acoplables entre sí, provista de una freza en la punta inferior para el trabajo de perforación. Por el interior de esta mecha perforadora, se fuerza un flujo de agua a presión para la extracción del material por recirculación de agua. Los pozos fueron encamisados con un tubo de PVC de 63mm de diámetro, ranurado y engravado en la base, a los cuales se les colocó una tapa en el extremo superior para evitar el ingreso de agua o suciedad. Finalizada la red de freatímetros, se realizó una nivelación topográfica de los pozos (nivelación geométrica) para que las mediciones -de recurrencia semanal- puedan ser referidas tanto a la superficie topográfica (metros bajo nivel del terreno: mbnt) como al nivel medio del mar (metros sobre el nivel del mar: msnm). Las medidas del pelo de agua, correspondientes a la capa freática, se obtuvieron con una cinta métrica metálica provista de una plomada en la punta (Figura IV.5).

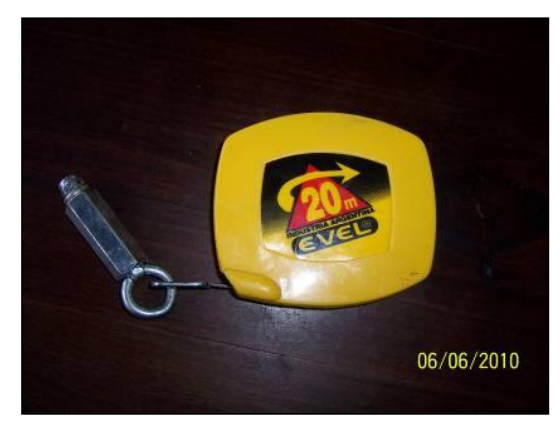

Figura IV.5. Cinta métrica adaptada para medición de los niveles de capa freática.

El cálculo de la infiltración surge de la suposición de que los cambios en los niveles de capa freática responden primordialmente al agua de las precipitaciones que llega a capas inferiores por el proceso de infiltración o movimiento vertical en el perfil. A este respecto, Eamus et al. (2006) explica que cuando hay un cambio en las reservas de agua subterránea (agua freática), ya sea por aporte o remoción, se produce un cambio en la capa freática sustancialmente mayor que el equivalente en agua. Esto quiere decir que un aporte de agua hacia niveles profundos de por ejemplo $20 \mathrm{~mm}$, significan un aumento mucho mayor de la capa freática, debido al espacio que ocupan las partículas terrosas. Esto hace que ese volumen de agua de $0,02 \mathrm{~m}^{3}$ por $\mathrm{m}^{2}$ de superficie $(20 \mathrm{~mm})$, se magnifique en función de la porosidad del suelo, tal como muestra la ecuación IV.1. Esto 
resulta en que bajo una porosidad de 0,1; un aporte de agua hacia niveles profundos de $20 \mathrm{~mm}$ equivale a un incremento del nivel de capa freática de $200 \mathrm{~mm}$.

$$
\Delta \mathrm{H}=\Delta \mathrm{h} / \mathrm{Sy}
$$

Donde: $\Delta \mathrm{H}$, es el cambio en la altura de la capa freática; $\Delta \mathrm{h}$, es la adición de agua en equivalentes de profundidad y $\mathrm{Sy}$, es el rendimiento específico o porosidad efectiva ${ }^{20}$ (Custodio y Llamas, 1996)

Para todos los cálculos se consideró como nulo el flujo horizontal a nivel subterráneo, debido a que el gradiente hídrico presenta valores muy bajos y por lo tanto despreciables (inferiores a $0,1 \%$ ). A su vez, se adoptó un valor de porosidad eficaz de los sedimentos del suelo igual a 0,07 en el PFD (Nuñez et al., 2007) y a 0,1 en la EEC. Este último valor, responde a una media tomada de experiencias efectuadas en áreas circundantes, con valores de 0,08 (Auge, 1995) a 0,11 (González et al., 1997).

Por último, se realizó el contraste entre la variación de los niveles de capa freática de cada pozo y entre estos y los registros de precipitación (apartado 2.3.1). La finalidad de este análisis es establecer algún patrón de comportamiento entre las distintas coberturas vegetales y el grado de correlación con las precipitaciones, si es que existe. Las escalas temporales empleadas para estos contrastes fueron tres (3): anual, estacional y mensual; a fin de poder integrar este flujo al balance hidrológico del capítulo 5.

\subsubsection{Flujos subterráneos}

El grado de susceptibilidad a la contaminación de los acuíferos está relacionado, entre otras cosas, con la cercanía de estos con la superficie. El exceso de vertidos domiciliarios, la actividad agrícola ganadera, el riego complementario con aguas inadecuadas y el exiguo desagüe son algunos de los principales causantes de contaminación que afectarán de forma directa al acuífero freático -acuífero más superficial

${ }^{20}$ Traducción literal de Effective porosity, equivalente al término de Porosidad eficaz. Es también conocida como rendimiento específico (traducción literal de Specific yield), pero no debe confundirse con retención específica ya que son conceptos opuestos (Sánchez, 2012). 
y de tipo libre-. Un mejor entendimiento de su dinámica y respuesta ante un cambio de uso, resulta muy conveniente para la correcta gestión del recurso.

En este sentido, es importante destacar que para planificar un uso racional y sostenible de los recursos hídricos, es preciso generar modelos de flujo de agua subterránea. Los cuales se encuentran sujetos a la estimación de la recarga o descarga a partir de las variaciones de los niveles freáticos (Laurencena et al., 2005).

En los casos estudiados, la variación de los niveles de capa freática, fueron acotados a nivel predial por las redes de monitoreo de pozos y su integración se llevó a cabo en forma de mapas de flujo de las aguas subterráneas (freática). Esto permitió conformar un modelo del efecto de las forestaciones en las reservas de agua del suelo, necesario para la proyección de posibles escenarios de uso en estas tierras: aumento o disminución de superficies forestadas, cambio de especies, utilización de distintas disposiciones y densidades de plantación (corinas, macizos densos, sistemas silvopastoriles, etc.).

Para la confección de los mapas de flujo, fue preciso identificar aquellos momentos, a lo largo del período de muestreo (EEC ene2009-dic2011; PFD sep2009-ago2012), en los que por una elevada pluviometría, ausencia de la misma o grado particular de demanda atmosférica, se originaron descensos o ascensos extremos de los niveles de napa freática.

Identificadas estas fechas, se elaboraron en base SIG los mapas de flujo. En ellos se indicaron los límites prediales; designación de los pozos; posición topográfica de los mismos (cota); profundidad del nivel de la capa freática, líneas de isofreáticas y direcciones de flujo.

Paralelamente, se verificó el supuesto de que los flujos subterráneos horizontales son tan pequeños que no justifica su inclusión en la presente tesis dada la escala de trabajo y grado de detalle utilizado.

Para la obtención de un valor modal de aporte subterráneo horizontal, se trabajó con los mapas de flujo correspondientes a las situaciones extremas de máximo ascenso de nivel de capa freática. Con estos mapas se definieron las isofreáticas máximas y mínimas que actuarían como frentes de ingreso y egreso horizontal de agua y se calcularon los gradientes medios entre curvas. Luego, se determinó la longitud de las isofreáticas 
seleccionadas en base SIG y se aplicó la ecuación IV.2 para obtener los caudales de ingreso (recarga horizontal) y salida (descarga horizontal) a nivel predial.

$$
\mathrm{R}_{\text {subt }}=\mathrm{T} * \mathrm{~m} * \mathrm{i}
$$

Donde: $\mathrm{T}$ es la transmisividad horizontal $\left[\mathrm{m}^{2} / \mathrm{d}\right] ; \mathrm{m}$ es la longitud de las isofreáticas de ingreso y salida [m], e i representa el gradiente existente entre curvas isofreáticas.

Para este cálculo se tomó un valor modal de transmisividad presentado por Laurencena et al. (2005) e igual a $200 \mathrm{~m}^{2} / \mathrm{d}$. 


\subsection{RESULTADOS}

\subsubsection{Infiltración}

A continuación se muestran los gráficos completos de la marcha de los niveles de capa freática de las redes de monitoreo de napas, correspondientes al período considerado y para los dos sitios en estudio, EEC (Gráfico IV.2) y PFD (Gráfico IV. 3). En el eje temporal de estos gráficos (eje de ordenadas), se encuentran los meses y años correspondientes a los períodos: enero de 2009 a diciembre de 2011 (EEC) y septiembre de 2009 a septiembre de 2012 (PFD); y en el eje de abscisas se indican las profundidades del nivel freático expresadas en metros sobre el nivel del mar (msnm).

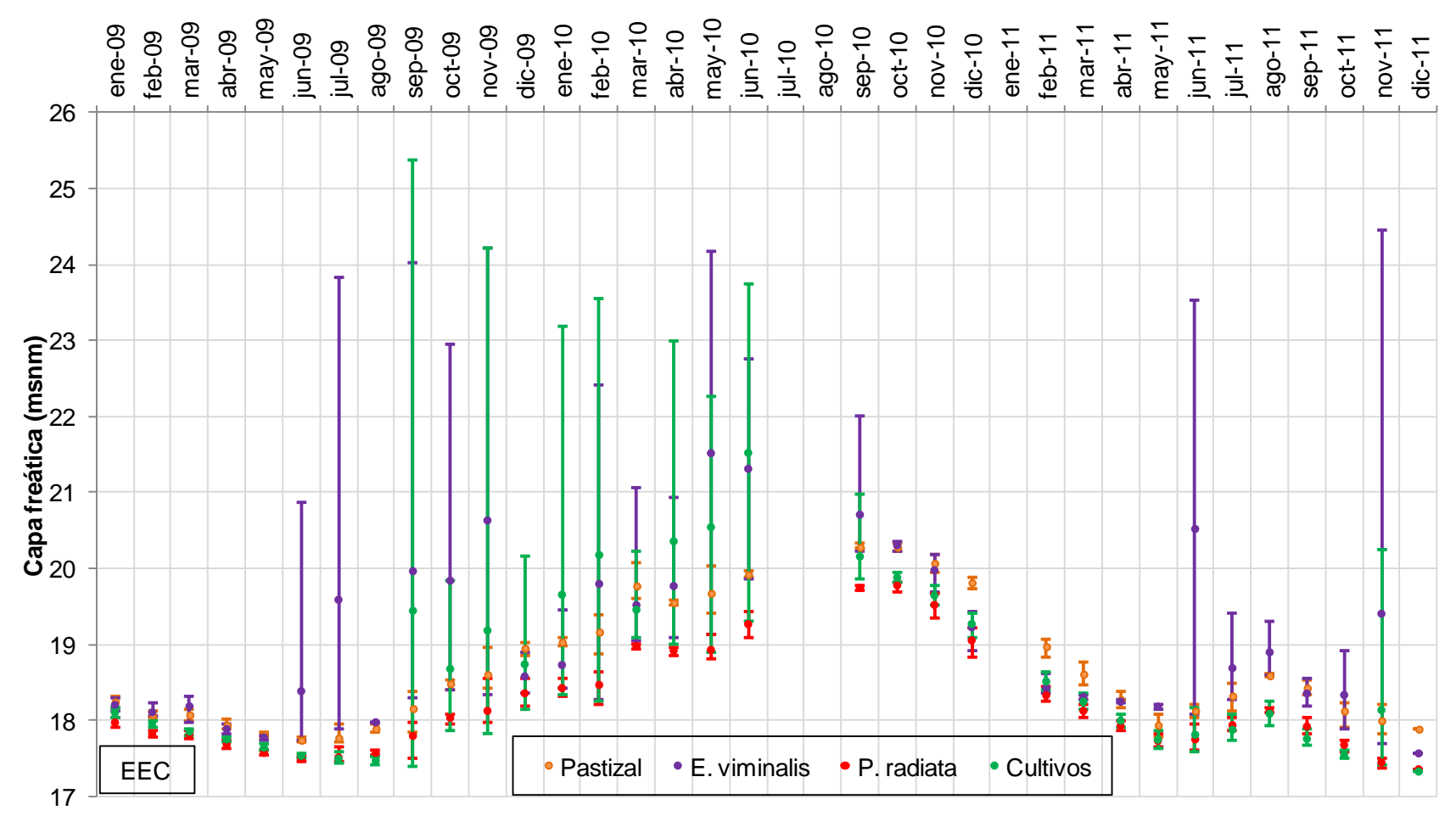

Gráfico IV.2. Evolución de los niveles de capa freática bajo cuatro coberturas vegetales de la pampa ondulada. Niveles de capa freática expresados en metros sobre el nivel del mar (msnm). 


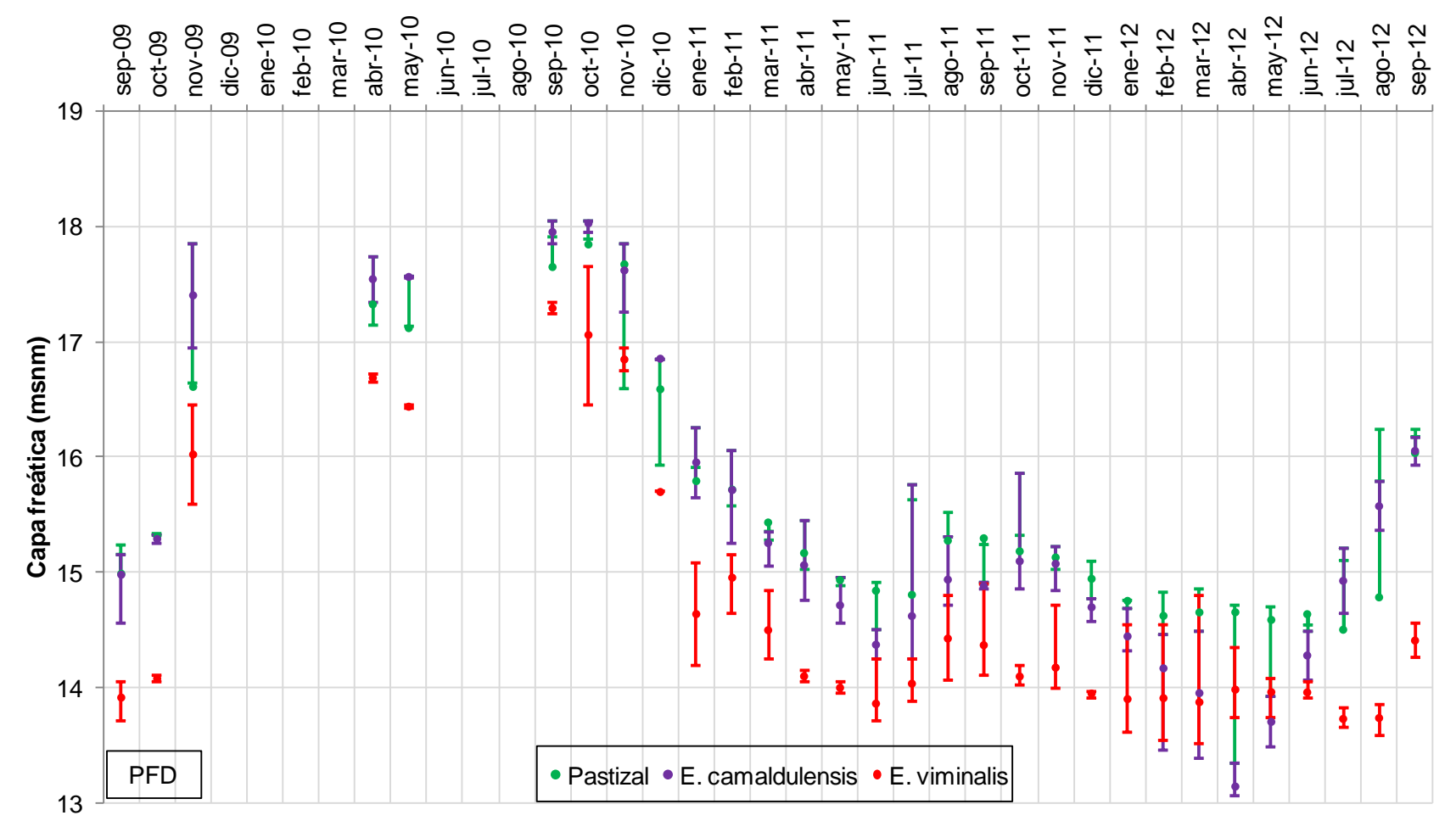

Gráfico IV.3. Evolución de los niveles de capa freática bajo tres coberturas vegetales de la pampa deprimida. Niveles de capa freática expresados en metros sobre el nivel del mar (msnm).

En estos gráficos (Gráficos IV.2 y IV.3) se visualizan los tipos de uso/cobertura por sitio de estudio (EEC y PFD). En ellos, y para cada mes del período total considerado, se indican los valores máximos y mínimos reales (medidos) y los valores medios del nivel de capa freática (calculados). Debe tenerse en cuenta, que los valores individuales asignados a la cobertura de pastizal, son el resultado de promediar los datos provenientes de los pozos designados con ese uso/cobertura en el apartado 4.2.2.

En el caso del PFD, los pozos bajo pastizal muestran una elevada correlación lineal $(0,95 \geq r \geq 0,85 ; \alpha=0,05)$. No obstante, el pozo 2 de la EEC demostró un comportamiento diferencial respecto a los otros pozos en situación de pastizal, expresado por valores de correlación lineal significativos pero bajos $(0,62 \geq r \geq 0,56 ; \alpha=0,05)$. Este comportamiento se atribuyó al efecto de la rotación de cultivos que se desarrolla junto al pozo (a menos de $10 \mathrm{~m}$ de distancia), por lo que se individualizó este último bajo el uso/cobertura de "Cultivos". El resto de los pozos de EEC situados sobre pastos, mostraron una elevada correlación $(0,97 \geq r \geq 0,88 ; \alpha=0,05)$ y se promediaron en el uso "Pastizal". 
De los gráficos IV.2 y IV.3, se desprende que el comportamiento o evolución temporal del nivel freático es similar para todos los usos/coberturas. Esto responde a que cada uno de los pozos muestreados constituyen puntos de monitoreo de un sistema subterráneo integrado, cuyo comportamiento regional es homogéneo y dependiente del gradiente topográfico general, de las lluvias, de la demanda atmosférica y de las características de los suelos. Resulta importante destacar que las diferencias halladas entre la profundidad de la capa freática bajo cada uso, deben vincularse a la posición topográfica de los pozos (Tabla IV.6, apartado 4.2.2), y es por eso que se eligió mostrar los niveles freáticos como cotas (msnm) y no como profundidades.

Las diferencias observables entre las alturas de los niveles freáticos bajo cada uso/cobertura en EEC permiten identificar gradientes hídricos entre estos usos (Gráficos IV.2). Este comportamiento es aún más evidente en PFD (Gráfico IV.3), donde las diferencias entre los usos/cobertura forestales y el pastizal llegan a superar los $2 \mathrm{~m}$, y puede atribuirse a un consumo diferencial del recurso agua por parte de las distintas coberturas. Sin embargo, al tratarse de un análisis entre pozos y no entre isofreáticas ${ }^{21}$, no es correcto hablar de gradientes hídricos sino más bien de diferencias entre los niveles de capa freática o desniveles. Aún así, es posible identificar la existencia de un consumo irregular y dependiente del tipo de vegetación o uso del terreno.

Al analizar los datos bajo un mismo nivel de referencia (msnm) y con la consideración de que ninguno de los pozos se encuentra en una situación topográfica de bajo, sino más bien de loma o media loma, fue posible establecer ciertas asociaciones de comportamiento que surgen de establecer los valores máximos, mínimos y medios de las variaciones del nivel de capa freática entre los distintos usos.

En EEC, llama sensiblemente la atención los picos de ascenso de capa freática bajo el rodal de E. viminalis y, ocasionalmente, bajo el uso de Cultivos (Gráfico IV.2). La causa de este comportamiento no es del todo clara, sin embargo, es posible identificar que estos picos ocurrieron luego de lluvias intensas y períodos prolongados sin ellas, donde el suelo se encontraba aparentemente seco en superficie. El carácter extraordinario de estos valores hizo que no sean considerados en los análisis y requerirán atención en futuras investigaciones.

\footnotetext{
${ }^{21}$ Curvas que unen puntos de igual nivel de capa freática
} 
Al margen de lo anterior, en EEC fue posible establecer un comportamiento similar de nivel freático en los pares: $E$. viminalis-Pastizal $(r=69 ; \alpha=0,05)$, con una profundidad de capa más superficial en comparación con el par: $P$. radiata-Cultivos $(r=0,98 ; \alpha=0,05)$. Este último par presentó un nivel sistemáticamente más bajo de capa freática, lo que puede atribuirse a un mayor consumo de agua por parte de estas coberturas. Las variaciones máximas de nivel hallado en EEC se muestran en la tabla IV.7.

Tabla IV.7. Variaciones máximas y medias del nivel de capa freática entre los distintos usos/coberturas del suelo en EEC.

\begin{tabular}{|c|c|c|c|c|c|c|}
\cline { 2 - 7 } \multicolumn{1}{c|}{} & Past.-Cult. & Past.-Euca. & Past.-Pino & Cult.-Euca. & Cult.-Pino & Euca.-Pino \\
\hline $\boldsymbol{\Delta}(+)[\mathrm{m}]$ & 0,80 & 0,97 & 1,09 & 0,81 & 0,38 & 0,90 \\
\hline$\Delta(-)[\mathbf{m}]$ & 0,00 & $-0,44$ & 0,00 & $-0,32$ & $-0,17$ & 0,00 \\
\hline$\Delta$ prom. [m] & 0,39 & 0,12 & 0,46 & 0,27 & 0,05 & 0,33 \\
\hline
\end{tabular}

Donde: $\Delta(+)$ es la variación positiva máxima entre el nivel de capa freática del par de usos considerados y representa una pendiente o gradiente negativo y por tanto un sentido de flujo de izquierda a derecha (eje: de Past. a Cult.); $\Delta(-)$, representa estas mismas variaciones pero en sentido opuesto (de derecha a izquierda); $\Delta$ prom., es el desnivel promedio; Past., indica la cobertura de pastizal; Cult., la rotación de cultivos; Euca., es el rodal de $E$. viminalis, y Pino, es el rodal de $P$. radiata.

Esta tabla (Tabla IV.7), permite distinguir las pendientes generadas por las variaciones del nivel de capa freática entre los distintos usos. Así, se distinguen gradientes de intensidad variable que muestran, por ejemplo, que los usos/coberturas de rotación de cultivos y $P$. radiata generan interrupciones en la recarga freática más grandes y por ende pendientes más pronunciadas hacia ellos. Se advierte además, que los sitios bajo pastizal actúan como lugares de recarga preferenciales, mientras que bajo $E$. viminalis se establecen las variaciones más extremas.

Estas variaciones manifiestan una gran capacidad de infiltración en ciertos momentos, mientras que en otros revelan una interrupción total de la recarga. A su vez, este comportamiento provoca que por momentos se generen gradientes hacia la forestación de $E$. viminalis $(\Delta=0,97 \mathrm{~m})$ y por momentos se inviertan estos gradientes hacia las coberturas de pastizal $(\Delta=0,44 \mathrm{~m})$ o de rotación de cultivos $(\Delta=0,32 \mathrm{~m})$. Dicha conducta parece estar supeditada a las condiciones de humedad antecedente del suelo, previa a los eventos de lluvias, dado que la ocurrencia de precipitaciones luego de un período prolongado sin ellas genera picos de infiltración y ascensos extraordinarios del nivel de 
capa freática. Pese a todo esto, es preciso tener en cuenta que, dado el distanciamiento existente entre los pozos, las pendientes o gradientes mencionados adoptan valores muy pequeños $(<0,11 \%)$. Esto sugiere que las relaciones observadas pueden ser meramente circunstanciales.

En PFD se observa que los niveles de capa freática son relativamente más profundos bajo las forestaciones, particularmente bajo la de E. viminalis. Esto puede responder a la existencia de gradientes hídricos hacia estos usos. Mientras que el par Pastizal-E. viminalis muestra diferencias de nivel cercanas a $0,5 \mathrm{~m}$, durante gran parte del período de estudio; las diferencias de nivel entre E. viminalis y los otros usos, se mantienen cercanos al metro para el período completo. Esto ubica al E. viminalis como el mayor consumidor del recurso (Tabla IV.8).

Tabla IV.8. Variaciones máximas y medias del nivel de capa freática entre los distintos usos/coberturas del suelo en PFD.

\begin{tabular}{|c|c|c|c|}
\cline { 2 - 4 } \multicolumn{1}{c|}{} & Pastizal-E. cam. & Pastizal-E. vim. & E. cam.-E. vim. \\
\hline$\Delta(+)[\mathrm{m}]$ & 1,58 & 1,74 & 2,26 \\
\hline$\Delta(-)[\mathbf{m}]$ & $-1,21$ & 0,00 & $-1,11$ \\
\hline$\Delta$ prom. $[\mathbf{m}]$ & 0,17 & 0,87 & 0,70 \\
\hline
\end{tabular}

Donde: $\Delta(+)$ es la variación positiva máxima entre el nivel de capa freática del par de usos considerados y representa una pendiente o gradiente negativo y por tanto un sentido de flujo de izquierda a derecha (eje: de Pastizal a E. cam.); $\Delta(-)$ corresponde a estas mismas variaciones pero en sentido opuesto (de derecha a izquierda); $\Delta$ prom., es el desnivel promedio; E. vim., representa al rodal de E. viminalis y E. cam., al de E. camaldulensis.

Es evidente que el desnivel generado entre la cobertura de pastizal y la de $E$. viminalis es invariante y siempre positivo $(\Delta$ prom. $=0,87 \mathrm{~m})$, mientras que no ocurre lo mismo al contrastar el pastizal con la cobertura de E. camaldulensis. Esto indica que mientras la cobertura de E. viminalis actúa como una zona preferencial de descarga y el pastizal como una zona de recarga; la cobertura de E. camaldulensis parece ser capaz de interrumpir o facilitar la recarga del acuífero al ser comparada con los otros usos. Esto último genera desniveles temporales hacia los pastizales $(\Delta=1,21 \mathrm{~m})$ y cobertura de $E$. viminalis $(\Delta=1,11 \mathrm{~m})$. Aún así, prevalecen los gradientes desde el pastizal hacia la cobertura de $E$. camaldulensis $(\Delta$ prom. $=0,17 \mathrm{~m})$ y desde ésta última a la de $E$. viminalis $(\Delta$ prom. $=0,70 \mathrm{~m})$. Del mismo modo que para EEC, el distanciamiento entre pozos hace que las pendientes referidas para PFD no superen el $0,10 \%$. 
A continuación se presentan los valores de aporte (infiltración eficaz) o remoción de agua subterránea (infiltración negativa) resultantes de vincular las variaciones del nivel de capa freática bajo cada tipo de uso/cobertura, con la porosidad del suelo asignada a cada sitio de estudio (Tablas IV.9 y IV.10).

Tabla IV.9. Variaciones mensuales de las reservas de agua subterránea (freática) en la EEC, producto del aporte o remoción de agua en el perfil.

\begin{tabular}{|c|c|c|c|c|c|c|c|c|c|c|c|c|}
\hline \multirow{2}{*}{ Fecha } & \multicolumn{3}{|c|}{ Pastizal } & \multicolumn{3}{|c|}{ Cultivos } & \multicolumn{3}{|c|}{ E. viminalis } & \multicolumn{3}{|c|}{ P. radiata } \\
\hline & $\Delta H(m)$ & Sy & $\Delta \mathrm{h}(\mathrm{mm})$ & $\Delta \mathrm{H}(\mathrm{m})$ & Sy & $\Delta \mathrm{h}(\mathrm{mm})$ & $\Delta H(m)$ & Sy & $\Delta \mathrm{h}(\mathrm{mm})$ & $\Delta H(m)$ & Sy & $\Delta \mathrm{h}(\mathrm{mm})$ \\
\hline ene-09 & $-0,19$ & 0,10 & $-19,2$ & $-0,16$ & 0,10 & $-16,2$ & $-0,19$ & 0,10 & $-19,0$ & $-0,18$ & 0,10 & $-17,6$ \\
\hline feb-09 & $-0,11$ & 0,10 & $-11,0$ & $-0,13$ & 0,10 & $-13,2$ & 0,23 & 0,10 & 22,8 & $-0,08$ & 0,10 & $-8,5$ \\
\hline mar-09 & $-0,01$ & 0,10 & $-0,8$ & $-0,09$ & 0,10 & $-8,8$ & $-0,36$ & 0,10 & $-36,4$ & $-0,05$ & 0,10 & $-5,3$ \\
\hline abr-09 & $-0,16$ & 0,10 & $-16,1$ & $-0,10$ & 0,10 & $-9,8$ & $-0,19$ & 0,10 & $-18,5$ & $-0,12$ & 0,10 & $-12,1$ \\
\hline may-09 & $-0,08$ & 0,10 & $-7,9$ & $-0,11$ & 0,10 & $-11,0$ & 0,02 & 0,10 & 1,6 & $-0,08$ & 0,10 & $-7,6$ \\
\hline jun-09 & $-0,07$ & 0,10 & $-6,5$ & $-0,10$ & 0,10 & $-10,3$ & 6,03 & 0,10 & 603,3 & $-0,07$ & 0,10 & $-6,7$ \\
\hline jul-09 & 0,24 & 0,10 & 24,0 & 0,06 & 0,10 & 6,0 & $-5,85$ & 0,10 & $-585,3$ & 0,14 & 0,10 & 14,2 \\
\hline ago-09 & $-0,11$ & 0,10 & $-11,0$ & $-0,13$ & 0,10 & $-13,1$ & 1,11 & 0,10 & 111,0 & $-0,09$ & 0,10 & $-9,3$ \\
\hline sep-09 & 0,55 & 0,10 & 55,2 & 0,47 & 0,10 & 46,7 & $-0,69$ & 0,10 & $-68,8$ & 0,44 & 0,10 & 44,1 \\
\hline oct-09 & 0,19 & 0,10 & 18,8 & 0,15 & 0,10 & 14,6 & 0,78 & 0,10 & 77,9 & 0,13 & 0,10 & 12,7 \\
\hline nov-09 & 0,43 & 0,10 & 43,3 & 0,37 & 0,10 & 36,9 & $-0,59$ & 0,10 & $-59,3$ & 0,29 & 0,10 & 28,9 \\
\hline dic-09 & $-0,02$ & 0,10 & $-2,4$ & 4,81 & 0,10 & 481,2 & 0,87 & 0,10 & 86,9 & 0,18 & 0,10 & 17,7 \\
\hline ene-10 & $-0,12$ & 0,10 & $-12,4$ & $-4,95$ & 0,10 & $-495,0$ & $-1,17$ & 0,10 & $-116,7$ & $-0,33$ & 0,10 & $-33,1$ \\
\hline feb-10 & 0,87 & 0,10 & 87,4 & 1,13 & 0,10 & 112,6 & 0,77 & 0,10 & 77,3 & 0,79 & 0,10 & 79,3 \\
\hline mar-10 & $-0,23$ & 0,10 & $-22,6$ & $-0,36$ & 0,10 & $-36,4$ & 0,03 & 0,10 & 3,1 & $-0,16$ & 0,10 & $-15,9$ \\
\hline abr-10 & $-0,09$ & 0,10 & $-8,8$ & $-0,10$ & 0,10 & $-9,9$ & 0,08 & 0,10 & 8,0 & $-0,02$ & 0,10 & $-2,1$ \\
\hline may- 10 & 0,45 & 0,10 & 44,8 & 0,39 & 0,10 & 39,3 & 0,71 & 0,10 & 70,6 & 0,27 & 0,10 & 27,0 \\
\hline jun-10 & 0,39 & 0,10 & 38,6 & 1,67 & 0,10 & 166,5 & 2,14 & 0,10 & 214,1 & 0,62 & 0,10 & 61,6 \\
\hline sep-10 & 0,07 & 0,10 & & $-1,03$ & 0,10 & $-103,0$ & $-1,66$ & 0,10 & $-166,2$ & 0,11 & 0,10 & 11,3 \\
\hline oct-10 & $-0,14$ & 0,10 & $-13,8$ & $-0,16$ & 0,10 & $-16,1$ & $-0,16$ & 0,10 & $-16,3$ & $-0,16$ & 0,10 & $-16,2$ \\
\hline nov-10 & $-0,36$ & 0,10 & $-35,9$ & $-0,37$ & 0,10 & $-37,0$ & $-0,76$ & 0,10 & $-75,8$ & $-0,45$ & 0,10 & $-44,9$ \\
\hline dic-10 & $-0,78$ & 0,10 & $-77,7$ & $-0,77$ & 0,10 & $-76,7$ & $-0,81$ & 0,10 & $-81,2$ & $-0,76$ & 0,10 & $-76,4$ \\
\hline feb-11 & $-0,29$ & 0,10 & $-29,4$ & $-0,28$ & 0,10 & $-28,2$ & $-0,28$ & 0,10 & $-27,8$ & $-0,24$ & 0,10 & $-24,0$ \\
\hline mar-11 & $-0,37$ & 0,10 & $-37,3$ & $-0,28$ & 0,10 & $-27,7$ & $-0,07$ & 0,10 & $-7,1$ & $-0,22$ & 0,10 & $-21,9$ \\
\hline$a b r-11$ & $-0,30$ & 0,10 & $-29,9$ & $-0,22$ & 0,10 & $-22,2$ & $-0,06$ & 0,10 & $-5,7$ & $-0,18$ & 0,10 & $-17,5$ \\
\hline may-11 & $-0,02$ & 0,10 & $-2,2$ & $-0,25$ & 0,10 & $-24,9$ & $-0,12$ & 0,10 & $-11,8$ & $-0,19$ & 0,10 & $-18,6$ \\
\hline jun-11 & 0,28 & 0,10 & 27,5 & 0,21 & 0,10 & 20,9 & 0,29 & 0,10 & 28,7 & 0,28 & 0,10 & 27,6 \\
\hline jul-11 & 0,27 & 0,10 & 27,4 & 0,43 & 0,10 & 42,7 & 0,68 & 0,10 & 67,7 & 0,25 & 0,10 & 24,8 \\
\hline ago-11 & $-0,09$ & 0,10 & $-9,0$ & $-0,37$ & 0,10 & $-36,8$ & $-0,50$ & 0,10 & $-49,7$ & $-0,11$ & 0,10 & $-11,1$ \\
\hline sep-11 & $-0,39$ & 0,10 & $-38,8$ & $-0,27$ & 0,10 & $-26,7$ & $-0,50$ & 0,10 & $-49,7$ & $-0,31$ & 0,10 & $-31,4$ \\
\hline oct-11 & $-0,15$ & 0,10 & $-14,7$ & $-0,17$ & 0,10 & $-17,2$ & $-0,32$ & 0,10 & $-32,0$ & $-0,23$ & 0,10 & $-23,2$ \\
\hline nov-11 & $-0,10$ & 0,10 & $-10,3$ & $-0,11$ & 0,10 & $-11,3$ & $-0,18$ & 0,10 & $-17,7$ & $-0,14$ & 0,10 & $-14,3$ \\
\hline dic-11 & 0,00 & 0,10 & 0,0 & 0,00 & 0,10 & 0,0 & 0,00 & 0,10 & 0,0 & 0,00 & 0,10 & 0,0 \\
\hline Total & & & $-43,7$ & & & $-84,1$ & & & $-72,1$ & & & $-68,5$ \\
\hline
\end{tabular}

Donde: $\Delta \mathrm{H}$, es la variación de nivel de la capa freática; Sy, es la porosidad eficaz 0 rendimiento específico (adimensional) y $\Delta \mathrm{h}$, es igual a la infiltración eficaz $\left(\mathrm{f}_{\mathrm{ss}}\right)$ cuando adopta valores positivos e igual a la "infiltración negativa" (remoción de agua por absorción directa o movimiento vertical en el perfil) cuando toma valores negativos. 
Tabla IV.10. Variaciones mensuales de las reservas de agua subterránea (freática) en el PFD, producto del aporte o remoción de agua en el perfil.

\begin{tabular}{|c|c|c|c|c|c|c|c|c|c|}
\hline \multirow{2}{*}{ Fecha } & \multicolumn{3}{|c|}{ Pastizal } & \multicolumn{3}{|c|}{ E. camaldulensis } & \multicolumn{3}{|c|}{ E. viminalis } \\
\hline & $\Delta \mathrm{H}(\mathrm{m})$ & Sy & $\Delta h(\mathrm{~mm})$ & $\Delta H(m)$ & Sy & $\Delta h(m m)$ & $\Delta H(m)$ & Sy & $\Delta \mathrm{h}(\mathrm{mm})$ \\
\hline sep-09 & 0,68 & 0,07 & 47,46 & 0,70 & 0,07 & 49,00 & 0,34 & 0,07 & 23,80 \\
\hline oct-09 & 1,36 & 0,07 & 95,06 & 2,59 & 0,07 & 181,30 & 1,55 & 0,07 & 108,50 \\
\hline nov-09 & 0,65 & 0,07 & 45,25 & $-0,50$ & 0,07 & $-34,72$ & 1,05 & 0,07 & 73,50 \\
\hline$a b r-10$ & $-0,15$ & 0,07 & $-10,67$ & 0,23 & 0,07 & 15,82 & $-0,20$ & 0,07 & $-14,00$ \\
\hline may-10 & 0,39 & 0,07 & 27,17 & 0,27 & 0,07 & 18,90 & 0,79 & 0,07 & 55,30 \\
\hline sep-10 & 0,31 & 0,07 & 21,96 & 0,00 & 0,07 & 0,00 & 0,41 & 0,07 & 28,70 \\
\hline oct-10 & 0,05 & 0,07 & 3,37 & 0,00 & 0,07 & 0,00 & $-0,90$ & 0,07 & $-63,00$ \\
\hline nov-10 & $-1,30$ & 0,07 & $-91,00$ & $-0,99$ & 0,07 & $-69,30$ & $-1,05$ & 0,07 & $-73,50$ \\
\hline dic-10 & $-0,94$ & 0,07 & $-65,66$ & $-0,60$ & 0,07 & $-42,00$ & $-0,62$ & 0,07 & $-43,40$ \\
\hline ene-11 & 0,26 & 0,07 & 18,34 & $-0,30$ & 0,07 & $-21,00$ & 0,00 & 0,07 & 0,00 \\
\hline feb-11 & $-0,33$ & 0,07 & $-23,38$ & $-0,60$ & 0,07 & $-42,00$ & $-0,23$ & 0,07 & $-16,10$ \\
\hline mar-11 & $-0,32$ & 0,07 & $-22,40$ & $-0,10$ & 0,07 & $-7,00$ & $-0,70$ & 0,07 & $-49,00$ \\
\hline$a b r-11$ & $-0,24$ & 0,07 & $-16,80$ & $-0,70$ & 0,07 & $-49,00$ & $-0,15$ & 0,07 & $-10,50$ \\
\hline may-11 & $-0,19$ & 0,07 & $-13,30$ & $-0,05$ & 0,07 & $-3,50$ & $-0,25$ & 0,07 & $-17,50$ \\
\hline jun-11 & 0,04 & 0,07 & 2,80 & $-0,15$ & 0,07 & $-10,50$ & 0,50 & 0,07 & 35,00 \\
\hline jul-11 & 0,24 & 0,07 & 16,52 & 0,36 & 0,07 & 25,20 & $-0,19$ & 0,07 & $-13,30$ \\
\hline ago-11 & 0,12 & 0,07 & 8,40 & 0,20 & 0,07 & 14,00 & 0,21 & 0,07 & 14,70 \\
\hline sep-11 & $-0,02$ & 0,07 & $-1,54$ & 0,04 & 0,07 & 2,80 & $-0,22$ & 0,07 & $-15,40$ \\
\hline oct-11 & $-0,12$ & 0,07 & $-8,54$ & 0,27 & 0,07 & 18,90 & $-0,06$ & 0,07 & $-4,20$ \\
\hline nov-11 & $-0,05$ & 0,07 & $-3,64$ & $-0,45$ & 0,07 & $-31,50$ & $-0,02$ & 0,07 & $-1,40$ \\
\hline dic-11 & $-0,30$ & 0,07 & $-20,72$ & $-0,34$ & 0,07 & $-23,80$ & $-0,22$ & 0,07 & $-15,40$ \\
\hline ene-12 & $-0,20$ & 0,07 & $-13,72$ & $-0,01$ & 0,07 & $-0,70$ & $-0,18$ & 0,07 & $-12,60$ \\
\hline feb-12 & 0,14 & 0,07 & 9,80 & $-1,04$ & 0,07 & $-72,80$ & $-0,05$ & 0,07 & $-3,50$ \\
\hline mar-12 & $-0,13$ & 0,07 & $-8,82$ & $-0,33$ & 0,07 & $-23,10$ & 0,23 & 0,07 & 16,10 \\
\hline abr-12 & $-0,06$ & 0,07 & $-4,06$ & 0,43 & 0,07 & 30,24 & $-0,01$ & 0,07 & $-0,70$ \\
\hline may-12 & 0,20 & 0,07 & 14,14 & 0,58 & 0,07 & 40,32 & 0,31 & 0,07 & 21,70 \\
\hline jun-12 & $-0,15$ & 0,07 & $-10,22$ & 0,58 & 0,07 & 40,32 & $-0,23$ & 0,07 & $-16,10$ \\
\hline jul-12 & $-0,11$ & 0,07 & $-7,56$ & 0,72 & 0,07 & 50,40 & $-0,23$ & 0,07 & $-16,10$ \\
\hline ago-12 & 1,39 & 0,07 & 97,44 & 0,58 & 0,07 & 40,32 & 0,67 & 0,07 & 46,90 \\
\hline sep-12 & 0,41 & 0,07 & 28,42 & 0,24 & 0,07 & 16,80 & 0,30 & 0,07 & 21,00 \\
\hline Total & & & 114,10 & & & 113,40 & & & 59,5 \\
\hline
\end{tabular}

Donde: $\Delta \mathrm{H}$, es la variación de nivel de la capa freática; Sy, es la porosidad eficaz 0 rendimiento específico (adimensional) y $\Delta \mathrm{h}$, es igual a la infiltración eficaz $\left(\mathrm{f}_{\mathrm{sS}}\right)$ cuando adopta valores positivos e igual a la "infiltración negativa" (remoción de agua por absorción directa o movimiento vertical en el perfil) cuando toma valores negativos.

Como se observa en estas tablas (Tablas IV.9 y IV.10), el comportamiento o tendencia general de los pozos bajo los distintos usos es semejante para cada sitio, sin embargo dejan en evidencia un proceso de descarga neta para el caso de EEC y de recarga neta para PFD. Esto no es extraño a nivel de paisaje, ya que estos sitios se 
caracterizan por presentar capas freáticas a distintas profundidades: mientras que en PFD se mantiene una capa freática superficial con fluctuaciones verticales que alcanzan los $5 \mathrm{~m}$ y un nivel promedio por encima de los 4 metros sobre el nivel del terreno (mbnt), en EEC los niveles freáticos se hallan por debajo de los $5 \mathrm{mbnt}$, con variaciones inferiores a los $2,8 \mathrm{~m}$. Con esto se quiere indicar que es esperable que en el balance general entre las entradas y salidas del sistema freático, prevalezcan los balances negativos en EEC, con el consecuente descenso o depresión del acuífero freático, y los balances positivos en PFD, con asensos graduales del nivel freático que, como es sabido, en ocasiones alcanzan la superficie terrestre y provocan las inundaciones características de la pampa deprimida.

Las descargas generales observadas en EEC se verifican parcialmente en el apartado 5.3 donde los balances seriados de Thornthwaite aportaron valores deficitarios de $379 \mathrm{~mm}$ para $E$. viminalis y de $510 \mathrm{~mm}$ para $P$. radiata. En el caso de PFD en cambio, este control no es posible ya que los balances del apartado 5.3 manifiestan excesos de $211 \mathrm{~mm}$ en Pastizal y déficits de $336 \mathrm{~mm}$ y $645 \mathrm{~mm}$ bajo $E$. camaldulensis y $E$. viminalis, respectivamente. Sin embargo, como fue aclarado en el apartado 5.3, los valores de agua útil estimados para el caso de PFD deberían ser superiores a los trabajados, ya que en este sitio el nivel de capa freática predomina por sobre los $4 \mathrm{~m}$ de profundidad, cosa que no sucede en EEC.

Si se analizan ahora, los períodos de toma de datos en ambos sitios, se evidencia que están desplazados. Esto permite inferir que en los años 2009 y parte del 2010 sucedieron lluvias extraordinarias que determinaron ascensos de la capa freática también extraordinarios, con máximos en junio-octubre de 2010 de hasta $4 \mathrm{~m}$ en la EEC y de $2 \mathrm{~m}$ en el PFD, y que los valores mínimos se encontrarían en junio de 2008, dado que fue un año atípico, muy seco.

En el caso de querer comparar los valores de variaciones del nivel de capa freática por aporte (infiltración eficaz) o remoción de agua por absorción directa o movimiento vertical en el perfil, se debe acotar los datos al período de tiempo que comparten (septiembre de 2009-diciembre de 2011), obteniéndose los valores que muestra la tabla IV.11. 
Tabla IV.11. Variaciones totales de las reservas de agua subterránea (freática) para el período septiembre de 2009-diciembre de 2011 en EEC y PFD.

\begin{tabular}{|c|c|c|c|c|c|}
\hline $\mathbf{\Delta} \mathbf{h}(\mathbf{m m})$ & Pastizal & Cultivos & E. viminalis & E. camaldulensis & P. radiata \\
\hline EEC & 4,7 & $-7,7$ & $-151,6$ & & $-15,6$ \\
\hline PFD & 8,7 & & 2,8 & $-8,4$ & \\
\hline
\end{tabular}

Donde: $\Delta h$, es igual a la infiltración eficaz $\left(\mathrm{f}_{\mathrm{sS}}\right)$ cuando adopta valores positivos e igual a la "infiltración negativa" (remoción de agua por absorción directa o movimiento vertical en el perfil) cuando toma valores negativos.

Las diferencias entre estos predios, en los 16 meses que comparten, se explican en parte por la mayor demanda atmosférica que presenta EEC frente a PFD, en forma de $\mathrm{ET}_{0}$ (Tabla V.3; apartado 5.3). Esto disminuye las reservas superficiales de agua debiendo recurrir a las del suelo y finalmente a las subterráneas (descarga) para satisfacer la demanda. En cambio, en el caso de PFD, las reservas de agua en superficie se mantienen más tiempo y se suman al contenido de agua del suelo. Completa esta demanda en forma de ETR, el agua sobrenadante infiltra en el suelo saturándolo y finalmente constituye la recarga del acuífero freático.

Si se consideran ahora los valores de aporte o remoción de agua subterránea para los períodos estacionales y anuales bajo cada tipo de uso y sitio de estudio (Tabla IV.12), es posible verificar parcialmente la hipótesis de que las forestaciones favorecen la infiltración en períodos de excesos hídricos, mientras que acentúan los procesos de descarga freática en los períodos con baja pluviometría. 
Tabla IV.12. Variaciones totales de las reservas de agua subterránea (freática) para el período septiembre de 2009-diciembre de 2011 en EEC y PFD.

\begin{tabular}{|c|c|c|c|c|c|c|c|}
\hline \multirow{2}{*}{ Período } & \multicolumn{4}{|c|}{ EEC - $\Delta h(\mathrm{~mm})$} & \multicolumn{3}{|c|}{ PFD - $\Delta h(\mathrm{~mm})$} \\
\hline & Pastizal & Cultivos & E. vim. & P. rad. & Pastizal & E. cam. & E. vim. \\
\hline ver-08 & $-18,7$ & $-30,8$ & $-19,7$ & $-22,4$ & & & \\
\hline oto-09 & $-39,7$ & $-33,2$ & $-34,0$ & $-34,4$ & & & \\
\hline inv-09 & 41,9 & 29,2 & 233,4 & 49,3 & 43,7 & 42,0 & 23,8 \\
\hline pri-09 & 80,6 & 45,6 & $-173,2$ & 23,0 & 144,1 & 153,6 & 182,0 \\
\hline 2009 & 64,7 & 199,3 & 116,2 & 50,5 & 187,8 & 195,6 & 205,8 \\
\hline ver-09 & 73,2 & 94,2 & 271,5 & 78,8 & & & \\
\hline oto-10 & 27,3 & 452,5 & 94,6 & 73,0 & 16,5 & 34,7 & 41,3 \\
\hline inv-10 & 35,6 & $-383,3$ & $-172,8$ & 4,8 & 15,4 & 0,0 & 7,7 \\
\hline pri-10 & $-60,4$ & $-60,0$ & $-136,0$ & $-92,1$ & $-81,1$ & $-69,3$ & $-115,5$ \\
\hline 2010 & 92,1 & $-106,3$ & $-83,1$ & $-9,4$ & $-114,8$ & $-76,6$ & $-109,9$ \\
\hline ver-10 & $-111,2$ & $-106,2$ & $-62,8$ & $-76,0$ & $-83,3$ & $-126,0$ & $-91,0$ \\
\hline oto-11 & $-56,4$ & $-65,9$ & 523,8 & $-28,2$ & $-39,2$ & $-56,0$ & $-10,5$ \\
\hline inv-11 & 37,2 & 14,2 & $-533,9$ & 1,7 & 29,3 & 45,5 & $-9,8$ \\
\hline pri-11 & $-53,2$ & $-40,4$ & $-63,0$ & $-46,0$ & $-30,5$ & $-23,1$ & $-14,0$ \\
\hline 2011 & $-200,4$ & $-177,1$ & $-105,2$ & $-109,6$ & $-64,3$ & $-127,4$ & $-93,1$ \\
\hline ver-11 & & & & & 0,1 & $-5,6$ & 62,3 \\
\hline oto-12 & & & & & $-14,1$ & 0,0 & $-60,9$ \\
\hline inv-12 & & & & & 113,3 & 117,6 & 44,1 \\
\hline 2012 & & & & & 105,4 & 121,8 & 56,7 \\
\hline Total & $-43,7$ & $-84,1$ & $-72,1$ & $-68,5$ & 114,1 & 113,4 & 59,5 \\
\hline
\end{tabular}

Durante la transición 2009-2010, como ya fue mencionado, ocurrieron lluvias extremas que condicionaron ascensos de la capa freática también extremos. Durante este período de excesos, las forestaciones de PFD manifestaron un incremento de la infiltración efectiva con respecto al pastizal (Primavera de 2009 - otoño de 2010), al igual que en EEC (verano 2009 - otoño de 2010). Sin embargo, en el período de déficit más extremo (2011), las forestaciones de PFD incrementaron la descarga del acuífero libre, mientras que en EEC no ocurrió lo mismo. Las forestaciones de EEC atenúan el proceso de descarga frente a los cultivos y a la situación de pastizal. Este fenómeno puede explicarse en parte por la mayor profundidad a la que se encuentra la capa freática y que hace que las forestaciones no cuenten con este recurso. Por otra parte, los mecanismos propios de cada especie para resistir períodos de sequía: control estomático en eucaliptos (Pardo, 2007) y reducida resistencia aerodinámica en pinos (Allen et al., 2006); el efecto de sombreado de la 
canopea forestal, y la capa de litter ${ }^{22}$ o mantillo que se deposita bajo las plantaciones, condicionan un ambiente donde se reduce el consumo de agua en forma de transpiración, a la vez que disminuye la evaporación de la humedad del suelo.

${ }^{22}$ Capa superficial propia de los suelos forestales que consta de restos muertos no alterados de plantas y animales (Hesselman, 1926). Se distingue de su capa inmediata inferior -Humus- porque a pesar de hallarse en cierta etapa de descomposición, el litter es tomado como parte de la cubierta forestal (Pritchet, 1991). 


\subsubsection{Flujos subterráneos}

En el gráfico IV.4 y IV.5 se muestra la evolución temporal del nivel de capa freática en cada uno de los pozos de la red de monitoreo de EEC y PFD, durante el período enero de 2009-diciembre de 2011 y septiembre de 2009-agosto de 2012, respectivamente. En el eje de ordenadas están las fechas de toma de datos para los pozos (eje inferior). En el eje de abscisas, se indica por un lado la profundidad del nivel de la capa freática en metros bajo el nivel del terreno (mbnt) (eje izquierdo inferior), y los valores de lluvia acumulada en $\mathrm{mm}$ (eje izquierdo superior) por el otro. El hietograma que se encuentra en la parte superior del gráfico, representa la precipitación medida semanalmente, conjuntamente con la medición de la capa freática y, por lo tanto, se trata de la precipitación acumulada semanal.

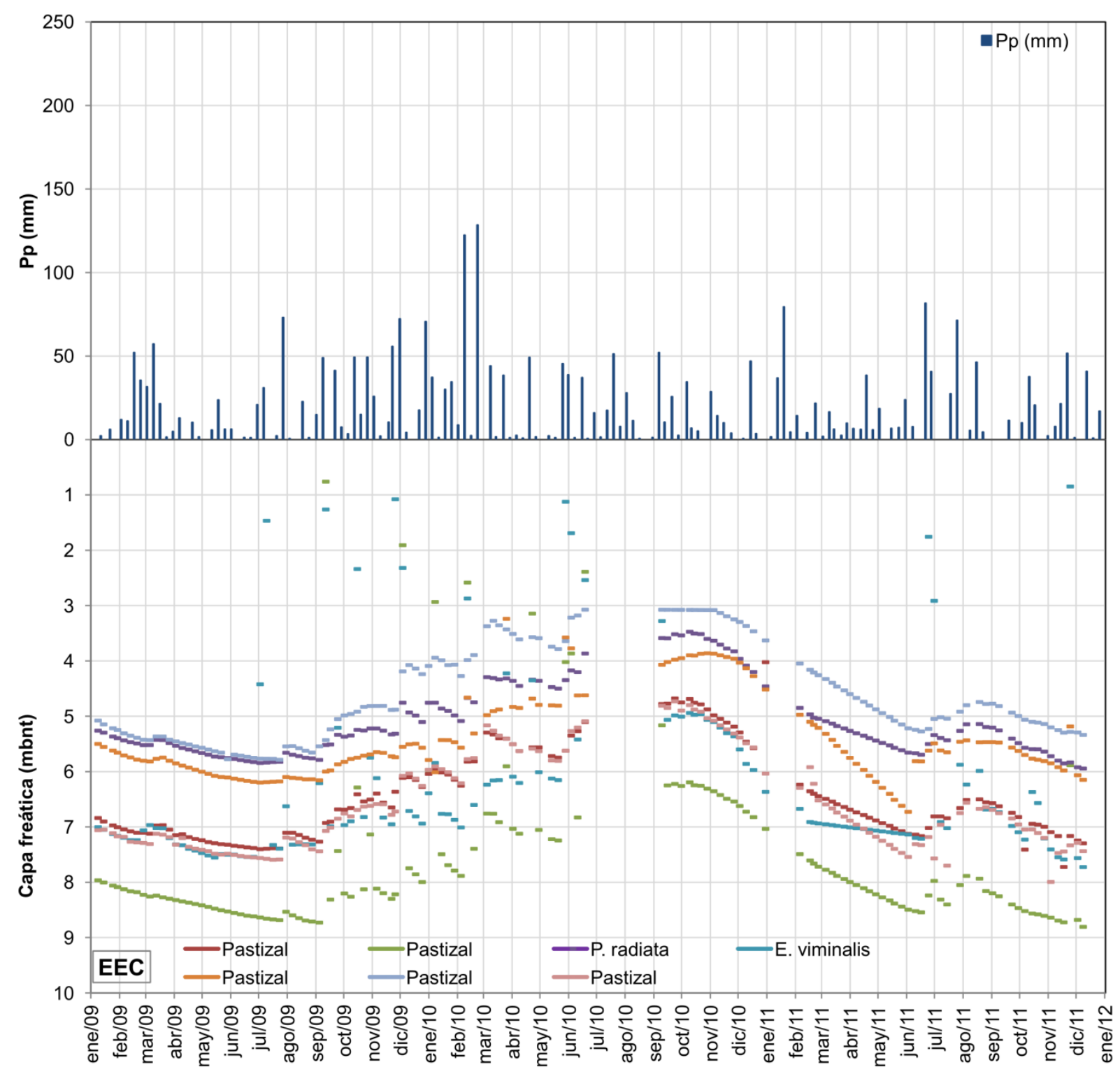

Gráfico IV.4. Precipitaciones acumuladas $(\mathrm{mm})$ y niveles de capa freática (mbnt) de la red de monitoreo de pozos en EEC, para un período de tres años de registros semanales. 


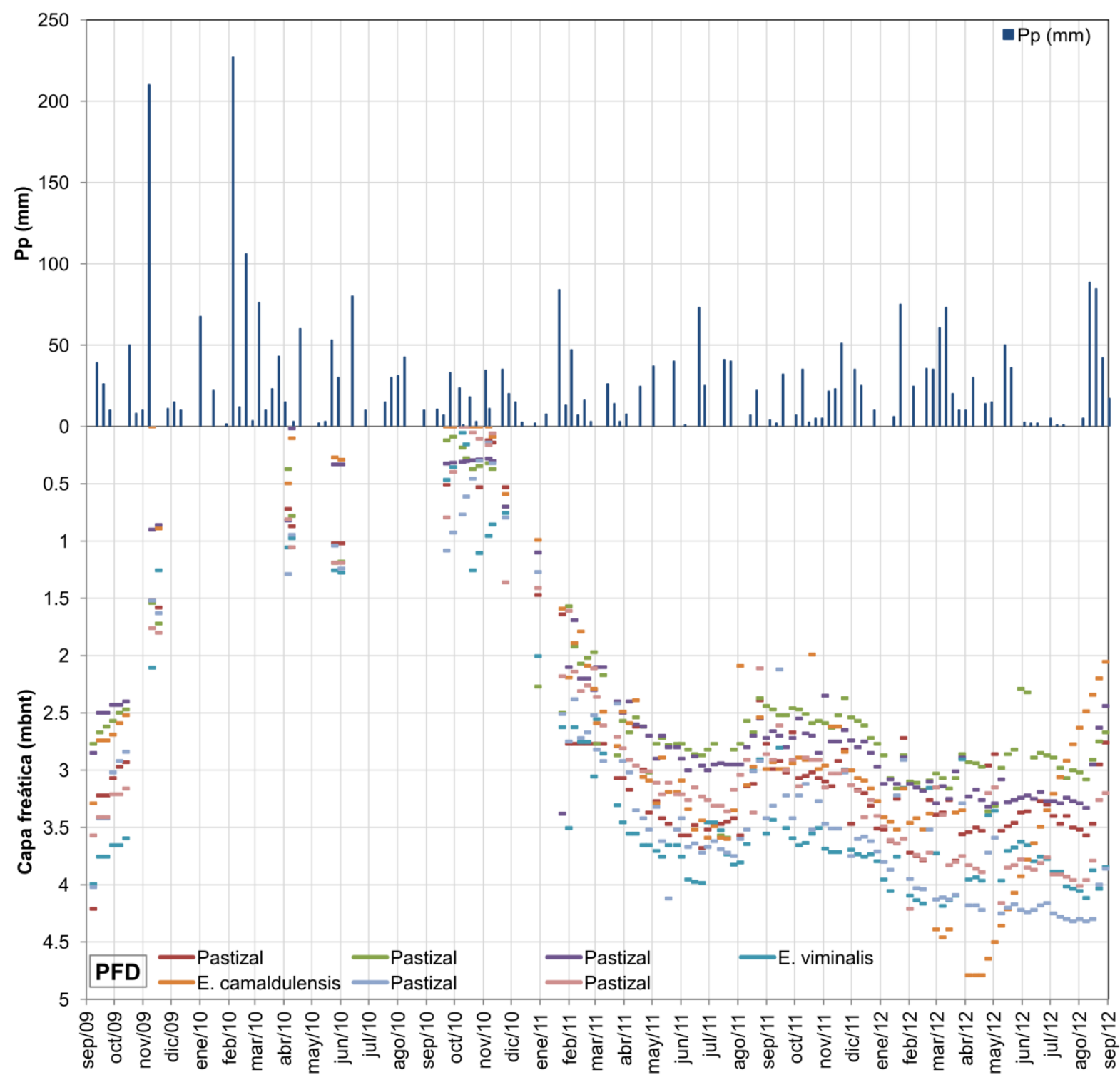

Gráfico IV.5. Precipitaciones acumuladas $(\mathrm{mm})$ y niveles de capa freática (mbnt) de la red de monitoreo de pozos de PFD, para un período de tres años de registros semanales.

En ambos gráficos se observa que la respuesta de la capa freática ante los eventos de lluvia, aunque algo demorada, es evidente y se contrapone a la descripción de suelos del INTA (1989) donde se menciona que estos suelos poseen un drenaje deficiente por impermeabilidad. En efecto, estos ambientes constituyen zonas de recarga donde la denominación de impermeabilidad resulta algo dura y es preferible pensar en que el movimiento vertical de agua es deficiente y logra estos efectos de recarga y descarga gracias a la existencia de sitios preferenciales de infiltración. La presencia de especies forestales freatófitas en estos ambientes, posee una incidencia directa sobre estos movimientos. 
El 2008 fue un año particularmente seco (balance hídrico negativo), con descensos de la capa freática a niveles mínimos extremos hacia fines de junio del 2009. Los dos años subsiguientes (2009 y 2010), revirtieron esta situación con aumentos progresivos del nivel freático hasta alcanzar su máximo en junio-septiembre de 2010. En el caso del PFD, estos aumentos hicieron que la capa freática alcance el nivel topográfico por un período no menor a dos meses. Los años 2011 y 2012, en cambio, se presentaron con variaciones normales de precipitación que no incurrieron en grandes desviaciones de la altura de capa freática $(<1 \mathrm{~m})$.

La evolución temporal de los niveles de capa freática, correspondientes a las redes de monitoreo de cada uno de los sitios de estudio (Gráficos IV.4 y IV.5), presentan una misma tendencia general. Este comportamiento fue mencionado oportunamente en el apartado anterior y no debe causar sorpresa. Sin embargo, al momento de identificar el efecto de las forestaciones en los flujos de agua subterránea, es necesario otro tipo de análisis o acercamiento del problema. Esto se logra con mapas de flujo, donde se representan las líneas de isofreáticas y las direcciones de flujo para distintas épocas. En los gráficos IV.6 y IV.7, se muestran mapas de los predios en estudio, correspondientes a las fechas donde se registraron los valores generales máximos y mínimos de nivel de capa freática. 


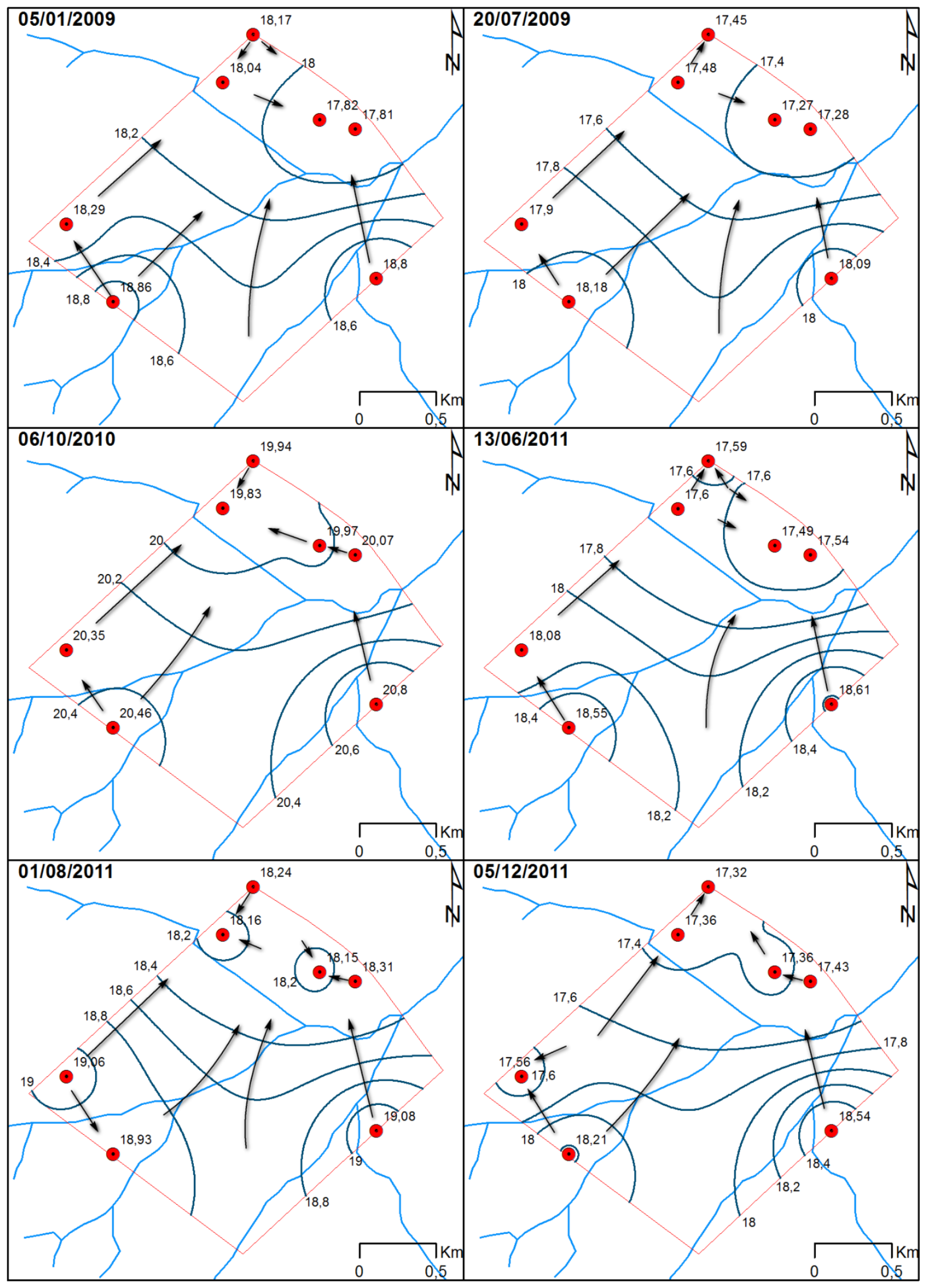

Gráfico IV.6. Isofreáticas y direcciones de flujo correspondientes para los puntos de inflexión de los niveles de capa freática de EEC. Máximos a la izquierda y mínimos a la derecha (Período: enero de 2009-diciembre de 2011). 


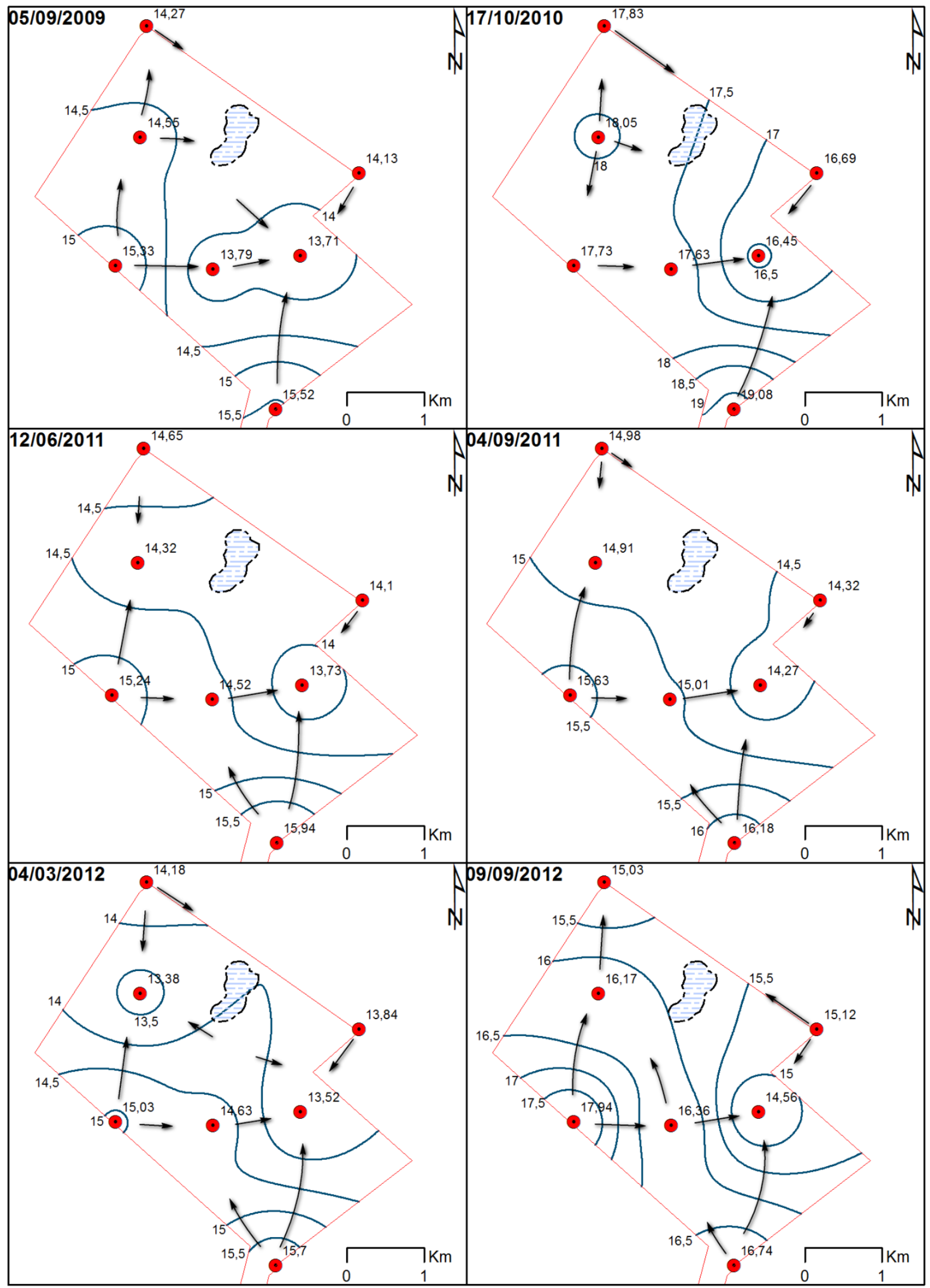

Gráfico IV.7. Isofreáticas y direcciones de flujo correspondientes para los puntos de inflexión de los niveles de capa freática en PFD. Máximos a la izquierda y mínimos a la derecha (Período: septiembre de 2009-agosto de 2012). 
En ambos sitios es posible distinguir un flujo subterráneo general en sentido Nordnordeste, que acompaña la pendiente topográfica regional. Si nos detenemos ahora en que pasa bajo las forestaciones particulares, es posible percibir el consumo diferencial que realizan las distintas especies en comparación con la situación de pastizal. Sin embargo, dado que los años muestreados fueron muy variables en cuanto a su pluviometría, no fue posible establecer un comportamiento de consumo específico u estacional. De esta manera, sucede que mientras que el rodal de $E$. viminalis se comporta como una zona de descarga neta a lo largo de prácticamente todo el período de muestréo en PFD, en EEC no logra revertir el gradiente regional y solo actúa retrazando parcialmente este flujo. El rodal de E. camaldulensis no es ajeno a este comportamiento, por lo que actúa como un lugar de descarga neta a lo largo de prácticamente todo el 2011 y primera mitad del 2012, y el resto del tiempo tampoco logra superar el gradiente regional. En EEC, durante el 2010, el rodal de pino tambien actua como una zona de descarga neta, mientras que el resto del tiempo retraza el flujo general sin lograr revertirlo. La intensidad de estos retrasos quedan representados mediante mapas de isovariaciones, que no son más que aquellos en los que se identifican rangos de igual variación vertical o desnivel de capa freática, generado entre distintas fechas de observación. Sin embargo, estos mapas no permitieron identificar un comportamiento diferencial por parte de las forestaciones y no justifica que sean mostrados.

En relación a los caudales subterráneos de carga y descarga horizontal, los valores calculados de variación confirman la hipótesis de que los flujos subterráneos horizontales no deben ser considerados en los balances hidrológicos de los sitios analizados, dada la escala de trabajo de esta tesis. A continuación se presenta una tabla con las variables correspondientes a los caudales de entrada y salida de cada predio y el valor correspondiente a la diferencia entre ambos expresada en mm/año.

Tabla IV.13. Variaciones de contenido de agua freática por aporte horizontal a nivel predial, expresadas como láminas acumuladas anuales. Parámetros para el cálculo de los caudales subterráneos de entrada y salida modales en los predios EEC y PFD.

\begin{tabular}{|c|c|c|c|c|c|c|c|c|c|}
\cline { 2 - 10 } \multicolumn{1}{c|}{} & \multicolumn{4}{c|}{ Entrada } & \multicolumn{4}{c|}{ Salida } & Variación \\
\cline { 2 - 10 } \multicolumn{1}{c|}{} & $\mathrm{T}\left[\mathrm{m}^{2} / \mathrm{d}\right]$ & $\mathrm{m}[\mathrm{m}]$ & $\mathrm{I}[\%]$ & $\begin{array}{c}\mathrm{R}_{\text {subt }} \\
{\left[\mathrm{m}^{3} / \mathrm{d}\right]}\end{array}$ & $\mathrm{T}\left[\mathrm{m}^{2} / \mathrm{d}\right]$ & $\mathrm{m}[\mathrm{m}]$ & $\mathrm{I}[\%]$ & $\begin{array}{c}\mathrm{R}_{\text {subt }} \\
{\left[\mathrm{m}^{3} / \mathrm{d}\right]}\end{array}$ & {$[\mathrm{mm} / \mathrm{año}]$} \\
\hline EEC & 200 & 2500,64 & 0,0004 & 200,05 & 200 & 1383,12 & 0,0004 & 110,65 & 10,9 \\
\hline PFD & 200 & 4045,30 & 0,0007 & 574,43 & 200 & 3770,27 & 0,0007 & 535,38 & 1,4 \\
\hline
\end{tabular}




\subsection{DISCUSIÓN}

La capacidad de infiltración depende fuertemente de la porosidad de los suelos (Mijares, 1994) y esta última del contenido de materia orgánica (Linsley et al., 1993). El incremento de la infiltración observado en las forestaciones está directamente relacionado a estos conceptos. Las forestaciones estudiadas no solo promueven la porosidad de los suelos por el trabajo mecánico de su profundo sistema radicular, sino que aportan un interesante volumen de materia orgánica al suelo, que se manifiesta a través de un mantillo forestal de espesor variable que puede llegar a superar los $15 \mathrm{~cm}$ (apartado 2.2.1).

La evolución del nivel freático bajo los distintos usos/coberturas analizados, al margen de presentar una evidente diferencia de profundidad que se mantiene más o menos constante a lo largo de todo el período de estudio, presentan variaciones estrechamente vinculadas a los registros de lluvias. Este comportamiento temporal demuestra el carácter integrado del acuífero, cuya conducta regional es homogénea y dependiente del gradiente topográfico, las lluvias y la demanda atmosférica. Las diferencias entre los distintos niveles en cambio, responden a un consumo diferencial por parte de estas coberturas o a variaciones en la estructura y conformación de los suelos bajo cada una de ellas. Este consumo diferencial es posiblemente el principal motivo de esta conducta, la cual sería mucho más evidente aún si se contara con registros temporales más cortos (días, horas). A este respecto, Jobbágy et al. (2006a) demostraron variaciones diarias del nivel freático que alcanzaron los $10 \mathrm{~cm}$, lo cual apoya este razonamiento y demuestra la existencia de una dinámica hídrica subterránea activa a nivel local.

Al analizar los datos provenientes de las redes de monitoreo de pozos en EEC y PFD, se señaló la situación topográfica de los sitios de toma de datos al indicar que se encontraban en posiciones de loma o media loma. Esta información resulta necesaria ya que identifica a estos sitios como zonas de recarga de agua de lluvia, donde no hay acumulación de los excesos hídricos como ocurriría en los bajos. Se entiende entonces, que el aporte o remoción de agua freática en estos puntos estarán dados principalmente por el efecto directo de las coberturas y de los aportes puntuales de las lluvias y no de aportes de zonas vecinas. Estas consideraciones permiten explicar los ascensos atípicos de nivel de capa freática en EEC dado que, como lugares naturales de recarga, son favorecidos por el efecto atribuido a las forestaciones de disminuir la capacidad de retención del agua en el suelo por el efecto estructurante de las raíces y la hidrofobicidad 
de la materia orgánica que ellas aportan (Silveira et al., 2006). A esta situación, se suma la presencia de arcillas expansibles en estos suelos, las cuales provocan la formación de grietas en el suelo ante una disminución importante de la humedad del suelo. Esto favorecería la existencia de sitios preferenciales de infiltración que se sierran rápidamente al humedecerse el suelo.

En virtud de las variaciones de los niveles de capa freática, fue posible establecer en EEC un mayor consumo de agua freática para las coberturas de $P$. radiata y rotación de cultivos frente a las de E. viminalis y pastizal. En PFD en cambio, predominó el consumo de la cobertura de E. viminalis frente al de E. camaldulensis y el de este último frente al de pastizal. La extrapolación de estos efectos no es posible sin un sustento estadístico, sin embargo es posible afirmar que la plantación de pino tuvo mayor disponibilidad de agua freática que la plantación de E. viminalis, posiblemente por un sistema radical más extenso en profundidad que el de eucalipto o simplemente por su alta capacidad de intercepción del agua de lluvia que reduce el ingreso de agua al suelo. De la misma manera, es posible indicar que a igual disponibilidad de agua, el E. viminalis superó en consumo a los rodales de E. camaldulensis, lo cual podría responder a un crecimiento más acelerado de esta especie pero que es necesario de constatar a campo. Finalmente, al confrontar los pastizales con las forestaciones, se observaron variaciones de nivel que superan los $2 \mathrm{~m}$ y representan una evidencia clara del mayor consumo de agua por parte de las forestaciones y de su capacidad de aprovechar el agua freática.

En términos de carga y descarga, fue posible establecer que mientras que los sitios bajo coberturas de pastizal actuaron como lugares preferenciales de recarga en ambos predios, las especies forestales presentaron comportamiento variables. En PFD, la forestación de E. viminalis actuó como un lugar de descarga preferencial durante todo el período de estudió mientras que la cobertura de E. camaldulensis mostró ser capaz de facilitar o interrumpir la recarga al ser comparado con otros usos/coberturas. En EEC en cambio, tanto los sitios bajo $E$. viminalis como los que se encuentran bajo $P$. radiata, manifestaron una gran capacidad de infiltración en ciertos momentos y en otros, una interrupción total de la recarga. Esto último podría estar asociado a las condiciones de humedad antecedente del suelo, dado que en el caso de EEC la ocurrencia de precipitaciones luego de un período prolongado sin ellas genera picos de infiltración y ascensos extraordinarios del nivel de capa freática. Por otro lado, la profundidad a la que se presenta la capa freática parece ser factor importante en el consumo de las 
forestaciones de EEC, dado que al superar los $6 \mathrm{~m}$ de profundidad, los arboles manifiestan una aparente disminución en el consumo hídrico. Esto último se sustenta en el hecho de que el nivel de capa freática bajo el lote de eucalipto en EEC, se encontró mayoritariamente por debajo de esta profundidad (Gráfico IV.4), y en el capítulo siguiente se verá que este lote presenta valores de evapotranspiración inferiores a los del lote de pino y a los lotes de eucalipto de PFD (Gráficos V.11 a V.14). La interpretación de estos resultados destacan que, a pesar de que existen antecedentes de que las raíces de las especies estudiadas alcanzan profundidades de 10 o más metros (Le Maitre et al., 1999), resulta factible adoptar como válido un límite de exploración de $6 \mathrm{~m}$ de profundidad, en coincidencia con lo expuesto por algunos autores (Kelliher et al., 1993; Jobbágy y Jackson, 2004).

Al abordar el análisis de los gradientes o desniveles de capa freática bajo los distintos usos/coberturas, fue posible establecer descensos del nivel freático bajo forestaciones (por sobre los niveles encontrados bajo pastizales), que triplicaron a los documentados por Jobbágy y Jackson (2004). Sin embargo, dada la separación existente entre las redes de pozos en cada sitio de estudio, los gradientes hallados no superaron el $0,11 \%$, encontrándose muy por debajo del valor de $0,5 \%$ indicado por Jobbágy et al. (2006a). Este análisis junto con los valores alcanzados en la tabla IV.13, corroboran el supuesto de que los flujos subterráneos horizontales se pueden despreciar para el grado de detalle abordado en este estudio. Sin embargo, no permiten constatar los gradientes documentadas por Jobbágy el al. (2006a).

Todo lo dicho hace posible verificar la hipótesis que menciona que las forestaciones de PFD favorecen los procesos de infiltración ante períodos de excesos hídricos, mientras que acentúan los períodos de déficits al incrementar la descarga del acuífero freático en períodos con baja pluviometría. En EEC, en cambio, este supuesto se comprueba parcialmente al observar que las forestaciones atenúan o disminuyen los procesos de descarga en épocas secas o de baja pluviometría lo cual no parece estar de acuerdo con los antecedentes locales (Poore y Fries, 1987; Farley et al., 2005; Jobbágy, 2011) y encuentra explicación en que los árboles al no tener libre acceso a una fuente de agua permanente restringen fuertemente su consumo a la vez que retienen humedad en el mantillo forestal y disminuyen su evaporación por el sombreado del mismo con el dosel arbóreo. 
Al analizar los resultados obtenidos del aporte (infiltración eficaz) o remoción de agua subterránea (infiltración negativa), resultantes de vincular las variaciones del nivel de capa freática bajo cada tipo de uso/cobertura con la porosidad de los suelos estudiados, se observa que el comportamiento o tendencia general de los pozos bajo los distintos usos es semejante para cada sitio pero dejan en evidencia un proceso de descarga neta para el caso de EEC y de recarga neta para PFD. A nivel de paisaje, esto se entiende porque PFD presenta un acuífero libre más superficial en relación a EEC. Sin embargo, es probable que estos valores respondan a las características particulares del período de estudio y a una dinámica más compleja cuyo seguimiento debe ser superior al período de estudio analizado.

El análisis de los flujos freáticos en forma de mapas, permitió distinguir nuevamente el consumo diferencial del agua freática por parte de las forestaciones, y además facilitó la percepción del flujo subterráneo general a nivel espacial. Esto posibilitó confirmar que el flujo subterráneo acompaña a la pendiente topográfica regional y que las forestaciones actúan como retardadoras de este flujo y en ocasiones como zonas de carga o descarga neta. No obstante, al querer profundizar el análisis no pudo establecerse un modelo de comportamiento para estos flujos.

Finalmente, es necesario traer a la memoria una característica que vincula los sitios estudiados. Se trata de la existencia de un horizonte Bt que, como fuera señalado por Nuñez et al. (2007), constituye una barrera que evita que el agua subterránea más cargada en sales alcance la superficie de los suelos, deteriorándolos. Esta característica alerta sobre una amenaza potencial en la conversión de pastizales por especies forestales de rápido crecimiento, debido a que esta acción puede contribuir a romper esta barrera y acentuar los problemas de salinidad documentados por Jobbágy y Jackson $(2003,2007)$ y Nosetto et al. (2008), y constituye un aspecto muy importante en estos ambientes que debe ser el objeto de estudio en futuras líneas de trabajo. 


\section{Capítulo 5}

\section{Evapotranspiración}




\subsection{INTRODUCCIÓN}

\subsubsection{Concepto de evapotranspiración}

Del total de agua que llega a la superficie terrestre, un gran porcentaje regresa a la atmosfera en forma de vapor por evaporación directa del agua acumulada en las capas superficiales del suelo, en espejos de agua (ríos, lagos, mares, océanos), de la interceptada por la vegetación, o por transpiración de las plantas. La influencia de la evapotranspiración sobre el ciclo hidrológico es, por tanto, evidentemente importante si se considera que en muchos lugares del mundo el $70 \%$ de la precipitación que llega a la tierra es devuelta a la atmósfera por esta vía y en algunos otros alcanza un $90 \%$ (Custodio y Llamas, 1996).

En condiciones controladas es posible tratar a la evaporación (E) y transpiración (T) como procesos independientes pero, en un ambiente natural con vegetación, se debe hablar de estos dos procesos de forma simultánea bajo el concepto de evapotranspiración (ET) ya que éstos son procesos simultáneos, interdependientes, y por tanto, de difícil medición por separado.

En el gráfico V.1 se esquematiza la evolución de los componentes de la ET (evaporación y transpiración) de un cultivo anual en relación al área foliar por unidad de superficie de suelo debajo de él. En el momento de la siembra, casi el $100 \%$ de la ET ocurre en forma de evaporación, mientras que cuando la cobertura vegetal es completa, más del de 90\% de la ET ocurre como transpiración (Allen et al., 2006). 


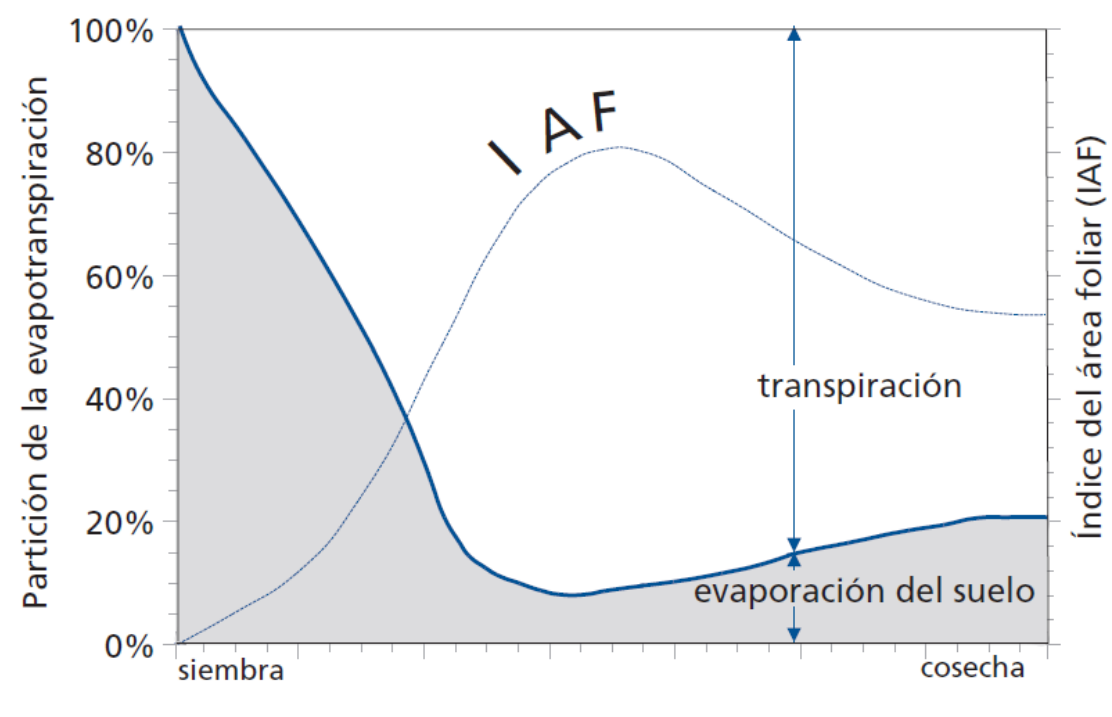

tiempo

Gráfico V.1. Repartición de la evapotranspiración en evaporación y transpiración durante el período de crecimiento de un cultivo anual. Extraído de Allen et al. (2006)

\subsubsection{Evapotranspiración potencial, real y de referencia}

La dificultad que conlleva la determinación de la ET y que depende, entre otros, de dos factores muy variables y de difícil medición como lo son el contenido de humedad del suelo y el desarrollo vegetal de la planta, ha producido a lo largo del tiempo la necesidad de unificar criterios y procurar definiciones que permitan mejorar estas aproximaciones. Por este motivo, Thornthwaite y Penman (Thornthwaite, 1948; Penman, 1948) instauraron el concepto de evapotranspiración potencial (ETP) para caracterizar la demanda atmosférica de agua en forma de vapor. El mismo, se define como la cantidad de agua que se podría evaporar y transpirar de una superficie de vegetación, sin más restricciones que la demanda atmosférica (Jensen et al., 1990), lo cual representa la máxima cantidad de agua que realmente volvería a la atmósfera por evaporación y transpiración y que se conoce con el nombre de evapotranspiración real (ETR) (Custodio y Llamas, 1996).

Con el tiempo, el concepto de ETP fue reevaluado por lo contradictorio de su definición, al presentarse ocasiones en las que su valor no representaba la capacidad evaporativa máxima. Se observó que la ET puede superar a la ETP en cultivos de mayor porte y por lo tanto dejar sin validez a este concepto, desde el punto de vista de su aplicación. Esto llevó al origen del concepto de evapotranspiración de referencia $\left(\mathrm{ET}_{\mathrm{r}}\right)$ 
(Smith et al., 1990) y finalmente al de evapotranspiración de referencia basada en la ecuación de combinación de Penman-Monteith (ET $\mathrm{ET}_{0}$ (Allen et al., 2006), correspondiente a la tasa de ET de un cultivo hipotético con valores fijos de altura $(12 \mathrm{~cm})$, resistencia de la cubierta vegetal $(70 \mathrm{~s} / \mathrm{m})$ y albedo $(0,23)$, que representa la ET de una superficie extensa cubierta de gramíneas verdes, de altura uniforme y crecimiento activo, que cubre completamente el terreno y no padece de falta de agua.

Una vez conocida la evapotranspiración de referencia de un cultivo ( $\mathrm{ET}_{0}$ ), ésta se multiplica por un factor corrector específico (Figura V.1), denominado coeficiente de cultivo $\left(\mathrm{K}_{\mathrm{c}}\right)$, obteniéndose así la ET del cultivo concreto (Domingo et al., 2003).

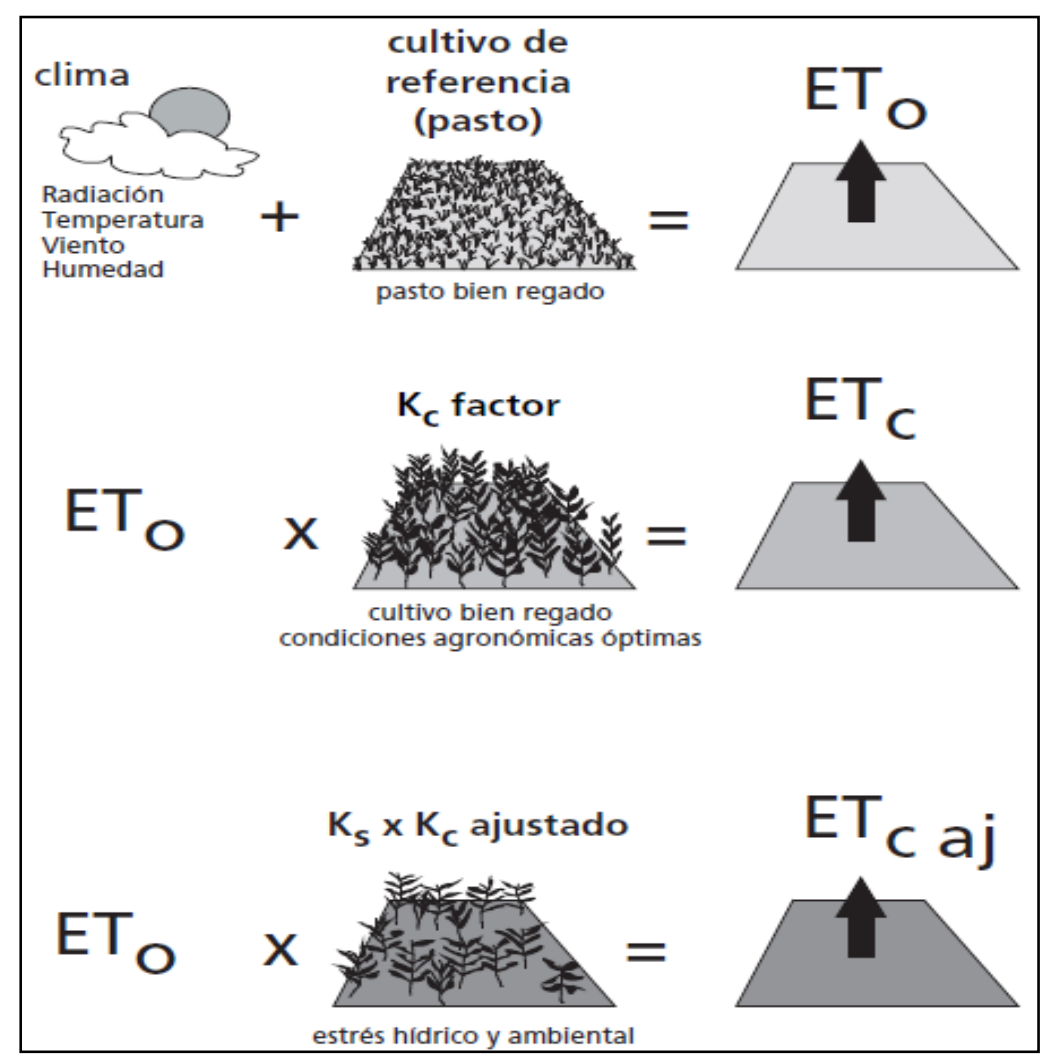

Figura V.1. Evapotranspiración del cultivo de referencia $\left(\mathrm{ET}_{0}\right)$, bajo condiciones estándar $\left(\mathrm{ET}_{\mathrm{c}}\right)$ y bajo condiciones no estándar $\left(\mathrm{ET}_{\mathrm{c} \text { aj }}\right)$. Extraído de Allen et al. (2006)

Los agentes condicionantes del fenómeno de evapotranspiración, son los mismos que afectan a los procesos individuales, evaporación y transpiración. Estos son: energía 
disponible ${ }^{23}$, déficit higrométrico de saturación ${ }^{24}$, temperatura del aire, velocidad y turbulencia del viento y, naturaleza y estado de la superficie evaporante (Mármol, 2006).

\subsubsection{Metodologías de cálculo}

Dentro de los métodos de medición de la ET, se dispone de métodos directos e indirectos. Los primeros están representados por los evaporímetros de suelo y lisímetros (Tanques lisímetros volumétricos y de pesada), y los segundos por la micrometeorología (Métodos aerodinámicos, de balance de energía y sensores remotos), los métodos fisiológicos (conductividad de savia) y los de balance hidrológico, que se aplican a distintas escalas temporales y espaciales.

En este sentido, Domingo et al. (2003) indican que los métodos e instrumentales más usados para la medición de la ET no están exentos de problemas intrínsecos, al requerir calibraciones periódicas, ausencia de lluvias al momento de su utilización, concentraciones de agua superiores al umbral impuesto por su resolución, longitudes de rodal suficiente para ser aplicados $y$, en definitiva, revela que su utilidad para validar modelos se aplica únicamente en períodos y situaciones particulares.

A las complicaciones derivadas de las mediciones de la ET se suman los costos del instrumental y lo laboriosa de su implementación a campo, por lo que resulta común la utilización de métodos empíricos de estimación de la ET. El número de estos métodos es grande y dada la naturaleza de la información que requieren se los divide en aquellos que están basados en la temperatura (Thornthwaite, Blaney y Criddle,), en la humedad del aire (Papadakis, Hamon, Halstead), en la radiación solar global (Markkink, Turc, Jensen y Haise, Hargreaves, Hargreaves y Samani, Doorembos y Pruitt), en la combinación de procesos de balance de energía y transferencia turbulenta (Penman, Penman-Monteith, Penman-FAO, Priestly y Taylor) y los basados en la evaporación (Boucehet, Doorembos y Pruitt, Christiansen y Hargreaves).

${ }^{23}$ Es aquella que proviene de la radiación solar y permite la vaporización del agua al movilizar sus moléculas y desprenderlas de la superficie evaporante.

24 Cantidad de agua necesaria para producir la saturación de la atmosfera. Cuando mayor es su valor, mayor es la capacidad de nuevas adiciones de humedad y por lo tanto mayor es la evaporación del ambiente. 
La FAO, a través de la División de Tierras y Aguas para el Desarrollo, ha sido fundamental en el desarrollo de directrices para la predicción de las necesidades hídricas de los cultivos a nivel mundial (Smith, 2000) al adoptar, en primera instancia, cuatro métodos empíricos para la determinación de ET en la publicación FAO Riego y Drenaje Nro. 24 (Smith et al., 1996) que fuera revisada en 1977 por Doorenbos y Pruitt (1977), entre los que se destaca el de Penman y Blaney Criddle y en segunda instancia, el método de Penman-Monteith.

Los estudios comparados de muchos de estos métodos son nutridos, destacándose, por su validez universal, el realizado en 1990 bajo el auspicio del Comité de Requerimientos de agua de riego de la Sociedad Americana de Ingenieros Civiles (ASCE), donde se evaluó la validez de 20 diferentes métodos mediante un conjunto de datos con lisímetros cuidadosamente seleccionados procedentes de 11 lugares con condiciones climáticas variables (Tabla V.1) (Jensen et al., 1990). En este estudio, tanto como en estudios paralelos (Choisnel et al., 1992), se recomienda la adopción del método de Penman-Monteith, cuya revisión y actualización se encuentra plasmada en la publicación FAO Riego y Drenaje Nro. 56 (Allen et al., 2006).

Tabla V.1. Evaluación de métodos de estimación de $\mathrm{ET}_{0}$ frente a datos lisimétricos en cinco localidades de climas húmedos (HR $\geq 60 \%$ ) y seis localidades de climas áridos (HR $<60 \%$ ). Extraído de Smith (2000)

\begin{tabular}{|c|c|c|c|c|c|c|}
\hline \multirow{2}{*}{$\begin{array}{l}\text { Locations } \\
\text { Performance indicator }\end{array}$} & \multicolumn{3}{|l|}{ Humid. } & \multicolumn{3}{|l|}{ Arid } \\
\hline & Rank No. & Over-estimate (\%) & Standard error & Rank No. & Over-estimate (\%) & Standard error \\
\hline \multicolumn{7}{|l|}{ Combination methods } \\
\hline Penman-Monteith & 1 & +4 & 0.32 & 1 & -1 & 0.49 \\
\hline FAO-24 Penman $(c=1)$ & 14 & +29 & 0.93 & 6 & +12 & 0.69 \\
\hline FAO-24 Penman (corrected) & 19 & +35 & 1.14 & 10 & +18 & 1.1 \\
\hline FAO-PPP-17 Penman & 4 & +16 & 0.67 & 5 & +6 & 0.68 \\
\hline Penman 1963 & 3 & +14 & 0.60 & 7 & -2 & 0.70 \\
\hline Penman 1963, VPD \#3 & 6 & +20 & 0.69 & 4 & +6 & 0.67 \\
\hline 1972 Kimberley Penman & 8 & +18 & 0.71 & 8 & +6 & 0.73 \\
\hline 1982 Kimberley Penman & 7 & +10 & 0.69 & 2 & +3 & 0.54 \\
\hline Businger-van Bavel & 16 & +32 & 1.03 & 11 & +11 & 1.12 \\
\hline \multicolumn{7}{|l|}{ Radiation methods } \\
\hline Priestley Taylor & 5 & -3 & 0.68 & 19 & -27 & 1.89 \\
\hline FAO-Radiation & 11 & +22 & 0.79 & 3 & +6 & 0.62 \\
\hline \multicolumn{7}{|l|}{ Temperature methods } \\
\hline Jensen-Haise & 12 & -18 & 0.84 & 12 & -12 & 1.13 \\
\hline Hargreaves & 10 & +25 & 0.79 & 13 & -9 & 1.17 \\
\hline Turc & 2 & +5 & 0.56 & 18 & -26 & 1.88 \\
\hline SCS Blaney-Crddle & 15 & +17 & 1.01 & 15 & -16 & 1.29 \\
\hline FAO Blaney-Criddle & 9 & +16 & 0.79 & 9 & 0 & 0.76 \\
\hline Thornwaite & 13 & -4 & 0.86 & 20 & -37 & 2.4 \\
\hline \multicolumn{7}{|l|}{ Pan evaporation methods } \\
\hline Class A pan & 20 & +14 & 1.29 & 17 & +21 & 1.54 \\
\hline Christiansen & 18 & -10 & 1.12 & 16 & -6 & 1.41 \\
\hline FAO Class A & 17 & -5 & 1.09 & 14 & +5 & 1.25 \\
\hline
\end{tabular}


Los métodos basados en el balance hídrico, por otro lado, son ampliamente utilizados pudiendo llegar a ser muy precisos. Se trata de una metodología para la estimación de la evapotranspiración (ET), que resulta muy útil en los casos en que es posible medir o estimar la precipitación (P), la escorrentía fluvial (R), las infiltraciones profundas $\left(\mathrm{f}_{\mathrm{sS}}\right)$, y las variaciones del almacenamiento $(\Delta \mathrm{S})$. La ecuación propuesta por la OMM (2011) es:

$$
\mathrm{ET}=\mathrm{P}-\mathrm{R}-\mathrm{f}_{\mathrm{ss}} \pm \Delta \mathrm{S}
$$

Esta ecuación puede ser presentada de una forma más sintética al tratarse de la determinación de la ET anual a lo largo de años hidrológicos (Ecuación V.2). El año hidrológico es aquel cuyo comienzo y fin coincide con la temporada seca y la cantidad de agua almacenada es relativamente pequeña, al punto de que las variaciones del almacenamiento de un año a otro son mínimas. Esto último representa el principio universal de igualdad en el mínimo contenido de agua anual (Novoa, 1998; Giraldo, 2002), y permitiría prescindir del término $\Delta S$ al tomar al año hidrológico como unidad temporal.

$$
\mathrm{ET}=\mathrm{P}-\mathrm{R}-\mathrm{f}_{\mathrm{ss}}
$$

\subsubsection{Evapotranspiración en plantaciones de pino y eucalipto}

Al considerar que el agua no representa una limitante, la evapotranspiración total (evaporación del piso mas la transpiración de las plantas) esta íntimamente vinculada a la radiación incidente y al viento (Poore y Fries, 1987). En esta situación, se esperara que una forestación, lago o pastizal evapotranspiren cantidades equivalentes por unidad de área 0 , dicho de otra forma, que este valor sea igual a la evapotranspiración potencial. Por el contrario, la evapotranspiración real será menor a la potencial en función de la disponibilidad de este recurso e indirectamente dependerá de los mecanismos de los distintos tipos vegetales para obtenerlos (Poore y Fries, 1987). 
Acompañando esta idea, Calder (1992) indicó que los eucaliptos transpiran de forma similar a otras especies de árboles pero aumentan enormemente sus tasas cuando tienen acceso al agua freática. Este comportamiento responde a las estrategias estomáticas y al patrón de sus raíces, y contribuye a la existencia de variadas tasas de transpiración entre especies de eucalipto. Del mismo modo, los pinos presentan un significativo control estomático, como resultado de su reducida resistencia aerodinámica (Allen et al., 2006), lo cual los convierte junto con los eucaliptos en especies muy eficientes en el uso del agua.

El balance netamente vertical que caracteriza la llanura pampeana, hace de la evapotranspiración un mecanismo fundamental en la evolución del nivel freático. La existencia de vegetación freatófita, permite que la evapotranspiración sea capaz de producirse a tasa cercana a la potencial, aún en condiciones en que no existe humedad suficiente en la capa más inmediatamente superior del suelo (Badano, 2010).

Desde la Agencia de Investigación de la Comisión Forestal del Reino Unido (Nisbet et al., 2011), se concluye que los arboles poseen la potencialidad de consumir más agua que otros tipos de vegetación. Esta potencialidad es función de numerosos elementos, como: la especie forestal; ubicación y clima local; el suelo y geología; la gestión; diseño del bosque y del tipo de cobertura que es reemplazado (Neal et al, 1991; Nisbet, 2005; Calder et al, 2008). Además, se indica que este consumo diferencial es el resultado de una mayor capacidad de intercepción por parte de los árboles (copas aerodinámicamente más ásperas) y a las tasas de transpiración potencialmente más elevadas, producto de una capacidad de enraizamiento profundo.

Como regla general, Nisbet et al. (2011), mencionan que un aumento del $10 \%$ en la cobertura forestal equivalen a una disminución en el rendimiento hídrico de 25-40mm (Bosch y Hewlett, 1982) o de 1,5-2\% (Calder y Newson, 1979) en tierras altas. Sin embargo, estas relaciones no pueden mantenerse en tierras bajas y más secas, debido a una ceñida correspondencia entre la precipitación y las pérdidas por evaporación de agua, que condicionan rendimientos mucho más bajos. En estas condiciones, la reducción de agua sería aún mayor, como lo demuestra Calder et al. (2003) en bosques de coníferas, donde un aumento del $10 \%$ en la cobertura forestal condiciona descensos del $10,7 \%$ en la producción de agua.

Bruijnzeel (1997), por su parte, señala que la plantación de especies de rápido crecimiento en áreas con pastos y rastrojos ha traído un decrecimiento considerable en el 
rendimiento hídrico en la estación seca (Mathur y Sajwan, 1978; Smith y Scott, 1992; Waterloo, 1994). Esto ha sido documentado por Calder (1992) para el caso de los eucaliptos, al observar que pueden mantener tasas de evaporación muy altas, particularmente cuando la demanda atmosférica también lo hace. A su vez, en plantaciones de pino (Pinus caribaea de 6 años) Waterloo (1994) ha obtenido valores de ET total de $1.770 \mathrm{~mm}$, producto de una transpiración de $1.250 \mathrm{~mm}$ y una intercepción de $520 \mathrm{~mm}$.

En Chile, Huber et al. (1998) obtuvieron una ET total de 861,836 y $776 \mathrm{~mm}$ para los rodales de $E$. nitens de 8 años y 1560, 850 y 663 árboles/ha, respectivamente. Esto indica una relación directa entre la pérdida de agua por ET del sistema y la densidad de los rodales.

Del mismo modo, Oyarzún y Huber (1999) estimaron que el consumo de agua por evapotranspiración, durante los dos primeros años de mediciones en plantaciones juveniles de $E$. globulus (2 años) y $P$. radiata (4 años), alcanzaba valores cercanos al $30 \%$ de la precipitación mientras que el tercer año llegaba al 58\%. Los valores de ET de los primeros dos años (431 a $639 \mathrm{~mm} / \mathrm{año}$ ) se asemejan a los de una pradera natural, sin embargo, la tendencia general en el consumo de agua, sugiere efectos negativos en las reservas de agua del suelo (disminución de rendimiento hídrico) y un efecto es semejante para ambas plantaciones.

Por su parte, Huber et al. (2010) estudiaron cuatro cuencas hidrográficas forestadas de la región de Biobío, Chile. De ellas, dos presentaban plantaciones de $P$. radiata de 23 años y $32,3 \mathrm{~m}^{2} /$ ha de área basal y las otras dos, plantaciones de $E$. globulus de 9 años y $24,7 \mathrm{~m}^{2} / \mathrm{ha}$ de área basal. Los resultados alcanzados en este estudio, manifestaron una evapotranspiración total de 76 y $70 \%$ para las cuencas con E. globulus y de 65 y $64 \%$ en las cuencas con $P$. radiata, mientras que la ET neta (la que proviene exclusivamente del suelo o, que es igual a la transpiración más la evaporación desde el suelo) presentó valores de 58 y $56 \%$ para pinos y de 73 y $66 \%$ para eucaliptos. Esto último daría cuenta de que los eucaliptos posiblemente manifiestan mayores tasas de transpiración que los pinos.

En Australia, un trabajo sobre el efecto de plantaciones de pino y eucalipto en las aguas subterráneas (Benyon et al., 2006), indica que los estudios hidrológicos alrededor del mundo han demostrado generalmente las plantaciones forestales demandan mayores cantidades de agua respecto a los pastizales y suelos agrícolas de secano (Hibbert, 1967; 
Bosch y Hewlett, 1982). Además, remarca que la mayor demanda evapotranspirativa que caracteriza a las forestaciones (evapotranspiran más que la vegetación de raíces superficiales o poco profundas), es resultado de su mayor porcentaje de intercepción, rugosidad y altura de canopea, su menor albedo, y a su capacidad de acceder a fuentes de agua más profundas (Holmes y Sinclair, 1986; Zhang et al., 1999). Estos autores (Benyon et al., 2006), tras estudiar una serie de situaciones edáficas que van desde suelos permeables, con freática profunda, baja salinidad a suelos arcillosos con freática superficial (0-3m), alcalinos o alcalinos-sódicos, encontraron que el rango de evapotranspiración (415 a $1343 \mathrm{~mm} / \mathrm{año}$ ) era sustancialmente mayor al de agua aplicada como lluvia y riego complementario (362 a 784mm/año), sin embargo, las plantaciones estudiadas solo fueron capases de hacer uso del agua freática bajo una combinación de suelos con texturas medias y capa freática superficial y de baja salinidad.

En Argentina, Rébori (2004) estudió dos montes de E. dunnii (uno joven y otro adulto), instalados en un paisaje plano de Santa $\mathrm{Fe}$, y comprobó que no presentaban diferencias evapotranspirativas entre ellos, ni con un doble cultivo de trigo/soja, aunque si evidenciaban un mejor rendimiento con respecto a este y, por lo tanto, un uso más eficiente del agua. Por otro lado, no se identificaron consumos de agua freática (de 13-15 metros de profundidad) ya que estas alcanzan solo los $10 \mathrm{~m}$ de profundidad.

En los pastizales del Río de la Plata, la sustitución de la vegetación nativa por forestaciones se han interpretado como un riesgo de deterioro en los recursos hídricos y edáficos (Jobbágy, 2011). Esto se sustenta en antecedentes mundiales del consumo diferencial que realizan ambas especies vegetales y se ha documentado localmente como aumentos de las pérdidas evapotranspirativas de 40-80\%, tras la instalación de plantaciones de eucaliptos donde antes había pastizales (Nosetto et al., 2005). Esto ha sido explicado, en gran medida, por un aporte de agua freática que suplementa las precipitaciones en $25-50 \%$ (Engel et al., 2005, Jobbágy y Jackson, 2007). La posibilidad de un consumo extra de agua por parte de las forestaciones, incrementa considerablemente su productividad a la vez que condiciona una fuerte acumulación de sales en el suelo, zona vadosa y acuífero, que puede alcanzar $6 \mathrm{~kg} / \mathrm{m}^{2}$ de sales (Jobbágy y Jackson 2003, 2004, 2007).

Finalmente, puede interpretarse que los balances hídricos de cualquier área o territorio, están fuertemente influenciados por el clima y tipo de uso/cobertura al cual están 
sometidos. Por tanto, si se reconoce que los sitios de estudio poseen características climáticas comparables, se espera que el rodal de pino presente un menor rendimiento hídrico (descarga freática) frente a los de eucalipto $y$, dentro de estos, que el rendimiento hídrico de los rodales de E. viminalis supere al de E. camaldulensis. 


\subsection{MATERIALES Y MÉTODOS}

\subsubsection{Cálculo de $\mathrm{ET}_{0}$ por el método de FAO Penman-Monteith (Agroclima)}

Para el cálculo de $\mathrm{ET}_{0}$ por el método FAO Penman-Monteith se utilizó el programa AGROCLIMA. El mismo fue creado por Pablo Abbate (pabbate@balcarce.inta.gov.ar), de la Estación Experimental Agropecuaria INTA Balcarce, y diseñado para calcular la ETP por el método FAO56 (Allen et al., 1998) en planillas de cálculo. Se trata de un programa gratuito protegido por leyes de derechos de autor, consistente en una librería escrita en lenguaje $\mathrm{C}++$ que contiene las funciones necesarias para calcular la ETP (Abbate, 2004). Estas funciones utilizan una interface de datos double, tipo de dato estándar en la mayoría de los lenguajes de programación, y una interface específica para la trasferencia de datos con las planillas Excel y Quattro Pro.

Las funciones con las que cuenta este programa se listan a continuación:

1) AGROCLIMA, devuelve la identificación del programa y su versión.

2) JDIA, calcula el día juliano, considerando los años bisiestos, a partir del año, el mes y el día calendario.

3) RADAF56, calcula la radiación astronómica o solar extraterrestre en $\mathrm{MJ} / \mathrm{m}^{2} / \mathrm{d}$; es decir, la cantidad de energía solar recibida en el límite superior de la atmósfera terrestre, en un plano perpendicular al de los rayos incidentes, por medio del método FAO 56 (Allen et al., 1998) para períodos diarios. Esta función se suministra para ajustar o verificar la relación entre la radiación solar y la heliofanía efectiva y es utilizada en el cálculo de RADF56A y RADF56P (la radiación global o total).

4) DDIAF56, devuelve la duración del día teórica (heliofanía teórica, horas de luz entre la salida y puesta del sol sin nubosidad), computada por el método FAO 56 (Allen et al., 1998). La salida y puesta del sol corresponden a una altura solar de $0^{\circ}$ respecto del horizonte. La duración del día devuelta es la utilizada para calcular RADAF56 (la radiación astronómica o solar extraterrestre) y RADF56A (la radiación solar global o total).

5) RADF56A y RADF56P, permiten estimar la radiación solar por medio de la ecuación de Anstromg, a partir del día juliano, de la heliofanía efectiva expresada en hs (RADF56A) o en porcentaje (RADF56P), las constantes de regresión lineal y la latitud. 
6) PVTRF56 y PVHRF56, permiten calcular la presión de vapor actual (kPa) a partir de la temperatura del punto de rocío (PVTRF56) o de las temperaturas y humedades máximas y mínimas (PVHRF56).

7) PVSF56, calcula la presión de vapor saturado (kPa), en función del método FAO 56 (Allen et al., 1998).

8) PVHM, calcula la presión de vapor actual $(\mathrm{kPa})$, a partir de las temperaturas máximas y mínimas y la humedad relativa media en función del método de Smith et al. (1992). Esta función se incluyó para mantener compatibilidad con otros programas (p.ej. CROPWAT); la función correspondiente al método FAO 56 (Allen et al., 1998) es PVHRF56.

9) ETPF56, calcula la ETP por el método FAO56, para períodos diarios, decádicos o mensuales, a partir del día juliano, la radiación solar, las temperaturas máximas y mínimas, la variación de la temperatura media entre períodos de cálculo, la presión de vapor actual, la velocidad del viento y su altura de medición, y la altitud y latitud de la localidad.

\subsubsection{Determinación de $\mathrm{ET}_{\mathrm{C}}$ para vegetación atípica (procedimiento FAO 56)}

Para la determinación de la Evapotranspiración de las plantaciones bajo estudio se implemento una secuencia de cálculo extractada del Estudio FAO Riego y Drenaje 56 (Allen et al., 2006). Es importante destacar que este método no contempla, dentro del cálculo de $\mathrm{ET}_{\mathrm{c}}$, el componente de intercepción por parte del follaje, lo cual es conveniente a los fines de esta tesis ya que el mismo fue determinado de forma independiente en el capítulo 2.

La metodología estandarizada de la FAO56 permite la utilización de un coeficiente único de cultivo que simplifica de alguna manera la secuencia de cálculos. Sin embargo, debido a que el este coeficiente constituye un promedio entre la evaporación del suelo y la tasa de transpiración, solo es aconsejado para el diseño y planificación de riegos, donde la escala temporal mínima de cálculo es la semana. Por el contrario, el procedimiento de coeficiente dual de cultivo, si bien es más complejo en cuanto a cálculos, es más preciso para fines de investigación y permite una precisión temporal de un día. 
La Evapotranspiración del cultivo $\left(\mathrm{ET}_{\mathrm{c}}\right)$ finalmente se obtiene del producto entre el valor de evapotranspiración de referencia $\left(\mathrm{ET}_{0}\right)$ y la suma de los coeficientes de transpiración del cultivo $\left(\mathrm{K}_{\mathrm{cb}}\right)$ y evaporación del suelo $\left(\mathrm{K}_{\mathrm{e}}\right)$ (Ecuación V.3).

$$
\mathrm{ET}_{\mathrm{c}}=\left(\mathrm{K}_{\mathrm{cb}}+\mathrm{K}_{\mathrm{e}}\right) \times \mathrm{ET}_{0}
$$

El primero de estos coeficientes, llamado también coeficiente basal del cultivo $\left(\mathrm{K}_{\mathrm{cb}}\right)$, se define como: "la relación entre el la evapotranspiración del cultivo y la evapotranspiración de referencia $\left(\mathrm{ET}_{\mathrm{c}} / \mathrm{ET}_{0}\right)$ cuando la superficie del suelo se encuentra seca pero la transpiración mantiene su tasa potencial, es decir donde la transpiración no está limitada por la ausencia del agua". El segundo coeficiente $\left(\mathrm{K}_{\mathrm{e}}\right)$, a su vez, representa el componente de evaporación de la evapotranspiración del cultivo $\left(\mathrm{K}_{\mathrm{e}} \times \mathrm{ET}_{0}\right)$, que será mínimo cuando la superficie del suelo se encuentra seca y sin agua remanente que pueda evaporarse.

Sin embargo, las especies estudiadas (Pinus radiata, Eucalyptus camaldulensis y Eucalyptus viminalis) son consideradas como atípicas, dado que no poseen un valor estandarizado de coeficientes de cultivo (único o dual) en la publicación FAO56, y por tanto demandan un ajuste en cada uno de los coeficientes para la obtención de la evapotranspiración del cultivo. De esta manera, la ecuación V.3 se sustituye por:

$$
\mathrm{ET}_{\mathrm{c} \mathrm{aj}}=\mathrm{K}_{\mathrm{c} \mathrm{aj}} \times \mathrm{ET}_{0}=\left(\mathrm{K}_{\mathrm{cb} \text { aj }}+\mathrm{K}_{\mathrm{e} \mathrm{aj}}\right) \times \mathrm{ET}_{0}
$$

Donde: $\mathrm{ET}_{\mathrm{c} \text { aj }}$ representa la evapotranspiración del cultivo ajustada para forestaciones; $\mathrm{K}_{\mathrm{caj}}$ es el coeficiente único de cultivo $\left(\mathrm{K}_{\mathrm{cb} \text { aj }}+\mathrm{K}_{\mathrm{e} \text { aj }}\right)$, y $\mathrm{ET}_{0}$ es la evapotranspiración de referencia calculada en el apartado 5.2.1.

Los valores de $\mathrm{k}_{\mathrm{C}}$ para especies forestales, son escasos en la bibliografía (Tabla V.2), y su procedencia, dudosa. En este sentido, es interesante el esfuerzo de algunos autores en el desarrollo de metodologías para su determinación. Novoa (1998), por ejemplo, indica que los valores de $\mathrm{k}_{\mathrm{C}}$ para bosques de clima templado son desconocidos $\mathrm{y}$ propone estimar la ET usando el $\mathrm{k}_{\mathrm{C}}$ de una pradera natural que luego será ajustada de 
forma iterativa en la ecuación universal de balance hidrológico, por medio de la curva de evolución de un estimador determinado experimentalmente.

Tabla V.2. Resumen de valores de $\mathrm{k}_{\mathrm{C}}$ encontrados en la bibliografía internacional $\mathrm{y}$ nacional, indicando las especies y autor/s del trabajo.

\begin{tabular}{ccc}
\hline Especie & $\mathrm{k}_{\mathrm{C}}$ & Fuente \\
\hline E. dunnii & $0,6-0,9$ & Rébori, 2007 \\
Eucaliptus & $0,86-1$ & Díaz y Rébori, 2003 \\
Coníferas & 1 & Allen et al., 2006 \\
\hline
\end{tabular}

Debe notarse que, en el caso de las plantaciones forestales, solo se calcula la evapotranspiración del cultivo en la temporada de crecimiento designada como media o de mediados de temporada. Dicho de otra manera, la etapa inicial (comprendida entre la fecha de siembra y el momento en el que el cultivo cubre el $10 \%$ de la superficie del suelo) transcurre prácticamente en invernáculo, mientras que la etapa final responde a la corta o aprovechamiento del rodal. Ambas etapas de desarrollo, son mínimas en relación a la etapa media o de desarrollo de plantaciones forestales de rápido crecimiento y pueden por tanto despreciarse. Sin embargo, existen antecedentes que revelan diferencias entre las pérdidas evapotranspirativas entre rodales jóvenes y adultos (Oyarzún y Huber, 1999), relacionados posiblemente con un cambio en la capacidad de intercepción.

Al mismo tiempo, es preciso considerar que las forestaciones de especies perennes que están expuestos a climas benignos a lo largo del año (sin grandes variaciones en las condiciones climáticas, como ocurre en climas tropicales), no requieren del ajuste temporal de la $\mathrm{ET}_{\mathrm{c}}$ por causas climáticas, ya que sus variaciones dependen principalmente de las variaciones de la $\mathrm{ET}_{0}$.

En base a estas consideraciones, se reconocieron como nulos los valores de evapotranspiración correspondientes a los períodos inicial y final y se simplificó el cálculo de $\mathrm{ET}_{\mathrm{c}}$, al considerarla equivalente a la evapotranspiración de mediados de temporada $\left(\mathrm{ET}_{\mathrm{c} \text { medaj }} \approx \mathrm{ET}_{\mathrm{c} \text { aj }}\right)$. De esta manera, solo se trabajó con un par de coeficientes duales para cada situación, los correspondientes a la etapa de desarrollo de mediados de temporada $\left(\mathrm{K}_{\mathrm{cb} \text { medaj }} \approx \mathrm{K}_{\mathrm{c} \text { aj }}\right.$ y $\mathrm{K}_{\mathrm{e} \text { medaj }} \approx \mathrm{K}_{\mathrm{e} \text { aj }}$ ). A continuación se sintetiza la secuencia de de cálculo utilizada: 
1) Evapotranspiración del cultivo. En la ecuación V.5, se integra el valor calculado de $\mathrm{ET}_{0}$ del apartado anterior y los coeficientes duales de transpiración del cultivo ( $\mathrm{K}_{\mathrm{cb} \text { aj }}$ ) y evaporación del suelo $\left(K_{e}\right.$ aj $)$, que serán desarrollados consecutivamente:

$$
\mathrm{ET}_{\mathrm{c} \mathrm{aj}}=\left(\mathrm{K}_{\mathrm{cb} \text { aj }}+\mathrm{K}_{\mathrm{eaj}}\right) \times \mathrm{ET}_{0}
$$

2) Coeficiente basal del cultivo. En la ecuación V.6 se muestra el cálculo del coeficiente basal de cultivo ( $\mathrm{K}_{\mathrm{cb} \text { aj }}$ ), que representa al componente de transpiración de la $\mathrm{ET}_{\mathrm{c}}$. Para la obtención del mismo fue necesario la fijación y cálculo de una serie de parámetros indicados en las ecuaciones V.7 a V.11:

$$
\mathrm{K}_{\mathrm{cb} \text { aj }} \approx \mathrm{K}_{\mathrm{cb} \text { medaj }}=\mathrm{K}_{\mathrm{c} \mathrm{min}}+\left(\mathrm{K}_{\mathrm{cb} \text { full }}-\mathrm{K}_{\mathrm{c} \mathrm{min}}\right)\left\{\min \left[\begin{array}{c}
1,2 \mathrm{f}_{\mathrm{c}} \\
\left(\mathrm{f}_{\mathrm{c} \mathrm{eff}}\right)
\end{array}\left(\frac{1}{1+\mathrm{h}}\right)\right]\right\} \quad \mathrm{V} .6
$$

Donde: $\mathrm{K}_{\mathrm{c} \text { min }}$, es el valor mínimo de $\mathrm{K}_{\mathrm{c}}$ para suelo descubierto (con presencia de vegetación), adopta valores de 0,15 a 0,$20 ; K_{c b}$ full, es el valor estimado de $\mathrm{K}_{\mathrm{cb}}$ durante la etapa de mediados de temporada para vegetación natural; $\mathrm{f}_{\mathrm{c}}$, es la fracción observada de la superficie del suelo que se encuentra cubierta por la vegetación, observada desde la posición nadir (vista vertical desde el cielo hacia el suelo), toma valores de 0,01 a $1 ; \mathrm{f}_{\mathrm{c} \text { eff, }}$, representa la fracción de la superficie del suelo que es sombreada por la vegetación; h, es la altura máxima promedio de las plantas, expresadas en metros; min (), es una función que selecciona el valor mínimo de los elementos contenidos entre las paréntesis y que se encuentran separados por comas

$$
\mathrm{f}_{\mathrm{c} \text { eff }}=\min \left(1, \mathrm{f}_{\mathrm{c}} / \operatorname{sen}(\mathrm{n})\right)
$$

Donde: $\mathrm{f}_{\mathrm{c} \text { eff }}$, es la fracción del suelo sombreada por la vegetación, calculada para vegetación de forma circular o esférica, como es el caso de los árboles; sen(n), es el seno del ángulo medio del sol sobre el horizonte, $\mathrm{n}$, durante el período de máxima evapotranspiración (generalmente entre 11:00 y 15:00hs.)

$$
\operatorname{sen}(n)=\operatorname{sen}(\varphi) \times \operatorname{sen}(\delta)+\cos (\varphi) \times \cos (\delta)
$$

Donde: $\varphi$, es la latitud expresada en radianes y con valor negativo para la latitud sur; $\delta$, es la declinación solar, también expresada en radianes 


$$
\delta=0,409 \times \operatorname{sen}\left(\frac{2 \pi}{365} \times J-1,39\right)=\text { "radianes" }
$$

Donde: J, es el número de día juliano

$$
\mathrm{K}_{\mathrm{cb} \text { full }}=\mathrm{K}_{\mathrm{cb}, \mathrm{h}}+\left[0,04\left(\mathrm{u}_{2}-2\right)-0,004 \times\left(\mathrm{HR}_{\min }-45\right)\right]\left(\frac{\mathrm{h}}{3}\right)^{0,3}
$$

Donde: $\mathrm{K}_{\mathrm{cb} \text { full }}$, es el valor estimado de $\mathrm{K}_{\mathrm{cb}}$ durante la etapa de mediados de temporada para vegetación natural, aproximado en función del clima y altura media de la planta, para áreas de vegetación que son mayores de unas pocas hectáreas; $\mathrm{K}_{\mathrm{cb}, \mathrm{h}}$, corresponde al valor de $\mathrm{K}_{\mathrm{cb} \text { med }}$ para vegetación con cobertura completa, en condiciones sub-húmedas y vientos suaves $\left(\mathrm{HR}_{\min }=45 \mathrm{y} \mathrm{u}_{2}=2 \mathrm{~m} \mathrm{~s}^{-1}\right)$, cuando $\mathrm{h}>2 \mathrm{~m}, \mathrm{~K}_{\mathrm{cb} \text { med }}$ está limitado a un valor $\leq 1,2^{25} ; \mathrm{u}_{2}$, es la velocidad promedio del viento a $2 \mathrm{~m}$ de altura durante la etapa de mediados de temporada [ $\left.\mathrm{m} \mathrm{s}^{-1}\right] ; \mathrm{HR}_{\mathrm{min}}$, es el valor promedio de humedad relativa mínima diaria durante la etapa de mediados de temporada [\%]

$$
\mathrm{HR}_{\min }=\frac{\mathrm{e}^{0}\left(\mathrm{~T}_{\min }\right)}{\mathrm{e}^{0}\left(\mathrm{~T}_{\max }\right)} 100
$$

Donde: $\mathrm{e}^{0}\left(\mathrm{~T}_{\min }\right)$, es la presión de vapor a saturación correspondiente a la temperatura mínima media diaria del aire; $\mathrm{e}^{0}\left(\mathrm{~T}_{\max }\right)$, es la presión de vapor a saturación correspondiente a la temperatura máxima media diaria del aires

$$
e^{0}(T)=0,6108 \exp \left[\frac{17,27 T}{T+237,3}\right]
$$

Donde: $e^{0}(T)$, es la presión de saturación de vapor para diferentes temperaturas $(T)$

3) Coeficiente de evaporación del suelo. En la ecuación V.13 se observa el ajuste del coeficiente de evaporación del suelo por la existencia de un mantillo forestal $\left(\mathrm{K}_{\mathrm{e}}\right.$ aj $)$, que representa el componente de evaporación de la $\mathrm{ET}_{\mathrm{c}}$. Luego, como en el punto anterior, se indican los parámetros necesarios para la obtención de dicho coeficiente (Ecuaciones V.14 a V.17):

${ }^{25}$ El valor de 1,2 representa un límite superior general de $\mathrm{K}_{\mathrm{cb} \text { med }}$ para vegetación alta que cubre completamente el suelo y con IAF>3 bajo condiciones sub-húmedas y vientos suaves (Allen et al., 2006) 
Donde: $\mathrm{K}_{\mathrm{e}}$, es el coeficiente de la evaporación del suelo

$$
\mathrm{K}_{\mathrm{e}}=\min \left[\mathrm{K}_{\mathrm{r}} \times\left(\mathrm{K}_{\mathrm{c} \text { max }}-\mathrm{K}_{\mathrm{cb} \text { aj }}\right), \mathrm{f}_{\mathrm{ew}} \times \mathrm{K}_{\mathrm{c} \text { max }}\right]
$$

Donde: $K_{r}$, es el coeficiente adimensional de reducción de la evaporación, dependiente de la lámina acumulada de agua agotada (evaporada) de la capa superficial del suelo; $\mathrm{K}_{\mathrm{c} \text { max }}$, es el valor máximo de $\mathrm{K}_{\mathrm{c}}$ después del riego o la lluvia; $\mathrm{K}_{\mathrm{cb}}$ aj, es el coeficiente basal de cultivo calculado en el punto 2); $\mathrm{f}_{\mathrm{ew}}$, es la fracción del suelo que se encuentra simultáneamente expuesto y humedecido, es decir la fracción de la superficie del suelo a partir de la cual ocurre la mayor parte de la evaporación.

$$
\mathrm{K}_{\mathrm{c} \max }=\max \left[\begin{array}{c}
\left\{1,2+\left[0,04\left(\mathrm{u}_{2}-2\right)-0,004\left(\mathrm{HR}_{\min }-45\right)\right]\left(\frac{\mathrm{h}}{3}\right)^{0,3}\right\}, \\
\left\{\mathrm{K}_{\mathrm{cb} \mathrm{aj}}+0,05\right\}
\end{array}\right]
$$

Donde: max (), es el valor máximo de los parámetros entre los paréntesis que están separados por comas.

$$
\mathrm{K}_{\mathrm{r}}={ }^{\mathrm{AET}}-\mathrm{D}_{\mathrm{e}, \mathrm{i}-1} / \mathrm{AET}-\mathrm{AFE} \quad \text { para } \mathrm{D}_{\mathrm{e}, \mathrm{i}-1}>A F E
$$

Donde: $\mathrm{K}_{\mathrm{r}}$, es el coeficiente adimensional de reducción de la evaporación, dependiente del agotamiento de la humedad (lámina acumulada de evaporación), en la parte superior del suelo (cuando De,i-1 $\leq \mathrm{AFE}, \mathrm{Kr}=1$ ); AFE, es el agua fácilmente evaporable en mm; AET, es la lámina acumulada máxima de evaporación (agua evaporable total) en la capa superficial del suelo cuando $K_{r}=0$, expresada en $\mathrm{mm} ; D_{e, i-1}$, es la lámina acumulada de evaporación (agotamiento) en la capa superficial del suelo al final del día anterior (i-1) en mm.

$$
f_{e w}=\min \left(1-f_{c}, f_{w}\right)
$$

Donde: $1-\mathrm{f}_{\mathrm{c}}$, es la fracción expuesta promedio del suelo que no se encuentra cubierta 0 sombreada por la vegetación, toma valores de 0,01 a $1 ; \mathrm{f}_{\mathrm{w}}$, es la fracción promedio de la superficie del suelo humedecida por el riego o la lluvia, toma valores de 0,01 a 1.

Para la determinación de los valores de AFE y AET se adoptó un valor de profundidad efectiva de la capa evaporante del suelo de $0,125 \mathrm{~m}$, tal como lo recomienda el 
método FAO56. La determinación de los tipos de suelos presentes en cada situación estudiada, surge del análisis de las cartas de suelo 1:50000 de la provincia de Bs.As. (INTA, 2010; INTA, 2011). Luego, con los tipos de suelos y superficies relativas de ocupación, se obtuvieron los valores de AFE y AET correspondientes del cuadro 19 de la publicación FAO56 (Allen et al., 2006). 


\subsection{RESULTADOS}

\subsubsection{Valores de $\mathrm{ET}_{\mathrm{C}}$ por desarrollo de método FAO 56}

En la tabla V.3 se muestran los valores de ETP correspondientes al cultivo de referencia $\left(\mathrm{ET}_{0}\right)$, obtenidos para cada sitio de estudio y para los períodos: enero de 2009diciembre de 2011 (EEC) y septiembre de 2009-agosto de 2012 (PFD). Estos valores fueron calculados diariamente y luego se obtuvieron los promedios mensuales, en función de estos últimos, expresados en mm.

Tabla V.3. Valores medios mensuales de $\mathrm{P}$ y $\mathrm{ET}_{0}$ expresados en $\mathrm{mm}$, para cada sitio de estudio, calculados por la metodología FAO Penman-Monteith

\begin{tabular}{ccccccccccccccc}
\hline & & ene & feb & mar & abr & may & jun & jul & ago & sep & oct & nov & dic & \\
\hline \multirow{2}{*}{ EEC } & $\mathbf{P}$ & 84,3 & 126,8 & 79,9 & 49,0 & 56,4 & 69,1 & 103,5 & 40,6 & 76,6 & 74,2 & 90,3 & 71,7 & $\mathbf{9 2 2 , 5}$ \\
& ET $_{0}$ & 192,8 & 145,4 & 123,8 & 76,7 & 45,2 & 30,7 & 35,8 & 57,2 & 83,8 & 120,8 & 155,1 & 182,2 & $\mathbf{1 2 4 9 , 3}$ \\
\hline \multirow{2}{*}{ PFD } & $\mathbf{P}$ & 86,6 & 106,9 & 105,6 & 66,7 & 49,8 & 80,9 & 73,0 & 87,4 & 59,5 & 66,6 & 133,6 & 59,9 & $\mathbf{9 7 6 , 6}$ \\
& $\mathbf{E T}_{0}$ & 195,4 & 147,5 & 121,4 & 73,3 & 43,2 & 27,1 & 33,2 & 49,2 & 83,1 & 120,4 & 155,5 & 186,1 & $\mathbf{1 2 3 5 , 3}$ \\
\hline
\end{tabular}

Del cálculo de las $\mathrm{ET}_{0}$ diarias ( $\mathrm{mm} /$ día), se determinaron los valores de ETP para cada cultivo $\left(\mathrm{ET}_{\mathrm{c}}\right)$. Los valores de $\mathrm{ET}_{\mathrm{c}}$ de cada rodal, también expresados en $\mathrm{mm}$, se muestran en la tabla V.4.

Tabla V.4. Valores medios mensuales $\mathrm{ET}_{\mathrm{c}}$ expresados en $\mathrm{mm}$, para distintos rodales y situaciones de pastizal.

\begin{tabular}{|c|c|c|c|c|c|c|c|c|c|c|c|c|c|c|}
\hline & & ene & feb & mar & $a b r$ & may & jun & jul & ago & sep & oct & nov & dic & Total \\
\hline \multirow{3}{*}{ 岀 } & $E T_{\text {Pino }}$ & 226,5 & 162,2 & 137,6 & 88,5 & 51,1 & 34,6 & 40,7 & 66,1 & 98,0 & 137,9 & 176,3 & 213,2 & 1432,9 \\
\hline & $\mathrm{ET}_{\text {Evim }}$ & 209,1 & 146,8 & 124,2 & 78,6 & 44,9 & 30,1 & 35,5 & 58,3 & 88,9 & 125,5 & 160,7 & 199,5 & 1302,0 \\
\hline & $\mathrm{ET}_{\text {Past }}$ & 134,9 & 101,8 & 86,6 & 53,7 & 31,6 & 21,5 & 25,0 & 40,1 & 58,7 & 84,6 & 108,5 & 127,5 & 874,5 \\
\hline \multirow{6}{*}{ 足 } & $\mathrm{ET}_{\text {Evim1 }}$ & 267,2 & 182,8 & 152,4 & 92,5 & 54,2 & 34,6 & 42,9 & 62,4 & 109,3 & 157,9 & 202,1 & 255,0 & 1613,5 \\
\hline & $\mathrm{ET}_{\text {Ecam2 }}$ & 230,0 & 157,5 & 129,4 & 79,0 & 45,8 & 28,4 & 36,0 & 52,6 & 93,2 & 136,8 & 174,3 & 221,2 & 1384,3 \\
\hline & $\mathrm{ET}_{\text {Ecam } 3}$ & 251,2 & 172,3 & 142,1 & 86,4 & 50,3 & 31,7 & 39,7 & 58,0 & 102,5 & 149,4 & 190,9 & 241,3 & 1515,9 \\
\hline & $\mathrm{ET}_{\text {Ecam4 }}$ & 215,4 & 149,1 & 122,6 & 74,8 & 43,4 & 27,0 & 34,1 & 49,9 & 87,9 & 129,1 & 164,1 & 207,0 & 1304,4 \\
\hline & $\mathrm{ET}_{\text {Ecam5 }}$ & 262,8 & 178,1 & 147,9 & 89,2 & 51,9 & 33,1 & 41,1 & 60,0 & 106,1 & 154,1 & 198,1 & 251,1 & 1573,7 \\
\hline & $\mathrm{ET}_{\text {Past }}$ & 136,8 & 103,2 & 85,0 & 51,3 & 30,2 & 19,0 & 23,2 & 34,4 & 58,2 & 84,3 & 108,8 & 130,2 & 864,7 \\
\hline
\end{tabular}


Los valores de $\mathrm{K}_{\mathrm{c}}$ utilizados para el cálculo de $\mathrm{ET}_{\mathrm{c}}$ surgen de sumar los coeficientes duales diarios $\left(\mathrm{K}_{\mathrm{cb}}+\mathrm{K}_{\mathrm{e}}\right)$. Los valores medios, máximos y mínimos de estos coeficientes, se muestran en la tabla V.5 y V.6 para cada uno de los meses muestreados. En el caso particular de los pastizales, tomados como condición natural de uso en cada uno de los sitios estudiados, los valores de $\mathrm{K}_{\mathrm{c}}$ se fijaron en 0,7 para el total de los períodos considerados, aunque en la bibliografía se indica variaciones de 0,3 a 0,75 según sea el período de crecimiento que se considere (Allen et al., 2006).

Tabla V.5. Valores mínimos (mín), medios (med) y máximos (máx) mensuales de los coeficientes únicos de cultivo $\left(\mathrm{K}_{\mathrm{c}}\right)$ correspondientes a las plantaciones forestales y situación natural de la Estancia El Centauro (EEC).

\begin{tabular}{|c|c|c|c|c|c|c|c|c|c|c|c|c|c|c|}
\hline \multirow{3}{*}{ fecha } & \multicolumn{14}{|c|}{ EEC } \\
\hline & \multicolumn{3}{|c|}{$\mathrm{K}_{\mathrm{c} \text { Pino }}$} & \multicolumn{3}{|c|}{$\mathbf{K}_{\mathrm{c}}$ Evim } & \multirow{2}{*}{ fecha } & \multicolumn{3}{|c|}{$\mathbf{K}_{\mathrm{c} \text { Evim }}$} & \multicolumn{3}{|c|}{$\mathrm{K}_{\mathrm{c} \text { Pino }}$} & \multirow{2}{*}{$\mathrm{K}_{\mathrm{c} \text { Past }}$} \\
\hline & mín & med & máx & mín & med & máx & & mín & med & máx & mín & med & máx & \\
\hline ene09 & 0,9 & 1,2 & 1,7 & 0,8 & 1,2 & 1,5 & jul10 & 0,9 & 1,1 & 1,3 & 0,8 & 1,0 & 1,1 & 0,7 \\
\hline feb09 & 1,0 & 1,1 & 1,2 & 0,9 & 1,0 & 1,1 & ago10 & 0,9 & 1,1 & 1,3 & 0,8 & 1,0 & 1,1 & \\
\hline mar09 & 0,8 & 1,1 & 1,2 & 0,7 & 1,0 & 1,1 & sep10 & 1,0 & 1,1 & 1,3 & 0,9 & 1,0 & 1,1 & \\
\hline abr09 & 1,1 & 1,2 & 1,4 & 1,0 & 1,1 & 1,2 & oct10 & 0,9 & 1,1 & 1,3 & 0,8 & 1,0 & 1,3 & \\
\hline may09 & 0,9 & 1,1 & 1,3 & 0,8 & 1,0 & 1,2 & nov10 & 1,0 & 1,2 & 1,3 & 0,9 & 1,1 & 1,3 & \\
\hline jun09 & 0,9 & 1,1 & 1,3 & 0,8 & 1,0 & 1,2 & dic10 & 1,1 & 1,2 & 1,4 & 1,0 & 1,2 & 1,3 & \\
\hline jul09 & 0,9 & 1,1 & 1,3 & 0,8 & 1,0 & 1,1 & ene11 & 1,0 & 1,2 & 1,4 & 0,9 & 1,0 & 1,3 & \\
\hline ago09 & 1,0 & 1,2 & 1,4 & 0,9 & 1,0 & 1,3 & feb11 & 0,9 & 1,1 & 1,3 & 0,8 & 1,1 & 1,3 & \\
\hline sep09 & 1,0 & 1,1 & 1,2 & 0,8 & 1,0 & 1,1 & $\operatorname{mar} 11$ & 1,0 & 1,2 & 1,3 & 0,9 & 1,1 & 1,2 & \\
\hline oct09 & 0,9 & 1,1 & 1,4 & 0,8 & 1,0 & 1,3 & abr11 & 0,9 & 1,1 & 1,3 & 0,8 & 1,0 & 1,2 & \\
\hline nov09 & 0,9 & 1,1 & 1,3 & 0,8 & 1,0 & 1,1 & may11 & 0,9 & 1,1 & 1,3 & 0,8 & 1,0 & 1,1 & \\
\hline dic09 & 0,9 & 1,1 & 1,2 & 0,8 & 1,0 & 1,2 & jun11 & 0,9 & 1,1 & 1,3 & 0,8 & 1,0 & 1,1 & \\
\hline ene10 & 0,9 & 1,1 & 1,3 & 0,8 & 1,0 & 1,3 & jul11 & 0,9 & 1,1 & 1,3 & 0,8 & 1,0 & 1,1 & \\
\hline feb10 & 0,9 & 1,1 & 1,3 & 0,8 & 1,0 & 1,1 & ago11 & 0,8 & 1,1 & 1,2 & 0,7 & 1,0 & 1,1 & \\
\hline $\operatorname{mar} 10$ & 0,9 & 1,1 & 1,3 & 0,9 & 1,0 & 1,2 & sep11 & 1,0 & 1,2 & 1,4 & 0,9 & 1,2 & 1,3 & \\
\hline abr10 & 0,8 & 1,1 & 1,3 & 0,7 & 1,0 & 1,1 & oct11 & 0,9 & 1,1 & 1,3 & 0,8 & 1,0 & 1,3 & \\
\hline may10 & 0,8 & 1,1 & 1,2 & 0,7 & 1,0 & 1,1 & nov11 & 0,9 & 1,1 & 1,2 & 0,8 & 1,1 & 1,2 & \\
\hline jun10 & 0,7 & 1,1 & 1,3 & 0,6 & 1,0 & 1,1 & dic11 & 1,1 & 1,2 & 1,3 & 1,0 & 1,1 & 1,2 & \\
\hline
\end{tabular}

Donde: $\mathrm{K}_{\mathrm{c} \text { Pino, }}$, corresponde a los coeficientes de cultivo $\left(\mathrm{K}_{\mathrm{c}}\right)$ del rodal de $P$. radiata de la EEC; $\mathrm{K}_{\mathrm{c} \text { Evim }}$, son los valores de $\mathrm{K}_{\mathrm{c}}$ para el rodal de $E$. viminalis de la $\mathrm{EEC}$; $\mathrm{K}_{\mathrm{c} \text { Past }}$, es el $\mathrm{K}_{\mathrm{c}}$ correspondiente a los pastizales de EEC. 
Tabla V.6. Valores mínimos (mín), medios (med) y máximos (máx) mensuales de los coeficientes únicos de cultivo $\left(\mathrm{K}_{\mathrm{c}}\right)$ correspondientes a las plantaciones forestales y situación natural del Predio Forestal Dolores (PFD).

\begin{tabular}{|c|c|c|c|c|c|c|c|c|c|c|c|c|c|c|c|c|}
\hline \multicolumn{17}{|c|}{ PFD } \\
\hline \multirow{2}{*}{ fecha } & \multicolumn{3}{|c|}{$\mathrm{K}_{\mathrm{c} \text { Evim1 }}$} & \multicolumn{3}{|c|}{$\mathrm{K}_{\mathrm{c} \text { Ecam2 }}$} & \multicolumn{3}{|c|}{$\mathrm{K}_{\mathrm{c} \text { Ecam } 3}$} & \multicolumn{3}{|c|}{$\mathrm{K}_{\mathrm{c} \text { Ecam4 }}$} & \multicolumn{3}{|c|}{$\mathrm{K}_{\mathrm{c} \text { Ecam5 }}$} & \multirow{2}{*}{$K_{\text {c Pas }}$} \\
\hline & mín & med & máx & mín & med & máx & mín & med & máx & mín & med & máx & mín & med & máx & \\
\hline sep09 & 1,1 & 1,3 & 1,6 & 0,9 & 1,1 & 1,3 & 1,0 & 1,2 & 1,5 & 0,8 & 1,0 & 1,2 & 1,0 & 1,2 & 1,5 & 0,7 \\
\hline oct09 & 1,1 & 1,3 & 1,6 & 0,9 & 1,2 & 1,4 & 1,0 & 1,3 & 1,5 & 0,9 & 1,1 & 1,2 & 1,1 & 1,3 & 1,6 & \\
\hline nov09 & 1,0 & 1,3 & 1,6 & 0,8 & 1,1 & 1,3 & 0,9 & 1,2 & 1,4 & 0,8 & 1,0 & 1,2 & 1,0 & 1,3 & 1,5 & \\
\hline dic09 & 1,1 & 1,3 & 1,6 & 0,9 & 1,1 & 1,3 & 1,0 & 1,2 & 1,4 & 0,9 & 1,1 & 1,2 & 1,1 & 1,3 & 1,5 & \\
\hline ene10 & 1,1 & 1,4 & 1,6 & 0,9 & 1,2 & 1,3 & 1,0 & 1,3 & 1,5 & 0,9 & 1,1 & 1,2 & 1,1 & 1,3 & 1,6 & \\
\hline feb10 & 1,0 & 1,2 & 1,4 & 0,8 & 1,0 & 1,3 & 0,9 & 1,1 & 1,4 & 0,8 & 1,0 & 1,2 & 1,0 & 1,2 & 1,4 & \\
\hline $\operatorname{mar} 10$ & 0,9 & 1,2 & 1,5 & 0,8 & 1,0 & 1,3 & 0,8 & 1,1 & 1,5 & 0,7 & 1,0 & 1,2 & 0,9 & 1,1 & 1,5 & \\
\hline abr10 & 0,9 & 1,2 & 1,5 & 0,8 & 1,0 & 1,3 & 0,9 & 1,1 & 1,4 & 0,7 & 1,0 & 1,2 & 0,9 & 1,2 & 1,5 & \\
\hline may10 & 0,8 & 1,2 & 1,3 & 0,7 & 1,0 & 1,2 & 0,7 & 1,1 & 1,3 & 0,7 & 0,9 & 1,1 & 0,8 & 1,1 & 1,3 & \\
\hline jun10 & 0,9 & 1,2 & 1,5 & 0,7 & 1,0 & 1,2 & 0,8 & 1,1 & 1,4 & 0,7 & 1,0 & 1,2 & 0,8 & 1,2 & 1,4 & \\
\hline jul10 & 0,9 & 1,2 & 1,5 & 0,7 & 1,0 & 1,3 & 0,8 & 1,1 & 1,4 & 0,7 & 1,0 & 1,2 & 0,8 & 1,2 & 1,5 & \\
\hline ago10 & 1,1 & 1,2 & 1,5 & 0,9 & 1,0 & 1,3 & 1,0 & 1,1 & 1,4 & 0,8 & 1,0 & 1,2 & 1,0 & 1,2 & 1,5 & \\
\hline sep10 & 1,1 & 1,3 & 1,6 & 0,9 & 1,1 & 1,3 & 1,0 & 1,2 & 1,5 & 0,9 & 1,0 & 1,3 & 1,0 & 1,2 & 1,6 & \\
\hline oct10 & 1,0 & 1,3 & 1,7 & 0,9 & 1,1 & 1,4 & 1,0 & 1,2 & 1,5 & 0,9 & 1,1 & 1,3 & 1,0 & 1,3 & 1,6 & \\
\hline nov10 & 1,1 & 1,3 & 1,7 & 1,0 & 1,1 & 1,4 & 1,0 & 1,2 & 1,6 & 0,9 & 1,1 & 1,3 & 1,1 & 1,3 & 1,6 & \\
\hline dic10 & 1,2 & 1,4 & 1,7 & 1,0 & 1,2 & 1,4 & 1,1 & 1,3 & 1,5 & 1,0 & 1,1 & 1,3 & 1,2 & 1,4 & 1,7 & \\
\hline ene11 & 1,2 & 1,3 & 1,5 & 1,0 & 1,1 & 1,3 & 1,1 & 1,2 & 1,5 & 0,9 & 1,1 & 1,2 & 1,1 & 1,3 & 1,6 & \\
\hline feb11 & 1,0 & 1,3 & 1,5 & 0,9 & 1,1 & 1,3 & 1,0 & 1,2 & 1,4 & 0,8 & 1,0 & 1,2 & 1,0 & 1,2 & 1,5 & \\
\hline mar11 & 1,2 & 1,3 & 1,7 & 1,0 & 1,1 & 1,4 & 1,1 & 1,2 & 1,6 & 1,0 & 1,1 & 1,3 & 1,1 & 1,3 & 1,7 & \\
\hline abr11 & 1,1 & 1,3 & 1,6 & 0,9 & 1,1 & 1,4 & 1,0 & 1,2 & 1,5 & 0,8 & 1,0 & 1,3 & 1,0 & 1,3 & 1,6 & \\
\hline may11 & 1,1 & 1,3 & 1,6 & 0,9 & 1,1 & 1,3 & 1,0 & 1,2 & 1,4 & 0,8 & 1,0 & 1,2 & 1,0 & 1,2 & 1,5 & \\
\hline jun11 & 0,9 & 1,2 & 1,5 & 0,7 & 1,0 & 1,2 & 0,8 & 1,1 & 1,3 & 0,7 & 1,0 & 1,1 & 0,8 & 1,2 & 1,4 & \\
\hline jul11 & 1,0 & 1,2 & 1,7 & 0,8 & 1,0 & 1,4 & 0,9 & 1,1 & 1,6 & 0,8 & 1,0 & 1,3 & 0,9 & 1,2 & 1,6 & \\
\hline ago11 & 0,9 & 1,2 & 1,6 & 0,8 & 1,0 & 1,3 & 0,8 & 1,1 & 1,4 & 0,7 & 1,0 & 1,2 & 0,9 & 1,2 & 1,5 & \\
\hline sep11 & 1,2 & 1,4 & 1,6 & 1,0 & 1,2 & 1,4 & 1,1 & 1,3 & 1,5 & 0,9 & 1,1 & 1,3 & 1,1 & 1,3 & 1,6 & \\
\hline oct11 & 1,0 & 1,3 & 1,6 & 0,8 & 1,1 & 1,4 & 0,9 & 1,2 & 1,5 & 0,8 & 1,0 & 1,3 & 0,9 & 1,2 & 1,6 & \\
\hline nov11 & 1,1 & 1,3 & 1,6 & 0,9 & 1,1 & 1,3 & 1,0 & 1,3 & 1,5 & 0,9 & 1,1 & 1,3 & 1,1 & 1,3 & 1,6 & \\
\hline dic11 & 1,2 & 1,3 & 1,7 & 1,0 & 1,2 & 1,4 & 1,1 & 1,3 & 1,6 & 0,9 & 1,1 & 1,4 & 1,1 & 1,3 & 1,7 & \\
\hline ene12 & 1,2 & 1,4 & 1,7 & 1,0 & 1,2 & 1,3 & 1,1 & 1,3 & 1,5 & 0,9 & 1,1 & 1,2 & 1,1 & 1,4 & 1,6 & \\
\hline feb12 & 1,0 & 1,3 & 1,5 & 0,8 & 1,1 & 1,3 & 0,9 & 1,2 & 1,4 & 0,8 & 1,0 & 1,2 & 0,9 & 1,2 & 1,4 & \\
\hline mar12 & 1,0 & 1,2 & 1,5 & 0,8 & 1,0 & 1,3 & 0,9 & 1,1 & 1,5 & 0,8 & 1,0 & 1,2 & 0,9 & 1,2 & 1,5 & \\
\hline abr12 & 1,0 & 1,2 & 1,5 & 0,8 & 1,1 & 1,3 & 0,9 & 1,1 & 1,4 & 0,8 & 1,0 & 1,2 & 0,9 & 1,2 & 1,5 & \\
\hline may12 & 0,9 & 1,2 & 1,5 & 0,8 & 1,0 & 1,3 & 0,8 & 1,1 & 1,5 & 0,7 & 1,0 & 1,2 & 0,9 & 1,2 & 1,5 & \\
\hline jun12 & 1,0 & 1,3 & 1,6 & 0,8 & 1,0 & 1,3 & 0,9 & 1,2 & 1,5 & 0,8 & 1,0 & 1,3 & 1,0 & 1,2 & 1,6 & \\
\hline jul12 & 1,0 & 1,3 & 1,6 & 0,8 & 1,1 & 1,4 & 0,9 & 1,2 & 1,5 & 0,8 & 1,0 & 1,3 & 1,0 & 1,2 & 1,6 & \\
\hline ago12 & 1,1 & 1,3 & 1,7 & 0,9 & 1,1 & 1,4 & 1,0 & 1,2 & 1,5 & 0,9 & 1,0 & 1,3 & 1,1 & 1,2 & 1,6 & \\
\hline
\end{tabular}

Donde: $\mathrm{K}_{\mathrm{c} \text { Evim1 } 1}$, corresponde a los coeficientes de cultivo $\left(\mathrm{K}_{\mathrm{c}}\right)$ del rodal de E. viminalis del PFD (parcela 1); $\mathrm{K}_{\mathrm{cEcam} 2}-\mathrm{K}_{\mathrm{c} \text { Ecam5 }}$; son los valores de $\mathrm{K}_{\mathrm{c}}$ para los rodales de $E$. camaldulensis del PFD (parcelas 2 a 5); $\mathrm{K}_{\mathrm{c} \text { Past }}$, es el $\mathrm{K}_{\mathrm{c}}$ correspondiente a los pastizales del PFD.

A pesar de que los coeficientes de las Tablas V.5 y V.6 no se comportan de forma normal (ya que el producto entre el coeficiente medio anual y la $\mathrm{ET}_{0}$ media anual, no es igual a la $\mathrm{ET}_{\mathrm{C}}$ media anual calculada de los $\mathrm{ET}_{\mathrm{C}}$ diarios), los máximos y mínimos son valores absolutos que se hallan entre los rangos 0,6-1,7 para EEC y 0,7-1,7 para PFD, y se encuentran muy por encima de los correspondientes a las situaciones de pastizal en su 
punto máximo de consumo $\left(\mathrm{K}_{\mathrm{C}}=0,7\right)$. Esto da una noción de que las forestaciones presentan un consumo superior del recurso frente a otros tipos vegetales.

Los valores así obtenidos fueron trabajados con balances seriados a nivel del suelo (balance de thornthwaite) para observar el comportamiento temporal de las reservas del suelo en cada uno de los sitios estudiados, y para cada uno de las condiciones de uso consideradas. Además, para cada sitio se tomo una situación natural o de pastizal, con un contenido de agua disponible en el suelo de $200 \mathrm{~mm}$ para EEC (Hurtado et al., 2006) y de $180 \mathrm{~mm}$ para el PFD (Nuñez et al., 2007), y una con forestación. En el caso de las forestaciones, el agua disponible en el suelo se determinó por la aplicación del programa "Soil Water Characteristics" (Saxton y Rawls, 2006), dado que ha tenido buenos resultados en la región pampeana (Landini et al., 2007). Para ello, se asumió una profundidad de raíces de $6 \mathrm{~m}$, por parte de las forestaciones de pino y eucalipto, y se utilizó información de suelos provenientes de las cartas 1:50000 del INTA $(2010,2011)$ y observaciones realizadas a campo. Los valores obtenidos de agua disponible en el suelo para EEC y PFD fueron 838,8 y $841,2 \mathrm{~mm}$ respectivamente, sin embargo, en los casos donde la freática se mantuvo por encima de los $6 \mathrm{~m}$ de profundidad, estos valores deberían ser mayores. Esto se debe a que el agua disponible en el suelo se calcula como la existente entre los puntos de marchitez permanente y capacidad de campo, y en el caso de la freática el suelo se encuentra saturado y el contenido de agua es superior. Además, si bien la carga y descarga del acuífero es básicamente vertical, existe un aporte horizontal que a nivel local puede ser importante.

A continuación se exponen los balances obtenidos (Tablas V.7 a V.15) junto con los gráficos de la evolución mensual de los componentes: P, ETP (=ET ${ }_{\mathrm{C}}$ ) y ETR (Gráficos V.2 a V.10). Cabe aclarar que en los balances no se han considerado los aportes de agua horizontales por la presencia del acuífero freático. Esto sugiere que los balances solo representan el rendimiento hídrico promedio mensual de cada situación analizada, y que estos rendimientos constituyen la recarga del sistema, al mostrarse como excedentes (balances positivos), o descargas, al manifestarse como déficits (balances negativos). 
Tabla V.7. Balance hidrológico mensual de Thornthwaite, con un factor de cultivo general correspondiente a un pastizal de la $\mathrm{EEC}(\mathrm{Kc}=0,7)$ y un valor de retención de agua útil en el suelo de $200 \mathrm{~mm}$.

\begin{tabular}{|r|r|r|r|r|r|r|r|r|r|r|r|r|r|r|}
\hline \multicolumn{2}{|c|}{ EEC (Past) } & ene & \multicolumn{1}{c|}{ feb } & mar & abr & may & jun & jul & ago & sep & Oct & nov & dic & Total \\
\hline $\mathbf{P}$ & & 84,3 & 126,8 & 79,9 & 49,0 & 56,4 & 69,1 & 103,5 & 40,6 & 76,6 & 74,2 & 90,3 & 71,7 & 922,5 \\
\hline ETP & 134,9 & 101,8 & 86,6 & 53,7 & 31,6 & 21,5 & 25,0 & 40,1 & 58,7 & 84,6 & 108,5 & 127,5 & 874,5 \\
\hline P-ETP & & $-50,6$ & 25,0 & $-6,7$ & $-4,7$ & 24,8 & 47,7 & 78,5 & 0,5 & 17,9 & $-10,4$ & $-18,3$ & $-55,8$ & 48,0 \\
\hline $\mathbf{R}$ & 115,6 & 65,0 & 90,0 & 83,3 & 78,6 & 103,4 & 151,1 & 200,0 & 200,0 & 200,0 & 189,6 & 171,4 & 115,6 & \\
\hline$\Delta \mathbf{R}$ & & $-50,6$ & 25,0 & $-6,7$ & $-4,7$ & 24,8 & 47,7 & 48,9 & 0,0 & 0,0 & $-10,4$ & $-18,3$ & $-55,8$ & 0,0 \\
\hline ETR & 134,9 & 101,8 & 86,6 & 53,7 & 31,6 & 21,5 & 25,0 & 40,1 & 58,7 & 84,6 & 108,5 & 127,5 & 874,5 \\
\hline Déf & & 0,0 & 0,0 & 0,0 & 0,0 & 0,0 & 0,0 & 0,0 & 0,0 & 0,0 & 0,0 & 0,0 & 0,0 & 0,0 \\
\hline Exc & 0,0 & 0,0 & 0,0 & 0,0 & 0,0 & 0,0 & 29,5 & 0,5 & 17,9 & 0,0 & 0,0 & 0,0 & 48,0 \\
\hline
\end{tabular}

Donde: $\mathrm{P}$, representa a la precipitación; ETP, la evapotranspiración potencial de cada cultivo (=ETC); $R$, es la reserva de agua en el suelo; $\Delta R$ es la variación de reserva del suelo; ETR es la evapotranspiración real; Déf, es el déficit de agua en el suelo, y Exc, son los excedentes de agua.

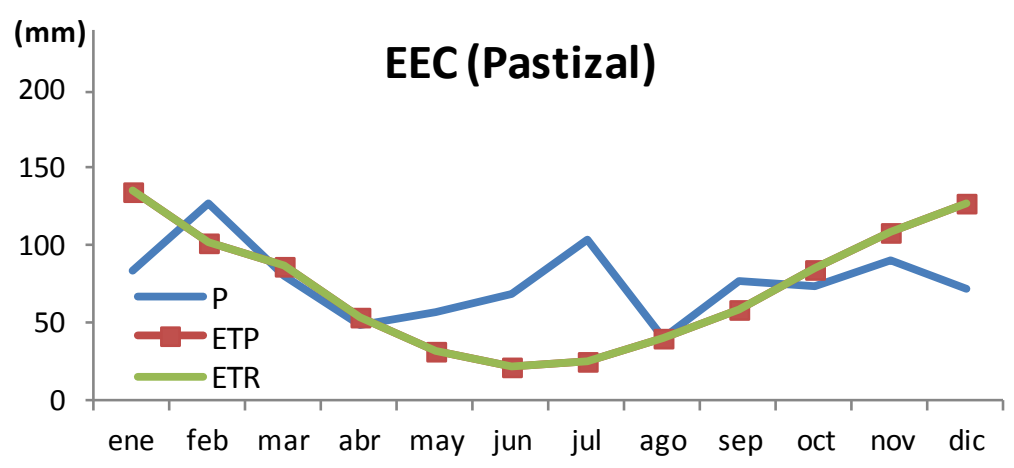

Gráfico V.2. Comportamiento de la ETP, P y ETR (expresados en mm de lámina) para un ciclo hidrológico promedio de un pastizal de la EEC.

Tabla V.8. Balance hidrológico mensual de Thornthwaite, con un factor de cultivo general correspondiente a un pastizal del PFD $\left(\mathrm{K}_{\mathrm{C}}=0,7\right)$ y un valor de retención de agua útil en el suelo de $180 \mathrm{~mm}$.

\begin{tabular}{|r|r|r|r|r|r|r|r|r|r|r|r|r|r|r|}
\hline \multicolumn{2}{|c|}{ PFD (Past) } & \multicolumn{1}{c|}{ ene } & \multicolumn{1}{c|}{ feb } & \multicolumn{1}{c|}{ mar } & abr & may & \multicolumn{1}{c|}{ jun } & jul & ago & sep & oct & nov & dic & Total \\
\hline $\mathbf{P}$ & & 86,6 & 106,9 & 105,6 & 66,7 & 49,8 & 80,9 & 73,0 & 87,4 & 59,5 & 66,6 & 133,6 & 59,9 & 976,6 \\
\hline ETP & 136,8 & 103,2 & 85,0 & 51,3 & 30,2 & 19,0 & 23,2 & 34,4 & 58,2 & 84,3 & 108,8 & 130,2 & 864,7 \\
\hline P-ETP & & $-50,2$ & 3,7 & 20,6 & 15,4 & 19,6 & 61,9 & 49,8 & 53,0 & 1,3 & $-17,7$ & 24,8 & $-70,3$ & 111,8 \\
\hline $\mathbf{R}$ & 109,7 & 59,5 & 63,1 & 83,7 & 99,2 & 118,7 & 180,0 & 180,0 & 180,0 & 180,0 & 162,3 & 180,0 & 109,7 & \\
\hline$\Delta \mathbf{R}$ & & $-50,2$ & 3,7 & 20,6 & 15,4 & 19,6 & 61,3 & 0,0 & 0,0 & 0,0 & $-17,7$ & 17,7 & $-70,3$ & 0,0 \\
\hline ETR & 136,8 & 103,2 & 85,0 & 51,3 & 30,2 & 19,0 & 23,2 & 34,4 & 58,2 & 84,3 & 108,8 & 130,2 & 864,7 \\
\hline Déf & & 0,0 & 0,0 & 0,0 & 0,0 & 0,0 & 0,0 & 0,0 & 0,0 & 0,0 & 0,0 & 0,0 & 0,0 & 0,0 \\
\hline Exc & & 0,0 & 0,0 & 0,0 & 0,0 & 0,0 & 0,6 & 49,8 & 53,0 & 1,3 & 0,0 & 7,1 & 0,0 & 111,8 \\
\hline
\end{tabular}




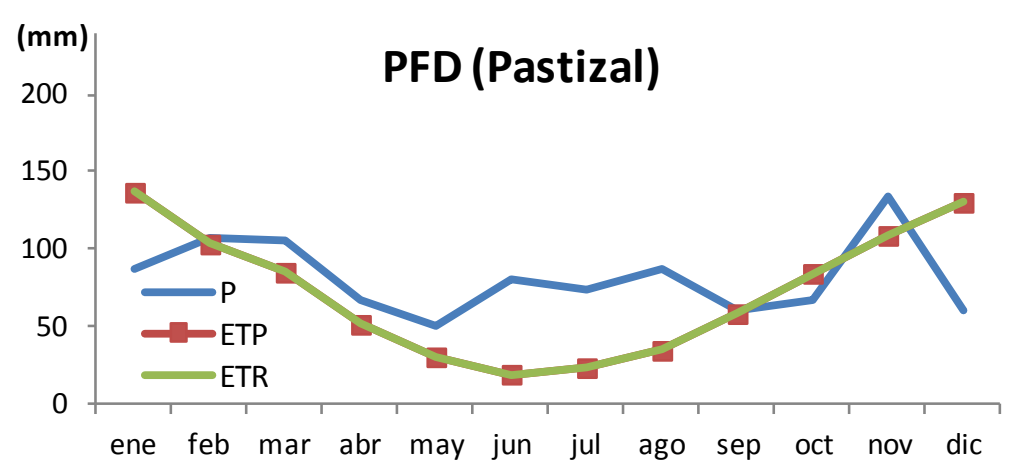

Gráfico V.3. Comportamiento de la ETP, P y ETR (expresados en $\mathrm{mm}$ de lámina) para un ciclo hidrológico promedio de un pastizal del PFD.

Los balances correspondientes a las situaciones naturales de ambos sitios de estudio (Tablas V.7 y V.8), evidencian excesos de 48,0 y 111,8 mm para EEC y PFD respectivamente. Los mismos, se concentran en invierno y primavera (período húmedo), donde la demanda evapotranspirativa de la atmósfera es mínima y el suelo se encuentra a capacidad de campo. Al graficar estos balances (Gráficos V.2 y V.3), se observa con mayor facilidad la evolución de los componentes precipitación media mensual (P), evapotranspiración media mensual (ETP) y evapotranspiración media real (ETR), donde las variaciones positivas de las reservas del suelo suceden gran parte del año (prácticamente de febrero a noviembre) y solo diciembre y enero se presentan con altos valores negativos en la reserva, sin llegar a agotarla. La recarga subterránea, entonces, se concentra en el período de excesos (invierno y primavera). Esto demuestra que los excesos hídricos prevalecen frente al déficit (rendimientos hídricos positivos) y explican en parte la presencia de una capa freática elevada y las situaciones de estrés hídrico por anegamiento prolongado que acompañan al lento drenaje superficial que caracteriza estos paisajes.

En las situaciones subsiguientes (Tablas V.9 a V.15 y Gráficos V.4 a V.10) se analizan las coberturas forestales de EEC y PFD, donde los balances demuestran solo rendimientos hídricos negativos de distintas magnitudes. En los casos donde hay aporte continuo de agua freática, el consumo de agua por parte de las forestaciones estaría representado por la ETP y no por la ETR a nivel mensual. Al margen de esto, estos análisis permiten identificar que en los períodos de menor demanda atmosférica (mayo-agosto), el aporte de agua por precipitación es suficiente para satisfacer la demanda de las plantaciones por lo que, en teoría, no se generaría descarga freática, cosa que si ocurre el resto del año. 
Tabla V.9. Balance hidrológico mensual de Thornthwaite ajustado en función de un factor de cultivo diario, calculado para una plantación de $P$. radiata de la pampa ondulada y un valor de retención de agua útil del suelo de $838,8 \mathrm{~mm}$.

\begin{tabular}{|c|c|c|c|c|c|c|c|c|c|c|c|c|c|c|}
\hline \multicolumn{2}{|c|}{ EEC (Pino) } & ene & feb & mar & $a b r$ & may & jun & jul & ago & sep & oct & nov & dic & Total \\
\hline $\mathbf{P}$ & & 84,3 & 126,8 & 79,9 & 49,0 & 56,4 & 69,1 & 103,5 & 40,6 & 76,6 & 74,2 & 90,3 & 71,7 & 922,5 \\
\hline ETP & & 226,5 & 162,2 & 137,6 & 88,5 & 51,1 & 34,6 & 40,7 & 66,1 & 98,0 & 137,9 & 176,3 & 213,2 & 1432,9 \\
\hline P-ETP & & 42,2 & $-35,4$ & $-57,7$ & $-39,5$ & 5,3 & 34,5 & 62,8 & $-25,5$ & $-21,4$ & $-63,7$ & $-86,1$ & $-141,5$ & $-510,3$ \\
\hline $\mathbf{R}$ & 0,0 & & 0,0 &,$v$ & & 5,3 & 39,8 & 102,6 & 77,1 & 55,7 & & 0 & 0,0 & \\
\hline$\Delta \mathbf{R}$ & & 0,0 & 0,0 & 0,0 & 0,0 & 5,3 & 34,5 & 62,8 & $-25,5$ & $-21,4$ & $-55,7$ & 0,0 & 0,0 & 0,0 \\
\hline ETR & & 84,3 & 126,8 & 79,9 & 49,0 & 51,1 & 34,6 & 40,7 & 66,1 & 98,0 & 129,9 & 90,3 & 71,7 & 922,5 \\
\hline Déf & & 142,2 & 35,4 & 57,7 & 39,5 & 0,0 & 0,0 & 0,0 & 0,0 & 0,0 & 8,0 & 86,1 & 141,5 & 510,3 \\
\hline Exc & & 0,0 & 0,0 & 0,0 & 0,0 & 0,0 & 0,0 & 0,0 & 0,0 & 0,0 & 0,0 & 0,0 & 0,0 & 0,0 \\
\hline
\end{tabular}

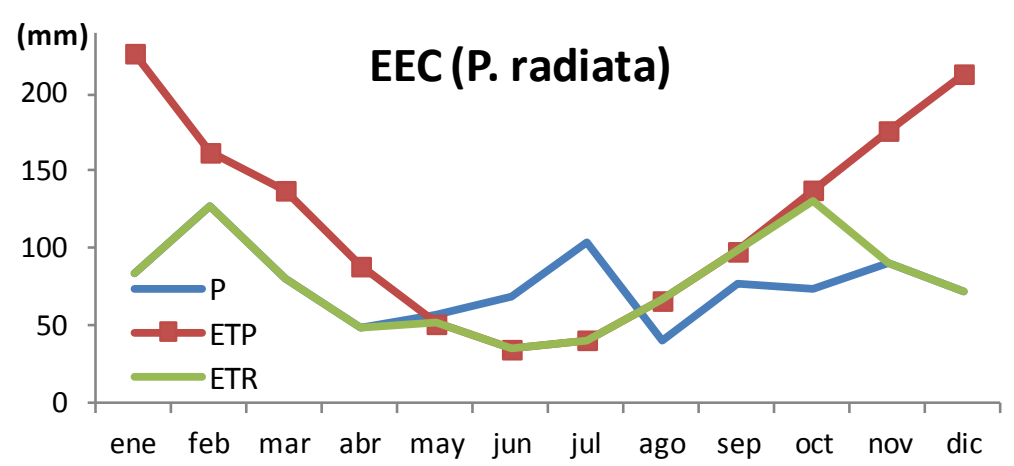

Gráfico V.4. Comportamiento de la ETP, P y ETR (expresados en $\mathrm{mm}$ de lámina) para un ciclo hidrológico promedio de una plantación de $P$. radiata de la pampa ondulada.

Tabla V.10. Balance hidrológico mensual de Thornthwaite ajustado en función de un factor de cultivo diario, calculado para una plantación de $E$. viminalis de la pampa ondulada y un valor de retención de agua útil del suelo de $838,8 \mathrm{~mm}$.

\begin{tabular}{|c|c|c|c|c|c|c|c|c|c|c|c|c|c|c|}
\hline EEC (E. V & & ene & feb & mar & $a b r$ & may & jun & jul & ago & sep & oct & nov & dic & Total \\
\hline $\mathbf{P}$ & & 84,3 & 126,8 & 79,9 & 49,0 & 56,4 & 69,1 & 103,5 & 40,6 & 76,6 & 74,2 & 90,3 & 71,7 & 922,5 \\
\hline ETP & & 209,1 & 146,8 & 124,2 & 78,6 & 44,9 & 30,1 & 35,5 & 58,3 & 88,9 & 125,5 & 160,7 & 199,5 & 1302,0 \\
\hline P-ETP & & 24,8 & $-19,9$ & $-44,3$ & $-29,6$ & 11,5 & 39,0 & 68,0 & $-17,7$ & $-12,3$ & $-51,3$ & $-70,4$ & $-127,7$ & $-379,5$ \\
\hline $\mathbf{R}$ & & & 0,0 & 0,0 & 0,0 & 11,5 & 50,5 & 118,5 & 100,9 & 88,6 & 37,3 & 0,0 & 0,0 & \\
\hline$\Delta \mathbf{R}$ & & & & 0,0 & 0,0 & 11,5 & 39,0 & 68,0 & $-17,7$ & $-12,3$ & $-51,3$ & $-37,3$ & 0,0 & 0,0 \\
\hline ETR & & 84,3 & 126,8 & 79,9 & 49,0 & 44,9 & 30,1 & 35,5 & 58,3 & 88,9 & 125,5 & 127,6 & 71,7 & 922,5 \\
\hline Déf & & 124,8 & 19,9 & 44,3 & 29,6 & 0,0 & 0,0 & 0,0 & 0,0 & 0,0 & 0,0 & 33,1 & 127,7 & 379,5 \\
\hline Exc & & 0,0 & 0,0 & 0,0 & 0,0 & 0,0 & 0,0 & 0,0 & 0,0 & 0,0 & 0,0 & 0,0 & 0,0 & 0,0 \\
\hline
\end{tabular}




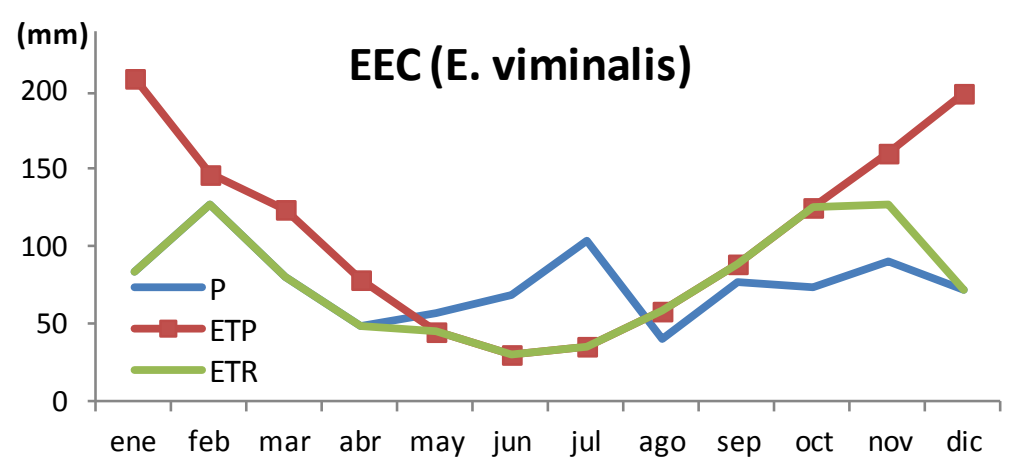

Gráfico V.5. Comportamiento de la ETP, P y ETR (expresados en mm de lámina) para un ciclo hidrológico promedio de una plantación de E. viminalis de la pampa ondulada.

Tabla V.11. Balance hidrológico mensual de Thornthwaite ajustado en función de un factor de cultivo diario, calculado para una plantación de E. viminalis de la pampa deprimida (Parcela 1) y un valor de retención de agua útil del suelo de $841,2 \mathrm{~mm}$.

\begin{tabular}{|c|c|c|c|c|c|c|c|c|c|c|c|c|c|c|}
\hline \multicolumn{2}{|c|}{ PFD (E. vim 1 ) } & ene & feb & mar & $a b r$ & may & jun & jul & ago & sep & oct & nov & dic & Total \\
\hline $\mathbf{P}$ & & 86,6 & 106,9 & 105,6 & 66,7 & 49,8 & 80,9 & 73,0 & 87,4 & 59,5 & 66,6 & 133,6 & 59,9 & 976,6 \\
\hline ETP & & 67,2 & 182,8 & 152,4 & 92,5 & 54,2 & 34,6 & 42,9 & 62,4 & 109,3 & 157,9 & 202,1 & 255,0 & 613,5 \\
\hline P-ETP & & 80,6 & $-75,9$ & $-46,8$ & $-25,8$ & $-4,4$ & 46,3 & 30,1 & 25,0 & $-49,8$ & $-91,3$ & $-68,5$ & $-195,1$ & 37,0 \\
\hline $\mathbf{R}$ & & 0,0 & 0,0 & 0,0 & 0,0 & 0,0 & 46,3 & 76,4 & 101,4 & 51,5 & 0,0 & 0,0 & 0,0 & \\
\hline$\Delta \mathbf{R}$ & & 0,0 & 0,0 & 0,0 & 0,0 & 0,0 & 46,3 & 30,1 & 25,0 & $-49,8$ & $-51,5$ & 0,0 & 0,0 & 0,0 \\
\hline ETR & & 86,6 & 106,9 & 105,6 & 66,7 & 49,8 & 34,6 & 42,9 & 62,4 & 109,3 & 118,1 & 133,6 & 59,9 & 976,6 \\
\hline & & 80,6 & 75,9 & 46,8 & 25,8 & 4,4 & 0,0 & 0,0 & 0,0 & 0,0 & 39,8 & 68,5 & 195,1 & 637,0 \\
\hline Exc & & 0,0 & 0,0 & 0,0 & 0,0 & 0,0 & 0,0 & 0,0 & 0,0 & 0,0 & 0,0 & 0,0 & 0,0 & 0,0 \\
\hline
\end{tabular}

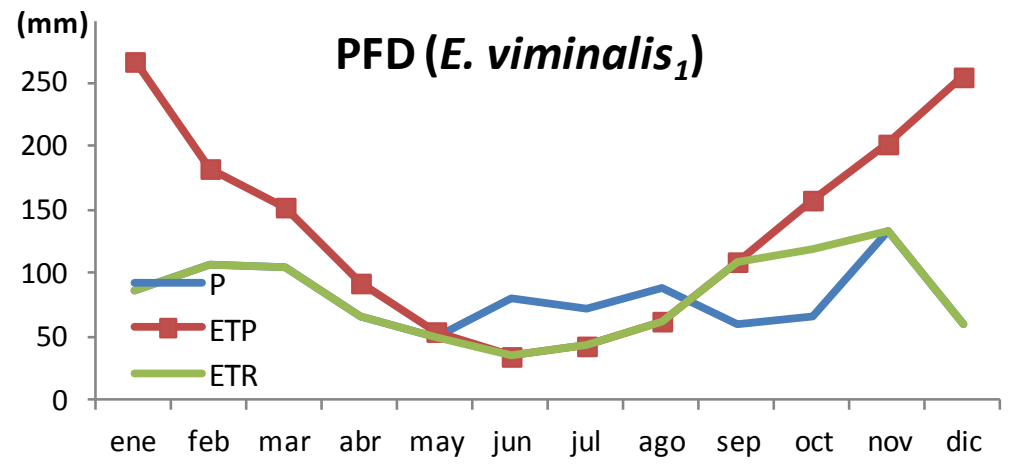

Gráfico V.6. Comportamiento de la ETP, P y ETR (expresados en mm de lámina) para un ciclo hidrológico promedio de una plantación de E. viminalis de la pampa deprimida (Parcela 1). 
Tabla V.12. Balance hidrológico mensual de Thornthwaite ajustado en función de un factor de cultivo diario, calculado para una plantación de E. camaldulensis de la pampa deprimida (Parcela 2) y un valor de retención de agua útil del suelo de $841,2 \mathrm{~mm}$.

\begin{tabular}{|c|c|c|c|c|c|c|c|c|c|c|c|c|c|c|}
\hline \multicolumn{2}{|c|}{ PFD (E. cam ${ }_{2}$ ) } & ene & feb & mar & $a b r$ & may & jun & jul & ago & sep & oct & nov & dic & Total \\
\hline $\mathbf{P}$ & & 86,6 & 106,9 & 105,6 & 66,7 & 49,8 & 80,9 & 73,0 & 87,4 & 59,5 & 66,6 & 133,6 & 59,9 & 976,6 \\
\hline TP & & 230,0 & 157,5 & 129,4 & 79,0 & 45,8 & 28,4 & 36,0 & 52,6 & 93,2 & 136,8 & 174,3 & 221,2 & 1384,3 \\
\hline P-ETP & & 43,4 & $-50,6$ & $-23,8$ & $-12,3$ & 4,0 & 52,5 & 37,0 & 34,8 & $-33,7$ & $-70,2$ & $-40,7$ & $-161,3$ & $-407,8$ \\
\hline $\mathbf{R}$ & & 0 & 0,0 & 0,0 & 0,0 & 4,0 & 56,5 & 93,5 & 128,2 & 94,6 & 24,3 & 0,0 & 0,0 & \\
\hline$\Delta \mathbf{R}$ & & 0,0 & 0,0 & 0,0 & 0,0 & 4,0 & 52,5 & 37,0 & 34,8 & $-33,7$ & $-70,2$ & $-24,3$ & 0 & 0,0 \\
\hline ETR & & 86,6 & 106,9 & 105,6 & 66,7 & 45,8 & 28,4 & 36,0 & 52,6 & 93,2 & 136,8 & 157,9 & 59,9 & 976,6 \\
\hline & & 143,4 & 50,6 & 23,8 & 12,3 & 0,0 & 0,0 & 0,0 & & 0,0 & 0,0 & 16,3 & 161,3 & 407,8 \\
\hline Exc & & 0,0 & 0,0 & 0,0 & 0,0 & 0,0 & 0,0 & 0,0 & 0,0 & 0,0 & 0,0 & 0,0 & 0,0 & 0,0 \\
\hline
\end{tabular}

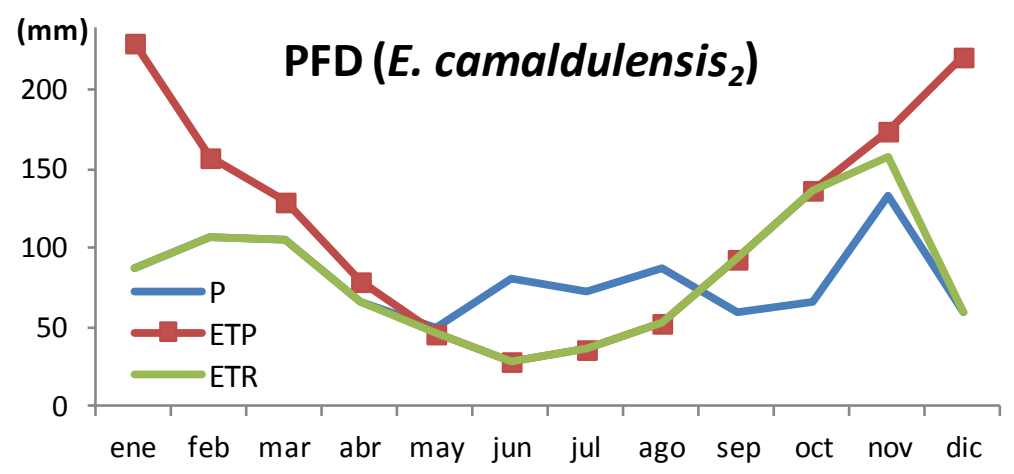

Gráfico V.7. Comportamiento de la ETP, P y ETR (expresados en mm de lámina) para un ciclo hidrológico promedio de una plantación de E. camaldulensis de la pampa deprimida (Parcela 2).

Tabla V.13. Balance hidrológico mensual de Thornthwaite ajustado en función de un factor de cultivo diario, calculado para una plantación de E. camaldulensis de la pampa deprimida (Parcela 3) y un valor de retención de agua útil del suelo de $841,2 \mathrm{~mm}$.

\begin{tabular}{|c|c|c|c|c|c|c|c|c|c|c|c|c|c|c|}
\hline \multicolumn{2}{|c|}{ PFD (E. cam 3 ) } & ene & feb & mar & $a b r$ & may & jun & jul & ago & sep & oct & nov & dic & Total \\
\hline $\mathbf{P}$ & & 86,6 & 106,9 & 105,6 & 66,7 & 49,8 & 80,9 & 73,0 & 87,4 & 59,5 & 66,6 & 133,6 & 59,9 & 976,6 \\
\hline TP & & 251,2 & 172,3 & 142,1 & 86,4 & 50,3 & 31,7 & 39,7 & 58,0 & 102,5 & 149,4 & 190,9 & 241,3 & 1515,9 \\
\hline ETP & & 4,6 & $-65,4$ & $-36,5$ & $-19,7$ & $-0,5$ & 49,2 & 33,3 & 29,4 & $-43,0$ & $-82,8$ & $-57,3$ & & $-539,4$ \\
\hline $\mathbf{R}$ & & 0,0 & 0,0 & 0,0 & 0,0 & 0,0 & 49,2 & 82,6 & 112,0 & 69,0 & 0,0 & 0,0 & 0,0 & \\
\hline$\Delta \mathbf{R}$ & & 0,0 & 0,0 & 0,0 & 0,0 & 0,0 & 49,2 & 33,3 & 29,4 & $-43,0$ & $-69,0$ & 0,0 & 0,0 & 0,0 \\
\hline ETR & & 86,6 & 106,9 & 105,6 & 66,7 & 49,8 & 31,7 & 39,7 & 58,0 & 102,5 & 135,6 & 133,6 & 59,9 & 976,6 \\
\hline Déf & & 164,6 & 65,4 & 36,5 & 19,7 & 0,5 & 0,0 & 0,0 & 0,0 & 0,0 & 13,9 & 57,3 & 181,4 & 539,4 \\
\hline Exc & & 0,0 & 0,0 & 0,0 & 0,0 & 0,0 & 0,0 & 0,0 & 0,0 & 0,0 & 0,0 & 0,0 & 0,0 & 0,0 \\
\hline
\end{tabular}




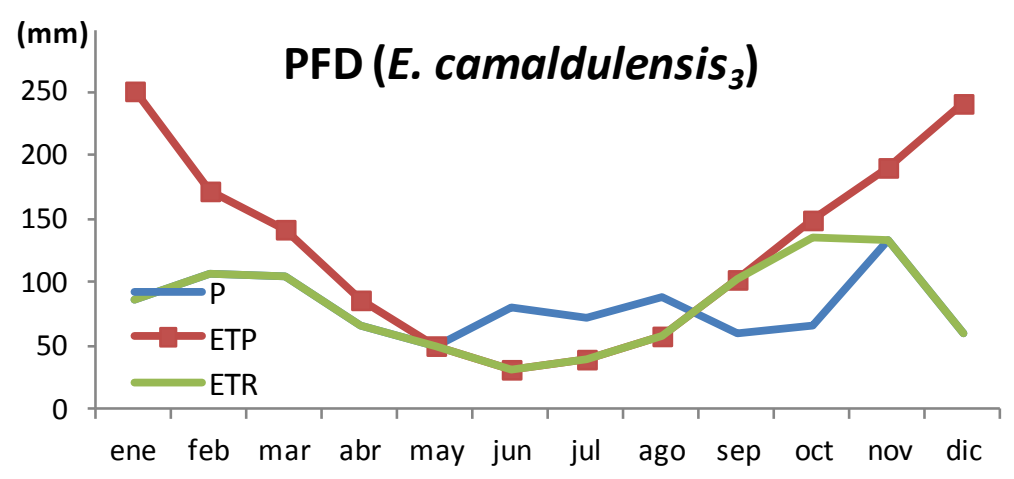

Gráfico V.8. Comportamiento de la ETP, P y ETR (expresados en $\mathrm{mm}$ de lámina) para un ciclo hidrológico promedio de una plantación de E. camaldulensis de la pampa deprimida (Parcela 3).

Tabla V.14. Balance hidrológico mensual de Thornthwaite ajustado en función de un factor de cultivo diario, calculado para una plantación de E. camaldulensis de la pampa deprimida (Parcela 4) y un valor de retención de agua útil del suelo de $841,2 \mathrm{~mm}$.

\begin{tabular}{|c|c|c|c|c|c|c|c|c|c|c|c|c|c|c|}
\hline \multicolumn{2}{|c|}{ PFD (E. cam 4 ) } & ene & feb & mar & $a b r$ & may & jun & jul & ago & sep & oct & nov & dic & Total \\
\hline $\mathbf{P}$ & & 86,6 & 106,9 & 105,6 & 66,7 & 49,8 & 80,9 & 73,0 & 87,4 & 59,5 & 66,6 & 133,6 & 59,9 & 976,6 \\
\hline ETP & & 215,4 & 149,1 & 122,6 & 74,8 & 43,4 & 27,0 & 34,1 & 49,9 & 87,9 & 129,1 & 164,1 & 207,0 & 1304,4 \\
\hline & & 28,8 & $-42,2$ & $-17,0$ & $-8,1$ & 6,4 & 53,9 & 38,9 & 37,5 & $-28,4$ & $-62,5$ & $-30,5$ & & 327,9 \\
\hline $\mathbf{R}$ & & & & & 0,0 & 6,4 & 60,3 & 99,3 & 136,8 & 108,4 & 45,8 & 15,3 & & \\
\hline$\Delta \mathbf{R}$ & & 0,0 & 0,0 & 0,0 & 0,0 & 6,4 & 53,9 & 38,9 & 37,5 & $-28,4$ & $-62,5$ & $-30,5$ & 15,3 & 0,0 \\
\hline ETR & & 6,6 & 106,9 & 105,6 & 66,7 & 43,4 & 27,0 & 34,1 & 49,9 & 87,9 & 129,1 & 164,1 & 75,2 & 76,6 \\
\hline Déf & & 128,8 & 42,2 & 17,0 & 8,1 & 0,0 & 0,0 & 0,0 & 0,0 & 0,0 & 0,0 & 0,0 & 131,8 & 327,9 \\
\hline Exc & & 0,0 & 0,0 & 0,0 & 0,0 & 0,0 & 0,0 & 0,0 & 0,0 & 0,0 & 0,0 & 0,0 & 0,0 & 0,0 \\
\hline
\end{tabular}

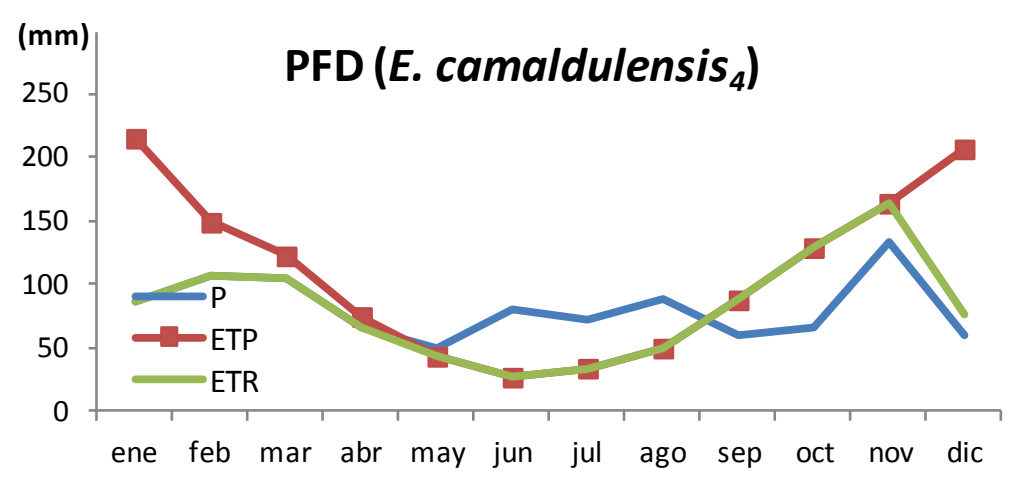

Gráfico V.9. Comportamiento de la ETP, P y ETR (expresados en $\mathrm{mm}$ de lámina) para un ciclo hidrológico promedio de una plantación de E. camaldulensis de la pampa deprimida (Parcela 4). 
Tabla V.15. Balance hidrológico mensual de Thornthwaite ajustado en función de un factor de cultivo diario, calculado para una plantación de E. camaldulensis de la pampa deprimida (Parcela 5) y un valor de retención de agua útil del suelo de $841,2 \mathrm{~mm}$.

\begin{tabular}{|c|c|c|c|c|c|c|c|c|c|c|c|c|c|c|}
\hline \multicolumn{2}{|c|}{ PFD (E. cam 5 ) } & ene & feb & mar & $a b r$ & may & jun & jul & ago & sep & oct & nov & dic & Total \\
\hline $\mathbf{P}$ & & 86,6 & 106,9 & 105,6 & 66,7 & 49,8 & 80,9 & 73,0 & 87,4 & 59,5 & 66,6 & 133,6 & 59,9 & 976,6 \\
\hline TP & & 262,8 & 178,1 & 147,9 & 89,2 & 51,9 & 33,1 & 41,1 & 60,0 & 106,1 & 154,1 & 198,1 & 251,1 & 1573,7 \\
\hline P-ETP & & $-176,2$ & $-71,2$ & $-42,3$ & $-22,5$ & $-2,1$ & 47,8 & 31,9 & 27,4 & $-46,6$ & $-87,5$ & $-64,5$ & $-191,2$ & $-597,2$ \\
\hline $\mathbf{R}$ & & 0,0 & 0,0 & 0,0 & 0,0 & 0,0 & 47,8 & 79,6 & 107,0 & 60,4 & 0,0 & 0,0 & 0,0 & \\
\hline$\Delta \mathbf{R}$ & & 0,0 & 0,0 & 0,0 & 0,0 & 0,0 & 47,8 & 31,9 & 27,4 & $-46,6$ & $-60,4$ & 0,0 & 0,0 & 0,0 \\
\hline ETR & & 86,6 & 106,9 & 105,6 & 66,7 & 49,8 & 33,1 & 41,1 & 60,0 & 106,1 & 127,0 & 133,6 & 59,9 & 976,6 \\
\hline & & 176,2 & 71,2 & 42,3 & 22,5 & 2,1 & 0,0 & 0,0 & 0,0 & 0,0 & 27,1 & 64,5 & 191,2 & 597,2 \\
\hline Exc & & 0,0 & 0,0 & 0,0 & 0,0 & 0,0 & 0,0 & 0,0 & 0,0 & 0,0 & 0,0 & 0,0 & 0,0 & 0,0 \\
\hline
\end{tabular}

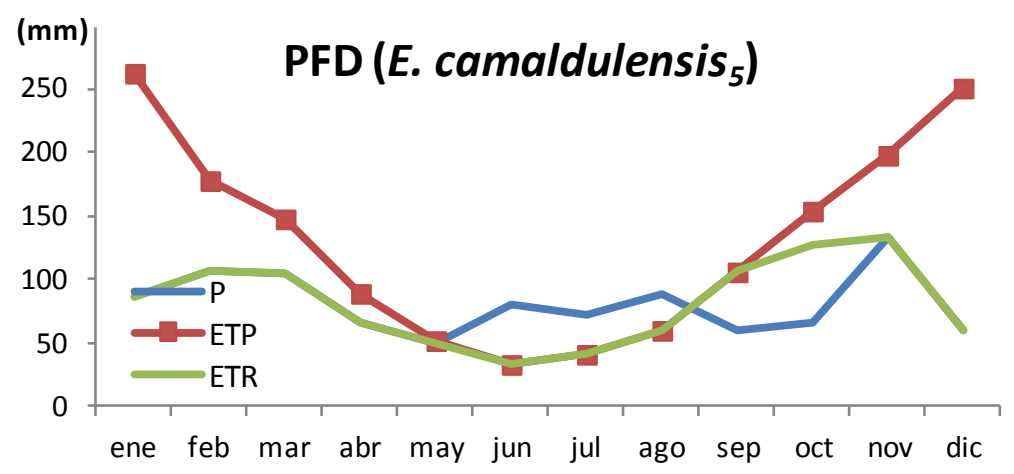

Gráfico V.10. Comportamiento de la ETP, P y ETR (expresados en mm de lámina) para un ciclo hidrológico promedio de una plantación de E. camaldulensis de la pampa deprimida (Parcela 5).

Finalmente se presenta la evolución mensual de los valores absolutos y acumulados de $\mathrm{ET}_{0}$ y $\mathrm{ET}_{\mathrm{C}}$ para cada sitio de estudio (EEC y PFD), junto con las precipitaciones diarias correspondientes (Gráficos V.11 y V.14). 


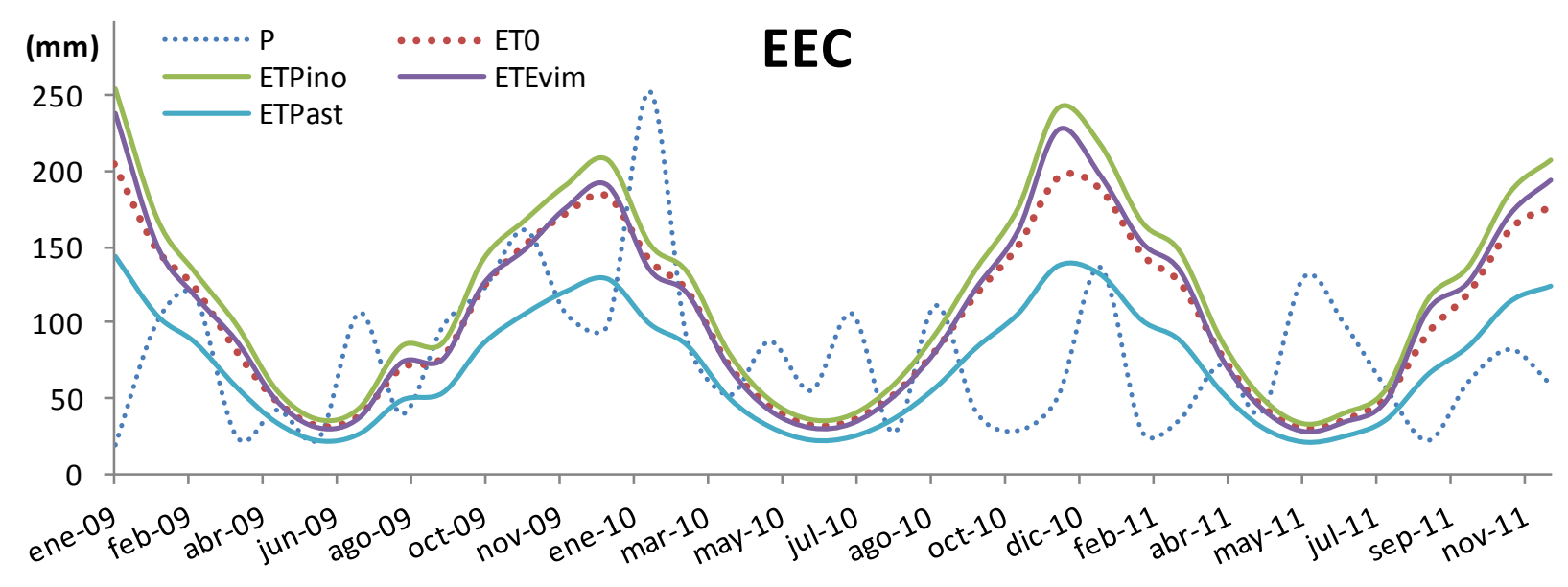

Gráfico V.11. Evolución temporal de los componentes P y ETP correspondiente a la situación de referencia $\left(\mathrm{ET}_{0}\right)$; a la plantación de $P$. radiata $\left(\mathrm{ET}_{\text {Pino }}\right)$; a la plantación de $E$. viminalis $\left(\mathrm{ET}_{\mathrm{Evim}}\right)$, y a una situación de pastizal $\left(\mathrm{ET}_{\text {Past }}\right)$ en la $\mathrm{EEC}$.

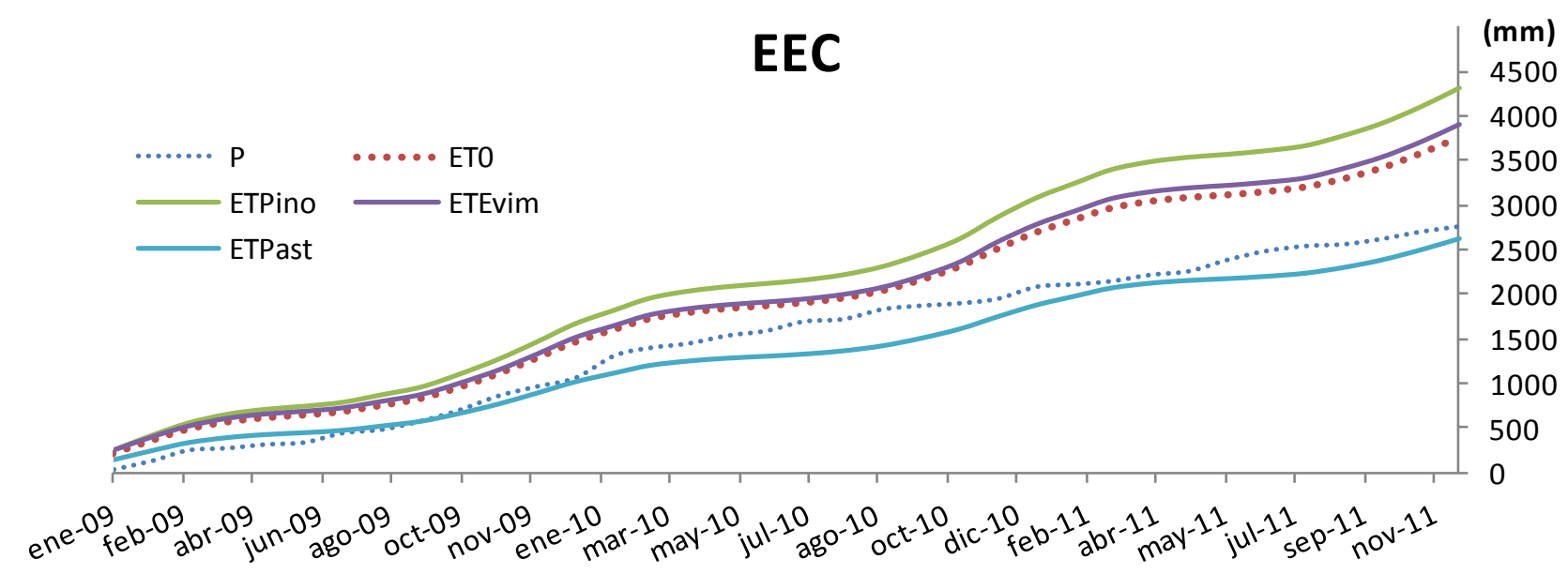

Gráfico V.12. Evolución temporal de los componentes acumulados de $\mathrm{P}$ y ETP correspondiente a la situación de referencia $\left(\mathrm{ET}_{0}\right)$; a la plantación de $P$. radiata $\left(\mathrm{ET}_{\text {Pino }}\right)$; a la plantación de $E$. viminalis ( $\left.\mathrm{ET}_{\mathrm{Evim}}\right)$, y a una situación de pastizal $\left(\mathrm{ET}_{\text {Past }}\right)$ en la $\mathrm{EEC}$.

Los Gráficos V.11 y V.12 permiten observar el comportamiento temporal del aporte de agua por precipitación y el consumo por evapotranspiración de cada plantación evaluada de la $\mathrm{EEC}\left(\mathrm{ET}_{\text {Pino }}, \mathrm{ET}_{\text {Evim }}\right)$, natural y de referencia $\left(\mathrm{ET}_{\text {Past }}\right.$ y $\left.\mathrm{ET}_{0}\right)$. $\mathrm{A}_{\text {simple vista se }}$ observa que las forestaciones consumen más agua que el pastizal. Este consumo diferencial condiciona balances positivos en el caso de los pastizales $(+48 \mathrm{~mm})$ y negativos en el de las forestaciones de pino y eucalipto $(-510,3$ y $-379,5 \mathrm{~mm})$, lo cual provoca un déficit que es suplido por el aporte de agua freática. Es interesante notar, que al existir un 
aporte continuo de agua freática, las curvas de evapotranspiración no mantienen una correlación con las precipitaciones sino más bien con las condiciones climáticas y demuestran un comportamiento cíclico, con máximos en verano y mínimos en invierno. Además, se puede diferenciar que el consumo de agua por parte de las forestaciones se encuentra por encima del de referencia, y aun más, que el componente de evapotranspiración en el rodal de pino es superior al del eucalipto.

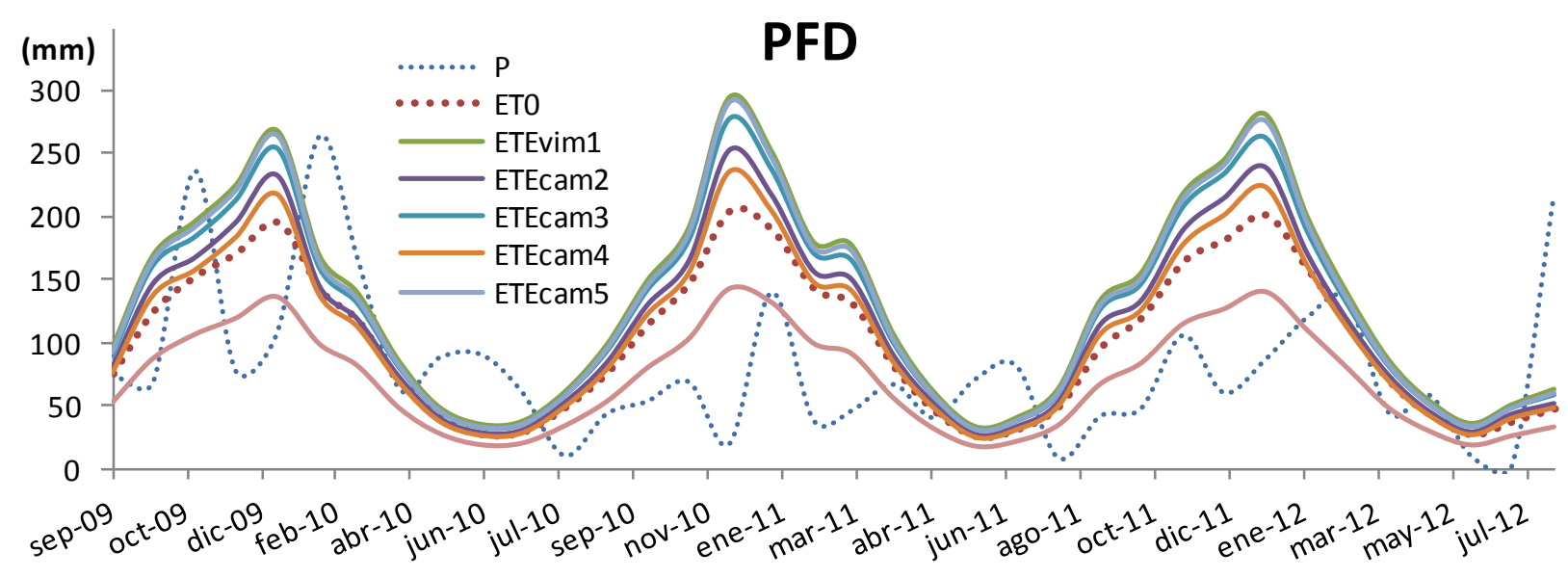

Gráfico V.13. Evolución temporal de los componentes P y ETP correspondiente a la situación de referencia $\left(\mathrm{ET}_{0}\right)$; la plantación de $E$. viminalis de la parcela $1\left(\mathrm{ET}_{\mathrm{Evim} 1}\right)$; las plantaciones de E. camaldulensis de las parcelas 2 a $5\left(\mathrm{ET}_{\mathrm{Evim} 2}-\mathrm{ET}_{\mathrm{Evim} 5}\right)$, y la de una situación de pastizal ( $\mathrm{ET}_{\text {Past }}$ ) en el PFD.

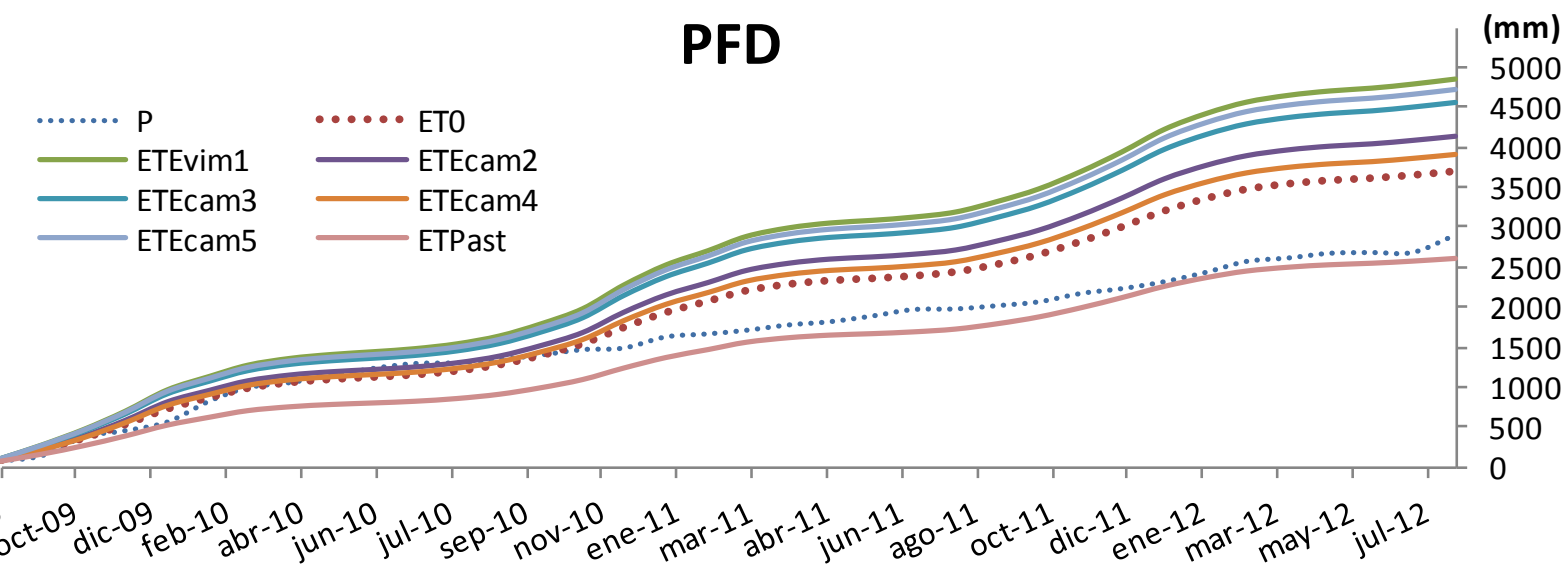

Gráfico V.14. Evolución temporal de los componentes acumulados de P y ETP correspondiente a la situación de referencia $\left(\mathrm{ET}_{0}\right)$; la plantación de $E$. viminalis de la parcela 1 ( $\left.\mathrm{ET}_{\mathrm{Evim} 1}\right)$; las plantaciones de E. camaldulensis de las parcelas 2 a $5\left(\mathrm{ET}_{\mathrm{Evim} 2}-\mathrm{ET}_{\mathrm{Evim} 5}\right)$, y la de una situación de pastizal (ET Past $_{\text {) }}$ en el PFD. 
En los gráficos V.13 y V.14, al igual que en EEC, se evidencia un consumo diferencial de agua entre el pastizal y las forestaciones que genera un balance promedio anual positivo para el pastizal $(+111,8 \mathrm{~mm})$ y balances negativos para las forestaciones (637,$0 ;-407,8 ;-539,4 ;-327,9$ y -597,2mm) que también serían suplidos por aporte de agua freática. Esto nos demuestra un ranquin de consumo de agua ordenado de la siguiente manera: $\mathrm{ET}_{\mathrm{Evim} 1}>\mathrm{ET}_{\mathrm{Ecam} 5}>\mathrm{ET}_{\mathrm{Ecam} 3}>\mathrm{ET}_{\mathrm{Ecam} 2}>\mathrm{ET}_{\mathrm{Ecam} 4}, \mathrm{y}$ que mantiene relación con las coberturas determinadas para cada rodal (apartado 2.3.2, Tabla II.3). 


\subsection{DISCUSIÓN}

Las forestaciones estudiadas demostraron un consumo de agua muy superior a las situaciones de pastizal en ambos sitios de estudio. Estos resultados son congruentes con las referencias mundiales al respecto (Bosch y Hewlett, 1982; Calder, 1992, 2003, 2008; Bruijnzeel, 1997; Benyon et al., 2006; Nisbet et al., 2011) y coincide con los antecedentes locales en cuanto a consumo de las forestaciones de rápido crecimiento (Jobbágy y Jackson, 2004; Nosetto et al., 2005; Jobbágy et al. 2006a, 2006b). Bajo el supuesto de que no poseen limitaciones hídricas, estas forestaciones alcanzan valores de evapotranspiración muy superiores al agua proveniente de las lluvias, al punto de ser equivalentes a la evapotranspiración potencial. Debe tenerse en cuenta sin embargo, que al no estimarse los aportes reales de la napa no puede hablarse de evapotranspiración real y que las limitaciones hídricas pueden ser el resultado de una capa freática profunda e inaccesible, como también, el resultado de una baja conductividad hidráulica de los sedimentos o un alto contenido de sales bajo las forestaciones.

Los valores de ET para pastizales en cambio, se establecieron por debajo de los valores de precipitación media (875mm en EEC y $865 \mathrm{~mm}$ en PFD), pero 100mm por encima de los valores esperables para estas zonas (Laurencena et al., 2005; Nuñez et al., 2007). Una posible explicación se encuentra en haber considerado un $\mathrm{K}_{\mathrm{C}}$ alto y constante para los pastizales.

Con los valores logrados de $\mathrm{ET}_{\mathrm{C}}$, se podrían contrastar todos los componentes obtenidos en esta tesis. Para ello, es necesario considerar que la evapotranspiración real calculada solo considera la transpiración y la evaporación desde el suelo húmedo a capacidad de campo, por lo que los excesos y déficit calculados serían absorbidos por los componentes de intercepción, escurrimiento, y variaciones de humedad de la zona saturada y no saturada del suelo.

Para la evaluación de los componentes individuales, se puede usar la ecuación V 18, donde: P es la precipitación directa; I representa agua interceptada por el dosel; ET es la evapotranspiración desde el suelo, vegetación y reservorios de agua superficial; R son los escurrimientos superficiales, y $\Delta S$ y $\Delta \mathrm{G}$, representan la variación del contenido de humedad de la zona vadosa o no saturada del suelo y la zona saturada (freática), respectivamente. 
De esta forma, se considera que del agua que ingresa al suelo como infiltración (f), parte es utilizada por las plantas (T), parte se pierde por evaporación (E) y parte se almacena $(\Delta S)$ (FAO, 2000). Superada la capacidad de almacenamiento del suelo (capacidad de campo), el agua percola a capas más profundas (infiltración eficaz, efectiva o recarga: $f_{s s}$ ) y alimenta los acuíferos $(\Delta G)$ (Soares y Almeida, 2001). Este comportamiento puede observarse en un sencillo esquema (Figura V.2).

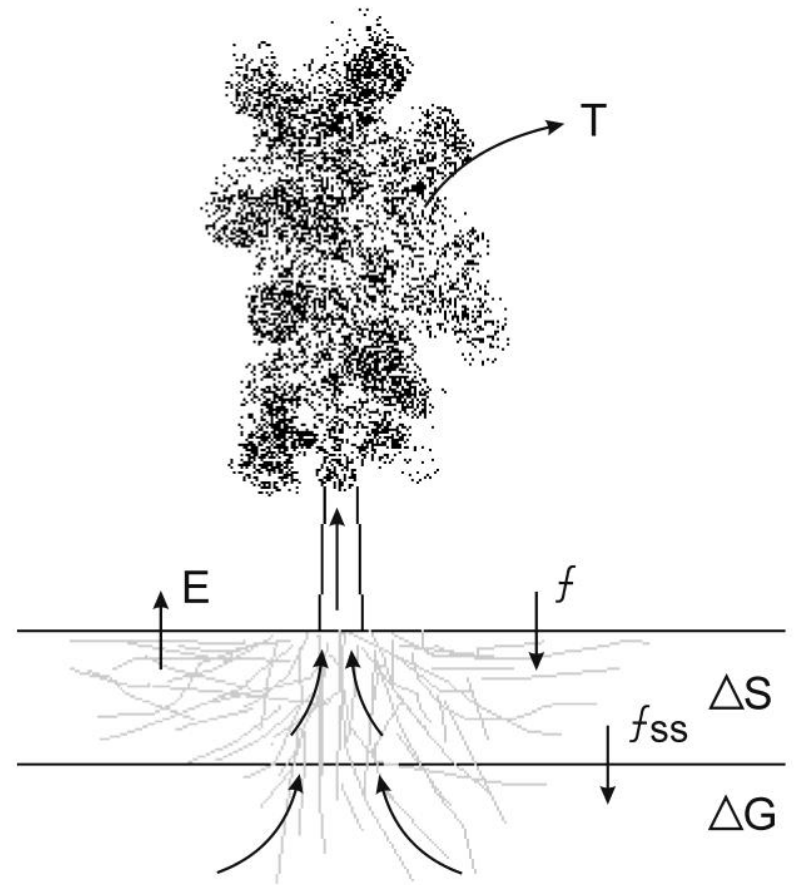

Figura V.2. Esquema del movimiento vertical del agua en el suelo.

En este esquema se identifican los elementos primarios que han sido abordados en esta tesis, con excepción de la variación del contenido de agua en el suelo $(\Delta S)$. Este componente puede obtenerse de la ecuación V.18. En la tabla V.16 se observa el desarrollo de los componentes de esta ecuación, para cada sitio y cobertura estudiado, y bajo la consideración de que no existen limitaciones hídricas para las coberturas. 
Tabla V.16. Principales componentes del balance hidrológico anual para los tres años de estudio en EEC y PFD.

\begin{tabular}{|c|c|c|c|c|c|c|c|}
\hline Lugar & Cobertura & $P(\mathbf{m m})$ & I (mm) & $\mathbf{R}(\mathbf{m m})$ & $\Delta G(\mathrm{~mm})$ & $\operatorname{ETR}_{C}(\mathbf{m m})$ & $\Delta S(\mathrm{~mm})$ \\
\hline \multirow{3}{*}{ 岀 } & P. radiata & \multirow{3}{*}{922,5} & 187,3 & \multirow{2}{*}{76,3} & $-22,8$ & 922,5 & $-240,8$ \\
\hline & E. viminalis & & \multirow[t]{2}{*}{87,6} & & $-24,0$ & 922,5 & $-139,9$ \\
\hline & Pastizal & & & 111,8 & $-14,6$ & 874,5 & $-49,2$ \\
\hline \multirow{6}{*}{ 吊 } & E. viminalis & \multirow{6}{*}{976,6} & 209,0 & \multirow{5}{*}{92,0} & 19,8 & 976,6 & $-320,8$ \\
\hline & E. cam.2 & & 285,2 & & \multirow{4}{*}{37,8} & 976,6 & $-415,0$ \\
\hline & E. cam.3 & & 243,2 & & & 976,6 & $-373,0$ \\
\hline & E. cam. 4 & & 203,1 & & & 976,6 & $-332,9$ \\
\hline & E. cam.5 & & 374,0 & & & 976,6 & $-503,8$ \\
\hline & Pastizal & & & 122,4 & 38,0 & 864,7 & $-48,5$ \\
\hline
\end{tabular}

Donde: E. cam. representa la cobertura de Eucalyptus camaldulensis y los subíndices 1 a 5 , las parcelas del predio PFD (apartado 2.2.1.2c). P indica la precipitación promedio para el período de toma de datos (apartado 2.3.1); I, la intercepción del agua de lluvia (apartado 2.3.2); $\mathrm{R}$, es el escurrimiento superficial determinado por la metodología del número de curva (apartado 3.3.3); $\Delta \mathrm{G}$, es la variación de contenido de agua en la zona saturada 0 freática del suelo (carga o descarga según el signo + 0 -) (apartado 4.3.1); $\mathrm{ETR}_{\mathrm{C}}$, indica los valores de evapotranspiración real de cada cobertura (apartado 5.3.1), y $\Delta \mathrm{S}$, es la variación del contenido de agua en la zona no saturada.

Al analizar esta tabla surgen irregularidades en los componentes, despreciables para los objetivos particulares de esta tesis pero notorios en el balance hidrológico anual. Se puede observar un descenso importante del contenido de humedad del suelo que no es correspondido por la variación del contenido de humedad en la zona vadosa. Esto podría responder a las características propias del período de estudio, caracterizado por años atípicos (irregularmente secos o húmedos), donde las variables estudiadas no tuvieron un comportamiento regular y/o a imprecisiones acumuladas por la aplicación de cada una de las metodologías.

Dejando de lado estas consideraciones, es posible indicar que el consumo diferencial de agua, producto de la conversión de pastizales por forestaciones de rápido crecimiento, ha demostrado superar en un 51-87\% a la situación natural y tornar los rendimientos hídricos de positivos a marcadamente negativos. Tal como lo sostienen Engel et al. (2005) y Jobbágy y Jackson (2004, 2007), estos balances negativos son mantenidos gran parte del año por el aporte de agua freática (períodos enero-abril y septiembrediciembre, gráficos V.4 a V.10), lo que representa un aporte del 41-55\% y 35-67\% por encima de la precipitación media anual de EEC y PFD, respectivamente. 
En estas condiciones, si se considerara una sustitución a gran escala de la vegetación herbácea por forestaciones de pino y eucalipto en la pampa húmeda, se esperaría una profundización del nivel de capa freática. Esta especulación coincide con lo expuesto por Jobbágy (2011), al indicar que situaciones de forestación masiva en la llanura podrían generar descensos regionales del nivel freático y afectar humedales cercanos, sin embargo no encuentra respaldo en los resultados de $\Delta \mathrm{G}$ obtenidos en esta tesis (apartado 4.3.1). Por otra parte, resulta oportuno advertir que este aparente consumo masivo de agua subterránea, contrariamente a lo expuesto por Poore y Fries (1987), no afectaría gravemente a las poblaciones que se encuentran aguas abajo, en parte porque se abastecen de aguas más profundas y menos salobres, y en parte porque la actividad reinante en estas zonas son los cultivos de secano y el pastoreo de pastura natural, que no hace uso del agua freática y podrían verse beneficiadas por un aumento de la capacidad de infiltración de estos suelos y el consecuente lavado de sales y disminución de anegamientos. En definitiva, uno de los problemas más alarmantes del consumo de agua por parte de las plantas esta dado por la posibilidad de salinización de los suelos y napas, cuestión que ha sido abordada intensamente por estudios locales (Jackson et al. 2005; Jobbágy y Jackson 2003, 2007; Nosetto et al. 2007, 2008) y es necesario seguir profundizando.

En los gráficos V.11 a V.14 es posible identificar consumos diferenciales de agua entre especies vegetales y los distintos rodales. Este comportamiento evidencia una fuerte influencia climática, donde se corresponden los momentos de mayor consumo de agua con los de mayor demanda atmosférica. De la misma manera es posible identificar que aquellos rodales con mayor cobertura del suelo son los que presentaron los mayores consumos de agua, en coincidencia con los expuesto por Calder et al. (2003) en bosques de coníferas y Huber et al. (1998) para bosques de E. nitens en Chile. 


\section{Capítulo 6}

\section{Consideraciones finales}




\subsection{CONSIDERACIONES FINALES}

En función de los resultados alcanzados en esta tesis es posible identificar algunas pautas generales de manejo del agua en ambientes de llanura. Para ello, es necesario comprender que la intervención de ambientes degradados mediante la incorporación y manejo de especies forestales para consolidación de márgenes de ríos torrenciales, cárcavas y cabecera de cuencas, representa una actividad recomendable en el manejo de cuencas hidrográficas típicas, donde la erosión de tipo laminar es potenciada por las altas pendientes y formación de torrentes.

En el caso de los sistemas llanos estas estructuras entran en desuso al punto de preguntarse si no representan un perjuicio. Los estudios recientes indican que las forestaciones afectan la dinámica hídrica al deprimir el acuífero freático y generar aumentos en la concentración de sales por migración desde zonas aledañas (George et al., 1999; Farley et al. 2005; Jobbágy et al., 2006a; Jobbágy et al., 2006b; Nosetto et al. 2008). Sin embargo, este proceso, lejos de poder ratificarlo con la evaluación de los componentes del balance bajo forestaciones, debe ser tomado en cuenta en futuras líneas de trabajo y es preciso considerarlo al incorporar forestaciones en estos ambientes.

Se manifiesta entonces, la necesidad de identificar pautas o criterios de conservación del suelo que nos permitirá escoger las medidas de manejo del agua que mejor se adapten a la problemática local. Para ello, se establece como primera medida, el diagnóstico temprano y el desarrollo y mantenimiento de estudios de tipo multidisciplinarios. No es posible la implementación de prácticas de uso y manejo del suelo-agua con criterios conservacionistas, si desconocemos la dinámica y los procesos de degradación que en ellos operan. Por tanto, el diagnóstico temprano de estos procesos y el desarrollo y mantenimiento de estudios de tipo multidisciplinarios, son esenciales para hallar soluciones concretas a problemas concretos.

El siguiente paso consistiría en definir la escala de trabajo en función de los recursos y capacidades disponibles. Una escala regional, llevaría a adoptar a la cuenca hidrográfica como unidad de estudio e integrar en ella todos los actores que la componen. En cambio, la elección de una escala local, permitiría actuar a nivel predial (tranqueras adentro), donde cada predio formaría parte de un área topo-hidrográfica en el que el productor puede y debe efectuar el control de su agua según su relieve. Independientemente de la escala de trabajo que sea considerada, es preciso contemplar 
las prácticas y obras más convenientes a las características y circunstancias locales y regionales.

La adopción de una escala predial, cuyo objetivo es el aprovechamiento ordenado del recurso hídrico, posibilitaría la aplicación de medidas de manejo de agua y suelos en cualquier situación de la pampa ondulada o deprimida. Se prefiere aquí la retención del agua y no su evacuación, bajo el precepto de retener el agua donde cae.

La idea de retener agua en vez de canalizarla surge en 1884 con Florentino Ameghino en su obra de "Las secas y las inundaciones". Hoy en día, estas ideas se complejizan al adaptarlas al nuevo estado de conocimiento de la dinámica de aguas subterráneas. A este respecto, Sallies (1999) indica que retener agua de períodos de excesos para utilizarla en los de sequía es una utopía imposible de realizar por poderosas razones técnicas y económicas y no existe un solo proyecto que demuestre como puede ser llevado a la práctica en un área tan extensa como la llanura pampeana.

A este respecto, varios especialistas han evidenciado las ventajas de retener el agua en la provincia de Buenos aires (CADIA, 1987) al aumentar el volumen de agua infiltrada por medio del almacenamiento de la misma en cubetas naturales y la utilización de bordos en los límites de las mismas.

El aumento de la retención del agua tiene por finalidad el disminuir la necesidad de esta en períodos deficitarios. Ello puede lograrse por el aumento del volumen naturalmente acumulado en los terrenos bajos, mediante la instalación de bordos forestados. De esta manera, se facilitaría la fijación de estos bordos a la vez que aumentaría la infiltración de agua en el perfil (efecto estructurante de las raíces forestales), y se reduciría la evaporación del agua almacenada (efecto de sombreado y barrera contra el viento).

Otra medida consiste en manejar los escurrimientos provenientes de campos vecinos y los propios por la implementación de canales o pequeñas lomadas con líneas de forestación en sentido contrario al sentido de la pendiente, provocando su retardo e infiltración en el suelo.

Puede observarse que estas medidas platean el uso de cortinas como el sistema agroforestal más promisorio, consideradas un método de ordenamiento predial de alto beneficio económico, ambiental y paisajístico, con o sin la integración de los negocios del cultivo protegido y el aprovechamiento maderero de la cortina (Alarcón y Matzner, 2002). 
La instalación de cortinas representa una medida recomendable, ya que reduce la evapotranspiración de los cultivos por frenado del viento y sombra, y aumentaría consecuentemente la humedad del suelo en el período estival de mayor demanda evapotranspirativa y reduciría los excesos de invierno al evitar el ascenso freático por consumo directo. Sin embargo, no es posible implementar estos sistemas en los casos estudiados ya que se trata de forestaciones en macizo, de difícil conversión a cortinas, y además, una de ellas tiene un destino netamente maderero. Aquí, el alto poder evapotranspirante de las masas forestales condiciona balances mayormente negativos a nivel anual, donde los déficit son grandes. En años secos esto se vuelve perjudicial y podría ser regulado mediante la reducción de su capacidad de intercepción a través de podas y raleos, y así evitar descensos locales pronunciados del nivel freático.

El uso de plantaciones de pino y eucaliptus como biodrenajes a ha tenido buen resultado en diversos países para el control de inundaciones, salinización del suelo y elevación de la superficie freática y se ha documentado como una alternativa válida y financieramente viable en la llanura pampeana en sistemas de silvopastoreo (Alconada et al., 2009). La instalación de plantaciones con bajas densidades, es considerada como una alternativa de menor impacto en estas regiones que podría reducir la intensidad del los procesos de salinización asociados a estas coberturas (Jobbágy et al., 2006a)

En el caso del Predio Forestal Dolores, se realiza manejo de rebrote para lograr una homogeneidad en las dimensiones de madera a extraer y de esta manera estarían trabajando sobre la capacidad evapotranspirativa de las forestaciones. Sin embargo, en años secos, la densidad de estas forestaciones acentuaría el déficit hídrico de forma alarmante. Facilitar el ingreso de los escurrimientos de predios vecinos y su infiltración por medio de una reorganización de caminos sería recomendable, pero el anegamiento de plantaciones no es algo buscado en la actividad forestal por lo que debería acompañarse con obras de arte que permitan controlar estos flujos al momento de las intervenciones silvícolas. Una de estas obras de arte puede ser el uso de compuertas en canales de desagües.

En el caso de la Estancia El Centauro, donde la forestación tiene un destino incierto, podría pensarse en realizar una limpieza o raleo fuerte en fajas trasversales a la dirección del escurrimiento para propender a su retención e infiltración a la vez que se utilizan como montes de reparo para el ganado con desarrollo de pasturas entre fajas. La instalación de 
cortinas puede significar entonces una medida recomendable por su efecto se sombreado y barrera contra el viento. Esto aumentaría consecuentemente la humedad del suelo en el período estival, de mayor demanda evapotranspirativa, y reduciría los excesos de invierno a la vez que evita el ascenso freático por consumo directo. 


\section{Capítulo 7}

\section{Conclusiones}




\subsection{CONCLUSIONES}

La identificación y caracterización de las áreas de estudio permitió definir a estas como sistemas hidrológicos atípicos caracterizados por el predominio de suelos salino sódicos, pendientes que no superan el 1\% y movimientos verticales del agua que vinculan una capa freática poco profunda con el sistema hidrológico superficial. El clima se estableció como templado húmedo con precipitaciones que oscilan en 900 a 1000mm/año, ligeramente concentradas en verano y que alcanzan a delinear, en la Estancia El Centauro (EEC), débiles redes de escurrimiento que alimentan el drenaje de la cuenca del Arroyo El Pescado. Esto no ocurre en el Predio Forestal Dolores (PFD), dado que responde a un paisaje típicamente lacunar con pendientes aun menores y una capa freática más cercana a la superficie, que agrava la situación ante excesos hídricos.

El inventario realizado sobre las forestaciones de Pinus radiata Don y Eucalyptus viminalis Labill en EEC, y las de Eucalyptus camaldulensis Dehnh en el PFD, permitió caracterizarlas como rodales adultos provistos de una canopea que supera los $20 \mathrm{~m}$ de altura y densidades que varían entre 650 y 1440pl/ha. Asimismo, sus áreas basales y porcentajes de cobertura se estimaron en $73,5 \mathrm{~m}^{2} /$ ha y $53,5 \%$ para pino, $8,9-9,6 \mathrm{~m}^{2} / \mathrm{ha}$ y $36,7-60,0 \%$ para $E$. viminalis y $10,7-54,3 \mathrm{~m}^{2} /$ ha y $26,2-47,1 \%$ para $E$. camaldulensis. $E$ estado de conocimiento actual frente a las exiguas plantaciones forestales de la pampa ondulada y pampa deprimida, permiten extrapolar estos valores como representativos de las plantaciones de pino y eucalipto de estos ambientes.

Del análisis de los datos pluviográficos se obtuvo una buena correlación entre los valores anuales y mensuales de las estaciones meteorológicas Julio Hirschhorn y Aeródromo Dolores (EEJH y EMAD) junto con un elevado grado de correlación para cada uno de los pares (“EEJH-Testigo EEC" y "EMAD-Testigo PFD”). Esto permitió utilizar indistintamente tanto los datos pluviométricos de las estaciones meteorológicas como los de los pluviómetros testigo. El consecuente estudio de la redistribución de estas lluvias demostró la importancia parcial de cada uno de los flujos analizados (intercepción, trascolación, escurrimiento fustal y precipitación neta), los cuales se mostraron altamente correlacionados y en proporción constante a nivel mensual y estacional para cada una de los rodales. Por tanto, se pudo definir que los valores de intercepción (I) obtenidos en los pinos duplica a la de los eucaliptos en EEC, mientras que los correspondientes a $E$. viminalis en PFD duplican a los medidos para la misma especie en EEC. Dicho 
comportamiento responde a un mejor estado fisiológico y crecimiento más activo de los rodales de PFD, provocado por posibilidad de acceso ininterrumpido al agua freática, y permite aceptar la hipótesis de que la capacidad de intercepción de los pinos estudiados supera a la de los eucaliptos. La trascolación $\left(\mathrm{T}_{\mathrm{r}}\right)$, por otro lado, predominó ampliamente sobre el escurrimiento fustal $\left(\mathrm{E}_{\mathrm{f}}\right)$ y manifestó ser el principal componente de la precipitación neta. Por su parte $\mathrm{E}_{\mathrm{f}}$, en principio despreciable, cobra importancia en períodos de escasas precipitaciones por tratarse de un flujo concentrado alrededor del tronco donde se localiza la mayor densidad de raíces. Se observa además que las plantaciones de E. viminalis de ambos sitios de estudio comparten similares valores de $\mathrm{E}_{\mathrm{f}}$, superiores a los encontrados en pinos, mientras que los distintos rodales de E. camaldulensis manifiestan amplias variaciones respecto a este componente, que guarda relación con la densidad de árboles por hectárea.

Paralelamente, se estableció que el rango de intercepción determinado en PFD para E. camaldulensis no presenta una relación directa con la densidad de árboles por hectárea; DAP; altura máxima promedio; el porcentaje de cobertura o el área basal de los rodales. En cambió, se pudo inferir tanto para los rodales de E. camaldulensis como para los otros rodales del mismo género, una relación directa entre el porcentaje anual de intercepción y la edad de los rodales. Ello indica que a mayor edad de los rodales puede esperarse un incremento en los porcentajes de intercepción del agua de lluvia y permite rechazar la hipótesis de que la capacidad de intercepción de estos rodales aumente con la densidad de los mismos.

Los valores de escurrimiento obtenidos por la metodología del número de curva fueron muy superiores a los registrados para la llanura pampeana. Dichos resultados no permitieron verificar la hipótesis de que las forestaciones anulan el componente de escurrimiento superficial, pero si permitieron establecer una importante reducción del escurrimiento superficial anual en la conversión de pastizales por forestaciones. Las particularidades hídricas del período de estudio y la ausencia de calibraciones sobre este modelo, impidió verificar la las fuentes de variación que provocaron estos resultados, sin embargo se destaca la utilidad de esta metodología como una poderosa herramienta de diagnóstico en el estudio del comportamiento de los escurrimientos superficiales en situaciones hipotéticas de uso de la tierra. 
La evolución del nivel freático bajo los distintos usos/coberturas y el análisis de flujos, permitieron identificar un comportamiento integrado del acuífero, con un flujo subterráneo que acompaña a la pendiente topográfica regional. Las forestaciones intervienen sobre este flujo retardándolo y en ocasiones actúan como zonas de carga o descarga neta del mismo. Este comportamiento se manifestó como un consumo diferencial por parte de estas coberturas y permitió identificar variaciones de nivel que superan los $2 \mathrm{~m}$ al confrontar las coberturas de pastizal con las forestales, lo cual constituye una evidencia clara del mayor consumo de agua por parte de las forestaciones y de su capacidad de aprovechar el agua freática. Al profundizar el análisis, se estableció en EEC un mayor consumo de agua freática bajo la cobertura de $P$. radiata frente a las de $E$. viminalis y pastizal. En PFD en cambio, predominó el consumo de la cobertura de E. viminalis frente al de E. camaldulensis y el de este último frente al de pastizal. Este análisis, permitió establecer que la plantación de pino tuvo mayor disponibilidad de agua freática que la plantación de E. viminalis, producto posiblemente de un sistema radical más extenso en profundidad o su mayor capacidad de intercepción que reduce el ingreso de agua al suelo. De la misma manera, se observó que a igual disponibilidad de agua, el E. viminalis superó en consumo a los rodales de E. camaldulensis, lo cual podría responder a un crecimiento más acelerado de esta especie o un uso más eficiente del recurso.

En términos de carga y descarga, fue posible establecer que mientras que los sitios bajo coberturas de pastizal actuaron como lugares preferenciales de recarga en ambos predios, las especies forestales presentaron comportamiento variables. En PFD, la forestación de E. viminalis actuó como un lugar de descarga preferencial durante todo el período de estudió mientras que la cobertura de E. camaldulensis mostró ser capaz de facilitar o interrumpir la recarga al ser comparado con otros usos/coberturas. En EEC en cambio, tanto los sitios bajo $E$. viminalis como los que se encuentran bajo $P$. radiata, manifestaron una gran capacidad de infiltración en ciertos momentos y en otros, una interrupción total de la recarga. Esto último se asoció a las condiciones de humedad antecedente del suelo y a la profundidad que se presenta la capa freática, dado que al superar los $6 \mathrm{~m}$ de profundidad, los arboles manifiestan una aparente disminución en el consumo hídrico.

En suma, los resultados alcanzados en el capítulo de infiltración y flujos subterráneos, hacen posible verificar la hipótesis de que las forestaciones de PFD favorecen los procesos de infiltración ante períodos de excesos hídricos, mientras que 
acentúan los períodos de déficits al incrementar la descarga del acuífero freático en períodos con baja pluviometría. En EEC, en cambio, este supuesto se comprueba parcialmente al observar que las forestaciones atenúan o disminuyen los procesos de descarga en épocas secas o de baja pluviometría. Dicho comportamiento, responde a que los árboles, al no tener libre acceso a una fuente de agua permanente, restringen fuertemente su consumo a la vez que retienen humedad en el mantillo forestal y disminuyen su evaporación por el sombreado del mismo con el dosel arbóreo. Por otro lado, los gradientes hallados entre los distintos usos/coberturas resultaron mínimos, al igual que los valores calculados de flujo subterráneo horizontal, y permite corroborar el supuesto de que los flujos subterráneos horizontales pueden despreciarse para el grado de detalle abordado en este estudio.

Al abordar el estudio de la evapotranspiración, se demostró que las forestaciones de ambos sitios de estudio presentaron un consumo de agua muy superior a las situaciones de pastizal, que superaron los registros medios de precipitación anual. Los valores de ET para pastizales en cambio, se establecieron por debajo de los valores de precipitación media pero $100 \mathrm{~mm}$ por encima de los valores esperables para estas zonas, producto posiblemente de haber considerado un $\mathrm{K}_{\mathrm{C}}$ alto y constante para los pastizales. La conversión de pastizales por forestaciones de rápido crecimiento, demostró superar en un $51-87 \%$ a la situación natural y tornar los rendimientos hídricos de positivos a marcadamente negativos durante gran parte del tiempo. Esto representó un aporte del 41$55 \%$ y 35-67\% por encima de la precipitación media anual de EEC y PFD, respectivamente. De esta manera, si consideran los valores calculados de ETP para cada cobertura, es posible identificar que la plantación de pino en EEC y la de E. viminalis en PFD son las coberturas que con mayor consumo hídrico. Dicho comportamiento también se observa al comparar los coeficientes de cultivo establecidos y condicionan en última instancia balances más negativos para estas dos especies, en los respectivos predios. En suma, se interpreta que los balances hídricos obtenidos están fuertemente influenciados por el clima y tipo de uso/cobertura al cual están sometidos. Puede verificarse entonces, la hipótesis de que el rodal de pino presenta un menor rendimiento hídrico (descarga freática) frente a los de eucalipto y, dentro de estos, que el rendimiento hídrico de los rodales de $E$. viminalis supera al de E. camaldulensis. Sin embargo, a pesar de que las metodologías utilizadas presentan una validez comprobada, al no contar con una verificación de estos 
valores a campo o un sustento estadístico fuerte, esta conclusión puede resultar especulativa.

Se concluye finalmente que las forestaciones realizan un uso más exhaustivo del agua frente a las coberturas herbáceas. Sus canopeas determinan altos porcentajes de intercepción que reducen el agua que alcanza el suelo, y una vez que lo hace, se encuentra con un mantillo que reduce la posibilidad de escurrir superficialmente y facilita su infiltración en el suelo. Esta infiltración, facilitada por un aumento de la porosidad y la hidrofobicidad de la materia orgánica, es rápidamente absorbida por la forestación y liberada al ambiente. La existencia de un acuífero libre a menos de $6 \mathrm{~m}$ de la superficie del suelo constituye un aporte de agua extra para las forestaciones, que la utilizan activamente cuando las condiciones ambientales son propicias, al punto de generar depresiones de más de $2 \mathrm{~m}$ de profundidad y convertir sitios naturales de recarga en sitios de descarga neta. Uno de los problemas más alarmantes del consumo de agua por parte de las plantas esta dado por la posibilidad de salinización de los suelos y napas, cuestión que ha sido abordada intensamente por estudios locales y es necesario seguir profundizando. 


\section{Bibliografía}




\section{BIBLIOGRAFÍA}

Abbate, P.E. 2004. AGROCLIMA: un programa para el cálculo de la evapotranspiración por el método FAO Penman-Monteith desde planillas de cálculo 0 lenguajes de programación. $10^{\circ}$ Reunión Argentina y $4^{\circ}$ Latinoamericana de Agrometeorología, Mar del Plata, 13 y 14 de octubre 2004. 2 p.

Alconada M., M.M.; A. Bussoni; R. Rosa y J.J. Carrillo R. 2009. El bio-drenaje para el control del exceso hídrico en Pampa Arenosa, Buenos Aires, Argentina. Investigaciones Geográficas, Boletín del Instituto de Geografía, UNAM ISSN 0188-4611, N $68,50-72$

Allen, R.G.; L.S. Pereira; D. Raes y M. Smith. 2006. Evapotranspiración del cultivo. Guías para la determinación de los requerimientos de agua de los cultivos. Serie de Riego y Drenaje, FAO-56. Roma. 301 p.

Allen, R.G.; L.S. Pereira; D. Raes and M. Smith. 1998. Crop evapotranspiration Guidelines for computing crop water requirements. FAO Irrigation and drainage paper 56. Food and Agriculture Organization of the United Nations, Rome. 301 p.

Ameghino, F. 1884. Las secas y las inundaciones: en la provincia de Buenos Aires. Obras de retención y no obras de desagüe. Secretaría de Política Ambiental, Buenos Aires. $97 \mathrm{p.}$

Andrade, M.I. y O.E. Scarpati. 2008. Agua: Sequía e incertidumbre. X Jornadas de Investigación del Centro de Investigaciones Geográficas y del Departamento de Geografía, 6 y 7 de noviembre. Universidad Nacional de La Plata. Facultad de Humanidades y Ciencias de la Educación. Departamento de Geografía. 8 p.

Alarcón, C. y K. Matzner. 2002. Manual de cortinas forestales. INFOR, Instituto forestal. Santiago de Chile. $59 \mathrm{p}$.

Aragón, R.; E.G. Jobbágy and E.F. Viglizzo. 2011. Surface and groundwater dynamics in the sedimentary plains of the Western Pampas (Argentina). Ecohydrology. 4, 433-447.

Atlas 2010 de Cuencas y Regiones Hídricas la República Argentina (www.hidricosargentina.gov.ar) 
Auge, M.P. 2009. Hidrogeología de llanuras. Universidad de Buenos Aires. 85 p. [Disponible en: http://tierra.rediris.es/hidrored/ebooks/miguel/HidrogeoLlanuras.pdf]

Auge, M.P. 2006. Agua subterránea. Deterioro de calidad y reserva, Buenos Aires, Facultad de Ciencias Exactas y Naturales. Departamento de Ciencias Geológicas. Cátedra de Hidrogeología, Universidad de Buenos Aires. 173 p.

Auge, M.P. 2005. Hidrogeología de La Plata, Provincia de Buenos Aires. Relatorio del XVI Congreso Geológico Argentino. p. 293-311.

Auge, M.P. 1995. Similitudes hidrogeológicas entre los acuíferos Pampeano y Puelche en La Plata, Argentina. II Seminario Hispano Argentino de Hidrología Subterránea. Tucumán. p. 235-241.

Auge, M.; C. Wetten; G. Baudino; G. Bonorino; R. Gianni; N. González; M. Grizinik; M. Hernández; J. Rodríguez; A. Sisul; A. Tineo; C. Torres. 2006. Hidrogeología de Argentina. Boletín Geológico y Minero, 117 (1): 7-23.

Auge, M. y M. Hernández. 1984. Características geohidrológicas de un acuífero semiconfinado (Puelche) en la Llanura Bonaerense. Su implicancia en el ciclo hidrológico de las Ilanuras dilatadas. Coloquio Internacional sobre Hidrología de Grandes Llanuras, Buenos Aires- París, 2, 1019-1041.

Badano, D.N. 2010. Modelación Integrada de Grandes Cuencas de Llanura con Énfasis en la Evaluación de Inundaciones. Tesis de grado en Ingeniería Civil. FIUBA, Bs.As. 172 p.

Bailly, C.; G. Benoit de Coignac,; C. Malvos,; J.M. Ningre and J.M. Sarrailh. 1974. Etude de l'influence du couvert naturel et de ses modifications á Madagascar. Experimentations en bassins versants elementaires. C.T.F.T. (Centre Techni que Forestier Tropical), Cahiers Scientifiques No. 4.114 p.

Barbagallo, J.F. 1983. Las áreas anegables de la Pampa Deprimida. Un planteo agrohidrológico para su solución. Hidrología de Grandes Llanuras. Actas del coloquio de Olavarría.Abril 1983. II: 787-864.

Batista, W.B.; M.A. Taboada; R.S. Lavado; S.B. Perelman y R.J.C. León. 2005. Asociación entre comunidades vegetales y suelos en el pastizal de la Pampa Deprimida. 
En: M. Oesterheld, M. R. Aguilar, C. M. Ghersa y J. M. Paruelo (eds.) La heterogeneidad de la vegetación en los agroecosistemas. Un homenaje a Rolando J.C. León. Ed. Facultad Agronomía. Universidad de Buenos Aires. 113-129.

Belmonte Serrato, F. y A. Romero Díaz. 1999. Balance hídrico y distribución espacial de la trascolación bajo cobertura de pino: influencia de la dirección del viento y la pendiente de la ladera. Lurralde inves. esp. 22: 339-350.

Benyon, R.G.; S. Theiveyanathan and T.M. Doody. 2006. Impacts of tree plantations on groundwater in south-eastern Australia. Australian Journal of Botany, 54: 181-192.

Besteiro, S.I. y A.M. Rodríguez V. 2012. Redistribución de las precipitaciones sobre plantaciones forestales en un predio del partido de La Plata, Buenos Aires. Revista de la Facultad de Agronomía, La Plata. Vol. 111 (2): 75-82.

Besteiro, S.I. y M.I. Delgado. 2011. Evaluación de la agresividad de las precipitaciones en la cuenca del Arroyo El Pescado, provincia de Buenos Aires (Argentina). Revista de la Facultad de Agronomía, La Plata. Vol. 110 (2): 82-90.

Besteiro, S.I. 2010. Incidencia de la cobertura forestal sobre la dinámica del agua en la cuenca alta del arroyo El Pescado, Partido de La Plata. Mg. Sc. Tesis. Inédita. Facultad de Ciencias Agrarias y Forestales, Universidad Nacional de La Plata, Argentina. $125 \mathrm{p}$.

Bosch, J.M. and J.D. Hewlett. 1982. A review of catchment experiments to determine the effects of vegetation changes on water yield and evaporation. Journal of Hydrology 55: 3-23.

Bruijnzeel, L.A. 1997. Hydrology of forest plantations in the tropics. Pp. 125-168. En: Nambiar, E.K.S., Brown, A. (eds), Management of soil, nutrients and water in tropical plantation Forests. CSIRO. 571 p.

Bruijnzeel, L.A. 1990. Hydrology of Moist Tropical Forests and Effects of Conversion: a State of Knowledge Review. Humid Tropics Programme, IHP-UNESCO, Paris, and Vrije Universiteit, Amsterdam, $224 \mathrm{p}$. 
BURGOS, J.J. y A.L. VIDAL. 1951. Los climas de la República Argentina según la nueva clasificación de Thornthwaite. Meteoros 1:3-32.

CADIA (Centro Argentino de Ingenieros Agrónomos). 1987. Inundaciones y Manejo de Cuencas. Mesa redonda realizada el 16 de diciembre de 1985, en la sede del CADIA. Editorial CADIA. Buenos Aires. 125 p.

Calder, I.R. 1998. Water use by forests, limits and controls. Tree Physiology, 18: 625-631.

Calder, I.R. 1992. Water use of eucalypts - a review. In: Calder, I.R., R.L. Hall and P.G. Adlard. ed. Growth and Water Use of Forest Plantations. J. Wiley, New York. 167-179.

Calder, I.R.; J. Harrison; T.R. Nisbet and R.J. Smithers. 2008. Woodland actions for biodiversity and their role in water management. Woodland Trust. $23 \mathrm{p}$.

Calder, I.; T. Hofer; S. Vermont y P. Warren. 2007. Hacia una nueva comprensión de los bosques y el agua. En: unasylva 229, Vol. 58, 2007/4. 72 p.

Calder, I.R., Reid, I., Nisbet, T. and J.C. Green. 2003. Impact of lowland forests in England on water resources-application of the HYLUC model. Water Resources Research 39: 1319-1328.

Calder, I.R. and M.D. Newson. 1979. Land use and upland water resources in Britain - a strategic look. Water Resources Bulletin, 15: 1628-1639.

Canadell, J.; R.B. Jackson; J.R. Ehleringer; H.A. Mooney; O.E. Sala and E.D. Schulze. 1996. Maximum rooting depth of vegetation types at the global scale. Oecologia, 108: 583-595.

Cantú S., I. y H. González R. 2002. Propiedades hidrológicas de dosel de los bosques de pino encino en el Noreste de México. Ciencia UANL, V(1):72-78.

Carlevari, I.J.F. y R.D. Carlevari. 2007. La Argentina, Geografía económica y humana. Ed Alfaomega Grupo Editor Argentino S. A. Paraguay 1307, PB, oficina 11; Buenos Aires, Argentina. 14를 Ed. 543 p

Chinnamani, S.; S.C. Gupte,; N.D. Rege, y P.K. Thomas. 1965. Run-off studies under different forest covers in the Nilgiris. Indian Forester 91 (8) 676-679. 
Choisnel, E.; O. de Villele; F. Lacroze. 1992. 'Une aproche uniformisée du calcul de l'évapotranspiration potentielle pour l'ensemble des pays de la Communauté Européenne. Com. Commun. Européennes', EUR 14223 FR, Luxembourg, 176 p.

Chow, V.T.; D.R. Maidment y L.W. Mays. 1994. Hidrología aplicada. Ed. McGRWHILL INTERAMERICANA, S. A. Santafé de Bogotá, Colombia. 584 p.

Chu-San Lin, P. 1968: Einflüsse verschiedener Pflanzenbestände auf den Wasserhaushalt in ainem Einzugsgebiet. Inaugural dissertation zur Erlangung der DoktorWürde. Lud- wig-Maximilians-Universität zu München. 108 pág.

Colaboradores de Wikipedia. 2013a. "Dosel arbóreo" Wikipedia, La enciclopedia libre. [http://es. wikipedia.org/w/index.php?title=Dosel arb\%C3\%B3reo\&oldid=66157796]. Consulta: marzo de 2013.

Colaboradores de Wikipedia. 2013b. "Píxel" Wikipedia, La enciclopedia libre. [http://es. wikipedia.org/w/index.php?title=P\%C3\%ADxel\&oldid=66669761]. Consulta: mayo de 2013.

Colotti, E.B.; A.T. Blanco y J.G. Rodríguez. 2003. Aplicación de coeficiente de inconsistencia como criterio de comparación entre mediciones convencionales y automáticas de lluvia diaria. Terra. Vols. XVIII-XIX, Nos. 27-28, 2002-2003, p. 85-101.

CONIF. 1998. Efectos de plantaciones forestales sobre el suelo y agua. Serie Técnica No. 40. Bogotá. Min ambiente. Investigadores: Sicard, T. L. y Suarez, D. A. 145 p.

Custodio, E. y R.M. Llamas. 1996. Hidrología Subterránea. Ediciones Omega, S. A., Barcelona. Segunda edición, Tomo 1. 1154 p.

Damiano, F. y M.A. Taboada. 2000. Predicción del agua disponible usando funciones de pedo-transferencia en suelos agrícolas de la región Pampeana. Ciencia del Suelo, 18(2): 77-88.

Dabral, B.G. y B.K. Subba Rao. 1969. Interception studies en sal (Shorea robusta) and Khair (Acacia catecú) plantation-New Forest. Indian Forester 95(5) 314-323.

Dabral, B.G. y B.K. Subba Rao. 1968. Interception studies in chir and teak plantations-New Forest. Indian Forester 94(7) 541-551. 
De Francesco, F.; R.O. Gentile; E. Fucks y U. Colado. 2001. Caracterización geoambiental del sector comprendido entre Punta Lara y Punta Blanca, provincia de Buenos Aires. Reunión Nacional de Geología Ambiental y Ordenación del Territorio Nro.3, Mar del Plata. 1-12.

De Francesco, F.O.; O. Gentile; G. Nuccetelli; E. Fucks y U. Colado. 1999. Mapa Geológico de las hojas Chascomús y Buenos Aires. Escala 1:250.000. Actas XIV Congreso Geológico Argentino Salta, 1: 287-290.

De la Vega, M.A.; M.A. Pinazo; J. Marquina y E. Crechi. 2010. Efectos de los raleos sobre las características del canopeo en plantaciones de Pinus elliottii var. elliottii Engelm. x Pinus caribaea var. hondurensis Morelet. En la provincia de Misiones. 14as Jornadas Técnicas Forestales y Ambientales. Facultad de Ciencias Forestales, UNAM-EEA Montecarlo, INTA. 10, 11 y 12 de Junio de 2010-Eldorado, Misiones, Argentina

de Paula Lima, W. 2008. Hidrología florestal aplicada ao manejo de bacias hidrográficas. Escola Superior de Agricultura "Luiz de Queiroz", Departamento de Ciências Florestais Piracicaba, Universidade de São Paulo, Brasil. 245 p.

Dewalle, D.R. and L.K. Paulsell. 1969. Canopy interception, stemflow and streamflow on a small drainage in the Missouri Ozarks. Res. Bull. Mc. Agric. Exp. Sta. No. 951. 26 p. In: Forestry Abstracts, 31 (2): 1854.

Díaz, R.A. y M.G. Rébori. 2003. Intercepción de la lluvia en un monte de Eucalyptus dunnii. XII Congreso Forestal Mundial, Quebec City, Canadá. 6 p.

Domingo, F.; L. Villagarcía y A. Were. 2003. ¿Cómo se puede medir y estimar la evapotranspiración?: estado actual y evolución. Ecosistemas Año XII Nro1: 15 p.

Donoso, S., F. Ruiz y M. Herrera. 2002. Distribución y cantidad de biomasa de raíces finas en plantaciones clonales de Eucalyptus globulus. Ciencias Forestales 16(1-2). $8 \mathrm{p.}$

Doorenbos, J. and W.O. Pruitt. 1977. Guidelines for predicting crop water requirements. FAO Irrigation and Drainage Paper 24, ( $2^{\text {nd }}$ ed). Rome, $156 \mathrm{p}$.

Dye, P.J. 1993. Development of Generalized Models for Rainfall Interception by Eucalyptus grandis and Pinus patula plantations. Contract report, FOR-DEA 623, to the 
Department of Water Affairs and Forestry. CSIR Division of Forest Science and Technology, Pretoria.

Eagleson, P.S. 2002. Ecohydrology: Darwinian expression of vegetation form and function. Cambridge University Press. UK. 443 p.

EASNE. 1972. Contribución al estudio geohidrológico del Noreste de la Provincia de Buenos Aires. EASNE-CFI. Serie. Téc.24, Tomo I y II.

Eastham J.; C.W. Rose; D.M. Cameron; S.J. Rance and T. Talsma. 1988. The effect of tree spacing on evaporation from an agroforestry experiment. Agric For Met 42: 355-368.

Eamus, D.; T. Hatton; P. Cook y C. Colvin. 2006. Ecohydrology Vegetation Function, Water and Resource Management. ISBN 064306834 1.Csiro Publishing. Australia. 348 p.

Engel, B; J. Harbor; S. Muthukrishnan; S. Pandey and K.J. Lim. 2003. LTHIA NPS Versión 2.3.User Manual.

Engel, V.; E.G. Jobbágy; M. Stieglitz; M. Williams and R.B. Jackson. 2005. Hydrological consequences of Eucalyptus afforestation in the Argentine Pampas, Water Resources Research, 41, W10409, doi:10.1029/2004WR003761. 14 p.

Etchevehere, P. 1961. Bosquejo de regiones geomorfológicas y de drenaje de la República Argentina. IDIA 162: 7-25.

FAO. 2011. Situación de los bosques del mundo 2011. Roma (Italia) (disponible también en http://www.fao.org/docrep/013/l2000s/l2000s.pdf). 176 p.

FAO. 2010a. Evaluación de los recursos forestales mundiales, 2010 - Informe principal. Estudio FAO Montes 163. Roma (Italia). 346 p. (Disponible también en http://www.fao.org/docrep/013/i1757s/i1757s.pdf).

FAO. 2010b. Evaluación de los recursos forestales mundiales, 2010 - Informe Nacional. Argentina. FRA2010/009. Roma (Italia). 66 p. (Disponible también en http://www.fao.org/docrep/013/al445S/al445S.pdf). 
FAO. 2002. Participación de la FAO en el sector de los productos no madereros. URL: http://www.fao.org/docrep/t0431s/t0431s03.htm

FAO. 2001. Global Forest Resources Assessment 2000. Main Report. FAO, Forestry Paper 140. Roma.

FAO. 2000. Manual de Captación y Aprovechamiento del Agua de Lluvia, Experiencias en América Latina. Tomo II. Serie: Zonas Áridas y Semiáridas Nro. 13. Oficina regional de la FAO para América Latina y el Caribe. Santiago, Chile. 235 p.

FAO. 1995. Sistemas de realización de la ordenación forestal sostenible. Estudio FAO Montes 122. ISBN 92-5-303401-7. Roma (Italia). 298 p. (Disponible en: http://www.fao.org/docrep/016/ap430s/ap430s00.pdf

FAO. 1962. La influencia de los montes. Estudios de silvicultura y productos forestales. No. 15. Roma. 335 p.

Farrington, P.; G.D. Watson; G.A. Bartle and E.A.N. Greenwood.1990. Evaporation from dampland vegetation on a groundwater mound. J. Hydrol., 115: 65-75.

Farley, K.A.; E.G. Jobbágy and R.B. Jackson. 2005. "Effects of afforestation on water yield: a global synthesis with implications for policy." Global Change Biology (2005) 11(doi: 10.1111/j.1365-2486.2005.01011.x): p. 1565-1576.

Fernández, M.E.; J.E. Gyenge and T.M. Schlichter. 2009. Water flux and canopy conductance of natural versus planted forests in Patagonia, South America. Trees 23: 415427.

Fernández, M.E.; J.E. Gyenge and T.M. Schlichter. 2007. Balance of competitive and facilitative effects of exotic trees on a native Patagonian grass. Plant Ecol. 188: 67-76. DOI 10.1007/s11258-006-9148-x.

Fertonani, M. y H. Prendes. 1983. Hidrología en áreas de llanura. Aspectos conceptuales teóricos y metodológicos. Actas del Coloquio de Olavarría de Hidrología de las grandes Ilanuras. Buenos Aires, Argentina. Vol. I: 118-156.

Fidalgo, F., F.O. De Francesco y R. Pascual. 1975. Geología Superficial de la Llanura Bonaerense. Relatorio del VI Congo Geo I. Arg. (Bs. As.): 103-138. 
Fidalgo, F., F.O. De Francesco y U.R. Colado. 1973. Geología superficial en las Hojas Castelli, J. M. Cobo y Monasterio (Pcia. de Bs. As.). Actas V Congreso Geológico Argentino (Cba., 1972), 4 27-39.

Forte Lay, J., O. Scarpati and A. Capriolo. 2008. Precipitation variability and soil water content in Pampean Flatlands (Argentina). Geofísica Internacional 47(4): 341-354.

Frangi, J.L. y L.L. Richter.1994. Balances hídricos de bosques de Nothofagus de Tierra del Fuego, Argentina. Revista de la Facultad de Agronomía (UNLP), 70: 65-79.

Fuschini Mejía, M.C. 1994. "El agua en las Ilanuras". UNESCO/ORCYT. Montevideo, Uruguay. 54 p.

Gaspari, F.J. 2002. Ordenamiento territorial en cuencas serranas. Aplicación de Sistemas de Información Geográfica (S.I.G.). Ediciones Cooperativas. 116 p.

Gaspari, F.J.; G.E. Senisterra; M.I. Delgado; A.M. Rodríguez Vagaría y S.I. Besteiro. 2009. Manual de Manejo Integral de Cuencas Hidrográficas. 1aㅡ. ed., ISBN 978987-05-6165-1. La Plata. 321 p.

Gattinoni, N.; T. Boca; C. Rebella y C. Di Bella. 2011. Comparación entre observaciones meteorológicas obtenidas de estaciones convencionales y automáticas a partir de la estimación de parámetros estadísticos. RIA, vol. 37 (1): 75-85.

Geiger, R. 1966. The Climate Near the Ground. Harvard University Press. Cambridge, Mass. $611 \mathrm{p}$.

George, M. 1978. Interception, stemflow and throughfall in a Eucalyptus hybrid plantation. Indian Forester 104(11) 719-726.

George, R.J.; R.A. Nulsen; R. Ferdowsian and G.P. Raper. 1999. Interactions between trees and groundwater's in recharge and discharge areas - a survey of Western Australian sites. Agricultural Water Management, 39, 91-113.

Giordano, E. 1969. Osservazioni sull'apparato radícale del l'Eucalyptus globulus Labill. Pubblicazioni del Centro di Sperimentazione Agrícola e Forestale 10 135-147.

Giraldo L., L.G. 2002. Memorias: Hidrología Forestal (Influencia de los bosques). Departamento de Ciencias Forestales, Universidad Nacional de Colombia, Medellín. 230 p. 
Giraut, M. 2006. Dinámica geomorfológica del humedal fluvial del Río Paraná en la Provincia del Chaco. Tesis Doctoral. Facultad de Ciencias Naturales y Museo - UNLP.

González H.F., M. López A. y M.T. Minaya G. 1993. Intercepción, trascolación y escorrentía cortical en masas de Eucalyptus globulus Labill y Pinus pinea L. del sur de la provincia de Huelva. Congreso Forestal Español-Lourinzán 1993. Ponencias y comunicaciones. Tomo III.

González, N., M.A. Hernandez y A. Ruiz de Galarreta. 1997. Balance hidrológico a nivel de la zona no saturada en un área de la cuenca de los Arroyos Martín y Carnaval, La Plata, Provincia de Buenos Aires, Argentina. III Seminario Hispano - Argentino sobre temas actuales de Hidrología Subterránea. Bahía Blanca. 97-106.

Gottle, A. y E.H. Sène. 1997. Funciones protectivas y ambientales de los bosques. Revista Unasylva Nro 190-191. Undécimo congreso forestal mundial, Vol. 48. [Disponible en: http://www.fao.org/docrep/w6251s/w6251s00.htm\#Contents]

Green W.H. and G.A. Ampt. 1911. Studies on soil physics. The flow of air and wáter through soils. Journal of Agricultural Science. Vol. 4, 1-24.

Gyenge, J.; M.E. Fernández; J. Licata; M. Weigandt; B.J. Bond y T. Schlichter. 2011. Uso del agua y productividad de los bosques nativos e implantados en el NO de la Patagonia: aproximaciones desde la ecohidrología y la ecofisiología. Ecología Austral 21: 271-284.

Gyenge, J.; M.E. Fernández and T. Schlichter. 2009. Effects on site wáter balance of conversión from native mixed forest to Douglas-fir plantation in N.W. Patagonia. New Forests 38: 67-80. DOI 10.1007/s11056-009-9132-0.

Gyenge, J.; M.E. Fernández and T. Schlichter. 2003. Water relations of ponderosa pines in Patagonia Argentina: implications for local water resources and individual growth. Trees 17: 417-423. DOI 10.1007/s00468-003-0254-2.

Gyenge, J.E.; M.E. Fernández; G. Dalla Salda and T.M. Schlichter. 2002. Sylvopastoral systems in Northwestern Patagonia II: wáter balance and wáter potential in a stand of Pinus ponderosa and native grassland. Agroforestry Systems 55: 47-55. 


\section{Hamilton, L.S.; N. Dudley; G. Greminger; N. Hassan; D. Lamb; S. Stolton y S.}

Tognetti. 2009. Los bosques y el agua. Estudio temático elaborado en el ámbito de la evaluación de los recursos forestales mundiales 2005. Estudio FAO Montes 155, Roma. 86 p.

Hamilton, L.S. and P.N. King. 1983. Tropical forested watersheds: hydrologic and soils response to major uses or conversions. Boulder, Colorado, EE.UU. Westview Press. $168 \mathrm{p}$.

Henaos, J. 1988. Introducción al manejo de cuencas hidrográficas. Universidad Santo Tomas. Centro de Enseñanza descolarizada, Bogotá. 399 p.

Hesselman, H. 1926. Studier över barrskogens hunustache. Dess egenskaper och beroende av skogsvarden. Statens Skogsförsöksant Meddel. 22:162-552.

Hibbert, A.R. 1967. Forest treatment effects on water yield. In: International symposium on forest hydrology. Eds WE Sopper, HW Lull. Pergamon, Oxford. 527-543.

Hofstede, R., J. Lips, W. Jongsma y J. Sevink. 1998. Geografía, ecología y forestación de la Sierra Alta del Ecuador; Revisión de literatura. Quito, Abya Yala. 242 p.

Holmes, J.W. and J.A. Sinclair. 1986. Water yield from some afforested catchments in Victoria. In: Hydrology and water resources symposium, Griffith University, Brisbane, 25-27 November 1986. The Institute of Engineers Australia: Barton, ACT. 214218.

Holtan, H.N. 1961. A concept for infiltration estimates in watershed engineering. USDA - ARS Paper n. 41-51.

Horton, R.E. 1933. The role of infiltration in the hydrologic cycle. Trans American Geophysical Union 14: 440-446.

Huber, A. 2003. Cambios en el balance hídrico provocados por la forestación con Pinus radiata D. Don en el secano interior del centro de Chile. Gestión Ambiental 9: 57-66.

Hewlett, J.D. 1982. Principles of forest hydrology. Athens. Ga. University of Georgia. $178 p$. 
Huber, A.; A. Iroumé; C. Mohrc y C. Frênea. 2010. Efecto de plantaciones de Pinus radiata y Eucalyptus globulus sobre el recurso agua en la Cordillera de la Costa de la región del Biobío, Chile. Bosque 31(3): 219-230.

Huber, A. y R. Trecaman. 2000. El efecto de las características de una plantación de Pinus radiata en la distribución espacial del contenido de agua edáfica. Bosque 21(1): 37-44.

Huber, A.; P. Barriga y R. Trecaman. 1998. Efecto de la densidad de plantaciones de Eucalyptus nitens sobre el balance hídrico en la zona de Collipulli, IX Región (Chile). BOSQUE 19(1): 61-69.

Huber, J.A. y C. Oyarzún O. 1983. Precipitación neta e intercepción en un bosque adulto de Pinus radiata (D. Don). Bosque (5) 1: 13-20

Huber, J.A. y C. Oyarzún O. 1984. Factores reguladores de la intercepción en un bosque adulto de Pinus radiata (D. Don). Bosque 5(2): 59-64.

Hurtado, M.A.; J.E. Giménez y M.G. Cabral. 2006. Análisis ambiental del partido

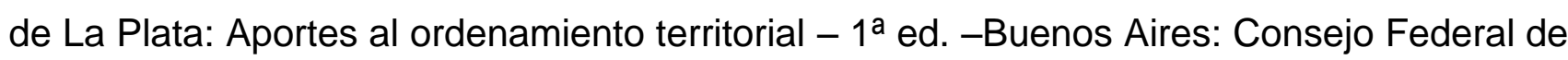
Inversiones. $134 \mathrm{p}$.

INTA (Instituto Nacional de Tecnología Agropecuaria). 2011. Cartas de suelos de la República Argentina -Provincia de Buenos Aires-. Imágenes 1:50000 extraídas de la mapoteca digital del Instituto de Suelos. Cartas: 3757-07-1 Estancia los Hijonales; 375707-2 Estancia El Sermón; 3757-07-3 Paraje La Protegida y 3757-07-4 Paraje La Unión. Consulta: enero de 2012 [www.anterior.inta.gob.ar/suelos/cartas/index.htm]

INTA. 2010. Cartas de suelos de la República Argentina -Provincia de Buenos Aires. Imágenes 1:50000 extraídas de la mapoteca digital del Instituto de Suelos. Cartas: 355719-2 Gómez y 3557-20-1 Ignacio Correas. Consulta: enero de 2012 [www.anterior.inta.gob.ar/suelos/cartas/index.htm]

INTA. 1989. Mapa de Suelos de la Provincia de Buenos Aires. 544 p.

INTA. 1977. La pampa Deprimida, Condiciones de drenaje de sus suelos, Departamento de suelos del INTA, Publicación oㅜ 152. Serie suelos, $162 \mathrm{p}$. 
Iroume, A. y A. Huber. 2000. Intercepción de las lluvias por la cubierta de bosques $y$ efecto en los caudales de crecida en una cuenca experimental en Malalcahuello, IX Región, Chile. BOSQUE 21(1): 45-56.

Isidoro, D. 2011. Minimización de impactos en la agricultura de regadío. Riegos del Alto Aragón. Monográfico Riego por aspersión. 24-32 p.

Jackson, R.B. 1999. The importance of root distributions for hydrology, biogeochemistry, and ecosystem functioning. 219-240. En: Tenhunen, J.D., Kabat, P. (eds.), Integrating hydrology, ecosystem dynamics and biogeochemistry in complex landscapes. John Wiley \& Sons Ltd., Chichester, UK.

Jackson, R.B.; E.G. Jobbágy; R. Avissar; S.B. Roy; D.J. Barrett; Ch.W. Cook; K.A. Farley; D.C. le Maitre; B.A. McCarl And B.C. Murray. 2005. Trading Water for Carbon with Biological Carbon Sequestration. SCIENCE 310: 1944-1947.

Jensen, M.E., R.D. Burman, and R.G. Allen (ed). 1990. "Evapotranspiration and Irrigation Water Requirements." ASCE Man. and Rep. on Engineering Pract. No. 70, New York, $332 \mathrm{p}$.

Jobbágy, E.G. 2011. Servicios Hídricos de los ecosistemas y su relación con el uso de la tierra en la llanura chaco-pampeana. Valoración de Servicios Ecosistémicos Conceptos, herramientas y aplicaciones para el ordenamiento territorial. Ediciones INTA, 163-183.

Jobbágy, E.G., M.D. Nosetto, C.S. Santoni y G. Baldi. 2008. El desafío ecohidrológico de las transiciones entre sistemas leñosos y herbáceos en la llanura ChacoPampeana. Ecología Austral - Sección especial 18: 305-322.

Jobbágy, E.G. and R.B. Jackson. 2007. Groundwater and soil chemistry changes under phreatophytic tree plantations. Journal of Geophysical Research-Biogeosciences 112- 10.1029/2006JG000246. $15 \mathrm{p}$.

Jobbágy, E.G. and R.B. Jackson. 2004. "Groundwater use and salinization with grassland afforestation." Global Change Biology (2004) 10 (doi: 10.1111/j.13652486.2004.00806.x): p. 1299-1312. 
Jobbágy, E.G. and R.B. Jackson. 2003. Patterns and mechanisms of soil acidification in the conversion of grasslands to forests. Biogeochemistry 54:205-229.

Jobbágy, E.G.; R. Aragón y M.D. Nosetto. 2007a. Los cultivos y la napa freática en la llanura pampeana. Grupo de Estudios Ambientales-Universidad Nacional de San Luis y IMASL-CONICET. Agrociencia $n^{\circ} 268$.

Jobbágy E.G., G. Sznaider, M. Nosetto, R. Aragón, G. Mangas y S. de Forteza. 2007b. Dinámica de napas y riesgo de inundación: Influencias y efectos en la variabilidad de los cultivos. Mundo Agro. Buenos Aires, Argentina. 8 p.

Jobbágy, E.G.; M.D. Nosetto; J.M. Paruelo y G. Piñeiro. 2006a.Las forestaciones rioplatenses y el agua. Ciencia Hoy, Vol. 16 Nro 95. 12-21.

Jobbágy, E.G.; M. Vasallo; K.A. Farley; G. Piñeiro; M.F. Garbulsky; M.D. Nosetto; R.B. Jackson y J.M. Paruelo. 2006b. Forestación en pastizales: hacia una visión integral de sus oportunidades y costos ecológicos. Agrociencia X(2):109-124.

Kallarackal, J. 1992. Water use of eucalypts In Kerala. In: Calder, I.R., Hall, R.L. and Adlard, P.G. ed. Growth and Water Use of Forest Plantation. J. Wiley, New York. 290297.

Karschon, R. and D. Heth. 1967. The water balance of plantation of Eucalyptus camaldulensis Dehn. Contributions of Eucalyptus in Israel, III 7-34.

Kelliher, F.M.; R. Leuning and E.D. Schulze. 1993. Evaporation and canopy characteristics of coniferous forests and grasslands. Oecologia, 95: 153-163.

Kostiakov, A.N. 1932. On the dynamic point of view for purpose of amelioration. Trans. Int. Ongr. Soil Sc. J. (A): 17-21.

Landini, A.M.; D. Martínez; H. Díaz; E. Soza; D. Agnes y C. Sainato. 2007. Modelos de infiltración y funciones de pedotransferencia aplicados a suelos de distinta textura. Ci. Suelo (Argentina) 25(2): 123-131.

Laprida C. 2006. Ostrácodos recientes de la llanura pampeana, Buenos Aires, Argentina: ecología e implicancias paleolimnológicas. Ameghiniana 43(1): 181-204. 
Laurencena, P.; E. Kruse; A. Rojo; M. Deluchi y E. Carol. 2005. Variaciones de niveles freáticos en la cuenca del Arroyo El Pescado (Provincia de Buenos Aires)" XVI Congreso Geológico Argentino. La Plata. Argentina. Tomo III, p 725-730.

Laurencena, P.; E. Kruse; A. Rojo y M. Deluchi. 2002. Características de las variaciones freáticas en un área del noreste de la provincia de Buenos Aires. XXXII IAH \& VI ALSHUD Congreso 'Aguas Subterráneas y Desarrollo Humano'. Mar del Plata. Argentina. 9 p.

Lavado, R.S. 1992. Río de la Plata Grasslands. Soils. In: Coupland, R.T. (ed.). Ecosystems of the World 8A: Natural Grasslands, Elsevier, Amsterdam. 377-380.

Lavado, R.S. y M.A. Taboada. 1988. Water, salt and sodium dynamics in a Natraquoll in Argentina. CATENA, vol. 15, p. 577-594.

Le Maitre, D.C.; D.F. Scott and C. Colvin. 1999. A review of information on interactions between vegetation and groundwater. Water SA Vol. 25(2) 137-152.

Lee, R. 1980. Forest Hydrology. Columbia University Press, New York.

Leite, F.P.; N.F. Barros; L.M.A. de Sans y A.S. Fabres. 1997. Soil water regime under a stand of eucalypts, natural forest and pasture, Guanhaes-MG-Brazil. Revista Arvore 21(4): 455-462.

León, R.J.C. 1992. Río de la Plata Grasslands. Regional subdivisions. In R.T. Coupland (ed.): Ecosystems of the World 8A. Natural Grasslands. Elsevier, Amsterdam. 367-407.

León, R.J.C. y S.E. Burkart. 1998. El pastizal de la Pampa Deprimida: estados alternativos. ECOTROPICOS, 11(2): p. 121-130.

León, R.J.C.; G.M. Rusch y M. Oesterheld. 1984. Pastizales Pampeanos-impacto agropecuario. Phytocoenologia 12: 201-218.

Leslie, A. 2005. What will we want from the forests? ITTO Tropical Forest Update 15(1): 14-16.

Licata, J.A.; T.G. Pypker; M. Weigandt; M.H. Unsworth; J.E. Gyenge; M.E. Fernández; T.M. Schlichter y B.J. Bond. 2011. Decreased rainfall interception balances 
increased transpiration in exotic ponderosa pine plantations compared with native cypress stands in Patagonia, Argentina. Ecohydrol. 4, 83-93.

Licata, J.A.; J.E. Gyenge; M.E. Fernández; T.M. Schlichter y B.J. Bond. 2008. Increased water use by ponderosa pine plantations in northwestern Patagonia, Argentina compared with native forest vegetation. Forest Ecology and Management 255: 753-764.

Lima, W.P. 1976. Interceptaçáo da chuva por povoamentos de eucalipto e de pinheiros. IPEF, 13 75-90.

Linsley, R.K. JR.; M.A. Kohler y J.L.H. Paulhus. 1993. Hidrología para ingenieros. Segunda edición en español. Ed. McGraw - HILL. México, D.F. 386 p.

Llamas, J. 1993. Hidrología general: Principios y Aplicaciones. Servicio Editorial de la Universidad del País Vasco. España. 635 p.

Lloyd. C.R. and A. Marques. 1988. Spatial variability of throughfall and stemfiow measurements in Amazonian rain forest. Forest end Agricultural Meteorology, 42: 63-73.

López Cadenas de Llano, F. 1998. Restauración Hidrológico Forestal y control de la Erosión. Ingeniería Ambiental. Tragsa-Tragsatec, Ministerio de Medio Ambiente, Ediciones Mundiprensa, Madrid, España. 945 p.

Macfarlane, C., M. Hoffman, D. Eamus, N. Kerp, S. Higginson, R. McMurtrie y M. Adams. 2007. Estimation of leaf area index in eucalypt forest using digital photography. Agricultural and Forest Meteorology 143: 176-188.

Magrin, G.O., M.I. Travasso y G.R. Rodríguez. 2005. Changes in climate and crop production during the 20th century in Argentina. Climatic Change 72: 229-249.

Maresca S. 2010. Presente y futuro en la Cuenca. Revista Ida y Vuelta Rural. Ediciones INTA 27: 14-15.

Mármol, L.A. 2006. Introducción al Manejo de Cuencas Hidrográficas y Corrección de Torrentes. Universidad Nacional de Salta. Facultad de Ciencias Naturales. Ingeniería en Recursos Naturales y Medio Ambiente. 287 p.

Martín de Santa Olalla, F.; P. López F. y A. Calera B. 2005. Agua y Agronomía. Ed. Mundi-Prensa. España, 606. 
Mateos Rodríguez, B.A. y S. Schnabel. 2002. Interceptación de las precipitaciones por la encina (Quercus rotundifolia) en una zona adehesada de Extremadura. $1^{\text {a }}$ Reunión sobre Hidrología Forestal. Cuad. SOCo Esp. Cien. For. 13: 137-141.

Mathur, H.N. and S.S. Sajwan. 1978. Vegetation characteristics and their effect on runoff and peak rates from small watersheds. Indian Forester 104. 398-406.

Mathur, R.N.; R. Babu,; P. Joshie and B. Singh. 1976. Effect of clearfelling and reforestation on runoff and peak rates in small watersheds. Indian Forester 102 (4) 219226.

McNeill, J.R. 2003. Algo nuevo bajo el Sol. Historia medioambiental del mundo en el siglo XX. Alianza Editorial, Madrid. 504 p.

Méndez, W y E. Marcucci. 2006. Análisis Morfométrico de la microcuenca Quebrada Curucutí, estado de Vargas - Venezuela. RGV. Vol. 47 (1): 29-55.

Miaczynski, C. 1995. Los suelos hidromórficos e hidrohalomórficas de la provincia de Buenos Aires. Rev. Fac. Agr., 15, 23-36.

Mijares F., J.A. 1994. Fundamentos de hidrología de superficie. Editorial Limusa, S. A. de C. V. Grupo Noriega Editores. Balderas 95, México, D. F.303 p.

Mintegui Aguirre, J.A. y F. López Unzú. 1990. La Ordenación Agrohidrológica en la Planificación. Servicio Central de Publicaciones del Gobierno Vasco. 306 p.

Monteny, B.A., J.M. Barbier and C.M. Bernos. 1985. Determination of the energy exchanges of a forest type culture: Hevea brasiliensis. In: Hutchinson, B.A. and Hicks, B.B. ed. The Forest-Atmosphere Interaction. D. Reidel. Dordrecht. 211-233.

Montico, S. 2004. El manejo del agua en el sector rural de la región pampeana argentina. Revista THEOMAI. Número especial (invierno 2004). [Disponible en: http://revista-theomai.unq.edu.ar/]

Morello, J.; G.D. Buzai; C.A. Baxendale; S.D. Matteucci; A.F. Rodríguez; R.E. Godagnone y R.R. Casas. 2000. Ecología de la interfase metropolitana I. Urbanización y consumo de tierra fértil. Revista de Divulgación y Tecnología de la Asociación Ciencia Hoy. Vol. 10 Nro. 55.8 p. 
Movia, C.P. and S.E. Burkart. 1976. Relaciones entre unidades fisiográficas y comunidades vegetales en un área de la Pampa Deprimida (Argentina). Photointerprétation 76: 42-52.

Muñoz C., R. y A. Ritter R. 2005. Hidrología Agroforestal. Ediciones Mundi-Prensa. Gobierno de Canarias. ISBN 84-8476-245-9.348 p.

Neal, C.; A. Robson; R.L. Hall; G. Ryland; T. Conway and M. Neal. 1991. Hydrological impacts of hardwood plantation in lowland Britain: preliminary findings on interception at a forest edge, Black Wood, Hampshire, southern England. Journal of Hydrology, 127: 349-356.

New, M.D. Lister; M. Hulme and I. Makin. 2002. A high-resolution data set of surface climate over global land areas. Climate Research 21: 1-25.

Nisbet, T. 2005. Water use by trees. Information Note. Forestry Commission. Edinburgh. 8 p.

Nisbet, T.; M. Silgram; N. Shah; K. Morrow and S. Broadmeadow. 2011 Woodland for Water: Woodland measures for meeting Water Framework Directive objectives. Forest Research Monograph 4, Forest Research, Surrey, 156 p.

Nosetto, M.D.; E.G. Jobbágy; T. Tóth and R.B. Jackson. 2008. Regional patterns and controls of ecosystem salinization with grassland afforestation along a rainfall gradient. GLOBAL BIOGEOCHEMICAL CYCLES, VOL. 22, GB2015. 12 p.

Nosetto, M.D.; E.G. Jobbágy; T. Tóth and C.M. Di Bella. 2007. "The effects of tree establishment on water and salt dynamics in naturally salt-affected grasslands." Oecología 152 (DOI 10.1007/s00442-007-0694-2): 695-705.

Nosetto, D.M., Jobbágy, E.G. and Paruelo, J.M. 2005. Land use change and water losses: the case of grassland afforestation accross a soil textural gradient in central Argentina. Global Change Biology, 11: 1101-1117.

Novoa, P. 1998. Estimación de la evapotranspiración actual en bosques. Teoría. BOSQUE 19(1): 111-121.

Nuñez, M.N.; C. Saulo; S. Nuñez; M. González; O. Penalba; J.C. Bertoni; C.G. Catalini; A.H. Risiga; M.A. Taboada; F. Damiano; A. Juan; S. González; C. Natenzón. 
2007. B-2 Vulnerabilidad de la Pampa Bonaerense. Informe Final CIMA/CONICETHIDROESTRUCTURAS S.A. Segunda Comunicación Nacional del Gobierno de la República Argentina. Convención de Naciones Unidas sobre Cambio Climático.113 p.

Okali, D.U.U. 1980. Estimating water use by tropical forests: an example from a plantation teak forest. In: Furtado. J. ed. Tropical Ecology and Development. Society of Tropical Ecology, Varanasi. 581-591.

OMM (Organización Meteorológica Mundial). 2011. Guía de prácticas hidrológicas. Volumen I: Hidrología - De la medición a la información hidrológica. OMMNro.168 Sexta edición (2011). Ginebra, Suiza. 324 p.

Oyarzún, C.E. y A. Huber. 1999. Balance hídrico en plantaciones jóvenes de Eucalyptus globulus y Pinus radiata en el sur de Chile. Terra Vol. 17(1): 35-44.

Panario, D.; N. Mazzeo; G. Eguren; C. Rodríguez; A. Altesor; R. Cayssials y M. Achkar. 2006. Síntesis de los efectos ambientales de las plantas de celulosa y del modelo forestal en Uruguay. Facultad de Ciencias, Informe interno. Montevideo.

Pardo, J.A. 2007. Perspectiva fisiológica en la producción y mejora del eucalipto (Con énfasis en Eucalyptus globulus Labill). Boletín del CIDEU 3: 7-55.

Penman, H.L. 1948. "Natural evaporation from open water, bare soil and grass." Proc. Roy.Soc. London. A193: 120-145.

Pérez Ballari, A.; M.I. Botana y O. Scarpati. 2009. Distribución de la sequías e identificación de áreas de riesgo (Provincia de Buenos Aires, Argentina). Huellas Nro. 13: 130-146.

Pérez, R.A.; Rossi, C.A.; Otondo, J.; Torrá, E. y A. Bidart. 2007. Implantación de Gramíneas Subtropicales en Bajos Alcalino-Sódicos del Pastizal de la Cuenca del Salado. Primera Evaluación. IV Congreso Nacional sobre Manejo de Pastizales Naturales - I Congreso del Mercosur sobre Manejo de Pastizales Naturales - Villa Mercedes, San Luís, Argentina. 9, 10 y 11 de Agosto de 2007. 11 p.

Perlis, A. 2007. Los bosques y el agua. En: unasylva 229, Vol. 58, 2007/4. 72 p.

Philip, J.R. 1957. The theory of infiltration. 4. Sorptivity and algebraic infiltration equations. Soil Sci. 84: 257-264. 
Pienaar, L.V. 1964. Reënvalonderskepping deur 'n jong opstand van Pinus radiata, D. Don. For. in S. Afr. 5 23-37.

Pizarro T., R.; A. Benitez G.; C. Farias D.; C. Jordan D.; F. Santibañez Q.; C. Sangüesa P.; J.P. Flores V.; E. Martínez A. y L. Román A. 2005. Influencia de las masas boscosas en el régimen hídrico de una cuenca semiárida, Chile. BOSQUE 26(1): 77-91.

Poore, M.E.D. y C. Fries. 1987. Efectos ecológicos de los eucaliptos. Estudio FAO Montes 59, Roma. 106 p.

Posadas, C. 1934. La solución al problema de las inundaciones y desagües en la provincia de Buenos Aires. Ministerio de Obras Públicas, La Plata, Argentina.

Poupon, H. 1972. Description des appareils aérien et souterrain d'Eucalyptus camaldulensis Dehn. introduit en Tunisie du nord. Cahier ORSTOM, série Biologie No. 17, 47-59.

Pritchet W.L. 1991. SUELOS FORESTALES Propiedades, conservación y mejoramiento. Ed., Limusa, S. A. México. DF. 634 p.

PROSAP (Programa de Servicios Agrícolas Provinciales). 2010. Estrategia Provincial para el sector Agroalimentario (EPSA). Resolución del Ministerio de Asuntos Agrarios Nro. 84/10. Provincia de Buenos Aires. 99 p.

Rakhmanov, V.V. 1966. Role of forest in water conservation. Published for the U.SA. and The National Science Foundation. W. D. C. 171 p.

Rang, S.; J. Cisneros; A. Milanesio; H. Gil y A. Degioanni. 1999. Propuesta de Creación del Distrito de Ordenamiento Ambiental para el área sur de LaboulayeRosales_Leguizamón. Documento Técnico. CONICORADESUR-UNRC. 60 p.

Rébori, M.G. 2007. Sensibilidad de ecuaciones de Evapotranspiración en la estimación de los consumos de agua de Eucalyptus dunnii. Anais I Seminário de Recursos Hídricos da Bacia Hidrográfica do Paraíba do Sul: o eucalipto e o Ciclo Hidrológico, Taubaté, Brasil, 07-09 novembro 2007, IPABHi, p. 237-244.

Rébori, M.G. 2004. Investigación forestal al servicio de la producción II Resultados aplicables al cultivo de bosques y la producción de madera en Argentina. Bloque 4: Resultados y avances para las regiones Pampeana y Delta del Río Paraná. PIA 02/97: 
Requerimientos de agua del Eucalyptus dunnii en su implantación y monte adulto. Medición y contribución al balance hídrico regional. Buenos Aires. 260 p.

Roberts, J. and P.T.W. Rosier. 1993. Physiological studies in young Eucalyptus stands in southern India and derived estimates of forest transpiration. Agricultural Water Management 24. 103-118.

Rodríguez Suárez, J.A.; F. Díaz-Fierros y B. Soto. 2010. Características de la precipitación neta en una plantación de Pinus pinaster. Rev. C. \& G., 24(3-4): 25-31.

Rojo, A.; P. Laurencena; E. Kruse y M. Deluchi. 2008. Particularidades de la relación aguas subterráneas-aguas superficiales en un sector del noreste de la Provincia de Buenos Aires, Argentina. IX Congreso Latinoamericano de Hidrología Subterránea y Expo Agua 2008. Quito Ecuador. 7 p.

Rutter, A.J. 1963. Studies in the water relations of Pinus sylvestris in plantation conditions. I-Measurements of rainfall and interception. Journal of Ecology, 51 191- 203.

Sala, J. M. 1975. Recursos hídricos (especial mención de las aguas subterráneas). En: V. Angelelli et al., (eds.), Relatorio. Geología de la provincia de Buenos Aires. $6^{\circ}$ Congreso Geológico Argentino, Actas: 169-194.

Sala, O.; A. Soriano y S. Perelman. 1981. Relaciones hídricas de algunos componentes de un pastizal de la depresión del salado. Rev. Facultad de Agronomía, 2 (1): $1-10$.

Salazar Lea Plaza, J.C. y G. Moscatelli. 1989. Mapa de suelos de la Pcia. de Buenos Aires. SAGyP-INTA. Buenos Aires. 525 p.

Sallies, A.R. 1999. Clima e inundaciones en la Pampa Deprimida. Floodplain Management Association - 17 $7^{\text {th }}$ Semiannual Conference, del 27 de Set. al 01 de Oct. Sacramento, California-USA. 8 p.

Samraj, P.; S. Chinnamani, y B. Haldorai. 1977. Natural versus man-made forest in Nilgiris with special reference to run-off, soil loss and productivity. Indian Forester 103 (7) 460-465.

Sánchez, F.J. 2012. Conceptos fundamentales de Hidrogeología. Dpto. GeologíaUniv. Salamanca, España. [Disponible en: http://hidrología.usal.es] 10 p. 
Sancho Sanz, J. 2007. Agua es vida. Rev. Real Academia de Ciencias. Zaragoza. 62: 65-74.

Santa Regina, I.; J.F. Gallardo; C. San Miguel y A. Moyano. 1989. Intercepción, pluviolavado y escorrentía cortical en una plantación de Pinus sylvestris de la Cuenca de Candelario (centro-oeste de España). BOSQUE: 10(1): 19-27.

Sarochar, R.H.; H.H. Ciappesoni y N.E. Ruiz. 2005. Precipitaciones convectivas y estratiformes en la Pampa Húmeda: una aproximación a su separación y aspectos climatológicos de ambas. Meteorológica [online]. Vol. 30 (1-2) 77-88.

Saxton, K.E. and W.J. Rawls. 2006. Soil Water Characteristics Estimates by Texture and Organic Matter for Hydrologic Solutions. Soil Sci. Sco. Am. J. 70:1569-1578.

Schenk H.J. and Jackson, R.B. 2002. The global biogeography of roots. Ecological Monographs, 72: 311-328.

Schmaltz, J. 1969: Die Bedeutung des Waldes für den Wasserkreislauf. Forstarchiv. 40(7/8): 132-147.

Schulze E.D.; R. Hantschel; K.S. Werk and R. Horn. 1987. Water relations of two Norway spruce stands at different stages of decline. In: Schulze, E.D.; O.L. Lange and R. Oren (eds), Ecological studies, volume 77, Springer, Berlin Heidelberg New York, 341-351.

Scott, D.F. and W. Lesch. 1997. Streamflow responses to afforestation with Eucalypfus grandis and Pinus patula and to felling in the Mokobulaan experimental catchments, South Africa. Journal of Hydrology 199: 360-377.

Silveira, L.; C. Chreties; J. Alonso; C. Amorín; P. De Izaguirre; M. Crisci; S. Symonds; L. Martínez; M. García; F. García; S. Delgado; C. Clérici; L. Betancor; M. Hill; F. Alliaume; P. Cabral; P. Audicio; A. Iroumé; A. Huber y A. Schipilov. 2011. Efecto de la actividad forestal sobre los recursos suelos y aguas, en microcuencas similares sometidas a distinto manejo. Proyecto FPTA 210. Sitio Argentino de Producción Animal. Serie: FPTA N³2. 34 p.

Silveira, L., J. Alonso y L. Martínez. 2006. Efecto de las plantaciones forestales sobre el recurso agua en el Uruguay. Agrociencia. Vol. $X^{\circ} N^{\circ}$ : 75-93. 
Sims, P.L.; J.S. Singh and W.K. Lauenroth. 1978. The structure and function of ten western North American grasslands. I. Abiotic and vegetational characteristics. J Ecol 66: 251-285.

Smith, M. 2000. The application of climatic data for planning and management of sustainable rainfed and irrigated crop production. Agricultural and Forest Meteorology 103 (2000) 99-108.

Smith, M.K. 1974. Throughfall Stemflow and Interception in Pine and Eucalypt Forest. Australian Forestry 36(3) 190-197.

Smith, R.E. and D.F. Scott. 1992. The effects of afforestatlon on low flows In various regions of South Africa. Water SA 18, 185-194.

Smith, M., R. Allen and L. Pereira, 1996. Revised FAO Methodologies for Crop Water requirements, In: Proceedings of the International Conference on Evapotranspiration and Irrigation Scheduling, November 1996, San Antonio, TX, ASCE, p. 116-123

Smith M.; R. Allen; J.L. Monteith; L.A. Pereira; A. Perrier and A. Segeren. 1992. Report on the Expert Consultation for the Revision of FAO methodologies for crop water requirements. FAO, Rome, Italy, 54

Smith, M.; J.L. Monteith; A. Perrier; L.S. Pereira and A. Segeren. 1990. Expert consultation on revision of FAO methodologies for crop water requirements. FAO, Rome, Italy. $46 \mathrm{p}$.

Soares, J.V. and A.C. Almeida. 2001. Modeling the wáter balance and soil wáter fluxes in a fast growing Eucalyptus plantation in Brazil. Journal of Hydrology (253) p 130147.

Soil Survey Staff. 2006. Keys to Soil Taxonomy. 10th Ed. USDA, NRCS, Washington DC, $341 \mathrm{p}$.

SSSA (Soil Science Society of América). 2001. Glossary of Soil Science Terms. Madison WI. En: Martín de Santa Olalla Mañas, F.; P. López F. y A. Calera B. 2005. Agua y Agronomía. Ed. Mundi-Prensa. España, Madrid. 606 p.

Suárez Moreno, F. 2009. El agua en Canarias. Historia, estrategias y procedimientos didácticos. Bienmesabe.org.- Infonortedigital-Artevirgo.org. DP GC 1.323. 56 p. 
Szpeiner, A.; M.A. Martínez G. y C. Gherza. 2007. Agricultura pampeana, corredores biológicos y biodiversidad. Ciencia Hoy. Vol. 17 Nro. 101. 9 p.

Teixeira Días, H.C. 2004. Precipitação efetiva e aporte de nutrientes pelas chuvas em florestas plantadas. Anais do Seminário sobre silvicultura em florestas plantadas. Vitoria. Espíritu Santo. Brasil. 196-211.

Tesón, N. 2012. Balance hidrológico y flujo de nutrientes asociados al agua en plantaciones de Eucalyptus grandis, en Concordia (Entre Ríos). Tesis Doctoral, FCNyMUNLP. [Disponible en: http://sedici.unlp.edu.ar/handle/10915/24225]

Thornthwaite, C.W. 1948. "An approach toward a rational classification of climate". Geographycal Rev. Vol. 38 Nro 1: 55-94.

Tobón, G.D. 1989. Evaluación de pérdidas por interceptación de la precipitación en tres coberturas vegetales: Cupressus lusitánica Mill, Pinus patula y bosque natural secundario. Tesis Ingeniería Forestal. Universidad Nacional de Colombia. Medellín. 125 p.

Torrán, E.A. y J.C. Piter. 2009. Contenido de agua en suelos cultivados con Eucalyptus grandis y Pinus taeda. Análisis de un caso en la provincia de Entre Ríos, Argentina. BOSQUE 30(1): 10-17.

Tricart, J.L. 1973. Geomorfología de la Pampa Deprimida. Base para los estudios edafológicos y agronómicos. Plan mapa de suelos de la Región Pampeana. XII Colección Científica, INTA.

USDA-SCS. 1964. Hydrology. Section 4, Part I, Watershed planning. In: National Engineering Handbook. US Department of Agriculture, Soil Conservation Service, Washington DC.

Usunoff, E.; M. Varni; P. Weinzettel y R. Rivas. 1999. Hidrogeología de las grandes llanuras: la pampa húmeda argentina. Boletín Geológico y Minero. Vol. 110(4) 391-406.

Vázquez, P. 2003. Emergencias Agropecuarias: Seguimiento y evaluación a escala parcelaria de la superficie afectada por las inundaciones en la Cuenca del Salado. Convenio CONAE - INTA, Unidad Operativa Cuenca del Salado - INTA. Partido de Pila. www.conae.gov.ar/emergencia/inundaciones-iconos/Pila/informe inta-pila.htm 
Vázquez, P.; S. Masuelli; G. Platzeck y O. Boolsen. 2011. Recurrencia de anegamiento en la pampa deprimida, Provincia de Buenos Aires. Capítulo 2. En: R. Rivas; F. Carmona y D. Ocampo. 2011. Teledetección: Recientes aplicaciones en la Región Pampeana. Ed. Martín. 112 p.

Vázquez, P.; S. Masuelli; G. Platzeck y O. Boolsen. 2008. Recurrencia de anegamiento en la depresión del río Salado: subcuenca B4. Revista de Teledetección, 30, 47-59.

Vázquez, P.; J.L. Costa; G. Monterubbianesi y P. Godz. 2001. Predicción de la productividad primaria de pastizales naturales de la pampa deprimida utilizando propiedades del horizonte A. Asociación Argentina de la Ciencia del Suelo, 19(2), 136-143.

Vega, M.A.L.; R. Sistac y M.A. González. 1995. Diagnóstico ambiental de la provincia de Buenos Aires. Tomo I. Aspectos básicos. Ministerio de la Producción de la Provincia de Buenos Aires, $245 \mathrm{p}$.

Versfeld, D.B. 1988. Rainfall interception in stands of Pinus radiata and Protea neriifolia. In: Research Contributions to Plantation Forestry. Festschrift in honour of Prof. A. van Laar, Forestry Faculty, Univ. of Stellenbosch. 130-149.

Vertessy, R.; L. Connell; J. Morris; R. Silberstein; A. Heuperman; P. Feikema; L. Mann; M. Komarzynski; J. Collopy and D. Stackpole. 2000. Sustainable Hardwood Production in Shallow Watertable Areas. A report for the RIRDC/ LWRRDC/ FWPRDC Joint Venture Agroforestry Program. Water and Salinity Issues in Agroforestry No. 6. RIRDC Publication No. 00/163 RIRDC Project No. CSI- 3A. 115 p.

Vervoorst, F.B. 1967. Las comunidades vegetales de la Depresión del Salado (prov. de Buenos Aires). Serie Fitogeográfica 7. INTA. Buenos Aires.

Viglizzo, E.F.; A.J. Pordomingo; M.G. Castro y F.A. Lértora. 2002. La sustentabilidad de la agricultura pampeana: ¿Oportunidad o pesadilla?. Revista Ciencia Hoy en línea. Vol. 12(68): 38-51.

Voigt, G.K. 1960. Distribution of rainfall under forest stands. Forest Science 6(1) 210. 
Walter, H. 1967. Das Pampa problem in Vergleichend Okologischer Betrachtung und seine Losung. Erdkunde 21: 181-203.

Waterloo, M.J. 1994. Water and Nutrient Dynamics of Pinus caribaea Plantation Forests on Former Grassland Soils in Southwest Viti Levu, Fiji. PhD Thesis. Faculty of Earth Sciences. Vnje Universiteit, Amsterdam.

Whitehead, D. and P.G. Jarvis. 1981. Coniferous plantation. In: Kozlowski TT (ed) Plant growth and water deficit, vol 6, Academic Press, London, 49-152 p.

Whitehead, D.; F.M. Kelliher; P.M. Lane; D.S. Pollock. 1993. Seasonal partitioning of evaporation between trees and understorey in a widely spaced Pinus radiata stand. J Appl Ecol, 31: 528-542.

Winkler, R.D.; R.D. Moore; T.E. Redding; D.L. Spittlehouse; D. Carlyle M. and B.D. Smerdon. 2009. Chapter 6 - Hydrologic Processes and Watershed Response. In Compendium of Forest Hydrology and Geomorphology in British Columbia [In Prep.] R.G. Pike et al. (editors). B.C. Ministry of Forests and Range Research Branch, Victoria, B.C. and FORREX Forum for Research and Extension in Natural Resources, Kamloops, B.C. Land Management Handbook (TBD). http://www.forrex.org/program/water/compendium.asp

Wooldridge, D.D. 1970. Chemical and physical properties of forest litter layers in central Washington. En la obra de C. T. Youngberg and C. B Davey (ed.) Tree Growth and Forest Soils. Oregon State Univ. Press, Corvallis. 327-337.

Zar, J.H. 1999. Biostatistical Analysis. Ed. Deirdre Lynch. Prentice Hall New Jersey. Vol. 4, 663 p.

Zhang, L., W.R. Dawes and G.R. Walker. 2001. Response of mean annual evapotranspiration to vegetation changes at catchment scale. Water Resources Research, 37: 701-708.

Zhang, L., W.R. Dawes and G.R. Walker. 1999. Predicting the effect of vegetation changes on catchment average water balance. (Co-operative Research Centre for Catchment Hydrology: Canberra)

Zinke, P.J. 1967. Rainfall interception studies in the United States. In: Sopper WE and Lull HW (eds.) Int. Symp. Forest Hydrol., Pergamon, Oxford. 137-161. 


\section{ANEXOS}

Modelo de planilla usado para el registro semanal del nivel freático de la red de pozos de la EEC, junto con el de los pluviómetros de precipitación interna y escurrimiento fustal. La planilla 1 corresponde a la utilizada en EEC y la planilla 2 a la utilizada en el PFD.

\section{Planilla 1:}

\begin{tabular}{|c|c|c|c|}
\hline \multicolumn{2}{|c|}{ Pluviómetro del Campo } & \multicolumn{2}{l|}{ Pluviómetro testigo } \\
\hline \multicolumn{2}{|c|}{ Medida } & & \\
\hline 1 & & & \\
\hline 2 & & & \\
\hline 3 & & & \\
\hline 4 & & & \\
\hline 5 & & & \\
\hline 6 & & Collarin & \\
\hline 7 & & Pino avena & \\
\hline Pluviómetro & & Pino & \\
\hline Pino avena & & Euc. Calle & \\
\hline Pino & & Euc. & \\
\hline Euc. Calle & & & \\
\hline Euc. & & & \\
\hline
\end{tabular}

\section{Planilla 2:}

\begin{tabular}{|c|c|c|c|c|c|}
\hline \multirow{2}{*}{$\begin{array}{c}\text { FECHA } \\
\text { (día/mes/año) }\end{array}$} & \multirow{2}{*}{ RESPONSABLE } & \multirow{2}{*}{ POZO } & \multicolumn{2}{|c|}{ MEDICIONES C/CINTA METRICA } & \multirow{2}{*}{ OBSERVACIONES } \\
\hline & & & $1^{\text {er }}$ medida* $(m)$ & $2^{\text {da }}$ medida $^{\star \star}(\mathrm{m})$ & \\
\hline & & 1 & & & \\
\hline & & 2 & & & \\
\hline & & 3 & & & \\
\hline & & 4 & & & \\
\hline & & 5 & & & \\
\hline & & 6 & & & \\
\hline & & 7 & & & \\
\hline \multirow{7}{*}{$\begin{array}{c}\text { FECHA } \\
\text { (día/mes/año) } \\
\end{array}$} & \multirow{2}{*}{ RESPONSABLE } & \multirow{2}{*}{ PARCELA } & \multicolumn{2}{|c|}{ MEDICION DE LOS NIVELES DE TANQUES } & \multirow{2}{*}{ OBSERVACIONES } \\
\hline & & & $\mathrm{CHICO}(\mathrm{Lts})$ & GRANDE & \\
\hline & & 1 & & & \\
\hline & & 2 & & & \\
\hline & & 3 & & & \\
\hline & & 4 & & & \\
\hline & & 5 & & & \\
\hline
\end{tabular}

